UNIVERSIDADE DE SÃO PAULO

ESCOLA DE ENFERMAGEM

JAQUELINE ALCÂNTARA MARCELINO DA SILVA

EDUCAÇÃO INTERPROFISSIONAL EM SAÚDE E ENFERMAGEM NO CONTEXTO

DA ATENÇÃO PRIMÁRIA 


\section{EDUCAÇÃO INTERPROFISSIONAL EM SAÚDE E ENFERMAGEM NO CONTEXTO DA ATENÇÃO PRIMÁRIA}

Tese apresentada ao Programa de PósGraduação em Gerenciamento em Enfermagem da Escola de Enfermagem da Universidade de São Paulo, para obtenção do título de Doutor em Ciências.

Área de Concentração: Fundamentos e Práticas de Gerenciamento em Enfermagem e em Saúde.

Orientadora: Prof ${ }^{a}$. Dr ${ }^{\mathrm{a}}$. Marina Peduzzi. 
AUTORIZO A REPRODUÇÃO E DIVULGAÇÃO TOTAL OU PARCIAL DESTE TRABALHO, POR QUALQUER MEIO CONVENCIONAL OU ELETRÔNICO, PARA FINS DE ESTUDO E PESQUISA, DESDE QUE CITADA A FONTE.

Assinatura:

Data:

\section{Catalogação na Publicação (CIP) \\ Biblioteca "Wanda de Aguiar Horta" \\ Escola de Enfermagem da Universidade de São Paulo}

Silva, Jaqueline Alcântara Marcelino da

Educação interprofissional em saúde e enfermagem no contexto da atenção primária / Jaqueline Alcântara Marcelino da Silva. São Paulo, 2014.

$281 \mathrm{p}$.

Tese (Doutorado) - Escola de Enfermagem da Universidade de São Paulo.

Orientadora: Prof. ${ }^{\text {a }}$ Dr. ${ }^{\text {a }}$ Marina Peduzzi

Área de concentração: Fundamentos e Práticas de Gerenciamento em Enfermagem e em Saúde

1. Enfermagem. 2. Educação interprofissional. 3. Trabalho. 4. Ensino superior. 5. Atenção primária à saúde. I. Título. 
Jaqueline Alcântara Marcelino da Silva.

Educação interprofissional em saúde e enfermagem no contexto da Atenção Primária.

Tese apresentada ao Programa de Pós-Graduação em Gerenciamento em Enfermagem da Escola de Enfermagem da Universidade de São Paulo para obtenção do título de Doutor em Ciências.

Aprovado em:

\section{Banca Examinadora}

$\operatorname{Prof}^{\underline{0}} \operatorname{Dr}^{0}$ Instituição:

Julgamento: Assinatura:

$\operatorname{Prof}^{\underline{0}} \operatorname{Dr}^{\mathrm{o}}$ Instituição:

Julgamento: Assinatura:

$\operatorname{Prof}^{\mathrm{o}} \operatorname{Dr}^{\mathrm{O}}$ Instituição:

Julgamento: Assinatura:

$\operatorname{Prof}^{0} \operatorname{Dr}^{0}$ Instituição:

Julgamento: Assinatura:

$\operatorname{Prof}^{0} \operatorname{Dr}^{0}$ Instituição:

Julgamento: Assinatura: 


\section{Dedicatória}

A Deus por seu infinito amor que traz

sentido e alegria a vida, com oportunidades diárias de crescimento reflexão e ressignificação.

Aos meus pais Edna e Reinaldo amigos e companheiros que me apoiam em todos os momentos da vida, com amor

Aos docentes e trabalhadores que acreditam e contribuem para a transformação da formação em saúde. 


\section{Agradecimentos}

A Deus pelas oportunidades concedidas, cuidado constante, amor, paz, saúde, proteção e esperança. Obrigada pela sabedoria e orientação em todos os caminhos da vida que se tornam mais felizes com Sua presença.

Aos meus pais à quem devo minha essência, valores e conquistas. Obrigada pelo amor, apoio, incentivo, ensinamentos e carinho incontáveis. Vocês também são responsáveis pelo resultado deste trabalho!

À Professora Marina Peduzzi, obrigada pela orientação e pelos sete anos compartilhados com muita dedicação, confiança, amizade, oportunidades de aprendizado, inspiração e crescimento. Minha admiração por sua trajetória!

Às Professoras Cláudia Prado, Elizabeth Artmann e Maria Helena Trench Ciampone pelas preciosas contribuições no exame de qualificação.

Ao departamento ENO pelo apoio da chefia das Professoras Heloísa e Fernanda. Agradeço o incentivo, companheirismo, oportunidades de desenvolvimento $e$ convivência com os professores Antônio, Cláudia, Daisy, Genival, Marcelo, Marta, Maria Cristina, Maria de Fátima, Maria Madalena, Paulina, Patrícia, Raquel, Valéria Castilho, Valéria Leonello, Vanda, Vera. Obrigada aos colegas Andreia, Edina e Osni da secretaria do ENO pelo apoio e alegria!

As enfermeiras especialistas Denise, Geisa, Irene e Milena pela amizade, companheirismo, apoio, experiências, atividades compartilhadas e contribuições pessoais em diferentes etapas do trabalho.

Ao Ricardo Góes pela convivência e constante disposição em ajudar.

Aos colegas da Escola de Enfermagem da USP, em especial à equipe da biblioteca Wanda Aguiar Horta, ao Serviço de Pós-Graduação e de Informática.

Aos integrantes do grupo de pesquisa 'Gestão de Recursos Humanos da Perspectiva do Processo de Trabalho em Saúde e Enfermagem' pelos debates e estudos compartilhados, especialmente à Geisa Colebrusco de Souza e Maiara Mancini que colaboraram de modo especial neste estudo.

Às amigas Agatha, Andrea, Ilma e Auri com quem compartilho momentos especiais desde a adolescência. Obrigada pela amizade e compreensão!

Aos participantes do estudo, docentes, trabalhadores da APS e estudantes que concederam seu tempo e preciosas reflexões.

A Silvia Mulé pelo brilhante e cuidadoso trabalho de transcrição do material empírico desde minha pesquisa de mestrado.

A Universidade de São Paulo e à Escola de Enfermagem da USP pela oportunidade de inserção e desenvolvimento profissional.

A Fundação de Amparo à Pesquisa do Estado de São Paulo (FAPESP) pelo auxílio financeiro que possibilitou a realização deste estudo (Processo 2012/11200-8). 


\section{Epígrafe}

O potencial de libertação embutido no agir comunicativo é um processo que se apresenta na história da humanidade como uma força vingadora contra toda a tentativa de reducionismo e todo o tipo de comunicação distorcida. É uma força que age de forma concreta no processo histórico, na vida dos indivíduos e grupos, promovendo a progressiva racionalização do agir humano e a diferenciação da estrutura simbólica do mundo. A racionalidade comunicativa pode ser, portanto detectada e reconstruída por sujeitos que argumentam e procuram apresentar boas razões para apreciação de suas vivências, dos seus saberes e do seu agir moral (...).

Vislumbramos que a perspectiva emancipadora da educação restabelece-se à medida que passa a assumir um papel reconstrutivo e crítico em relação aos acontecimentos e aos valores existentes, exercendo a função de uma ciência reconstrutiva, cuja função social destina-se a promover a descolonização do mundo da vida. À educação cabe, nessa perspectiva, um papel determinante no trabalho de destruir o 'brilho dogmático objetivista da racionalidade instrumental', consequência de uma compreensão restrita de conhecimento e de ciência, bem como um papel reconstrutivo no sentido de buscar contribuir para a superação das patologias provocadas pela comunicação sistematicamente distorcida.

Mühl, 2003 
Silva JAM. Educação interprofissional em saúde e enfermagem no contexto da Atenção Primária [tese]. São Paulo: Escola de Enfermagem, Universidade de São Paulo; 2014.

\section{RESUMO}

Introdução: $O$ tema central deste estudo é a prática e a educação interprofissional em saúde (EIP) e enfermagem. Na EIP as profissões aprendem conjuntamente sobre o trabalho coletivo e as especificidades de cada área profissional, orientadas para o trabalho colaborativo em equipe interprofissional, interdisciplinar e o compromisso com a integralidade. Objetivos: $O$ objetivo geral é analisar como ocorre a educação interprofissional na atenção primária à saúde (APS) no contexto brasileiro. Os objetivos específicos são: analisar as concepções da EIP e sua articulação com a prática interprofissional no cotidiano do trabalho da APS, na perspectiva de docentes, estudantes e trabalhadores. Método: Pesquisa qualitativa com abordagem compreensiva e interpretativa, cuja coleta de dados foi realizada em duas etapas. A primeira, por meio de 18 entrevistas semiestruturadas com docentes de oito universidades públicas brasileiras, que atuam na formação em saúde no contexto da APS. A segunda, com quatro sessões de grupos focais (GF) homogêneos, nas quais participaram cinco estudantes, seis docentes e 15 trabalhadores de duas Unidades Básicas de Saúde, vinculados ao Programa de Educação pelo Trabalho na Saúde (PET-Saúde). A análise dos dados foi realizada por meio da perspectiva crítico hermenêutica, com a triangulação dos resultados das duas etapas da pesquisa, à luz do quadro teórico, utilizando os conceitos: processo de trabalho em saúde e enfermagem, profissionalismo, teoria do agir comunicativo, interdisciplinaridade, EIP, prática colaborativa centrada no usuário e APS. Resultados: A triangulação dos resultados, da primeira e segunda fases da pesquisa, corroborou as três categorias empíricas contruídas a partir da análise das entrevistas, que indicam as concepções de EIP articuladas a prática de APS: 'A EIP desloca a ênfase da formação e das práticas para a integralidade do cuidado', 'A EIP contribui para a reconfiguração das relações profissionais colaborativas', 'Preservação das competências complementares da especificidade profissional, reconhecimento das competências comuns e construção das competências colaborativas'. Porém, os GF permitiram identificar diferenças no olhar dos atores sociais: os estudantes destacam a participação do usuário no cuidado, os docentes enfatizam a ausência de apoio institucional para EIP e os trabalhadores ressaltam a desarticulação ensino-serviço, pois usualmente não participam do planejamento das atividades de ensino no campo. A triangulação também revela tensões para o avanço da EIP, com destaque para incompatibilidade da grade curricular dos diferentes cursos. Conclusão: As concepções de EIP identificadas, indicam a necessidade da reconfiguração das relações profissionais, com articulação de competências comuns, complementares/específicas e colaborativas para promover a prática interprofissional centrada no usuário no contexto da APS no Sistema Único de Saúde (SUS).

PALAVRAS-CHAVE: Educação Interprofissional em Saúde, Trabalho, Ensino Superior, Agir Comunicativo, Atenção Primária à Saúde. 
Silva JAM. Interprofessional education in health and nursing in Primary Health Care [thesis]. São Paulo: Escola de Enfermagem, Universidade de São Paulo; 2014.

\begin{abstract}
Introduction: The central theme of this study is the practice and interprofessional education in health (IPE) and nursing. In IPE professions learn together on collective work and the specifics of each professional field, oriented collaborative work in interprofessional and interdisciplinary team and a commitment to comprehensive health care. Objectives: The overall objective is to analyze how IPE occurs in primary health care (PHC) in the Brazilian context. The specific objectives are: to analyze the conceptions of EIP and its articulation with the interprofessional practice in PHC daily work, from perspective of teachers, students and health workers. Method: Qualitative research with comprehensive and interpretative approach, which data collection was performed in two stages. The first, through structured interviews, with 18 teachers from eight Brazilian public universities, who work in health education in PHC. The second, with four sessions of homogeneous focus groups (FG), which involved five students, six teachers and 15 health workers of two PHC units linked to Education Program for Health Work (PET-Health). Data analysis was performed using the critical hermeneutic perspective, with the triangulation of the two stages results of research, based on theoretical framework, using concepts: work process in health and nursing, professionalism, Theory of Communicative Action, interdisciplinarity, IPE, patient centered collaborative practice and PHC. Results: The triangulation of results, the first and second phases of the study corroborated the three empirical categories from analysis of the interviews indicate that the conceptions of IPE articulated the practice of PHC: 'IPE emphasis of training and practice for comprehensive health care', 'IPE contributes to reconfiguration of collaborative professional relationships', 'Preservation of complementary competences of professional specificity, recognition of common competences and construction of collaborative competences'. However, the GF allowed to identify differences in the look of stakeholders: students highlight user participation in health care, teachers emphasize the lack of institutional support for IPE and health workers emphasize the teaching health service disarticulation, as usually workers do not participate in the planning of teaching activities in field. Triangulation also reveals tensions to advance of IPE, especially curriculum incompatibility of different courses. Conclusion: The conceptions of IPE identified indicate the need for professional relationships reconfiguration, with articulation of common, complementary/specific and collaborative competences to promote patient centered interprofessional practice in PHC settings in the Unified Health System (SUS).
\end{abstract}

KEYWORDS: Interprofessional Education, Work, Primary Health Care, Communicative Action. 


\section{LISTA DE SIGLAS E ABREVIATURAS}

$\mathrm{AB}$

ABRASCO

AIDS

AMA

APS

ASF

BI

BIS

CAIPE

CAPES

CAPS

CECCO

CEJAM

CEO

$\mathrm{CIHC}$

CNPQ

COFEN

CSE

DCN

EP

EIP

ENSP

ESF

FAMEMA

FAPESP

FFM

FNEPAS
Atenção Básica

Associação Brasileira de Saúde Coletiva

Síndrome da Imunodeficiência Adquirida

Ambulatório Médico de Especialidades

Atenção Primária à Saúde

Associação Saúde da Família

Bacharelado Interdisciplinar

Bacharelado Interdisciplinar em Saúde

Center for the Advancement of Interprofessional Education

Coordenação de Aperfeiçoamento de Pessoal de Nível

Superior

Centro de Atenção Psicossocial

Centro de Convivência e Cooperativa

Centro de Estudos e Pesquisas Dr. João Amorim

Centro de Especialidades Odontológicas

Canadian Interprofessional Health Care

Conselho Nacional de Desenvolvimento Científico e Tecnológico

Conselho Federal de Enfermagem

Centro Saúde-Escola

Diretrizes Curriculares Nacionais

Educação Permanente em Saúde

Educação Interprofissional em Saúde

Escola Nacional de Saúde Pública

Estratégia de Saúde da Família

Faculdade de Medicina de Marília

Fundação de Amparo à Pesquisa do Estado de São Paulo

Fundação Faculdade de Medicina

Fórum ancional de Educação das Profissões da Área da

Saúde 


\begin{tabular}{|c|c|}
\hline GF & Grupos focais \\
\hline ICB & Instituto de Ciências Biológicas \\
\hline IDA & Integração docente-assistencial \\
\hline INAMPS & $\begin{array}{l}\text { Instituto Nacional de Assistência Médica da Previdência } \\
\text { Social }\end{array}$ \\
\hline IPE & Interprofessional Education in Health \\
\hline IPEC & Interprofessional Education Collaborative \\
\hline IUSC & Integração Universidade-Saúde-Comunidade \\
\hline JUS & Jornada Universitária da Saúde \\
\hline MNNP & Mesa Nacional de Negociação Permanente \\
\hline NASF & Núcleo de Apoio à Saúde da Família \\
\hline NOB-RH & Norma Operacional Básica de Recursos Humanos \\
\hline OSS & Organização Social da Saúde \\
\hline PCCP & Prática Colaborativa Centrada no Paciente \\
\hline PCCU & Prática Colaborativa Centrada no Usuário \\
\hline PET-Saúde & Programa de Educação pelo Trabalho para Saúde \\
\hline PHC & Primary Health Care \\
\hline PRÓ-Saúde & $\begin{array}{l}\text { Programa Nacional de Reorientação da Formação } \\
\text { Profissional em Saúde }\end{array}$ \\
\hline MS & Ministério da Saúde \\
\hline MEC & Ministério de Educação e Cultura \\
\hline NASF & Núcleo de Apoio à Saúde da Família \\
\hline NISA & Núcleo de Reabilitação e Saúde Auditiva \\
\hline NIR & Núcleo Integrado de Reabilitação \\
\hline OMS & Organização Mundial de Saúde \\
\hline OPAS & Organização Pan-Americana de Saúde \\
\hline PROMED & $\begin{array}{l}\text { Programa de Incentivo às Mudanças Curriculares das } \\
\text { Escolas Médicas }\end{array}$ \\
\hline Projeto UNI & $\begin{array}{l}\text { Uma Nova Iniciativa na Formação de Profissionais de } \\
\text { Saúde em União com a Comunidade }\end{array}$ \\
\hline PROSAM & Pró-Saúde Mental \\
\hline PTS & Projeto Terapêutico Singular \\
\hline RAS & Redes de Atenção à Saúde \\
\hline
\end{tabular}


REUNI Reestruturação e Expansão das Universidades Federais

SAE Serviço de Assistência Especializada

SE Serviços de Especializados

SMS Secretaria Municipal de Saúde

SP São Paulo

SPDM Associação Paulista para Desenvolvimento da Medicina

STS Supervisão Técnica de Saúde

TAC Teoria do Agir Comunicativo

TO Terapia Ocupacional

SGTES Secretaria de Gestão do Trabalho e da Educação na Saúde

SUS Sistema Único de Saúde

TCLE Termo de Consentimento Livre Esclarecido

UBS Unidade Básica de Saúde

UEL Universidade Estadual de Londrina

UFBA Universidade Federal da Bahia

UNASUS Universidade Aberta do SUS

UNIFESP Universidade Federal de São Paulo

URSI Unidade de Referência de Saúde do Idoso

UTI Unidade de Terapia Intensiva

VD Visita Domiciliar

VERSUS Projeto de Vivências e Estágios na Realidade do SUS

VS Vigilância em Saúde

WHO World Health Organization 


\section{LISTA DE FIGURAS}

Figura 1 - $\quad$ O modelo de Janstch, 1972....................................... 67

Figura 2 - Estabelecimentos e serviços de saúde da rede municipal por Coordenadoria Regional de Saúde, Subprefeitura e Distrito Administrativo. Município de São Paulo

Figura 3- Concepções de educação interprofissional em saúde na APS na perspectiva dos docentes.

Figura 4 - Subcategorias da categoria 1 - A EIP desloca a ênfase da formação e das práticas para integralidade do cuidado.

Figura 5 - Subcategorias da categoria 2 - A EIP contribui para reconfiguraçãoo das relações profissionais colaborativas

Figura 6 - Subcategorias da categoria 3 - Preservação da especificidade profissional, reconhecimento das competências comuns e construção das competências colaborativas

Figura 7 - Barreiras para EIP na perspectiva dos docentes.

Figura 8 - Três tipos de competências profissionais de Barr, 1998.

Figura 9 - Resultados do grupo focal dos trabalhadores da unidade A

Figura 10 - Resultados do grupo focal dos trabalhadores da unidade B

Figura 11 - Resultados do grupo focal dos estudantes

Figura 12- Resultados do grupo focal dos docentes.

Figura 13 - Diagrama dos resultados com circularidade entre trabalho/ formação em saúde. 


\section{LISTA DE QUADROS}

Quadro 1 - $\quad$ Perfil dos docentes entrevistados.................................. 102

Quadro 2 - $\quad$ Perfil dos trabalhadores participantes do grupo focal 196 da unidade A

Quadro 3 - Perfil dos trabalhadores participantes do grupo da 208 unidade B

Quadro 4 - $\quad$ Perfil dos estudantes participantes do grupo focal........ 218

Quadro 5 - $\quad$ Perfil dos docentes participantes do grupo focal........... 228 


\section{APRESENTAÇÃO}

O interesse pelo tema deste estudo, a educação interprofissional em saúde (EIP) e a prática no contexto da Atenção Primária à Saúde (APS), surgiu no cotidiano do trabalho que desenvolvo como Enfermeira Especialista em Laboratório na Escola de Enfermagem da Universidade de São Paulo desde 2008. Durante o acompanhamento das atividades práticas dos estudantes de enfermagem, notei a sobreposição de ações com estudantes do curso de medicina nos mesmos campos de estágio da APS.

Ao longo desses anos, embora houvessem encontros ocasionais entre estudantes de enfermagem e medicina que realizavam atividades semelhantes, especialmente no primeiro ano da graduação, vivenciei restritas oportunidades de articulação em visitas domiciliares e projetos de intervenção nas unidades básicas de saúde cujo apoio dos trabalhadores e gerentes dos campos foi fundamental.

Pela novidade do tema da educação inteprofissional em saúde, trazida ao grupo de pesquisa pela orientadora deste estudo, senti a motivação em compreender quais são as concepções de EIP no cenário nacional e possibilidades de articulação com as práticas de saúde na APS.

As características do trabalho desenvolvido na APS em equipes integradas de saúde da família consistem em um espaço propício para o fortalecimento de iniciativas de EIP. Assim, parte-se do pressuposto da circularidade entre o processo de trabalho em saúde e as práticas de formação que se influenciam e se determinam mutuamente.

As aproximações ao tema do estudo, o aprofundamento teórico e empírico proporcionados pela pesquisa e a participação em pesquisas sobre a educaçãoo permanente em saúde na graduação e no mestrado possibilitaram a construção do trabalho apresentado nas próximas páginas.

A apresentação do texto está construída em oito capítulos:

$\checkmark$ No capítulo um está a contextualização da temática do estudo e sua justificativa.

$\checkmark$ No capítulo dois é apresentado o referencial teórico no qual se apoiam os pressupostos da pesquisa e também possibilitou 
a análise do material empírico: o processo de trabalho em saúde e enfermagem, profissões, profissionalismo e relações profissionais, teoria do agir comunicativo de Habermas e suas aplicações no campo da saúde, educação interprofissional em saúde e prática colaborativa, iniciativas de EIP no Brasil, a interdisciplinaridade da formação em saúde, prática colaborativa centrada no usuário, experiências de EIP na perspectiva habermasiana, a APS no Sistema Único de Saúde.

$\checkmark$ No capítulo três estão o objetivo geral e os objetivos específicos desta tese e o capítulo quatro descreve a trajetória metodológica da pesquisa composta de duas partes, o cenário do estudo, os sujeitos participantes, as técnicas de coleta de dados e de análise do material empírico, e também os aspectos éticos da pesquisa.

$\checkmark$ No capítulo cinco estão apresentados os resultados e discussão das duas partes da pesquisa com base na análise do material empírico à luz do quadro teórico, da revisão de literatura e do diálogo com autores que pesquisam o tema

No capítulo seis está exposta a síntese das convergências e contradições dos grupos focais.

$\checkmark$ No capítulo sete está a síntese final da triangulação dos resultados das duas partes da pesquisa em resposta aos objetivos pretendidos.

$\checkmark$ No capítulo 8 estão considerações finais sobre a pesquisa, com uma síntese percuso, contribuições do estudo, limitações e desdobramentos. 


\section{SUMÁRIO}

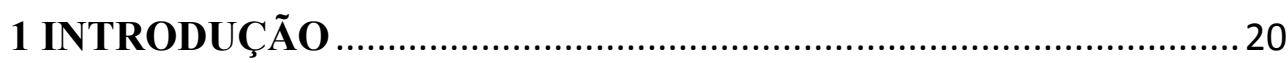

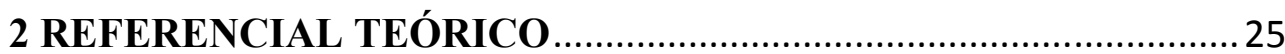

Processo de Trabalho em Saúde e Enfermagem ...........................................25

Profissões, Profissionalismo e Relações Profissionais ................................ 32

A Teoria do Agir Comunicativo de Jürgen Habermas e aplicações no

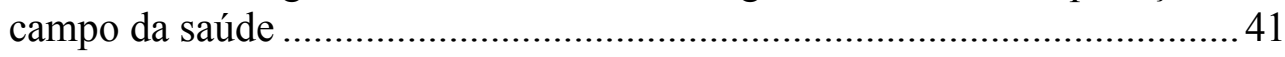

Educação Interprofissional em Saúde e Prática Colaborativa...................... 49

Iniciativas de Educação Interprofissional em Saúde no Brasil .................... 55

A Interdisciplinaridade na formação em saúde..........................................62

Prática colaborativa centrada no usuário.....................................................69

Experiências de educação interprofissional na perspectiva Habermasiana .73

Atenção Primária à Saúde no Sistema Único de Saúde ............................... 77

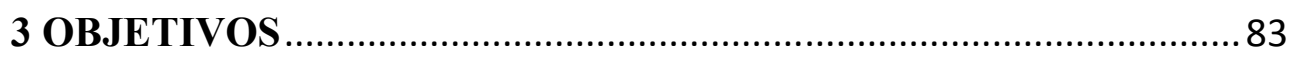

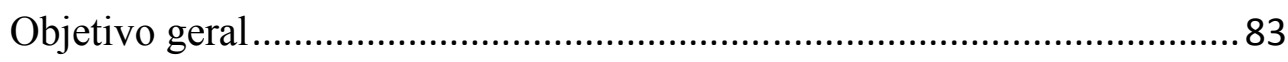

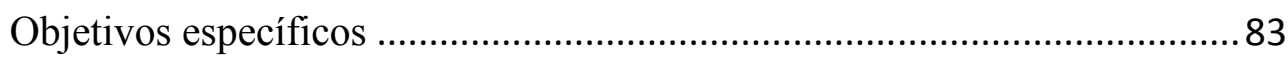

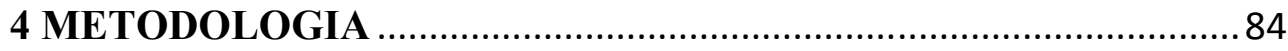

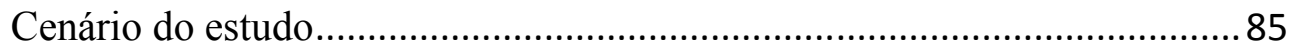

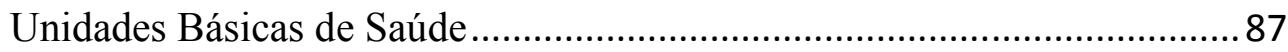

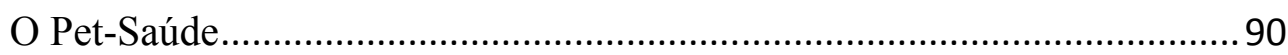

PRIMEIRA FASE DA PESQUISA DE CAMPO ................................... 91

Sujeitos participantes das entrevistas ..................................................... 91

SEGUNDA FASE DA PESQUISA DE CAMPO .................................... 92

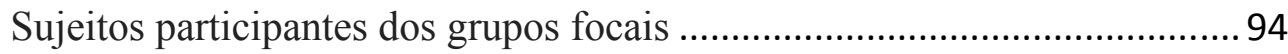

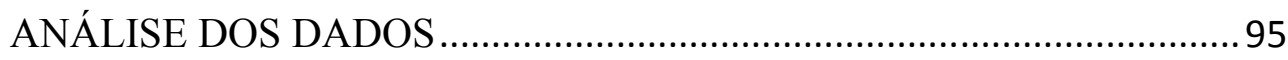

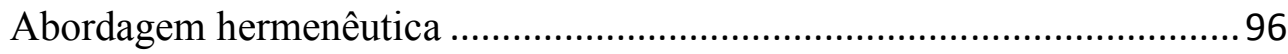

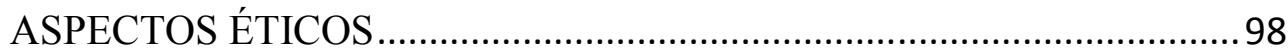

5 RESULTADOS E DISCUSSÃO ..................................................... 100

PRIMEIRA PARTE: RESULTADOS E DISCUSSÃO DAS

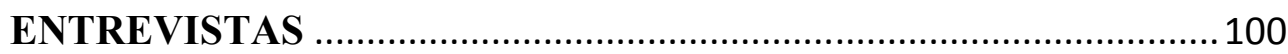


Categoria 1. A educação interprofissional em saúde desloca a ênfase da formação e das práticas para a integralidade do cuidado .....................103

Subcategoria 1.1 A formação orientada para atenção à complexidade das necessidades de saúde $\mathrm{x}$ prática fragmentada predominante .....................104

Subcategoria 1.2 Formação para o trabalho em equipe interprofissional em redes de atenção à saúde ........................................................................ 112

Subcategoria 1.3 Comunicação interprofissional para o cuidado ............... 121

Subcategoria 1.4 Educação interprofissional em saúde: modelo de formação contra-hegemônico.

125

Categoria 2. A educação interprofissional em saúde contribui para a reconfiguração das relações profissionais colaborativas .....................131

Subcategoria 2.1 Influência dos estereótipos profissionais na interação ... 132

Subcategoria 2.2 Interesses profissionais limitam a ampliação do escopo das profissões para atender as necessidades de saúde 134

Subcategoria 2.3 As interações interprofissionais pressupõe o respeito ao outro 149

Categoria 3. Preservação das competências complementares da especificidade profissional, reconhecimento das competências comuns e construção das competências colaborativas 156

Subcategoria 3.1 A formação em saúde com ênfase nas competências complementares/específicas e comuns.... 157

Subcategoria 3.2 Preservação da especificidade da identidade profissional na competência complementar/específica 165

Subcategoria 3.3 Influências da Educação Interprofissional em Saúde na construção da competência colaborativa: dinâmica de funcionamento das equipes de saúde. 168

Subcategoria 3.4 A Educação Interprofissional em Saúde possibilita o reconhecimento de competências comuns .............................................. 174

Barreiras para Educação Interprofissional em Saúde .......................178

Síntese dos resultados das entrevistas ............................................ 188

SEGUNDA PARTE: RESULTADOS E DISCUSSÃO DOS GRUPOS

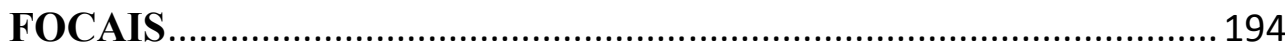

Grupo focal dos trabalhadores da unidade A ............................................ 195

Síntese dos resultados do grupo focal dos trabalhadores da unidade A.....206

Grupo focal dos trabalhadores unidade B .............................................. 207

Síntese dos resultados do grupo focal dos trabalhadores da unidade B... 216

Grupo focal dos estudantes ...........................................................217 
Síntese dos resultados do grupo focal dos estudantes..... 227

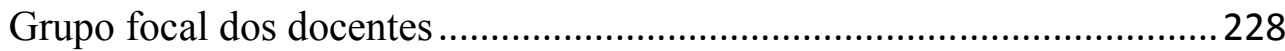

Síntese dos resultados do grupo focal dos docentes...................................238

6 SÍNTESE DAS CONVERGÊNCIAS E CONTRADIÇÕES DOS

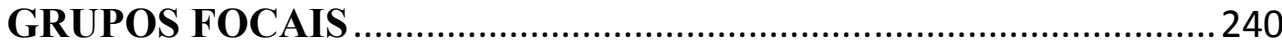

7 SÍNTESE FINAL: TRIANGULAÇÃO DOS RESULTADOS ......... 242

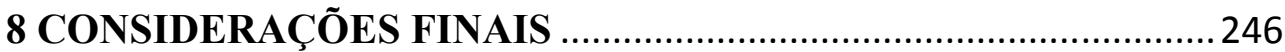

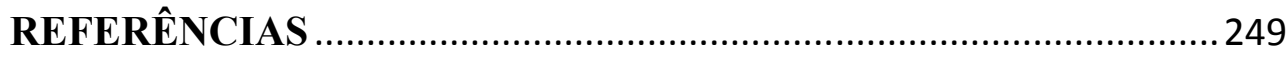

\title{
APÊNDICES
}

Apêndice 1 - Roteiro de entrevista........................................................2 274

Apêndice 2 - Roteiro para os grupos focais........................................... 275

Apêndice 3 - Termo de consentimento livre e esclarecido para as entrevistas 276

Apêndice 4 - Termo de consentimento livre e esclarecido para os grupos

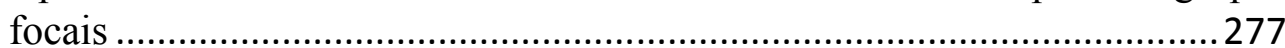

Apêndice 5 - Carta de autorização do serviço de saúde.............................278

\begin{abstract}
ANEXOS
Anexo 1 - Parecer do Comitê de Ética em Pesquisa da Escola de Enfermagem da USP 279

Anexo 2 - Parecer do Comitê de Ética em Pesquisa da Secretaria Municipal de Saúde de São Paulo 280
\end{abstract}




\section{INTRODUÇÃO}

O tema central deste estudo é a educação interprofissional (EIP) e a prática na enfermagem e na saúde. A EIP ocorre com a presença de dois ou mais estudantes de diferentes áreas da saúde, que aprendem juntos, por meio e sobre as demais profissões, para melhorar a colaboração e a qualidade do cuidado. Esta modalidade de educação possibilita maior interação entre estudantes e/ou profissionais e pode acontecer espontaneamente ou como produto de um programa de EIP (Barr et al., 2005).

A prática interprofissional, diz respeito ao trabalho em equipe realizado nos serviços de saúde, enquanto a EIP refere-se à formação inicial nos cursos de graduação e na educação permanente, dos profissionais no contexto do trabalho.

Internacionalmente, a EIP tem sido experenciada há mais de 30 anos na América do Norte, Europa e Ásia, como alternativa para mudança do perfil profissional na área da saúde, contudo, no Brasil o movimento da EIP ainda é incipiente e requer maiores investimentos. A experiência mais exitosa da EIP, conhecida no cenário nacional, está na Universidade Federal de São Paulo, Campus Baixada Santista, que possui um projeto pedagógico interprofissional.

A Organização Mundial de Saúde recomenda a implementação da EIP para transformar a educação profissional, com o objetivo de apoiar e promover avanços nos sistemas de saúde, em prol da equidade e atenção às necessidades de saúde dos usuários e população (WHO, 2013, 2010).

A educação permanente em saúde (EP), proposta como política pública de formação e desenvolvimento dos trabalhadores da saúde (Brasil 2004, 2007a) se aproxima da EIP, visto que pressupõe e promove a colaboração e interação dos saberes de diferentes áreas profissionais para a construção coletiva do aprendizado, tendo em vista, a ampliação da resolubilidade dos serviços e qualidade da atenção à saúde.

A educação contextualizada no trabalho, tem sido meu principal interesse de estudo desde a graduação, por meio de pesquisas realizadas sobre a EP, por acreditar que esse é um dos caminhos para a mudança das 
práticas de saúde, em direção à atenção das necessidades de saúde dos usuários/população do Sistema Único de Saúde (SUS) (Silva, 2006; Silva, Assano, 2006; Silva, Ogata, Machado, 2007; Peduzzi et al., 2007; Silva, 2009; Peduzzi et al., 2009a; Tronchin et al., 2009; Silva, Peduzzi; 2011).

As transformações são construídas no cotidiano das práticas pedagógicas e de saúde. Por isso, toma-se como pressuposto que as mudanças da formação profissional e do modelo de atenção à saúde ocorrem articuladamente (Feuerwerker, Capozzolo, 2013; Peduzzi et al., 2013; Pinto et al., 2013).

Destaca-se a relação de interdependência entre o sistema educacional e o sistema da saúde, que deve ser considerada em busca da reorganização do processo de trabalho em saúde, com foco nas necessidades dos usuários (Barr et al., 2005; Freeth et al., 2005; D’Amour, Oandasan, 2005; WHO, 2010; Frenk et al., 2010; IPEC, 2011).

Para a incorporação de mudanças na formação e nas práticas de saúde, conforme está previsto nas Diretrizes Curriculares Nacionais dos Cursos de Graduação em Saúde, o Ministério da Saúde (MS) do Brasil, por meio da Secretaria de Gestão do Trabalho e da Educação na Saúde (SGTES), com o apoio da Organização Pan-Americana da Saúde (OPAS), instituiu o Programa Nacional de Reorientação da Formação Profissional em Saúde (PRÓ-Saúde) com a Portaria Interministerial MS/MEC n.2.102 de 03 de novembro de 2005 (Brasil, 2005).

O PRÓ-Saúde, foi criado com o objetivo de integrar ensino-serviço, visando à reorientação da formação profissional, com mudanças curriculares, para incorporação da abordagem integral do processo saúdedoença, com ênfase na atenção primária (APS), para transformar a prestação de serviços à população brasileira (Brasil, 2005), e tem como estratégia o Programa de Educação pelo Trabalho para Saúde (PET-SAÚDE).

Para a implementação da EIP, torna-se necessário avançar no processo de consolidação do SUS, tendo em vista a transformação das práticas fundamentada na concepção da integralidade e qualidade da atenção à saúde. A integralidade é uma perspectiva promissora, frente ao atual quadro de aumento das doenças crônicas que requerem atuação 
interprofissional para atender as necessidades do usuário, prover a comunicação e integração entre os serviços que compõem a rede de atenção à saúde (Frenk et al., 2010).

O aumento da expectativa de vida e das doenças crônicas que caracterizam as mudanças epidemiológicas, requerem um novo perfil profissional, preparado para abordar as múltiplas dimensões das necessidades de saúde dos usuários/população, mediante a colaboração interprofissional (Feuerwerker, 2012; Mendes, 2011; Zwarenstein, Goldman, Koppel, 2009; Frenck et al., 2010; Baindridge, Nasmith, Orchard, 2010).

A integralidade como eixo norteador da formação em saúde requer articulação dos saberes e práticas, numa lógica interprofissional, a partir de um conceito ampliado de saúde, que respeita a subjetividade do usuário, mediante o acolhimento e a responsabilização profissional, para superar as práticas centradas em procedimentos com foco na doença (Ceccim, Feuerwerker 2004a; Ceccim 2005a, Feuerwerker, 2005).

Contudo, o modelo predominante de educação e desenvolvimento dos trabalhadores da saúde é uniprofissional (Costa et al., 2014; Feuerwerker, Capozzolo, 2013; Reeves, Zwarentein, Gooldman, 2008; Barr et al., 2005) e tem como desdobramento a fragmentação do cuidado e o corporativismo profissional. A formação uniprofissional, reforça a prática biomédica hegemônica com o isolamento profissional, fragmentação dos saberes e práticas.

Para a mudança do modelo biomédico de atenção à saúde no SUS, orientada para a integralidade das ações, torna-se necessário que também ocorram modificações na formação profissional em prol da EIP para o trabalho em equipe.

No trabalho em equipe, a integração do trabalho dos diferentes profissionais da saúde, depende em parte da identificação dos nexos presentes entre as ações. Ou seja, requer o reconhecimento do trabalho do outro e sua concepção do processo saúde-doença. Isso quer dizer que os profissionais podem estar apoiados na concepção da integralidade da saúde, 
que justifica e os motiva para o trabalho em equipe, em substituição do trabalho individualizado por profissão (Peduzzi, 2007).

Uma equipe interprofissional envolve profissionais que interagem entre si, com interdependência no processo de trabalho, compartilhando o processo de negociação/tomada de decisão para alcançar objetivos comuns à equipe, com foco nas necessidades de saúde dos usuários (Iribarry, 2003; Martín-Rodriguez et al., 2005; D'Amour et al., 2008; Peduzzi, Oliveira, 2009; Nugus et al., 2010; Peduzzi et al., 2011; Peduzzi et al., 2013). A EIP pode contribuir para a formação com ênfase trabalho colaborativo em equipe, centrado no usuário (Orchard et al., 2012; Olenick et al., 2010; Zwarenstein et al., 2009; Martín-Rodriguez et al., 2005).

O recente estudo de Reeves et al. (2014), aponta evidências da EIP para a satisfação do usuário, compartilhamento nos processos de tomada de decisão na prática clínica, desenvolvimento da prática colaborativa e redução das taxas de erros.

Com base nesse contexto, busca-se investigar as concepções da EIP na APS e sua articulação com as práticas da saúde no Brasil. A dinâmica do trabalho na APS, possibilita maior aproximação às necessidades de saúde da população e favorece sua apreensão ampliada e contextualizada em espaços de interação, nos processos de trabalho em saúde. Assim, a APS constitui um espaço privilegiado para o desenvolvimento da EP e da EIP.

O presente estudo tem como finalidade compreender as concepções da EIP e sua articulação com as práticas de saúde na APS. Justifica-se pela originalidade do estudo, pois no Brasil, não foram encontradas pesquisas sobre as concepções da EIP, assim torna-se necessário reconhecer o entendimento dos atores sociais envolvidos com os processos de trabalho e formação profissional sobre o tema, visto que este poderá subsidiar o fortalecimento tanto da prática como da EIP no SUS.

$\mathrm{O}$ conhecimento das concepções de trabalhadores, estudantes e docentes sobre EIP e suas relações com a prática interprofissional no contexto da APS, contribuirá para o planejamento e implementação de estratégias e ações que fortaleçam a APS interprofissional, interdisciplinar com mudanças na formação e prática profissional. 
Considera-se importante desenvolver pesquisas com ênfase no resgate da esfera do agir comunicativo no contexto da educação, pois, atualmente os processos de aprendizagem estão organizados com centralidade no agir instrumental ou técnico-científico.

Entende-se que a articulação entre as instituições de ensino e serviços da saúde, a promoção e ampliação da abordagem integral do processo saúde doença e a EIP constituem três eixos de mudanças. A incorporação conjunta dos eixos mencionados, tem o potencial de transformar as práticas de saúde para maior resolubilidade dos serviços e da qualidade da atenção à saúde. Espera-se que os resultados dessa pesquisa contribuam para o aprofundamento do saber sobre a prática e educação interprofissional em saúde/enfermagem na APS e possibilitem mudanças na formação e práticas da saúde na perspectiva da integralidade. 


\section{REFERENCIAL TEÓRICO}

Para fundamentar a compreensão do objeto de estudo, a educação e a prática interprofissional no contexto da Atenção Primária à Saúde, utilizamse os conceitos: processo de trabalho em saúde e enfermagem, profissões e profissionalismo, agir comunicativo, EIP, prática colaborativa, prática centrada no usuário e APS. A complexidade do referido objeto estimulou a busca de conceitos sociológicos presentes em teorias consolidadas como: o Trabalho de Karl Marx e a Teoria do Agir Comunicativo (TAC) de Jürgen Habermas, cuja utilização possibilita a análise das interações interprofissionais no âmbito da formação e das práticas de saúde.

\section{PROCESSO DE TRABALHO EM SAÚDE E ENFERMAGEM}

A produção científica sobre o processo de trabalho em saúde no Brasil está fundamentada nos estudos de Maria Cecília Ferro Donangelo (1975, 1976) e Ricardo Bruno Mendes-Gonçalves (1994, 1979). Ambos desenvolveram pesquisas sobre o trabalho médico e produziram contribuições fundamentais para compreensão do campo da saúde na sociedade, com a introdução da categoria marxiana trabalho, na abordagem do processo saúde-doença. Donangelo é considerada a pioneira do pensamento social na área da saúde (Nunes, 2008), que se tornou um referencial para a constituição da abordagem articulada das práticas de saúde na sociedade e seus determinantes sociais como, o modelo assistencial e o mercado de trabalho. Posteriormente, Mendes-Gonçalves desenvolveu o conceito de processo de trabalho em saúde (Peduzzi, Schraiber, 2009; Rocha, Almeida, 2000).

Considera-se que o processo de trabalho em saúde diz respeito à dimensão microssocial do exercício do cotidiano do trabalho, inserido na dinâmica macrossocial do trabalho humano, que se refere a aspectos das estruturas sociais e históricas que o constituem e se articulam a ele (Pires, Gelbecke, Matos, 2004; Peduzzi, Schraiber, 2009). 
A esfera macrossocial caracteriza-se por mudanças ocorridas no mundo do trabalho, a partir da década de 1970, com desdobramentos na organização do trabalho mediante a crescente introdução das tecnologias de informação e da microeletrônica (Peduzzi, 2002; Antunes, 2005). O desemprego, a internacionalização do capital e da produção, a qualificação e a desqualificação dos trabalhadores decorrentes da reestruturação tecnológica reduziu a inserção dos trabalhadores na produção industrial (Antunes, 2005).

A esfera microssocial do processo de trabalho em saúde pode ser compreendida pelas práticas sociais dos trabalhadores da saúde inseridos no dia-a-dia da produção e consumo de serviços de saúde, principalmente no tocante às interações e relações intersubjetivas na produção do cuidado em saúde (Pires, Gelbcke, Matos, 2004; Peduzzi, Schraiber, 2009).

Inserido no setor terciário do modo de produção capitalista o trabalho em saúde faz parte dos serviços. O setor dos serviços envolve as atividades que não estão diretamente relacionadas com a produção industrial e o setor primário da economia. Tratam-se de atividades comerciais de serviços como: saúde, educação, segurança pública entre outros (Ribeiro, Pires, Blank, 2004). Os serviços são caracterizados por sua utilidade imediata aos usuários como meios de recuperar, preservar ou melhorar algum bem que possuem ou para uso pessoal de acordo com os valores e comportamentos socialmente conhecidos (Nogueira, 1994). O serviço expressa-se na necessidade de cumprir uma finalidade, tal qual ocorre em todo processo de trabalho, e seu resultado constitui bens imateriais que podem ser comercializados.

A produção e consumo ocorrem simultaneamente nos serviços, por isso, o produto do processo de trabalho em serviços é intangível e inestocável, sendo impossível a sua utilização como mercadoria (Meirelles, 2006).

O serviço não é produzido como no setor industrial, desse modo, utiliza-se a expressão prestação de um serviço (Meirelles, 2006), que na saúde é caracterizada pela interação entre trabalhador e usuário para interpretação das necessidades de saúde. 
O caráter interativo do processo de trabalho em saúde concretiza-se no encontro entre trabalhadores da saúde e usuários, mediado pela interação intersubjetiva que permite caracterizá-lo como trabalho imaterial (Carvalho, Peduzzi, Mandú, Ayres, 2012; Lazzarato Negri, 2001).

O trabalho imaterial é caracterizado pela reprodução da subjetividade, ou seja, o processo de trabalho pautado na interação intersubjetiva (Lazzarato, Negri, 2001).

A perspectiva do trabalho imaterial se fortaleceu com as mudanças contemporâneas no mundo do trabalho que se iniciaram na década de 1970, no qual a indústria passou a controlar a venda dos produtos e sua relação com os consumidores além de todo o processo de produção. Assim, ocorreu um deslocamento da ênfase do momento da produção para o consumo fortalecido pela informação e propaganda (Lazzarato, Negri, 2001).

A reengenharia produtiva ou reestruturação do trabalho propiciou a valorização da dimensão subjetiva do trabalhador em detrimento à maisvalia, ou seja, o excedente da produção convertido em lucro foi substituído pelo desenvolvimento do trabalhador para a produção de riqueza. O trabalhador é reconhecido como o saber social geral" cuja atividade intelectual empregada na produção é o novo lócus de exploração no trabalho (Lazzarato, Negri, 2001, p. 30).

Neste contexto, no plano microssocial que envolve o cotidiano do trabalho, os sujeitos e a intersubjetividade, a discussão sobre o processo de trabalho não pode ser reduzida à ação instrumental. A intersubjetividade é uma dimensão presente no trabalho que permite reconhecer os sujeitos e sua ação comunicativa.

Por contemplar as dimensões macro e microssocial, entende-se que o trabalho em saúde possui uma dupla face: ação produtiva e interação social. O trabalho como ação produtiva se refere à ação instrumental da racionalidade técnico-científica, com finalidade determinada, ação dirigida a um fim. Como interação social, considera-se a ação comunicativa intersubjetiva na busca de entendimento e coordenação das ações entre os trabalhadores e usuários (Schraiber et al., 1999). Para o estudo do trabalho em serviços da saúde consideram-se tanto os elementos constitutivos do 
processo de trabalho quanto a dinâmica intersubjetiva, na qual é possível a comunicação/interação pautada na argumentação.

O processo de trabalho em saúde compreende a produção de cuidados, ações assistenciais e prestação de serviços para atender: as expectativas da sociedade de mercado, assistência à saúde e conquista do direito à saúde a partir da reforma sanitária brasileira (Schraiber et al., 1999).

As práticas sociais de saúde são entendidas como trabalho, definido por Marx como uma relação estabelecida entre o homem e natureza, na qual o homem procura suprir suas necessidades, apropriando-se da matéria mediante a transformação da natureza, que ao mesmo tempo o modifica (Marx, 1988).

"Os elementos (...) do processo de trabalho são a atividade orientada a um fim (...), seu objeto e seus meios" (Marx, 1988, p. 143). O objeto de trabalho pode ser a matéria em seu estado natural, ou matérias-primas resultantes de trabalho anterior. Os meios de trabalho são os instrumentos para transformação da natureza que ao longo do tempo se desenvolveram com a aplicação do conhecimento científico (Liedke, 2002).

"O meio de trabalho é (...) um complexo de coisas que o trabalhador coloca entre si e o objeto de trabalho, que serve como condutor de sua atividade sobre esse objeto" (Marx, 1988, p. 143).

O objeto de trabalho é aquilo sobre o qual incide a ação do trabalhador, que no campo da saúde corresponde às necessidades humanas de saúde, sentidas e trazidas aos serviços pelos usuários (Peduzzi, Schraiber, 2009).

A satisfação das necessidades de saúde dos usuários que procuram os serviços constitui a finalidade do processo de trabalho em saúde (Mendes-Gonçalves, 1994) e envolve tanto os aspectos circunscritos ao corpo biológico quanto os de ordem social, subjetiva e da dimensão política da vida (Mandú, Almeida, 1999).

Dada a complexidade da definição do conceito, Cecílio e Matsumoto (2006) construíram uma taxonomia de necessidades de saúde organizada em quatro grupos principais: necessidades de boas condições de vida, garantia 
de acesso a todas as tecnologias que prolonguem a vida, necessidade de ter vínculo com um profissional ou equipe (sujeito em relação), necessidade de autonomia e autocuidado na escolha do 'modo de andar a vida' (construção do sujeito).

As necessidades de saúde são construídas social e historicamente de modo consciente (Mendes-Gonçalves, 1979) e reconhecidas mediante a aplicação de um conjunto de saberes técnico-científicos, tais como a clínica e a epidemiologia, conhecidos como 'saber operante' por fundamentar a ação dos trabalhadores da saúde (Mendes-Gonçalves, 1994). O processo de trabalho constitui uma prática social capaz de transformar necessidades.

Entende-se que os modelos de organização do processo de trabalho em saúde se referem à operacionalização das tecnologias disponíveis para as práticas de atenção à saúde dos usuários/população (Ayres, 2009), pois orientam o recorte do objeto de intervenção.

O modelo hegemônico que orienta as práticas de saúde é o modelo biomédico, cuja ênfase está na abordagem restrita à patologia e seus comprometimentos biológicos em prol do tratamento para a remissão dos sinais e sintomas por meio da prática médica especializada centrada em procedimentos técnico-científicos (Mendes-Gonçalves, 1994).

Frente às práticas que reduzem a abordagem das necessidades de saúde dos usuários/população, a integralidade se constitui um horizonte para a organização das práticas de saúde, por possibilitar a apreensão ampliada das necessidades de saúde, contextualizadas na realidade social, econômica e cultural, com articulação das ações de promoção, prevenção e recuperação da saúde (Mattos, 2001, 2004).

O cuidado pode ser considerado uma possibilidade de expressão da integralidade. Nesse sentido, requer que algumas características estejam presentes nas práticas de cuidado, tais como: o agir comunicativo articulado ao instrumental, a integração entre ações de promoção à saúde, preventivas e curativas com articulação dentro de cada serviço, entre eles e com outros setores, para atender a complexidade das necessidades de saúde dos usuários/população, considerando suas singularidades e contexto histórico e social (Mattos, 2004). 
Uma proposta de trabalho interativa e argumentativa inclui o outro. Desse modo, a relação entre o profissional da saúde e os usuários se estabelece dialogicamente, por meio da produção de vínculo (Rivera, Artmam, 2012).

A organização do cuidado orientado pela integralidade pressupõe a gestão do trabalho em redes de atenção à saúde, um modelo assistencial orientado pela responsabilização e vínculo entre os profissionais da saúde e usuários, efetivo trabalho em equipe com colaboração entre os profissionais, disponibilidade de recursos para continuidade da assistência local e em outros níveis de atenção e sistemas de informação para possibilitar a gestão do processo terapêutico pelas equipes de saúde (Magalhães Junior, Oliveira, 2006).

Apesar das mudanças na prática clínica em decorrência da transição do perfil epidemiológico e o envelhecimento da população que requer intervenções coletivas com a participação de outros profissionais e a contribuição de seus saberes, nota-se que a prática médica ainda ocupa papel central na organização das práticas e dos serviços de saúde. Os estudos de Freidson (1978, 1998), Carapinheiro (1993), Schraiber (1993), Lima, Almeida, (1999), Lopes (2001), Farias, Vaitsman, (2002), abordam a posição nuclear do saber médico e a atuação periférica dos demais profissionais nas práticas de saúde.

Neste contexto, destaca-se o trabalho da enfermagem que consiste em uma área de saber que compõe o processo de trabalho em saúde, cuja produção brasileira baseia-se nos estudos de Almeida e Rocha (1986), Melo 1986 e Silva (1986) e outros. A inserção do enfermeiro no campo da saúde ocorreu nos hospitais, com a finalidade de organizar o ambiente terapêutico e controlar os profissionais da enfermagem e também executar ações subordinadas às decisões médicas, em prol do tratamento (Lopes, 2001; Almeida, Rocha, 1986).

Diferente de outras áreas profissionais, no Brasil, o trabalho da enfermagem é marcado pela acentuada divisão técnica do trabalho no interior da mesma composição profissional, com diferentes níveis de 
formação, enfermeiros e trabalhadores auxiliares (Melo, 1986; Peduzzi, Anselmi, 2002).

A fragmentação das ações profisssionais decorre da incorporação parcelar do trabalho e da lógica taylorista nas práticas de saúde (Ribeiro, Pires, Blank, 2004; Pires, Gelbcke, Matos, 2004). A divisão técnica do trabalho consiste em uma cisão entre o trabalho manual e intelectual, com momentos separados entre a concepção e a execução que impedem o acompanhamento completo do processo de produção (Pires, Gelbcke, Matos, 2004; Melo, 1986).

Com a divisão técnica do trabalho, os enfermeiros ficaram responsáveis pelas ações gerenciais e os trabalhadores de enfermagem de nível médio pelas ações de cuidado direto aos usuários (Almeida, Rocha, 1986; Peduzzi, Anselmi, 2002; Pires, 2009).

Apesar da ênfase nas ações gerenciais, o processo de trabalho do enfermeiro é reconhecido pela composição predominante de duas dimensões: assistencial e gerencial (Peduzzi, Anselmi, 2002; Felli, Peduzzi, 2005; Silva, 2010) às quais podem ser agregadas outras especificidades como a dimensão educacional (Kirchhof, 2003; Leopardi, Glebcke e Ramos; 2001), a pesquisa e a participação política (Sanna, 2007).

Peduzzi e Alnselmi (2002), consideram que a dupla dimensão assistencial gerencial também está presente no trabalho dos profissionais de enfermagem de nível médio, embora sua principal atribuição seja o cuidado direto dos usuários.

O enfermeiro é o profissional responsável pelas ações de gerenciamento, supervisão, treinamento e controle dos profissionais de enfermagem (Matumoto et al., 2011), é reconhecido por realizar a articulação entre os profissionais da equipe de saúde pelas habilidades de comunicação que utiliza junto aos usuários e profissionais (Propp et al., 2010; Orchard, 2010; Rossi, Lima, 2005; Willing, Lenardt, 2002).

Assim, entende-se que o enfermeiro e os demais profissionais de saúde compõem um amplo leque de profissões que contribuem para a abordagem mais ampla das necessidades de saúde dos usuários e população, bem como para aumentar a resolutividade e qualidade dos serviços de 
saúde, em particular na APS, para a qual é necessário iniciar essa abordagem desde a formação inicial de graduação.

Neste estudo, a EIP é entendida como uma nova perspectiva no modelo da formação profissional em saúde, que pode contribuir para a construção de práticas de saúde interprofissionais colaborativas.

\section{PROFISSÕES, PROFISSIONALISMO E RELAÇÕES PROFISSIONAIS}

Para compreender as relações interprofisssionais é importante entender os conceitos de profissão, profissionalismo, ocupação e suas origens.

No contexto da produção das abordagens sociológicas das profissões, destacam-se os autores funcionalistas como Carr-Saunders, Parsons, Goode e Merton que deram os primeiros passos no contexto da sociologia das profissões. Posteriormente, Eliot Freidson, um sociólogo da segunda geração de interacionistas simbólicos da Universidade de Chicago, assim como, Everett Hughes, Erving Goffman, Howard Becker e também os autores weberianos que enfocam o poder profissional, suas ideologias e projetos (Santos, 2011).

Neste estudo, optou-se pela construção sociológica desenvolvida por Freidson que é reconhecido pela relevância da contribuição de seus estudos à sociologia médica e das profissões. Seu primeiro trabalho, sobre o tema da profissionalização, nunca concluído, foi realizado em parceria com Howard Becker na Universidade de Chicago. Posteriormente, realizou um estudo sobre as interações dos profissionais de diferentes áreas que participam do tratamento de pacientes. A referida pesquisa, com um grupo interprofissional da área da saúde, foi à base para seus trabalhos subsequentes (Bonelli, 1998).

Os aspectos mais relevantes das contribuições de Freidson são: a conceituação das profissões, análise dos poderes, privilégios profissionais, e a defesa das profissões (Bonelli, 1998). 
Freidson sinaliza que Talcott Parsons foi o primeiro teórico americano a abordar o tema das profissões. Com destaque para os advogados e médicos, debateu a importância das profissões nas sociedades industriais (Bonelli, 1998).

Parte da conduta dos profissionais da saúde se refere às expectativas e demandas dos pacientes, por isso, Freidson considera importante analisar a percepção dos pacientes, sobre os profissionais que nem sempre organizam seu trabalho a partir dos objetivos profissionais (Bonelli, 1998).

Profissão é um conceito histórico e mutável de origem anglosaxônica. Requer formação específica para obter credenciamento profissional e posição no mercado de trabalho, afinal, as profissões constituem parte de um trabalho ou força de trabalho (Freidson, 1998).

Quando uma profissão organizada adquire o direito exclusivo de realizar determinado trabalho e controlar a formação necessária para seu exercício, ocorre a profissionalização (Freidson, 1978, 1998).

No início dos anos 70, as produções sobre o profissionalismo passaram a destacar questões de conflito e poder. Freidson concentrou-se em estudos sobre a medicina, medicalização, divisão do trabalho, sistema de saúde, relações com outras ocupações e pacientes (Freidson, 1978, 1998).

Michael Foucault destaca-se nos estudos sobre a influencia do conhecimento profissional, na política social e cotidiana, pois as profissões fazem avançar o saber incorporado nas disciplinas (Freidson, 1998).

O conhecimento profissional exerce forte influência sobre a formação da opinião pública, popular e institucional ao participar da elaboração da explicação de fatos oficialmente aceitos pela sociedade e comunidade científica (Freidson, 1998).

A sociologia das profissões carece de sólido embasamento teórico, pois se mantém fragilmente ligada à teoria de classes por alguns pesquisadores. Opostamente, Freidson defende a importância de pautar a discussão sobre as profissões na sociologia do trabalho e na teoria das ocupações, pelo fato da profissão representar uma ocupação e não uma classe. As ocupações podem ser diferenciadas pelo conhecimento e competências especializadas para a realização de diferentes ações, no 
processo de divisão do trabalho. A sociologia do trabalho possibilita a análise do conhecimento e competência especializados na diferenciação do trabalho em ocupações (Freidson, 1998).

Apesar do desenvolvimento da sociologia das profissões, falta consenso a respeito do conceito de profissão. Nesse contexto, uma opção sugerida pelo autor seria considerar o processo pelo qual as profissões são profissionalizadas, ao invés de destacar seus atributos. O principal problema para tratar o conceito de profissão está em reduzi-lo a um conceito genérico, ao invés de considerar sua natureza histórico-social em constante processo de mudança (Freidson, 1998).

A raiz histórica das ocupações está nas universidades medievais europeias, que propagaram as três principais profissões liberais: a medicina, a advocacia e o clero, reconhecidas como profissões de status, diferentemente das mais recentes profissões ocupacionais, cujo status depende exclusivamente de uma educação superior em escolas de elite (Freidson, 1978, 1998).

Assim, a profissão é tratada como uma entidade empirica sobre a qual há pouco terreno para generalizações como classe homogênea ou categoria conceitual logicamente excludente. A tarefa de uma teoria das profissões é documentar a desordem e a inconsistência do fenômeno empírico e explicar seu caráter naqueles países onde ele existe (Freidson, 1998 p. $60)$.

A questão do poder profissional pode ser elucidada ao considerar que o controle do trabalho é realizado muito mais pelos profissionais do que pelos consumidores. Nesse caso, ao pensar a respeito do trabalho realizado pelo proletariado industrial, na concepção clássica marxista, destaca-se que eram completamente destituídos de poder, pois vendiam sua força de trabalho para os donos do capital, das terras e dos meios de produção. O trabalho realizado por tal proletariado não requer qualquer conhecimento técnico especializado, é fragmentado e pode ser realizado por qualquer pessoa sem treinamento especial. O empregador planeja, supervisiona e avalia o trabalho realizado, de modo que o trabalhador não exerce poder algum sobre o processo de trabalho por ele desempenhado (Freidson, 1998).

Contrariamente, o profissional exerce o controle sobre seu trabalho que está organizado por meio de corporações ou associações profissionais que administram o rol de conhecimentos e competências, necessários para o 
exercício de sua prática profissional, assim como os requisitos mínimos para sua formação determinando também os critérios éticos e técnicos pelos quais são avaliados. Tais profissionais atuam como autoridade de sua área de saber, que detém o poder por meio do conhecimento exclusivo de suas práticas profissionais, com influência sobre a opinião popular e política (Freidson, 1998).

Em busca da produtividade na produção de bens e serviços, a divisão do trabalho como modo de organização do trabalho, é estabelecida com tarefas definidas e supervisionadas hierarquicamente, que contribuem para a alienação objetiva e subjetiva do trabalhador em relação ao trabalho por ele realizado (Freidson, 1998).

Em uma organização produtiva podem surgir novas formas de ocupação ou papéis especializados (Pettigrew, 1973). Na organização informal do trabalho, representada por aqueles que de fato estão envolvidos na administração e produção, os processos de interação interpessoal dos trabalhadores entre si e com os supervisores na negociação, podem modificar o modo de conceber e realizar as tarefas (Freidson, 1998).

Com a profissionalização, o controle da divisão do trabalho deixou de ser realizado pela administração para ser coordenado em torno da atuação profissionalizada, na medida em que, desempenha suas atividades e controla os serviços de suporte necessários. A hierarquia da autoridade passa a ser profissional e não administrativa (Freidson, 1998).

Na pós-Revolução Industrial com a divisão do trabalho socialmente organizada, tornou-se função do profissional saber como será realizado o trabalho estabelecido pelas associações profissionais (Freidson, 1998).

As associações profissionais representam a busca pelo poder político de profissões engajadas em um processo político para promover/defender interesses relacionados a conhecimentos e competências privativos da área, para garantir o controle e organização do seu trabalho. Estabelecem assim, os limites profissionais para o desempenho do trabalho profissional, interação com os pares, clientes e membros de outras ocupações. A ideologia profissional pode ser utilizada como um artifício na definição da área de atuação privativa e no processo de competição entre as 
profissões, na tentativa de controlar determinadas atividades e reivindicações (Freidson, 1998).

$\mathrm{Na}$ sociologia, ocupação pode ser definida como as atividades produtivas da sociedade (Freidson, 1998). As ocupações são criadas como parte da divisão organizacional do trabalho. Trata-se do modo pelo qual os trabalhadores produtivos se identificam.

Dois critérios são utilizados para definir as ocupações. O primeiro relaciona as tarefas e funções, contudo, não se pode definir uma ocupação exclusivamente por suas tarefas técnicas, pois poderia desencadear uma confusão entre os conceitos de ocupação e tecnologia. O segundo critério, estratifica as ocupações de acordo com sua hierarquia, prestígio e poder, com ênfase nas relações de produção que não permitem explicar porque o trabalho é realizado de determinada maneira e como são as relações entre os trabalhadores (Freidson, 1998).

Os grupos ocupacionais buscam a criação de abrigos de mercado, como uma consequência do controle obtido sobre o trabalho em busca de autoproteção e segurança econômica para os trabalhadores. Nesse processo, há exigência de que os consumidores utilizem o trabalho fornecido pelos membros da ocupação. O Estado pode impor o controle legal para proteção das atividades do grupo que constitui profissões, quando the é facultado o controle sobre o treinamento, recrutamento e identificação de membros competentes (Freidson, 1998).

Quando uma ocupação possui a capacidade de negociar coletivamente com consumidores e Estado para reivindicar jurisdição sobre um conjunto de tarefas, constitui um abrigo seguro no mercado de trabalho, reconhecido como corporação ocupacional (Freidson, 1998).

As profissões credenciadas e prestigiadas, como a medicina e advocacia, têm como diferencial a capacidade de se autocontrolar e autoregulamentar. Seu credenciamento comprova o treinamento formal, considerado como pré-requisito para sua prática, todavia, pequena parcela das ocupações credenciadas podem ser consideradas autônomas ou autogovernadas (Freidson, 1998). 
O conceito de profissionalização implica em um diferente princípio de autoridade sobre o trabalho. O controle sobre o modo como o trabalho é realizado e da sua qualidade, está sobre a responsabilidade dos trabalhadores e não da administração. Exemplifica-se esse modelo de organização da divisão do trabalho, ao analisar a medicina que é mais coordenada por si mesma como profissão dominante, do que pela administração do serviço, assim como, ordena o trabalho de outras ocupações, até mesmo de trabalhadores terceirizados (Freidson, 1998, p.134; Carapinheiro, 1993).

O uso mais comum da palavra profissão se refere à distinção entre profissional e amador, que realiza tarefas sem preocupar-se com seu valor de troca no mercado, ao contrário do profissional que realiza o trabalho pelo valor de troca no mercado, como uma forma de ganhar a vida. Em inglês, a palavra profissão é sinônimo de vocação e ocupação, que se estabelece como trabalho, com valor de troca, diferentemente das atividades realizadas por donas de casa e voluntários que não são reconhecidos como trabalho (Freidson, 1998).

Várias definições podem ser empregadas para definir um profissional. Primeiramente podem ser considerados aqueles que têm anos de formação com educação formal superior. O segundo aspecto define como profissional, aquele que possui conhecimentos e competências específicos para a realização de tarefas (Freidson, 1998).

Devido a dificuldade em diferenciar os profissionais pelo critério da formação de ensino superior, nos Estados Unidos foram incorporados os conceitos de categorias profissionais e técnicas. Contudo, a amplitude do conceito profissional, levou outro pesquisador, Bell a separar o conceito em profissional, semiprofissional e técnicos (Freidson, 1998).

Outro critério empregado para definir a profissionalização é o tipo de trabalho realizado na natureza ocupacional, com destaque para a presença ou ausência de poder dos trabalhadores, em controlar os termos e condições do seu próprio trabalho. Tal critério do profissionalismo, expresso como monopólio ou autoridade ocupacional, pode ser compreendido ao analisar a prática médica, cuja corporação profissional tem completo controle sobre o mercado de trabalho, para seu exercício com respaldo da legislação. A 
ocupação profissional organizada, controla as tarefas realizadas por seus profissionais. Embora haja interdependência entre os profissionais na área da saúde, o médico ainda mantém o monopólio sobre o ordenamento e supervisão do trabalho (Freidson, 1998).

Algumas mudanças incorporadas na APS brasileira, com a Estratégia de Saúde da Família, precisam ser consideradas, pois contribuíram para o estabelecimento da prática colaborativa entre médicos e enfermeiros das equipes de saúde da família. Nesse contexto, os enfermeiros realizam suas práticas com mais autonomia, pautados em protocolos clínicos para atenção à saúde dos grupos prioritários. Estes profissionais, tomam decisões compartilhadas frente à imprevisibilidade e complexidade das necessidades de saúde apresentadas pelos usuários (Brasil, 2012).

As principais características que diferenciam as profissões são expertise, credencialismo e autonomia. A expertise, envolve uma competência superior na execução do trabalho, que não é normal para qualquer trabalhador, pois requer um treinamento e práticas específicos para desenvolvê-la. O credencialismo das profissões refere-se ao licenciamento para o exercício profissional, a regulamentação de mercado e programas exclusivos de treinamento. A expertise é indissociável do credencialismo, devido o excesso de aprendizado disponível, utiliza-se as credenciais como indicadores. A autonomia profissional é manifesta por poucas ocupações e está relacionada à ideia de experiência que permite o exercício do arbítrio, julgamento próprio e responsabilidade profissional própria (Freidson, 1998).

A autonomia total seria mantida somente nos casos em que houvesse um monopólio ocupacional, composto por três dimensões: econômica, política e administrativa. O monopólio econômico ocorre quando a profissão controla o recrutamento, treinamento e credenciamento. O monopólio político ocorre quando a profissão é aceita como porta voz de assuntos relacionados à sua área de conhecimento e competência, como a definição da legislação e normas administrativas relacionadas ao seu trabalho. O monopólio administrativo estabelece padrões para o trabalho e sua avaliação (Freidson, 1998). 
Ao considerar as três dimensões necessárias para o exercício da autonomia profissional, pode-se dizer que a autonomia é relativa, pois os profissionais estão submetidos aos padrões e expectativas impostas pelo mercado de trabalho, com o controle do Estado que garante a autonomia condicional para algumas profissões (Freidson, 1978, 1998).

A autonomia profissional no campo da saúde se estende a todos os profissionais, pois não é possível planejar e padronizar completamente todas as ações de saúde, frente à imprevisibilidade das necessidades de saúde. Até mesmo a aplicação de protocolos clínicos requer que os profissionais tomem em consideração a singularidade do caso ou situação (Schraiber, Peduzzi, 1993).

A perda do controle sobre a organização profissional do trabalho, afeta diretamente a autonomia profissional e o status social das profissões. Situação que se acentua com a limitação do exercício da medicina liberal praticada mediante consultórios individuais e recebimento de honorários, que passa a estar condicionada às regras de empresas privadas que representam convênios privados de saúde. Apesar da limitação da autonomia médica, historicamente, a profissão médica impõe limites ao escopo de práticas das outras profissões da saúde (Freidson, 1978; Schraiber, 2008).

Freidson (1978), Lopes (2001), Carapinheiro (1993), consideram que a ampliação da autonomia profissional, torna-se possível para profissões que atuam fora de serviços de saúde, como hospitais e clínicas. Nesse sentido, o trabalho do enfermeiro fica subordinado às regras das instituições. Originado no contexto hospitalar, a profissão do enfermeiro caracterizada predominantemente pelo cuidado do usuário se consolidou subordinada ao trabalho médico.

A autonomia do exercício da medicina se expressa no domínio e conhecimento sobre o trabalho que possibilita sua regulação, avaliação e desempenho do trabalho sem supervisão, cuja profissão é a única capaz de reconhecer equívocos em sua prática e regular seu próprio trabalho. Pode-se dizer, que a autonomia é expressa pela capacidade de autorregulação profissional (Freidson, 1978). 
A autonomia técnica do trabalho médico confere liberdade no trabalho frente aos aspectos sociais e científicos que se traduz na autonomia decisória, como parte de seu desempenho profissional, tocante aos elementos subjetivos do julgamento clínico e da decisão terapêutica (Schraiber, 2008).

A regulação do trabalho envolve a disposição jurídico-legal das leis que regulamentam o exercício profissional, os aspectos éticos dos códigos de ética profissional e os elementos administrativos das normas das relações de trabalho (Bourgeault, Grignon, 2013; Brasil, 2006).

A autoregulação profissional consiste na abordagem tradicional que delimita o escopo de prática de determinada categoria profissional, com preservação de monopólios corporativos (Bourgeault, Grignon; 2013).

Nesse contexto, no Brasil, cabe considerar que a saúde constitui um direito universal e um bem público, por isso compete ao Estado dispor sobre a regulamentação do trabalho em saúde, fiscalização e controle, adequando o interesse particular de cada profissão ao interesse público. Nesse sentido, destaca-se a Mesa Nacional de Negociação Permanente (MNNP) do SUS, resolução n.52/19993, retomada em 2003 e a Norma Operacional Básica de Recursos Humanos do SUS (NOB/RH) implementada em 2005, para a requalificação e reestruturação do setor público com base na descentralização, financiamento e controle social (Brasil, 1993, 2005).

A MNNP é caracterizada como um projeto de democratização das relações de trabalho na saúde, com função político social em prol da regulação, profissionalização e qualificação profissional. Consiste em um fórum permanente e paritário de trabalhadores do SUS, empregadores e gestores municipais, estaduais e federais, que lidam com conflitos e demandas das relações funcionais de trabalho. Os temas da agenda de trabalho da MNNP são: diagnóstico situacional, regulação das profissões incluindo jornada de trabalho, cedência de pessoal, regulamentação da profissão do agente comunitário de saúde, inserção de profissionais para cuidados à saúde, desprecarização do trabalho, plano de carreiras, cargos e salários, saúde do trabalhador e instalação das Mesas Estaduais e Municipais de Negociação Permanente do SUS (Brasil, 2003). 
A Constituição Federal Brasileira, estabelece a competência privativa da União, de legislar sobre a organização das profissões, contudo geralmente são seguidas as regras impostas pelo mercado de trabalho. Prevalecem os interesses profissionais corporativos em detrimento das necessidades do SUS. Por isso, foi criada a Câmara de Regulação do Trabalho em Saúde, uma instância permanente de caráter consultivo que permite ao poder público reassumir a regulação do trabalho, conforme a Lei Orgânica da Saúde 8080/90 (Brasil, 2006).

\begin{abstract}
Numa análise mais aprofundada da situação, identifica-se uma característica básica do atual regime regulatório brasileiro: a existência de uma legislação que preserva monopólios corporativistas na regulação do trabalho, os quais, muitas vezes, extrapolam os seus próprios limites de atuação, disseminando conflitos que promovem competição entre as profissões da saúde. Sendo assim, é fundamental que um Estado presente e atuante no papel de gestor e regulador do trabalho (Brasil, 2006, p.4).
\end{abstract}

Para garantir a atenção aos interesses públicos da saúde, é necessária uma recomposição das relações profissionais em prol das necessidades de saúde dos usuários e população do SUS. A lógica profissional da autorregulação pode representar um impedimento desse avanço. Por isso, novas alternativas de regulação profissional precisam ser estabelecidas para a ampliação do escopo da prática profissional, com ênfase no campo comum do processo de trabalho na perspectiva da clínica ampliada centrada no usuário.

\title{
A TEORIA DO AGIR COMUNICATIVO DE JÜRGEN HABERMAS E APLICAÇÕES NO CAMPO DA SAÚDE ${ }^{1}$
}

Para compreender as interações interprofissionais em saúde e as relações intersubjetivas com os usuários, no contexto da formação e práticas

\footnotetext{
${ }^{1}$ As idéias elaboradas nesta parte do referencial teórico foram apresentadas em co-autoria com a orientadora desta pesquisa em um capítulo de livro. Silva, JAM; Peduzzi, M. A dimensão comunicativa na educação interprofisisonal em saúde. In: Jürguen Habermas Publicidade, direitos humanos e sociedade civil. Pinzani, A; Schmidt R (organizadores). Reflexões teóricas e empíricas. Editora da Universidade Federal de Santa Cararina (UFSC): Florianópolis (No Prelo).
} 
em serviços, utiliza-se a Teoria do Agir Comunicativo (TAC) de Jürgen Habermas.

Habermas é o autor de referência do agir comunicativo, representante da segunda geração da Escola de Frankfurt do Instituto de Pesquisa Social. Com a TAC, o autor buscou a renovação teóricocomunicativa do conceito de razão no plano científico, com a conexão entre a filosofia e as ciências sociais. Construiu uma teoria crítica da sociedade relacionada à hegemonia da racionalidade instrumental, pelo predomínio da ciência e da técnica (Pinzani, 2009).

As primeiras construções sociológicas de Habermas buscam mostrar os efeitos negativos que o progresso técnico produziu na vida em sociedade, mesmo com as melhorias econômicas. Nas indústrias, os operários passaram a realizar ações rotineiras e automatizadas, perdendo o espaço de atuação criativa e de conhecimento dos materiais, ou seja, tornaram-se alienados do trabalho industrial. De modo semelhante, o espaço de consumo é caracterizado pelo contato rápido e superficial com as coisas. Exemplos que mostram a expansão da racionalidade instrumental com a independência dos instrumentos técnicos (Honneth, 1999).

A construção da TAC fundamenta-se nos estudos de Weber, Mead, Durkheim e Parsons da sociologia e procura na linguagem, a interligação entre as pessoas, para tanto, está ancorada na pragmática universal que estuda as bases universais de validade da fala (Habermas, 2012, 2009; Rivera, Artmann, 2012).

A linguagem constitui o pano de fundo dos valores compartilhados pelas pessoas na sociedade, ou seja, a fala tem uma força de sociabilidade. Afinal, todas as ações humanas intersubjetivas estão sujeitas a leis morais universais que possuem uma validade a priori (Habermas, 2009).

A linguagem ou interação é um tipo de reprodução simbólica que se refere ao uso de símbolos por parte dos sujeitos que conferem nomes às coisas. Esta representação está ligada à função representativa das características que permitem a identificação dos objetos. Assim, o símbolo representativo mostra um objeto ou estado de coisas e designa-o (Habermas, 2009). 
O conhecimento é produzido a partir da interação, da linguagem e da intersubjetividade que é o aspecto central da teoria de Habermas. A dialética de conhecer-se no outro está relacionada com a ideia de uma relação de interação entre dois oponentes iguais em princípio, pois de acordo com Hegel, o modelo da intersubjetividade dos sujeitos que atuam e falam pressupõe que o EU tenha identidade universal e particular (Habermas, 2009).

A linguagem adquire existência como sistema de uma determinada tradição cultural de um povo e universalmente expressa o que cada indivíduo pensa. A linguagem faz parte da ação comunicativa, pois somente as significações válidas e constantes a partir da tradição de um povo resultam em orientações com reciprocidade. A interação depende de comunicações linguísticas familiares, do mesmo modo, a ação instrumental que ocorre no trabalho social depende de uma rede de interações e de cooperações possíveis, embora também possa ocorrer individualmente e constituir uma ação monológica (Habermas, 2009).

As interações intersubjetivas são caracterizadas pela relação dialética entre trabalho e linguagem que se constituem mutuamente, por isso não há primazia de um sobre o outro (Habermas, 2009).

Habermas debate a sociedade a partir de duas racionalidades que correspondem a duas formas distintas de ação social: o agir instrumental e o comunicativo. As racionalidades oferecem razões para o agir como uma disposição dos sujeitos capazes da linguagem e da ação. $O$ agir comunicativo é orientado pela busca do entendimento, que remete ao comum acordo almejado, e o agir instrumental ou estratégico, pode utilizar um telos comunicativo para convencer e manipular o outro para algo que interessa, de modo utilitarista (Habermas, 2012; Pinzani, 2009).

"Assim, ao buscarem um conhecimento de algo no mundo, os sujeitos já se encontram preliminarmente em uma situação na qual predominam relações intersubjetivas, que tornam possivel um entendimento entre eles" (Habermas, 2012, p. IX).

A interação ou racionalidade comunicativa possui natureza dialógica e intersubjetiva, voltada para o entendimento e produção de acordos ou 
consensos. Pressupõe o compartilhamento intersubjetivo de um horizonte ético comum, de normas e convicções (Habermas, 2009).

Diferentemente, a racionalidade instrumental teleológica (científica e técnica) é estabelecida monologicamente, isto é, sem entendimento prévio em busca da escolha adequada de meios para atingir determinados fins (Aragão, 2002; Habermas, 2009).

As duas racionalidades mencionadas, ação racional teleológica e interação, podem ser utilizadas na análise dos sistemas sociais. O sistema econômico e o mercado estão na esfera da ação instrumental, enquanto, o mundo vital, sociocultural e da família estão orientados pela racionalidade comunicativa (Habermas, 2009).

A distinção entre o agir comunicativo e o agir instrumental estratégico, baseia-se na teoria dos atos de fala de Austin, que define atos locucionários, ilocucionários e perlocucionários. $\mathrm{O}$ ato locucionário tem a função de referir, dizer, enunciar. $\mathrm{O}$ ato ilocucionário é elaborado para anunciar uma ação com determinado fim e o ato perlocucionário pode influenciar, estimular e convencer o outro sobre o que se pretende. Assim, no agir comunicativo os agentes em interação buscam harmonizar seus planos individuais entre si, em prol do entendimento intersubjetivo. Enquanto no agir estratégico, pelo menos um sujeito busca os efeitos perlocucionários da fala, para influenciar o comportamento do outro ou seja, com interesse no êxito instrumental de um sujeito sobre o outro (Ricoeuer, 2011; Artmann, 2001; Habermas, 2009, 2012; Aragão, 2002).

\begin{abstract}
(...) no decorrer de nossa formação precisamos adquirir a competência para os julgamentos morais pós-convencionais, caso queiramos participar de argumentações morais. Ao fazê-lo, precisamos admitir (o que em geral não corresponde aos fatos) que nos encontramos em uma situação comunicativa, na qual queremos convencer um outro, ou na qual nos deixamos convencer, ou seja, na qual só vale a força do melhor argumento (Habermas, 1989, p.19).
\end{abstract}

A ética discursiva habermasiana para a solução de um problema moral pressupõe o diálogo com a busca da integração dos argumentos do outro (Habermas, 1989).

Schraiber et al., (1999), Peduzzi (1998, 2001), Rivera, Artmann (1999), Ayres (2001), Artmann (2001), Rivera (2003), Rivera, Artmann 
(2012), são os pesquisadores da área da saúde que iniciaram a análise das práticas de saúde à luz da TAC.

$\mathrm{Na}$ ação comunicativa, para que os sujeitos se entendam mutuamente, os acordos são pautados em pretensões de validez que se referem à três planos: verdade proposicional, correção normativa e autenticidade expressiva. A verdade proposicional expressa a correspondência do que é dito com a realidade ou verdade do enunciado. A correção normativa, se refere a um mundo social comum que depende de relações interpessoais, pautadas no compartilhamento de aspectos éticos, políticos e morais do enunciado. A autenticidade expressiva, remete ao estabelecimento de uma relação de confiança e sinceridade entre os interlocutores (Habermas, 2012, 2001).

"As condições de validade das exteriorizações simbólicas remetem a um saber fundamental partilhado intersubjetivamente pela comunidade de comunicação" (Habermas, 2012, p. 41).

Quando nas tentativas de interação prevalece o dissenso, utiliza-se argumentação, tipo de discurso no qual os participantes tematizam pretensões de validade controversas. Nesse processo, a força de um argumento estará expressa em sua capacidade de convencer ou motivar os participantes de um discurso, a concordar com a pretensão de validez exposta (Habermas, 2012).

No campo da saúde, pode-se considerar a assimetria presente na relação entre o profissional de saúde e usuário, na qual predominam o uso de argumentos para tentar convencer o outro (Habermas, 2012). No tocante à pretensão de validez, nas práticas de saúde predomina o sentido de correção normativa relacionado à utopia do controle de doenças, aspecto que precisa ser revisto por meio da intersubjetividade quando as práticas são orientadas pelo êxito técnico, sem contemplar as subjetividades dos usuários (Ayres, 2001).

$\mathrm{Na}$ perspectiva da integralidade e da prática e educação interprofissional, o cuidado em saúde não pode estar restrito às tarefas técnicas, do agir instrumental, pois o sucesso prático das intervenções de saúde, também requer o diálogo (Ayres, 2001). 
As pretensões de validade da comunicação intersubjetiva, apoiam-se em no conceito tríplice de mundo, o mundo objetivo ou estado das coisas, o social ou normas sociais e o subjetivo. Nesse contexto, a comunicação ocorre em um mundo objetivo de eventos e fatos, no mundo social por meio da interação ou no mundo subjetivo na relação do sujeito com sua própria natureza e subjetividade dos outros. O conceito abstrato de mundo é condição necessária para que os sujeitos que agem comunicativamente, possam chegar a um entendimento mútuo sobre o que acontece no mundo, ou sobre o que se deve fazer nele (Habermas, 2012, p.40). A ação comunicativa pode ocorrer nessas três dimensões articuladas pelo mundo da vida (Artmann, 2001; Aragão, 2002; Pinzani, 2009).

O mundo da vida é o espaço de entendimento compartilhado pelos sujeitos envolvidos na interação comunicativa, ou seja, cada ato de fala é estabelecido em uma situação reconhecida intersubjetivamente pelo compartilhamento de um horizonte ético comum (Habermas, 2012; 2001; Artmann, 2001; Pinzani, 2009; Honneth, 1999).

A cultura, sociedade e personalidade constituem o mundo da vida. A cultura é o espaço de reprodução cultural, por meio do conhecimento, a sociedade possibilita a coordenação e integração das ações sociais e a personalidade, envolve os aspectos subjetivos dos indivíduos que possibilitam a comunicação e socialização (Habermas, 2012; 2001; Artmann, 2001; Pinzani, 2009).

As mudanças sociais são possibilitadas pelo fato do mundo da vida constituir um espaço de produção de questionamentos e reformulações das aspirações de validade, no qual são contestados a verdade dos fatos, validade das normas e veracidade das manifestações subjetivas. Entretanto, Habermas aponta a relação dialética presente entre o mundo da vida e os sistemas da sociedade moderna, que tendem a avançar sobre o mundo da vida. Nesse processo, de colonização do mundo da vida que representa a patologia da modernidade, a racionalidade técnico-científica ou dos sistemas (científico, jurídico, financeiro, entre outros), todos mediados pelo poder e pelo dinheiro, podem colonizar o mundo da vida por meio das ações instrumentais, em esferas da vida que deveriam estar orientadas pelo agir 
comunicativo (Habermas, 2012; 2001; Artmann, 2001; Pinzani, 2009; Artmann, Rivera, 2006).

No campo da saúde, a ciência e a técnica tendem a colonizar a práxis, por isso, é preciso defender a ideia de um potencial de racionalidade comunicativa, para resgatar o espaço do mundo da vida no qual se constroem as interações (Ayres, 2001).

Nas práticas de saúde, o sujeito é caracterizado pela intersubjetividade e não pode ser reduzido à questão individual, pois podem ser pensados sujeitos coletivos, representantes de certos grupos, como por exemplo, trabalhadores da saúde e usuários, de modo que participem da construção de melhores condições de saúde (Ayres, 2001).

As práticas de saúde preventivas dependem de que o "outro" seja sujeito de sua própria saúde. Por isso, a intersubjetividade é sempre uma relação no sentido do encontro com a circunstância - ato de se colocar diante do Outro com as possibilidades de ambos e seu mundo compartilhado (Ayres, 2001).

O processo de trabalho em saúde não deve ser reduzido à ação instrumental, pautada na fisiopatologia para a restauração biológica, pois a interação intersubjetiva com os usuários contribui para a ampliação da abordagem das necessidades de saúde (Rocha, Almeida, 2000).

Habermas analisa que há uma relação entre trabalho e interação que não ocorre automaticamente. Contudo, há uma progressiva racionalização do trabalho à medida que a técnica e a ciência invadem as outras esferas institucionais ou âmbitos da vida, transformando-os (Habermas, 2009).

Racionalização significa, em primeiro lugar, a ampliação das esferas sociais, que ficam submetidas aos critérios da decisão racional. (Habermas, 2009, p. 45). De acordo com Hegel o trabalho e a interação não poderiam ser dissociados, mas essa conexão foi perdendo importância com o passar do tempo mediante a racionalização (Habermas, 2009).

Para Max Weber, a racionalidade da ciência e da técnica pode resultar em dominação que enquanto política se torna irreconhecível. A técnica considerada como ideologia é um projeto histórico-social e nele se 
projeta o que uma sociedade e os seus interesses buscam para os homens e coisas (Habermas, 2009).

Pode-se afirmar que a ciência e a técnica estão relacionadas com um projeto de mundo determinado por interesses de classe e situação histórica, cuja emancipação depende da libertação da ciência e da técnica (Habermas, 2009).

O processo de trabalho em saúde, depende da ação instrumental e da interação. Contudo, tende-se a valorizar apenas ação racional dirigida a determinados fins, que elimina a socialização e estimula a individualização (Habermas, 2009).

Um dos grandes desafios nos serviços de saúde é conciliar um atendimento de qualidade, baseado em um saber consagrado, apoiado no processo saúde-doença e na dimensão da subjetividade, para além da aplicação protocolar de regras e normas do cientificismo, condicionado pelo contexto administrativo e econômico (Artmann, Rivera, 2006).

Campos (2007b), aponta a necessidade de conciliar a clínica tradicional à clínica do sujeito, por meio da ideia de clínica ampliada, na qual se realiza a atenção a cada caso singular, com decisões ponderadas com outros profissionais e compartilhamento de incertezas, por meio do trabalho em equipe interprofissional e do agir comunicativo. A clínica ampliada favorece a troca de informações e construção coletiva de projetos terapêuticos.

Com a evolução tecnológica, reduz-se o sentimento de auto suficiência médica e se fortalece o valor da interdependência profissional e da dependência profissional dos aparelhos de formação (Artmann, Rivera, 2006).

Os processos de aprendizagem estão organizados no subsistema da ação instrumental (Habermas, 2009). Por isso, torna-se importante o desenvolvimento de estudos que visem resgatar a esfera do agir comunicativo no contexto da educação. 


\section{EDUCAÇÃO INTERPROFISSIONAL EM SAÚDE E PRÁTICA COLABORATIVA}

A educação interprofissional em saúde (EIP) é definida como uma intervenção na qual os membros de mais de uma profissão da saúde, aprendem juntos interativamente, com a finalidade de melhorar a colaboração no cuidado dos usuários. A interação na aprendizagem requer a participação ativa, com a troca de conhecimentos entre diferentes áreas profissionais (Reeves et al., 2013).

A interdependência entre a formação profissional em saúde e as práticas de saúde é reconhecida como um elemento necessário para reorganizar o processo de trabalho em saúde com foco nas necessidades dos usuários (D’Amour, Oandasan, 2005; WHO, 2010; Frenk et al., 2010; IPEC, 2011). Nesse sentido, no presente estudo o tema da EIP é abordado de modo articulado à prática colaborativa.

A EIP é reconhecida como importante tema do campo da saúde, em nível global há mais de 30 anos. Diversas publicações internacionais apontam a mudança do perfil profissional, mediante a EIP (Hind et al., 2003; McNair et al., 2005; Cooper et al, 2001, 2005; Barr et al, 2005; Goelen et al, 2006). Na década de 2010, o tema ganhou destaque a partir de duas publicações que apontam a EIP orientada para o trabalho em equipe, como componente de uma ampla reforma no modelo de formação profissional e de atenção à saúde (WHO, 2010; Frenk et al, 2010). Ambas publicações do cenário internacional, destacam a necessidade de reorganizar a rede de atenção à saúde e a formação, com ênfase na colaboração entre os profissionais e com foco nas necessidades de saúde dos usuários/população.

Em 2013, a Organização Mundial de Saúde publicou um documento norteador para transformar a educação profissional, com o objetivo de apoiar e promover avanços nos sistemas de saúde, em prol da equidade e atenção às necessidades de saúde dos usuários e população. As recomendações são: educação e treinamento institucional com programas de desenvolvimento profissional para o corpo docente relacionado às necessidades de saúde das comunidades, implementação de políticas 
obrigatórias de educação, inovação na formação universitária com a contratação de profissionais da saúde, adaptações curriculares com ênfase nas necessidades de saúde da população, inclusão de métodos de simulação de alta e baixa fidelidade, desenvolvimento de políticas de inclusão social dos estudantes e adoção da EIP nos cursos de graduação e pós-graduação (WHO, 2013).

O estímulo à EIP, para quebrar os silos profissionais e fortalecer o trabalho colaborativo em equipe é uma das dez recomendações, no tocante ao preparo dos profissionais da saúde para os interesses globais das necessidades de saúde e fortalecimento dos sistemas de saúde (Frenk et al., 2010).

Para compreender o possível desdobramento da EIP no tocante ao trabalho colaborativo em equipe é importante distinguir os termos: trabalho em equipe e prática colaborativa. $\mathrm{O}$ trabalho em equipe é uma modalidade de trabalho coletivo, estabelecido por meio de relações recíprocas entre as intervenções técnicas e as interações entre os profissionais (Peduzzi, 2001, 2007a).

Peduzzi (2007a, p.161) analisa que "o trabalho em equipe é dinâmico e tem uma plasticidade que pode configurar equipes de trabalho integradas ou equipes que expressam um mero agrupamento de profissionais". A coexistência de vários profissionais não constitui o trabalho em equipe, pois a integração não ocorre automaticamente, pelo contato ou troca de informação com os outros. A integração dos profissionais em equipe, requer uma construção pautada na interação dialógica, em busca do entendimento e compartilhamento de um horizonte ético e premissas técnicas (Peduzzi, 2001, 2007a; Peduzzi et al., 2012).

Para a mudança das práticas na perspectiva do trabalho em equipe de saúde é necessário que haja um redirecionamento dos valores em que está ancorada a prática profissional, da fragmentação, hierarquização, trabalho individualizado, e modelo biomédico hegemônico, para a integração, democratização das relações de trabalho e integralidade das ações de saúde (Peduzzi, 2007a, Peduzzi et al., 2012). 
Desse modo, pode-se dizer que o trabalho em equipe representa um componente de reorganização das práticas de saúde com recomposição, articulação e integração profissional, que se justifica mediante mudanças concomitantes do modelo de atenção à saúde na perspectiva da integralidade (Peduzzi, 2007a; Peduzzi et al., 2012, Peduzzi et al., 2013).

Uma equipe integrada envolve profissionais que interagem entre si, e compartilham o processo de negociação/tomada de decisão para alcançar objetivos comuns à equipe, com foco nas necessidades de saúde dos usuários. As práticas das equipes integradas são caracterizadas pela colaboração, respeito mútuo e confiança, fundamentada no reconhecimento do papel profissional das diferentes áreas, com interdependência e complementaridade dos saberes e ações (Iribarry, 2003; Martin Rodriguez et al., 2005; D’Amour et al., 2008; Peduzzi, Oliveira, 2009; Nugus et al., 2010; Peduzzi et al., 2012; Peduzzi et al., 2013).

A prática interprofissional colaborativa se refere à articulação entre equipes de diferentes serviços de saúde na rede de atenção, ou seja, não se restringe ao trabalho de uma única equipe, ou intra equipe.

A abordagem das competências é um tema presente nas publicações relacionadas à EIP. As cinco competências necessárias para a efetividade do trabalho em equipe no tocante aos conhecimentos, habilidades e atitudes são: liderança da equipe, monitoramento da performance mútua, apoiar o comportamento e as ações dos membros da equipe, adaptabilidade e orientação para equipe (Leasure et al., 2013).

A colaboração é uma tendência relacionada à organização do cuidado em saúde, com novas práticas clínicas, integração do cuidado e estabelecimentos de redes de cuidado entre a atenção primária, secundária e terciária (D’Amour et al., 2008).

A EIP pode contribuir para a formação em prol do trabalho colaborativo em equipe, bem como inter-equipes e em rede de serviços, para o qual são necessárias mudanças no tocante à socialização dos papéis profissionais e do processo de trabalho em saúde. Requer o desenvolvimento de uma relação interdependente e interativa, com parceria entre equipes, profissionais de saúde e usuários para a tomada de decisão 
compartilhada sobre as necessidades de saúde no cuidado ao usuário (Orchard et al., 2012; Zwarenstein et al., 2009; Olenick et al., 2010, MartinRodriguez et al., 2005).

A colaboração está pautada na premissa de que os profissionais querem trabalhar juntos, para oferecer um cuidado melhor, com a defesa de seus interesses individuais e certo nível de autonomia profissional (D’Amour et al., 2008). A perspectiva colaborativa interprofissional referida, remete ao conceito de campo e núcleo profissional desenvolvido por Campos (2000). O campo de atuação, consiste no espaço comum das práticas dos profissionais da saúde que desenvolvem a clínica ampliada, enquanto o núcleo, envolve as ações específicas de cada profissão implicada no cuidado saúde. Ambas dimensões são imprescindíveis para a implementação das práticas colaborativas, pois expressam a construção de práticas comuns, com ênfase nas necessidades de saúde, articuladas às contribuições específicas do saber profissional das diferentes áreas.

D’Amour et al., (2008) desenvolveu um modelo e tipologia de colaboração profissional nos serviços de saúde baseado em quatro dimensões e seus respectivos indicadores. A primeira se refere a objetivos e visão compartilhada de modo consensual, com ênfase na promoção da prática centrada no usuário. A segunda é a internalização para o mútuo reconhecimento, respeito, conhecimento dos valores, competências e responsabilidades assumidas, de modo compartilhado pelos profissionais. A terceira é a governança relacionada ao papel do gerente, em estimular a colaboração e a liderança local necessária para a integração interprofissional e entre serviços de saúde da rede de atenção. Outros indicadores da governança são: o suporte para inovação que requer responsabilidades compartilhadas para o estabelecimento de mudanças na prática clínica e a conectividade entre os profissionais e serviços por meio de estratégias de integração da comunicação para a abordagem articulada dos problemas. A quarta dimensão, formalização diz respeito à responsabilidades e negociação compartilhada por meio de acordos entre serviços, protocolos e sistemas de informação. 
De acordo com a tipologia dos indicadores da colaboração pode haver três níveis de colaboração. Quando se identifica a presença de todas as dimensões mencionadas e seus respectivos indicadores ocorre a colaboração ativa. Nos casos em que os indicadores estão parcialmente presentes, considera-se que a colaboração está em desenvolvimento e se os indicadores não forem identificados o nível de colaboração pode ser potencial ou latente.

Também falam na direção da educação interprofissional e prática colaborativa, como apontado anteriormente, as mudanças de perfil epidemiológico com o aumento da expectativa de vida e das doenças crônicas que requerem acompanhamento à longo prazo e uma abordagem integral que contemple as múltiplas dimensões das necessidades de saúde de usuários e população. Isso torna a qualidade da comunicação e a colaboração entre os diferentes profissionais envolvidos no cuidado, fundamental e crítica para a resolubilidade dos serviços e a efetividade da atenção à saúde (Mendes, 2011; Zwarenstein, Goldman, Koppel, 2009; Frenck et al., 2010).

O aumento da complexidade das necessidades de saúde requer profissionais preparados para trabalhar colaborativamente em equipes comprometidas com o cuidado à saúde (Baindridge, Nasmith, Orchard, 2010).

O estudo de revisão desenvolvido por Reeves et al. (2014) sobre avaliação da efetividade da EIP no cuidado aos usuários e no processo de trabalho em saúde, mostra evidências sobre impacto nos resultados aos usuários. As evidências identificadas são: adesão a protocolos clínicos, satisfação do usuário, compartilhamento nos processos de tomada de decisão na prática clínica, comportamento colaborativo, redução das taxas de erros e capacidade de avaliação das competências dos parceiros de trabalho no cuidado em saúde. Tais evidências são de baixa qualidade, por isso, os autores consideram a necessidade de mais estudos com métodos rigorosos para produzir evidências relacionadas à EIP, tais como estudos randomizados controlados e estudos de caso controle. 
Juntamente com as evidências da EIP relacionadas às práticas colaborativas de cuidado à saúde, a literatura também mostra aspectos relacionados a mudanças na formação em saúde. Sunguya et al. (2014) realizaram uma revisão sistemática sobre os desafios na implementação de programas de EIP em países em desenvolvimento, dentre os quais destacamse a complexa estrutura curricular, a limitação de recursos, estereótipos profissionais, falta de programas de acreditação para EIP, pobre liderança

Frente aos desafios mencionados, as principais estratégias utilizadas para a mudança na formação em prol da EIP foram: introdução da aprendizagem baseada em problemas nos currículos para aumentar o interesse dos estudantes, ênfase nas atividades práticas da formação, introdução de inovações por meio da aprendizagem on-line, participação ativa de estudantes, corpo docente e profissionais dos campos de estágio na avaliação curricular dos cursos, introdução de currículos flexíveis, presença de docentes e dirigentes da universidade que apoiem a proposta, criação grupos de trabalho para planejamento de estratégias de EIP, busca de apoio financeiro, institucional e recursos para implementação e manutenção dos programas de EIP (Sunguya et al., 2014).

Pode-se dizer que a colaboração interprofissional é considerada um elemento necessário para a qualidade da atenção à saúde (Reeves et al., 2008; Berridge, 2010; Reeves et al., 2010; Suter, 2012; Zwarestein, 2000). Por isso, organizações norte-americanas, canadenses e inglesas desenvolveram um conjunto de competências para a prática colaborativa interprofissional, a fim de suprir limitações na formação em saúde em prol da EIP.

No Canadá, considera-se que mudanças no estilo de formação dos profissionais de saúde, são fundamentais para desenvolver conhecimento e treinamento efetivo para o trabalho em equipes interprofissionais. Tal formação tem como principais objetivos socializar os profissionais de saúde no trabalho conjunto por meio do compartilhamento da resolução de problemas e da tomada de decisão, beneficiando usuários e serviços de saúde, desenvolver o respeito mútuo pelas contribuições dos outros 
profissionais e implementar competências para prática colaborativa (CIHC, 2007).

O Canadian Interprofessional Health Collaborative (CIHC), estabeleceu seis domínios de competências de conhecimentos, habilidades, atitudes e valores essenciais para a prática interprofissional colaborativa que estão ancorados sobre duas competências centrais, a comunicação interprofissional e o cuidado centrado no paciente, cliente, família e comunidade. As outras quatro competências são: a clarificação de papéis profissionais, dinâmica de funcionamento da equipe, resolução de conflitos interprofissionais e liderança colaborativa (CIHC, 2010; Baindridge, Nasmith, Orchard, 2010).

Em 2011, o grupo norte-americano, Interprofessional Education Collaborative Expert Panel (IPEC), publicou um relatório sobre as competências centrais para a prática interprofissional colaborativa, que podem ser transformadas em objetivos de aprendizagem com ênfase na segurança, alta qualidade, acesso e cuidado centrado no paciente. As competências elaboradas pela IPEC são: valores/ética para a prática inetrprofissional, papéis e responsabilidades profissionais, comunicação interprofissional e trabalho em equipe (IPEC, 2011).

As competências dos modelos canadense e norte-americano podem ser consideradas colaborativas, conforme a tipologia de competências desenvolvida por Barr, (1998). As competências colaborativas são necessárias para o trabalho com outras profissões, as competências complementares se referem a especificidades de cada profissional e as competências comuns consistem em conhecimentos, habilidades e atitudes, comuns e compartilhadas entre os profissionais.

\section{INICIATIVAS DE EDUCAÇÃO INTERPROFISSIONAL EM SAÚDE NO BRASIL}

No Brasil, o modelo predominante de ensino superior é uniprofissional (Costa et al., 2014). A formação pautada no referido modelo 
de ensino está centrada nas disciplinas e na racionalidade biomédica, flexinerização, com ênfase na dimensão biológica e no substrato anatomopatológico do processo saúde-doença (Teixeira, Coelho, Rocha, 2013; Feuerwerker, Capozzolo, 2013; Khalili et al., 2013; Almeida Filho, 2010; Moraes, Manzini, 2006; Ceccim, Carvalho, 2005; Reeves et al., 2008; Barr et al., 2005; Almeida, Feuerwerker, 1999; Ribeiro, 2000).

A educação uniprofissional ocorre quando os estudantes de uma única profissão aprendem juntos (Barr et al., 2005). Consequentemente, os estudantes priorizam a sua área, sem valorizar o reconhecimento da complementaridade dos papéis de outros profissionais no cuidado em saúde (Feuerwerker, Capozzolo, 2013; Khalili et al., 2013; Almeida Filho, 2010; Reeves et al., 2008; Barr et al., 2005).

A formação uniprofissional tem como desdobramento, práticas de saúde fragmentadas, com o isolamento profissional e estímulo ao corporativismo e competição. Nesse modelo de formação tradicional, os estudantes são formados com ênfase no domínio técnico-científico em detrimento à interdisciplinaridade, interprofissionalidade, comunicação/ interação.

Considera-se que a racionalidade instrumental técnico-científica não recobre o complexo leque das necessidades de saúde dos usuários e população, visto que se construiu, intersubjetivamente, o reconhecimento da integralidade e da saúde como direito. Nesse sentido, os trabalhadores executam ações que vão além da recuperação da saúde, contemplam a prevenção de agravos e a promoção da saúde, para os que precisam recorrer a outras ferramentas de trabalho além do arsenal técnico-científico.

A formação em saúde na perspectiva da integralidade, oferece subsídios para o desenvolvimento de saberes e práticas que superem a fragmentação do ensino tradicional, uniprofissional e ações biomédicas centradas em procedimentos. Promove a abordagem da determinação social do processo saúde-doença, com ações de promoção, prevenção e recuperação da saúde (Pinheiro, Ceccim, 2005; Ceccim, Feuerwerker, 2004a; Gonzalez, Almeida, 2010). 
Para promover mudanças na formação em saúde em direção à integração ensino-serviço, com estímulo à interprofissionalidade, em 1973 a OPAS propôs o desenvolvimento da rede de integração docente assistencial (IDA) (Paiva, Pires-Alves, Hochman, 2008). A IDA tem sido desenvolvida desde a década de 60 , no Brasil, com a finalidade de diversificar os cenários de ensino e aprendizagem (Cavalheiro, Guimarães, 2011). É um dos recursos utilizados para integrar o ensino aos serviços, definida pelo MEC como: união de esforços em um processo de crescente articulação entre Instituições de Educação e Serviços de Saúde adequados às necessidades reais da população (Brasil, 1981).

$\mathrm{Na}$ década de 1980, foram implementadas mudanças curriculares para implementar a IDA na América Latina, com ênfase na atenção integral, ensino multiprofissional e integração ensino-serviço (Feuerwerker, Sena, 2002; Almeida, Feuerwerker, Llanos, 1999).

Posteriormente, no início dos anos 1990, na América Latina, foi implantado o Programa - Uma Nova Iniciativa na Educação dos Profissionais de Saúde: União a Comunidade (UNI), patrocinado pela Fundação Kellogg. Foram desenvolvidos 23 projetos UNI, em 11 países da América Latina (Argentina, Bolívia, Brasil, Chile, Colômbia, Equador, México, Nicarágua, Peru, Uruguai, Venezuela), dos quais seis foram no Brasil, nas cidades de Londrina, Marília, Botucatu, Brasília, Salvador e Natal. O programa envolveu 103 cursos de graduação de 23 universidades; 23 secretarias municipais ou coordenações regionais de saúde, serviços de diferentes níveis de complexidade e mais de 600 organizações comunitárias. (Ribeiro, 2000; Chaves, Kisil, 1999).

O Programa UNI foi elaborado em consonância com a Reforma Sanitária Brasileira, para melhorar a organização dos serviços de saúde e a educação dos profissionais, com a articulação entre a universidade, serviço e comunidade. A prática da parceria foi a mais importante inovação do projeto, cujas principais características são a educação de profissionais da saúde, voltada aos problemas de saúde da comunidade, estímulo ao ensino interdisciplinar e à aprendizagem baseada em problemas. Nessa perspectiva, o trabalho em equipe multiprofissional deve servir de modelo aos alunos e a 
organização comunitária para autogestão e responsabilização (Chaves, Kisil, 1999).

As reflexões mobilizadas pelo programa UNI, apontaram que a formação dos profissionais de saúde estava sustentada pela abordagem hegemônica da educação tradicional, centralizada no professor, como elemento indispensável na transmissão de conteúdo, o que comprometia o perfil do profissional formado. Em contrapartida, a abordagem educativa crítico-reflexiva que se buscou incentivar, tinha como preocupação a democratização do saber, a partir da problematização da realidade com a participação ativa do estudante (Feuerwerker, Sena, 2002).

A reorientação curricular proposta pelo UNI tinha como proposta a interdisciplinaridade e o trabalho em equipe para promover a articulação entre as áreas profissionais (Feuerwerker, Sena, 2002). As mudanças referidas se aproximam do conceito da educação interprofissional em saúde.

A interdisciplinaridade nos cursos da saúde tem como potencial a integração de conhecimentos para formar profissionais preparados para atenção ampliada das necessidades de saúde dos usuários (Vilela, Mendes; 2003; Venturelli, 1999; Nunes, 1995; Minayo, 1991).

Com o objetivo de superar a fragmentação na formação em saúde foi criada a Rede Unida, através da articulação do projeto UNI com o movimento IDA. Esta rede busca criar espaços sociais de reflexão e debate para construção da interdisciplinaridade, multiprofissionalidade, integralidade, participação social e integração ensino-serviço (Ceccim, Carvalho, 2005; Feuerwerker, Sena, 2002; Almeida, Feuerwerker, Llanos, 1999).

Outro desdobramento do projeto UNI, encontra-se na Faculdade de Medicina de Marília (FAMEMA) e na Universidade Estadual de Londrina (UEL), que adotaram projetos curriculares interdisciplinares e metodologias ativas como a aprendizagem baseada em problemas (Feuerwerker, Sena, 2002).

Em 2001, foram implementadas as Diretrizes Curriculares Nacionais dos Cursos de Graduação em Saúde (DCN), seguindo os princípios e diretrizes do SUS da Lei 8080/90. As DCN representam um marco legal da 
articulação entre a saúde e educação que preconiza a formação para o trabalho em equipe multiprofissional e interdisciplinar na perspectiva da integralidade e da qualidade da comunicação com a equipe usuários/famílias/comunidade (Almeida Filho, 2010; Feuerwerker, Capozzolo, 2013).

A articulação entre o Ministério da Saúde (MS) e o Ministério de Educação e Cultura (MEC) foi fortalecida com a criação da Secretaria de Gestão do Trabalho e da Educação na Saúde (SGTES) em 2003 (Dias, Lima, Teixeira, 2013). A SGTES propiciou o desenvolvimento de propostas de aproximação entre as universidades e o SUS, como: Pólos de Educação Permanente em Saúde, Comissão de Integração Ensino-Serviço, Projeto de Vivências e Estágios na Realidade do SUS (VERSUS), AprenderSUS, PROMED, Ensina SUS, Fórum Nacional de Educação das Profissões na Área da Saúde (FNEPAS), Telessaúde, Universidade Aberta do SUS (UNASUS), e o Pró-Saúde entre outros.

Para que as mudanças na formação dos estudantes fossem acompanhadas pela capacitação docente, o curso de Especialização em Ativação de Processos de Mudança na Formação Superior de Profissionais de Saúde foi implantado pelo Aprender-SUS, por meio da parceria com a SGTES, Rede Unida e Escola Nacional de Saúde Pública (ENSP/Fiocruz) (González, Almeida, 2010b).

No tocante a formação e desenvolvimento de recursos humanos para o SUS, destaca-se a política nacional de educação permanente em saúde (EP), que preconiza a articulação interprofissional de representantes das universidades, comunidades/usuários, trabalhadores da saúde e gestores de serviços de saúde que constituem o quadrilátero da formação proposto por Ceccim em 2004 no Brasil. A EP tem o objetivo de constituir uma rede de ensino-aprendizagem no exercício de trabalho do Sistema Único de Saúde (SUS), com a sua recomposição na direção das necessidades da população/usuários como cidadãos de direitos.

Em 2004 em prol da mudança na formação das profissões da saúde no Brasil, tendo a integralidade e a EP como eixos norteadores foi criado o Fórum Nacional de Educação das Profissões na Área da Saúde (FNEPAS). 
O diferencial é que neste espaço, as 14 profissões da saúde se unem em prol de mudanças na formação por meio de ações multi/interprofissionais (Lugarinho, Feuerwerker, 2006).

Em 2005, a OPAS promoveu a VII Reunião Regional dos Observatórios de Recursos Humanos em Saúde do continente americano, cujo enfoque foi a busca da promoção, fortalecimento e desenvolvimento da força de trabalho em saúde. Nesse evento, foi destacado que para a melhoria da capacidade da gestão e formação de recursos humanos em saúde nas Américas, é necessário desenvolver a educação multiprofissional e novos enfoques de capacitação para equipes de atenção primária (Brasil, 2006a).

Posteriormente, a SGTES também foi responsável pela criação do Programa Nacional de Reorientação da Formação Profissional em Saúde (Pró-Saúde), por meio da Portaria Interministerial MS/MEC n.2.102 de 03 de novembro de 2005 (Brasil, 2005, 2007b). De acordo com os objetivos de implementação do Pró-Saúde, é necessário promover a abordagem interdisciplinar e o trabalho em equipe, que raramente é explorado pelas instituições formadoras na graduação e se reproduz nas equipes de saúde, com a ação isolada de cada profissional e fragmentação do cuidado em saúde (Brasil, 2007b).

O Pró-Saúde investe na reorientação da formação em saúde para atender as demandas do SUS por profissionais com a humanização, comprometimento social e orientação para o conceito ampliado de saúde com foco na APS (Ferreira et al., 2012).

Como uma política indutora para a formação interprofissional em saúde, o Pró-Saúde estimulou a criação do Programa de Educação pelo Trabalho para a Saúde (PET- Saúde), como uma proposta da SGTES, instituído pela Portaria Interministerial MS/MEC n. 1802 de agosto de 2008. Este viabiliza programas de aperfeiçoamento e especialização em serviço dos profissionais da saúde, a iniciação ao trabalho, estágios e vivências, dirigidos aos estudantes da área, de acordo com as necessidades do SUS mediante grupos de aprendizagem tutorial, de natureza coletiva e interdisciplinar, com a articulação entre o ensino e serviços de saúde. Assim, o objetivo geral do PET-Saúde é estimular a formação de grupos de 
aprendizagem tutorial no âmbito da Estratégia de Saúde da Família para o fortalecimento dos serviços e da formação em saúde voltada para as premissas do SUS (Brasil, 2008a; Leite et al., 2012).

Cabe mencionar mais uma iniciativa de EIP no Brasil: a 'residência multiprofissional em saúde'. A residência, enquanto curso de pós-graduação senso lato, no Brasil, inicia em 1976, com a Residência em Medicina Comunitária, que logo se torna multiprofissional, a partir da implantação do Programa de Saúde da Família na década de 1990. Mas apenas em 2005 com a Portaria Interministerial MEC/MS n. 2.117, a Residência Multiprofissional em Saúde é instituída formalmente (Brasil, 2006b).

Entre as universidades brasileiras, destacam-se Universidade Federal de São Paulo (UNIFESP) campus Baixada Santista que mantém um projeto de educação integralmente interprofissional para cinco curso da área da saúde desde a sua criação. A Universidade Federal do Ceará mantém um Laboratório de Educação e Colaboração Interprofissional para a Promoção da Saúde Materno-Infantil e a Universidade Estadual de São Paulo, Campus Botucatu desenvolve um programa chamado Integração Universidade Saúde Comunidade (IUSC).

Na UNIFESP campus Baixada Santista, em 2006 foi implantado um projeto curricular interprofissional, que possibilita a formação integrada entre as diferentes áreas profissionais, com ênfase na integralidade e nas necessidades singulares dos usuários e população. O marco central dessa construção é a clínica do comum, realizada com a participação de diferentes áreas profissionais, por meio do diálogo entre os profissionais e com os usuários, sobre as múltiplas dimensões do trabalho e do processo saúdedoença (Feuerwerker, Capozzolo, 2013).

A política governamental do Programa de apoio à Planos de Reestruturação e Expansão das Universidades Federais (Reuni), implementada através do Decreto n.6096/2007, impulsionou a criação de dez cursos de Graduação em Saúde Coletiva e a implantação do Bacharelado Interdisciplinar em Saúde (BIS), a partir de 2008 na Universidade Federal da Bahia e posteriormente na Universidade Federal do 
Recôncavo Baiano e Universidade Federal da Sul da Bahia (Castellanos et al., 2013; Teixeira et al., 2013).

Em consonância com a EIP, os cursos de Graduação em Saúde Coletiva, representam um avanço em direção à formação interdisciplinar orientada às necessidades de saúde dos usuários e população do SUS, com a finalidade de formar profissionais orientados para as demandas do SUS e promover mudanças nas práticas da saúde (Castellanos et al., 2013; Belisário et al., 2013).

Os BIS representam uma possibilidade de evitar a profissionalização precoce e a especialização, pautados nos princípios curriculares norteadores da autonomia, flexibilidade, articulação interdisciplinar e atualização (Teixeira et al., 2013).

\section{A INTERDISCIPLINARIDADE NA FORMAÇÃO EM SAÚDE}

Algumas iniciativas interprofissionais e próximas a ela são denominadas na literatura como práticas interdisciplinares. Por isso, para compreender o tema da EIP e diferenciá-lo da proposta de interdisciplinaridade é preciso conhecer o conceito de disciplina, saber e suas derivações, que revelam os diferentes níveis de contato entre as ciências ou áreas de conhecimento: multidisciplinaridade, pluridisciplinaridade, interdisciplinaridade e transdisciplinaridade.

Disciplinas são organizadas por modelos científicos, coerentes que podem ser demonstrados, transmitidos, institucionalizados e ensinados como ciência (Foucault, 1995).

O saber, consiste nos elementos formados pela prática discursiva, com o enunciado de conceitos que são definidos, aplicados, transformados e necessários para a constituição da ciência. Trata-se do domínio de objetos que dependem da prática discursiva e podem ou não se tornar conhecimento científico (Foucault, 1995).

Comparativamente, o campo do saber é mais abrangente que o da ciência, pois o saber "não está contido somente em demonstrações; pode 
estar também em ficções, reflexões, narrativas, regulamentos institucionais, decisões políticas" (Foucault, 1995, p. 208).

O saber está fragmentado em múltiplas disciplinas científicas, que se subdividem em especialidades e subespecialidades, no contexto das universidades e centros de pesquisa (Siebeneichler, 1989). Com a crescente valorização da ciência no contexto científico, novas disciplinas são criadas, como subdivisões internas nos campos disciplinares. Essa organização da ciência com a fragmentação do objeto é designada como disciplinaridade (Almeida Filho, 2000).

Um exemplo é a fragmentação da profissão da enfermagem no Brasil, que encontra-se dividida em 42 especialidades, de acordo com a Resolução n. 388/2011 do Conselho Federal de Enfermagem (COFEN, 2011).

Disciplina inicialmente significava a ação de aprender, de instruir-se; posteriormente, veio a conotar o ensino-aprendizado em geral, incluindo todas as formas de educação e formação. Por metonímia, com a organização das primeiras universidades ainda no contexto da escolástica, disciplina passou a designar uma matéria ensinada, um ramo particular do conhecimento, o que depois viria a se chamar de "ciência". Por extensão, a disciplina tornou-se equivalente a princípios, regras e métodos característicos de uma ciência particular (Almeida Filho, 2000, p. 207).

Disciplina e disciplinaridade se referem à progressiva exploração científica especializada numa certa área de estudo. O termo disciplina, tal como entende-se é usado como sinônimo de ciência, embora seja mais utilizado para designar o ensino de uma ciência relacionada à atividade de pesquisa. Uma disciplina possui fronteiras constituintes bem delimitadas, que determinam seus objetos materiais e formais, seus métodos e sistemas, seus conceitos e teorias (Japiassu, 1976). Para Furtado (2007), a disciplina constitui um conjunto de saberes organizados em teorias, conceitos e métodos para a compreensão de fenômenos que na pedagogia podem ser desenvolvidos em matérias específicas do conhecimento científico.

A complexidade dos objetos e suas múltiplas dimensões, indicam que a organização tradicional da ciência com disciplinas estanques precisa ser superada. A superação da disciplinaridade requer a construção de interação ou integração dos campos disciplinares (Almeida Filho, 2000). 
Os precursores dos estudos sobre a interdisciplinaridade são Georges Gusdorf na Europa e Hilton Japiassu que introduz o tema no Brasil, com a obra "Interdisciplinaridade e a patologia do saber". No livro, aponta a perspectiva de totalidade presente no conceito, assim como o ideal da Paidéia da cultura grega que compõe um conjunto de estudos circulares e complementares em estado harmônico (Gattás, Furegato, 2006).

A maior parte dos estudos sobre interdisciplinaridade apresentam o consenso de que a ideia da especialização fracassou, por isso é necessário a recomposição do saber por meio da articulação entre as disciplinas (Furtado, 2007; Vilela Mendes, 2003; Gattás, Furegato, 2006; Saupe, Budó, 2006; Almeida Filho, 2000; Morin, 1999; Torres 1998; Nunes, 1995; Fazenda, 1994; Japiassu, 1976).

\begin{abstract}
O fenômeno da interdisciplinaridade talvez seja o sintoma da situação patológica em que se encontra o saber. A especialização exagerada e sem limites das disciplinas científicas, a partir sobretudo do século XIX, culmina cada vez mais numa fragmentação crescente do horizonte epistemológico. Assim, vislumbra nova adequação das atividades universitárias às necessidades sócio-profisisonais ou econômicas. Portanto, de um lado a interdisciplinaridade aparece como o instrumento e a expressão de uma critica interna do saber, como um meio de superar o isolacionismo das disciplinas, como uma maneira abandonar a pseudo-ideologia da independência de cada disciplina relativamente aos outros domínios da atividade humana e aos diversos setores do próprio saber; do outro como uma modalidade inovadora de adequar as atividades de ensino e pesquisa às necessidades sócio-profissionais bem como de superar o fosso que ainda separa a universidade da sociedade (Japiassu, 1976, p. 57).
\end{abstract}

A compreensão dos fenômenos sociais na presente realidade multifacetada, depende da disposição de levar em conta todas as suas dimensões, por isso torna-se pertinente a perspectiva da interdisciplinaridade que prevê a abordagem articulada dos processos e seus aspectos socioculturais (Torres, 1998; Fazenda, 2002; Saupe, Budó, 2006).

A interdisciplinaridade pode eliminar a distância existente entre a formação escolar e atividade profissional. Contudo, as disciplinas, ou ciências, classificadas segundo os valores sociais vigentes, individualização e especialização, representam obstáculos para execução da proposta interdisciplinar, devido à dificuldade em eliminar as barreiras entre as disciplinas, mediante a articulação das especialidades para superar a 
fragmentação curricular e anular o trabalho individual em prol do coletivo (Fazenda, 1994).

A proposta da interdisciplinaridade busca reconhecer e dar viabilidade à interdependência entre as disciplinas com interação e reciprocidade dos especialistas de diferentes áreas, em prol da construção de um saber integrado, para superar a fragmentação e possibilitar a compreensão da complexidade da realidade (Japiassu, 1976, Saupe, Budó; 2006).

A revisão de literatura sobre a interdisciplinaridade realizada por Gattás e Furegato (2006), revela que apesar das divergências no conceito que envolvem, tanto os saberes científicos quanto a intersubjetividade, prevalecem aspectos comuns, indispensáveis para à prática interdisciplinar como: atitude, capacidade de cooperação, respeito à diversidade, abertura para o outro e disposição para colaborar.

Uma disciplina sempre depende da interação com outras, assim é preciso estabelecer os níveis de agrupamento das disciplinas em contato, multi, pluri, inter e transdisciplinaridade, conceitos propostos por Janstch em 1972 (Furtado, 2007; Japiassu, 1976).

$\mathrm{Na}$ multidisciplinaridade várias disciplinas estão presentes, simultaneamente, com múltiplos objetivos, sem cooperação entre elas. Irribarry (2003), exemplifica o conceito, pela presença de vários profissionais reunidos em um hospital trabalhando isoladamente, ou diferentes cursos de graduação de uma mesma universidade, desenvolvidos com diferentes áreas que coexistem em relação, contudo sem interação. $\mathrm{Na}$ pluridisciplinaridade há justaposição de diversas disciplinas e suas relações são percebidas em um sistema com múltiplos objetivos, com cooperação entre os profissionais, por exemplo, quando um médico especialista encaminha o paciente que atendeu para outro profissional da saúde, sem se articular com ele, de modo a estabelecer contatos entre os profissionais e sua área de conhecimento, ou uma mesa redonda de especialistas sobre determinado tema, cuja síntese caberá aos ouvintes (Japiassu 1976; Almeida Filho, 2000; Iribarry, 2003; Furtado; 2007). Ou seja, a pluridisciplinaridade 
envolve várias disciplinas, com o objetivo de analisar um tema sob variados ângulos, por justaposição (Siebeneichler, 1989).

A interdisciplinaridade representa o grau mais avançado, no tocante à interação das disciplinas, para responder à dispersão e fragmentação das ciências e especialidades. Ocorre com um nível hierárquico imediatamente superior, que realiza a coordenação dos múltiplos objetivos disciplinares envolvidos e conectados com a mesma finalidade (Japiassu 1976; Almeida Filho, 2000; Siebeneichler, 1989). Esse sistema pode ser exemplificado pela relação interdisciplinar de diversos profissionais da saúde, que realizam o atendimento ao mesmo paciente, entre os quais prevalece o saber médico, responsável pela tomada de decisão e coordenação das ações (Iribarry, 2003).

No movimento habermasiano em prol da interdisciplinaridade, busca-se realizar uma análise interdisciplinar, dos modos de incorporação da razão comunicativa nos movimentos e instituições sociais que configuram a sociedade atual, que está em crise devido ao avanço colonizador dos sistemas não comunicativos, com a hegemonia da racionalidade técnica instrumental (Siebeneichler, 1989, p.166).

A transdisciplinaridade envolve um sistema interdisciplinar inovador, com múltiplos objetivos, sem fronteiras estáveis entre as disciplinas e uma coordenação que propõe a finalidade comum do sistema (Japiassu 1976). Na saúde, pode ser exemplificado pelo atendimento de um paciente de saúde mental que reunirá diversos profissionais em sua avaliação, de modo que cada profissional esteja situado em sua área de saber e na área de cada colega, a fim de propor a terapêutica para o caso em questão, mediante a especificidade de cada um, para a compreensão global do espaço transdisciplinar (Iribarry, 2003). Para alguns autores a transdisciplinaridade é um ideal inalcançável, sendo que para outros é a única maneira de superar os limites da interdisciplinaridade (Furtado, 2007).

A transdisciplinaridade é caracterizada por saberes compartilhados em um sistema de múltiplos níveis, com objetivos diversificados, baseado em conhecimentos comuns e tendência à horizontalização das relações interdisciplinares (Almeida Filho, 2000). 
O esquema a seguir mostra a lógica de cada um dos conceitos apresentados respectivamente: multidisciplinaridade, pluridisciplinaridade, interdisciplinaridade e transdisciplinaridade.

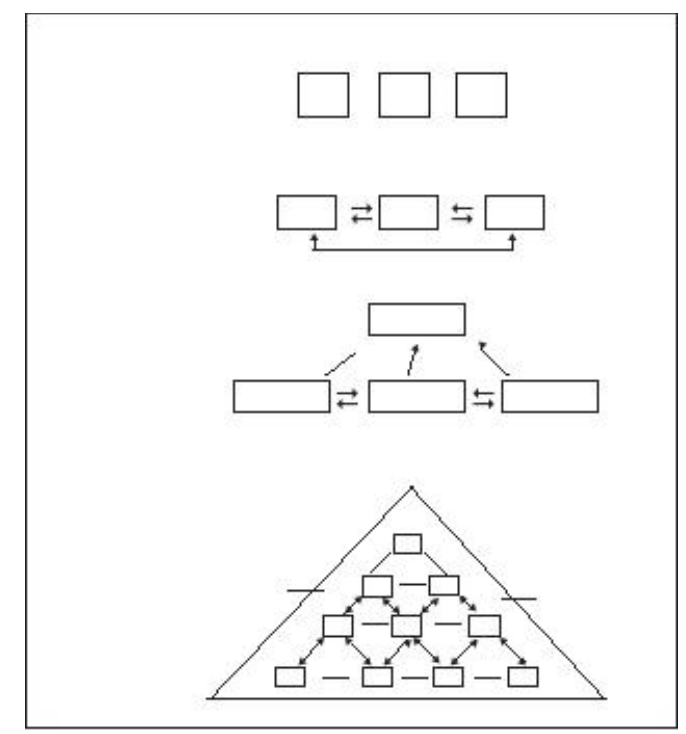

Figura 1. O modelo de Janstch, 1972.

Segundo Furtado (2007), o ideal da transdisciplinaridade supera as expectativas de interação da saúde e ultrapassa os limites aceitáveis dos conselhos de classe que regulamentam o exercício profissional em saúde. Por isso, no presente estudo falaremos da interprofissionalidade na perspectiva interdisciplinar, como princípio mediador entre as diferentes disciplinas, apesar da instigante proposta da transdisciplinaridade. $\mathrm{O}$ sufixo disciplinar está relacionado com a perspectiva epistemológica do saber, conceitos e teorias voltados para a compreensão de fenômenos, enquanto o termo profissional se refere às práticas de saúde das equipes em serviços.

Desse modo, falar em educação interprofissional em saúde reforça a relação direta da formação com o trabalho, ou educação contextualizada na realidade de trabalho, mediante a estreita conexão entre saberes e práticas, para superar a racionalidade positivista científica, enfrentar o antagonismo entre a lógica profissional que preconiza o núcleo do saber de cada área, com a diferenciação profissional em contraposição à necessária lógica da colaboração profissional, como uma condição de qualificação das práticas 
de saúde para educação e prática interprofissional (Saupe, Budó, 2006; Furtado, 2007).

Os conceitos de campo e núcleo de competência e responsabilidade profissional, propostos por Campos (2000), convergem com a discussão da lógica profissional e da colaboração. $\mathrm{O}$ núcleo diz respeito à identidade de cada profissão e o campo envolve as responsabilidades comuns dos diferentes profissionais.

Desde a década de 1970, as reformas na educação brasileira propuseram a necessidade de mudanças no ensino em direção à interdisciplinaridade (Fazenda, 2002), mediante os estudos de Japiassu (1976) e Fazenda (1994, 2002). Contudo, sabe-se que a formação em saúde está fundamentada majoritariamente, no modelo de ensino por disciplinas, desvinculadas da formação e do trabalho em saúde.

A formação em saúde, como prevê as Diretrizes Curriculares Nacionais (DCN) dos Cursos de Formação em Saúde no 9.394 de 20 de dezembro de 2001, passa por dois momentos complementares, o da formação peculiar de cada profíssão e do desenvolvimento de núcleos comuns de saberes em que se evidenciam a interdisciplinaridade em detrimento à formação desarticulada e fragmentada. Esta condição é fundamental para a abordagem integral do processo saúde-doença, com integração entre as disciplinas, articulação entre os cursos da saúde e o trabalho em saúde (Brasil, 2001; Garcia et al, 2006; Saupe, Budó, 2006).

A Lei de Diretrizes de Bases da Educação de 1996, que regulamenta o ensino no Brasil, prevê o desenvolvimento de projetos pedagógicos inovadores das Instituições de Ensino Superior, voltados para as necessidades do país e das comunidades locais, como uma iniciativa interdisciplinar com temas curriculares transversais e integração curricular (Berardinelli, Santos, 2005).

A revisão de literatura das publicações brasileiras realizada em outubro de 2011 sobre a IPE, revelou que o debate sobre o tema no contexto brasileiro ainda é incipiente, pois a maior parte das publicações enfoca a educação interdisciplinar na formação para a integração entre as disciplinas curriculares dos cursos da saúde, como sinônimo da educação 
interprofissional. Foram encontrados somente dois artigos publicados que utilizam o termo IPE no sentido da formação compartilhada como tomamos no presente estudo: um de Aguilar-da-Silva, Scapin e Batista (2011), sobre a avaliação da formação interprofíssional no ensino superior em saúde, aspectos da colaboração e do trabalho em equipe na Faculdade de Ciências Médicas e da Saúde de Juiz de Fora; e outro de Barreto et al. (2011), sobre o desenvolvimento da prática da colaboração interprofissional na graduação em saúde: estudo de caso da liga de saúde da família em Fortaleza, CearáBrasil.

O primeiro artigo revela que todos os estudantes que participaram da pesquisa apontaram para importância do trabalho em equipe e do aprendizado integrado com outras profissões, para promover colaboração, mediante o envolvimento e busca da satisfação no trabalho, no desenvolvimento de competências e criação de sinergia entre os participantes e definição dos papéis de cada um, pois quando os estudantes propõem medidas de cuidado para atender as necessidades de saúde dos usuários/população, aprendem a aprender juntos sobre si, o outro e suas profissões (Aguilar-da-Silva, Scapin, Batista, 2011).

O segundo artigo aponta que a dinâmica de trabalhos de mentores da Liga de Saúde da Família, um programa de extensão que estimula a colaboração interprofissional, na perspectiva da aprendizagem social por meio do planejamento e desenvolvimento integrado do ensino e colaboração interprofissional de médicos, enfermeiros, fisioterapeutas, psicólogos, educadores físicos e dentistas. Nessa proposta, o plano de ação dos estudantes depende da contextualização das necessidades de saúde da população, problemas e desafios, cuja centralidade está na colaboração, construção de relações e compartilhamento do saber de estudantes de diferentes áreas (Barreto et al 2011).

\section{PRÁTICA COLABORATIVA CENTRADA NO USUÁRIO}

A prática colaborativa centrada no paciente (PCCP) é um moderno modelo de cuidado dos sistemas de saúde, com destaque nos Estados 
Unidos, Reino Unido, Europa e Ásia. É definida como o processo de parceria ou coprodução entre profissionais e usuários para o planejamento, desenvolvimento e avaliação do cuidado, apropriado às necessidades de saúde com respeito às preferencias, valores, situação familiar, condição social e estilo de vida (Silva, 2014; Pelzang, 2010).

$\mathrm{Na}$ última década tem aumentado o foco das práticas no usuário (Silva, 2014), entretanto, os sistemas de saúde e formação estão predominantemente estruturados sob um modelo de práticas, no qual os profissionais tomam as decisões e raramente incluem o paciente no planejamento dos cuidados (Orchard, Curran, Kabene, 2005).

Os componentes chave da PCCP são: dignidade e respeito no processo de tomada de decisão, apoio para o gerenciamento do autocuidado e comunicação proativa (Silva, 2014; Kitson et al, 2012).

$\mathrm{Na}$ perspectiva da PCCP, considera-se o paciente em sua singularidade, cujas necessidades físicas, psicológicas e sociais estão no centro dos cuidados de saúde. Os princípios dessa prática são o respeito e a participação do usuário no processo de tomada de decisão sobre o cuidado, considerando seus valores, experiências, crenças e preferências (Silva, 2014; Pelzang, 2010; CIHC, 2010).

No Brasil, utiliza-se o termo usuário para se referir ao paciente, por isso, pode-se falar em prática colaborativa centrada no usuário (PCCU). Embora a nomenclatura PCCU não seja utilizada, considera-se a existência de um modelo tecnológico de atenção à saúde que veicula propostas semelhantes à PCCP, a clínica ampliada ou clínica do sujeito, que integra a abordagem voltada para a subjetividade do usuário e seu contexto social.

A clínica ampliada é uma modelo tecnoassistencial desenvolvido por Campos (1991, 2007b, 2007c), com a centralidade nos usuários, reconhecidos como sujeitos portadores de desejos e interesses que devem ser considerados na produção do cuidado em saúde, ao invés da abordagem com ênfase na doença. Ao incluir os sujeitos no processo de trabalho em saúde, amplia-se a capacidade de intervenção sobre os problemas apresentados com a construção de vínculos entre equipes e usuários. 
O vínculo é construído com a disposição de acolher os usuários e buscar apoio da equipe de saúde, em um processo de dependência mútua, em situações nas quais os usuários podem precisar de ajuda para resolver questões sanitárias e os trabalhadores precisam dessa relação intersubjetiva para exercer sua prática profissional (Campos, 2007b).

Os usuários são considerados corresponsáveis pela sua condição de saúde, influenciada pelo estilo e condições de vida, associada às influências e efeitos das ações dos trabalhadores dos serviços da saúde sobre as necessidades dos usuários (Campos, 2007b).

O deslocamento da ênfase na doença, pautada na abordagem reducionista que fragmenta o indivíduo em partes com, a finalidade de eliminar sintomas, para a lógica centrada no usuário é preconizado pela proposta da PCCU. Nessa perspectiva, considera-se as singularidades do usuário, com a inclusão de seu contexto como objeto de estudo e práticas da clínica ampliada (Campos, 2007b).

A literatura aponta que o cuidado centrado no paciente e a qualidade da atenção são desdobramentos da prática colaborativa na saúde, que dependem do domínio da boa prática clínica e da integração com pacientes, famílias e outros profissionais. As iniciativas internacionais em prol do cuidado do paciente, começaram em 1973 com a OMS e continuam crescendo (Pelzang, 2010; Carpenter, Dickinson, 2008; Oandasan et al., 2004).

A PCCP contribui para melhorar a continuidade do cuidado, responder as necessidades de saúde dos pacientes, integrar os profissionais da saúde em colaboração com os pacientes, promover autonomia e empoderar os pacientes e equipes (Silva, 2014; Pelzang, 2010).

Pesquisas apontam que a PCCP contribui para a melhora das condições crônicas de saúde, como diabetes, doença pulmonar obstrutiva crônica e problemas cardíacos (Silva, 2014; Mirzaei et al., 2013).

A educação interprofissional é um requisito básico para o desenvolvimento da PCCP, contudo predominam os currículos uniprofissionais, sendo que muitas vezes, nem mesmo habilidades de comunicação são ensinadas (Pelzang, 2010). 
As principais barreiras para o desenvolvimento da PCCP são: a falta de uma definição clara da PCCP, a falta de equipes de saúde, o modelo biomédico hegemônico, a falta de coordenação, colaboração e continuidade do cuidado, e ausência de bons modelos de ensino de currículos de formação voltados para PCP (Pelzang, 2010).

Orchard, Curran e Kabene (2005), desenvolveram um modelo conceitual para a PCCP e apontam três principais barreiras para sua efetivação: a estrutura organizacional, as relações de poder e a socialização dos papéis. A estrutura organizacional inclui as esferas de regulação profissional governamentais, jurídicas e das corporações profissionais. As relações de poder expressam conflitos entre profissionais, sobreposição de competências, responsabilidades e percepções sobre estereótipos profissionais. As relações de poder revelam assimetrias nas interações que podem provocar frustrações, naqueles que não estão participando do processo de tomada de decisão sobre o cuidado, assim como inadequadas prescrições terapêuticas, devido à ausência de escuta dos pacientes. Por fim, a socialização dos papéis pode contribuir para o desenvolvimento de uma cultura de colaboração interprofissional que depende do respeito às diferenças dos saberes, valores e crenças dos profissionais.

Frente às barreiras mencionadas, os elementos facilitadores para a PCCP são: o conhecimento dos diferentes papéis profissionais e sua valorização, reconhecimento da complementaridade e interdependência, desenvolvimento de relações de confiança para a tomada de decisão e o compartilhamento de poder (Orchard, Curran, Kabene, 2005).

Apesar da PCCP exigir investimentos na educação e recrutamento dos profissionais da saúde, vários estudos revelam que tem impactos positivos na redução dos custos dos tratamentos com melhores resultados no cuidado, satisfação dos usuários, famílias e profissionais (Leasure et al., 2013; Pelzang, 2010; Orchard, Curran, Kabene, 2005).

A avaliação da PCCP pode ser pautada na efetividade do trabalho em equipe relacionada com: planejamento conjunto, objetivos compartilhados, abertura para comunicação, criativo gerenciamento das barreiras, estratégias de delegação de tarefas, avaliação de resultados, consideração das 
contribuições de cada membro da equipe, repertório de formação, áreas de potência e limitações, evidências da conclusão de tarefas, recursos adequados, reconhecimento de conflitos e habilidades para gerenciá-los, resolução de problemas e liderança. Também podem ser avaliados a efetividade da tomada de decisão em equipe, satisfação com a colaboração interprofissional, performance, atitudes e percepções no trabalho em equipe, comportamento, adaptabilidade, liderança e orientação das equipes (Orchard, Curran, Kabene, 2005).

\section{EXPERIÊNCIAS DE EDUCAÇÃO INTERPROFISSIONAL NA PERSPECTIVA HABERMASIANA ${ }^{2}$}

Com a aplicação da teoria habermasiana busca-se destacar dois relevantes determinantes da educação interprofissional em saúde: a comunicação e a interação.

A comunicação interprofissional entre estudantes e profissionais é uma das competências necessárias para a formação e prática interprofissional colaborativa centrada no usuário. Esta prática pressupõe a formação para o trabalho em equipes integradas, pautado na negociação constante entre os agentes, para a tomada de decisões compartilhadas com a participação dos usuários, famílias e comunidade (CIHC, 2010; IPEC, 2011).

Martin Rodriguez et al., (2005) aborda os determinantes para a interação interprofissional colaborativa, entre os quais a educação para a tomada de decisões compartilhadas e o reconhecimento do trabalho e dos papéis profissionais são relevantes.

As práticas de formação pautadas na eficiente comunicação tem como resultado a segurança do paciente, com a redução de erros clínicos

\footnotetext{
${ }^{2}$ As ideias elaboradas nesta parte do referencial teórico foram apresentadas em co-autoria com a orientadora desta pesquisa em um capítulo de livro. Silva, JAM; Peduzzi, M. A dimensão comunicativa na educação interprofisisonal em saúde. In: Jürguen Habermas Publicidade, direitos humanos e sociedade civil. Pinzani, A; Schmidt R (organizadores). Reflexões teóricas e empíricas. Editora da Universidade Federal de Santa Cararina (UFSC): Florianópolis (No Prelo).
} 
(Reeves et al., 2013). Na mesma direção, a Organização Mundial de Saúde elaborou uma versão multiprofissional de um guia curricular de segurança do paciente (WHO, 2011). Apesar da nomenclatura multiprofissional remeter à justaposição das ações, com o agrupamento de profissionais ou a prática desenvolvida em equipes integradas (Peduzzi, 2001, 2007a), o guia traz contribuições da comunicação, no tocante à interação com os usuários, por indicar a importância do contexto, vulnerabilidades, respeito, confidencialidade, provisão de informações, encontros com familiares e cuidadores.

$\mathrm{Na}$ abordagem habermasiana, a comunicação interprofissional compartilhada é estabelecida em um mesmo mundo da vida, do qual devem fazer parte usuários, estudantes e profissionais da saúde, a fim de atingirem o entendimento mútuo para a elaboração de um plano terapêutico coletivamente.

A integração promovida pela EIP contribui para a redução de atitudes negativas dos estudantes em relação às outras áreas profissionais, por promover o respeito ao outro, reconhecimento do trabalho e do papel profissional do outro e eliminação de estereótipos negativos (Ateah et al., 2011; Coster et al, 2008; Hind et al, 2003; Pollard et al, 2006; Horshburg, Landim, Wiliamson; 2001; Barnes, Capenter, Dickinson, 2000).

A racionalização da sociedade, desencadeia a especialização do saber e o isolamento profissional nas práticas de saúde que são colonizadas pela organização do trabalho e da saúde na perspectiva da racionalidade instrumental, em detrimento a interação característica do agir comunicativo.

A presente divisão do trabalho entre vários profissionais da saúde é uma construção resultante de um complexo processo histórico que envolve, o progresso científico, o desenvolvimento tecnológico, as relações econômicas, os interesses políticos e culturais do esquema de valores e crenças. Por isso, é importante compreender a dinâmica do processo de trabalho em saúde e das fronteiras entre os diferentes grupos profissionais, assim como, os limites estabelecidos para suas respectivas esferas de práticas e relações hierárquicas. A mesma lógica hierárquica, presente nas práticas de saúde, se reproduz na formação dos profissionais da saúde, assim 
observa-se uma conexão entre profissionais de saúde e o objeto do processo educacional, ou seja, entre os sistemas de educação e saúde (Frenk, 2010).

Existe uma circularidade entre as características do trabalho em saúde e da formação em saúde. Na perspectiva habermasiana, a centralidade das ações racionais de caráter técnico-científico em busca do êxito técnico, leva ao estabelecimento de práticas fragmentadas no trabalho e na formação em saúde, cujo foco das ações é restrito ao saber técnico de determinada área.

Desse modo, é preciso resgatar a esfera interativa do trabalho e da formação em saúde, pois a complexidade das necessidades da saúde com o crescimento das doenças crônicas, requerem uma abordagem pautada na construção do entendimento e da colaboração entre profissionais e usuários para a qualidade do cuidado à saúde.

No caso de paciente hipertenso, por exemplo, o entendimento será possível se os profissionais/estudantes de medicina, enfermagem, nutrição, farmácia, educador físico e demais envolvidos, compartilharem do mesmo mundo da vida do paciente. A interação e o entendimento dependem do compartilhamento dos elementos estruturais do mundo da vida, a cultura, sociedade e personalidade. A abordagem ampliada das necessidades de saúde dos usuários por meio do agir comunicativo, possibilitará compreensão de que o paciente necessita de cuidados que não estarão reduzidos ao êxito técnico, da abordagem restrita aos sinais, valores pressólicos, sintomas, comorbidades e prescrição farmacológica.

Para estabelecer um projeto comum de ação os estudantes/profissionais estabelecerão um plano de cuidados contextualizado às condições sociais, econômicas e culturais do paciente, considerando sua singularidade/subjetividade. Ou seja, isso quer dizer que os profissionais de saúde acolherão o usuário considerando sua opinião no tocante às opções para o tratamento, considerarão as dificuldades para adesão e adaptarão o plano terapêutico sempre que necessário, considerando o contexto de vida do usuário, potencialidades e limitações.

A assimetria dos saberes entre profissionais/estudantes e usuários não impede o exercício da ação comunicativa. Pode-se configurar em uma 
prática argumentativa singular, baseada na correção normativa e no exercício da sinceridade. O cuidador se compromete a deslocar-se para o contexto do usuário, para entender sua problemática e sua fala, desde a cultura, história de interação e objetivo de aliviar o sofrimento. Compromete-se a ajudar a resolver seus problemas de saúde, dentro da moldura ética processada no interior de cada cuidado. Esse compromisso tem o potencial de reduzir a assimetria, não de anulá-la. $\mathrm{O}$ usuário tem o compromisso de colaborar com o cuidador ao fornecer informações que possibilitam a mais abrangente compreensão das múltiplas determinações que envolvem seu sofrimento, e se compromete a seguir as prescrições do profissional baseado em sua autoridade reconhecida (Artman, Rivera, 2006).

Um espaço privilegiado para a compreensão das múltiplas determinações de processo saúde-doença e interações interprofissionais é o contexto da Estratégia de Saúde da Família (ESF) na APS. Recente publicação de Giovanella et al. (2009), que discute a articulação da ESF com a rede assistencial do Sistema Único de Saúde (SUS), ressalta a necessidade da maior interação dos profissionais generalistas com os especialistas, como um desafio presente para a maior integração dos processos de trabalho, superando relações hierárquicas e o isolamento entre APS e atenção especializada.

A reprodução simbólica da linguagem comum entre estudantes e profissionais da saúde é um requisito fundamental para o entendimento intersubjetivo. Desse modo, a EIP pode favorecer a construção da interação comunicativa para eliminação das barreiras entre as áreas profissionais mediante a linguagem e saberes compartilhados.

$\mathrm{Na}$ avaliação de um curso interprofissional de cuidados paliativos, os participantes avaliaram que a diversidade do grupo foi muito importante para a compreensão dos diferentes papéis profissionais de cada um na equipe de cuidados paliativos, sentiram-se beneficiados por compartilharem informações e experiências, assim como se preocuparam com a presença do sentimento de inferioridade perante profissionais considerados mais qualificados. Contudo, a técnica de ouvir as experiências dos outros e compartilhar histórias foi efetiva para a quebra das barreiras 
interprofissionais. Outro ponto, é que um profissional não pode trabalhar isolado, ele precisa manter a comunicação com outros profissionais de modo apropriado, essa articulação lhe confere o desenvolvimento de novas habilidades e assim, sente-se mais confortável com o seu trabalho (Campion-Smith et al, 2011).

A interação intersubjetiva característica da EIP, que propicia o entendimento e colaboração entre estudantes de diferentes áreas profissionais para atenção centrada no usuário, mostra o potencial da teoria do agir comunicativo para analisar situações de interprofissionalidade.

A EIP pode constituir um modelo de formação necessário para a valorização da esfera interativa entre as áreas profissionais no contexto da formação e das práticas de saúde, frente ao predomínio do agir instrumental com os avanços da ciência e da técnica na área da saúde.

\section{ATENÇÃO PRIMÁRIA À SAÚDE NO SISTEMA ÚNICO DE SAÚDE}

O processo de construção do SUS é fruto da participação popular na reforma sanitária e está expresso na Constituição Federal Brasileira de 1988. O documento constitucional determina a saúde como direito de todos e dever do Estado, preconiza o acesso universal e igualitário em uma rede regionalizada e hierarquizada, organizada a partir da descentralização, atendimento integral e participação da comunidade (Brasil, 1988).

Entre as prioridades do SUS está o fortalecimento da atenção primária à saúde (APS), entendida como função central dos sistemas de saúde, a fim de melhorar a efetividade de seus serviços com o aumento da cobertura e acesso às ações de saúde pela população e integração da promoção, prevenção e reabilitação da saúde, também por meio da integração com outros setores para promover desenvolvimento social e enfrentar os determinantes de saúde (Giovanella, 2008).

A APS é priorizada desde a Declaração de Alma-Ata de 1978, promulgada na Conferência Internacional sobre Cuidados Primários de Saúde sob o lema "Saúde para todos no ano 2000". Neste documento, a 
APS é reconhecida como um conjunto de cuidados essenciais de saúde, baseados em métodos e tecnologias práticas, fundamentadas cientificamente e colocadas ao alcance universal de todos, para que os cuidados de saúde sejam levados o mais próximo possível do lugar onde as pessoas vivem e trabalham, representando o primeiro nível de contato com o sistema nacional de saúde de um continuado processo de assistência (OPAS, 1978).

Duas concepções de APS predominam, a de cuidados ambulatoriais como porta de entrada ao SUS e a de uma política para a reorganização do modelo assistencial (Conil, 2008).

Para a reorganização do sistema de saúde a APS atende aos grupos populacionais de uma área geográfica de abrangência no território. Organizada por meio da integração entre unidades de saúde e a comunidade, a APS possui Unidades Básicas de Baúde (UBS) com e sem a Estratégia de Saúde da Família (ESF), implantada em 1994. A ESF tem por finalidade a expansão e consolidação da APS, definida por um conjunto de ações e serviços estruturados com base no reconhecimento das necessidades de saúde da população e construção de vínculo entre trabalhadores da saúde e população para a proteção social, universalidade e equidade (Brasil, 2012a).

A implementação da ESF implica na interação com a comunidade, com vistas a construir de forma participativa, práticas e estratégias mais eficazes de enfrentamento aos problemas e necessidades de saúde. Isso exige dos trabalhadores e profissionais da saúde que atuam na ESF, a incorporação de contínuas discussões acerca do seu processo de trabalho e das relações que estabelecem com os usuários dos serviços de saúde (Merhy, 2006a). Entende-se que a consolidação da ESF é uma estratégia prioritária para a reorganização da APS brasileira (Brasil, 2012a).

A proposta de mudança do modelo tecnoassistencial da APS por meio da ESF consiste em uma estratégia implementada para construção da integralidade. Contudo, enfrenta problemas relacionados à fragmentação do cuidado por níveis de atenção, com dificuldades em concretizar relações de referência, contra-referência e efetivar o trabalho em equipe (Feuerwerker, 2012). 
A visão predominante sobre os serviços de APS é equivocada, pois na concepção piramidal e hierarquizada do SUS, considera-se que seja menos complexa que os cuidados de média e alta complexidade.

É a APS que deve atender a mais de $85 \%$ dos problemas mais comuns de saúde; é aí que se situa a clínica mais ampla e onde se deveriam ofertar, preferencialmente, tecnologias de alta complexidade, como aquelas relativas às mudanças de comportamentos e de estilos de vida em relação à saúde: cessação do hábito de fumar, adoção de comportamentos de alimentação saudável e de atividade física etc. Essa concepção distorcida de complexidade leva, consciente ou inconscientemente, os políticos, os gestores, os profissionais de saúde e a população, a uma sobrevalorização material e simbólica das práticas que são realizadas nos níveis de "média e alta complexidades" e, por consequência, a uma banalização da APS (Mendes, 2012:91).

A APS constitui um nível próprio de atendimento às necessidades básicas de saúde, que envolve um trabalho complexo e requer alta capacidade resolutiva, assim como, alta sensibilidade diagnóstica. Inclui demandas sanitárias, saneamento do meio, desenvolvimento nutricional, vacinação, informação em saúde, ações clínicas de prevenção, profilaxia, tratamento e recuperação de doenças de caráter epidêmico ou não. As técnicas diagnósticas e terapêuticas realizadas neste contexto, dependem de reduzido número de equipamentos, quando comparados aos demais níveis de atenção, mas necessitam de sofisticada síntese de saberes e complexa integração de ações individuais, coletivas, curativas, preventivas, assistenciais e educativas (Schraiber, Mendes-Gonçalves, 2000).

A política nacional de Atenção Básica $(\mathrm{AB})$ considera a equivalência entre os termos, AB e Atenção Primária (Brasil, 2012a). No presente estudo optou-se pela utilização do termo APS, por ser utilizado também internacionalmente.

Os princípios e atributos da APS brasileira são: ter um território adscrito para o desenvolvimento de ações com impacto sob os condicionantes e determinantes de saúde da população adscrita. Promover o acesso universal e contínuo de todos que procurarem aos serviços de saúde, mediante o acolhimento, escuta vínculo, responsabilização e resolutividade. Adscrever os usuários e desenvolver relações de vínculo, longitudinalidade e corresponsabilização entre as equipes e a população. Coordenar a integralidade no tocante à articulação entre as ações de promoção, prevenção, vigilância à saúde e recuperação da saúde com a gestão do 
cuidado na rede de atenção, cuidado centrado no usuário para o aumento da autonomia e do trabalho em equipe multiprofissional. Estimular a participação do usuário na construção do cuidado e do controle social (Brasil, 2012a).

Starfield (2002) define a APS a partir de quatro atributos, contato, longitudinalidade, integralidade e coordenação. A longitudinalidade é uma característica central e específica da APS, que envolve a responsabilização do cuidado à saúde, pela equipe de saúde ao longo do tempo, com estabelecimento de vínculos interpessoais. $\mathrm{O}$ contato se refere à acessibilidade e utilização dos serviços de saúde. A integralidade depende do reconhecimento do amplo espectro das necessidades dos usuários, para que a população receba todos os tipos de serviços de saúde que necessitar e seja encaminhada aos mesmos. A coordenação ou integração da atenção à saúde, requer a continuidade dos cuidados prestados por meio de referência, contra-referência e acompanhamento de prontuários.

Situada entre os princípios do SUS, a integralidade, já apresentada anteriormente, volta-se para a articulação de ações de promoção, prevenção e recuperação da saúde. Busca atender as necessidades dos usuários/população de modo ampliado, para além do foco reduzido à doença, ao tomar o contexto social, econômico e cultural dos usuários. Lógica que pode contribuir para reorganizar o processo de trabalho nos serviços da saúde (Mattos, 2004), por distanciar-se do modelo assistencial biomédico hegemônico, que reitera uma visão fragmentada da atenção à saúde e distante dos usuários/população.

Entretanto, o modelo médico hegemônico predomina nos serviços de saúde e fragiliza a construção da APS na perspectiva da integralidade. Esta depende da organização dos processos de trabalho de forma centrada no usuário e suas necessidades, na qual a assistência deve ser interprofissional, com a responsabilização da equipe pelo cuidado individual e vigilância à saúde (Franco, Magalhães Junior, 2006).

Para ampliar as ações da APS e consolidar a ESF, o Ministério da Saúde criou, em 2008, os Núcleos de Apoio à Saúde da Família (NASF). A composição das equipes do NASF varia em função da população do 
município no qual estão alocados. Podem ser compostos por três a cinco profissionais de nível superior: médico acupunturista, assistente social, profissional da educação física, farmacêutico, fisioterapeuta, fonoaudiólogo, médico ginecologista, médico homeopata, nutricionista, médico pediatra, psicólogo, médico psiquiatra e terapeuta ocupacional (Brasil, 2008b).

Os NASF são classificados em três modalidades de acordo com o número de profissionais que compõem a equipe: NASF-1 com no mínimo cinco profissionais que dão retaguarda para oito a 20 equipes, NASF-2 com no mínimo três profissionais responsáveis pelo apoio matricial de até três equipes, NASF-3 que atende a municípios de pequeno porte, com uma ou duas equipes de ESF. Em todas as modalidades NASF, recomenda-se a presença de no mínimo um profissional de saúde mental (Oliveira, 2013).

Os NASF possibilitam a ampliação da oferta das práticas integradas e complementares, em ações compartilhadas com as equipes da ESF. Oferecem ações diferenciadas para grande parte dos usuários com doenças crônicas e a revisão de tratamentos baseados apenas na medicalização das doenças (Mendonça et al., 2008).

Considera-se que o modo de organização do trabalho na APS com a ESF e o NASF, constituem espaços privilegiados para a prática e formação interprofissional em saúde, por isso, a fim de fortalecer e potencializar iniciativas de EIP é importante que sejam desenvolvidos estudos sobre esta temática no contexto da APS.

A nova política nacional de Atenção Básica, Portaria n ${ }^{\circ} 2.488$, de 21 de outubro de 2011, destaca o papel da APS, na coordenação das Redes de Atenção, com avanços em direção à gestão e coordenação do cuidado do usuário (Brasil, 2012a).

As redes de atenção à saúde (RAS) são definidas como a estratégia para atenção integral das necessidades de saúde dos usuários/população, cuja entrada preferencial no sistema ocorre pela APS, constituída por equipes interdisciplinares. Desse modo, o funcionamento das RAS depende da descentralização e capilaridade da APS, resolutividade, coordenação do cuidado, acompanhamento do usuário na rede, assim como em instâncias 
intersetoriais, centralidade da comunicação, estabelecimento do cuidado compartilhado e horizontalizado do usuário (Brasil 2012a).

Merecem destaque os incentivos para a articulação intersetorial da APS por meio do Programa Saúde na Escola, instituído em 2007, no âmbito dos Ministérios da Saúde e Ministério da Educação, que foi estendido às creches com o objetivo de contribuir para a formação de estudantes da rede básica no tocante à promoção, prevenção e recuperação da saúde (Brasil, 2012a). 


\section{OBJETIVOS}

\section{Objetivo geral}

Analisar como ocorre a Educação Interprofissional na Atenção Primária à Saúde no contexto brasileiro.

\section{Objetivos específicos}

Analisar as concepções de Educação Interprofissional em Saúde na perspectiva de docentes, estudantes e trabalhadores da saúde da Atenção Primária.

Analisar a articulação da Educação Interprofissional com a prática interprofissional no cotidiano do trabalho da Atenção Primária à Saúde. 


\section{METODOLOGIA}

Ao considerar o objeto de pesquisa do presente estudo, a educação e a prática interprofisssional em saúde na Atenção Primária à Saúde (APS), no contexto brasileiro, e seus objetivos que envolvem a análise de concepções da EIP e sua articulação com a prática interprofissional, optou-se por realizar um estudo de abordagem qualitativa com caráter compreensivo e interpretativo desenvolvido em duas fases.

A abordagem qualitativa contempla os significados, valores e atitudes que correspondem a um âmbito mais profundo das relações humanas, dos processos e dos fenômenos dos grupos sociais e sujeitos de pesquisa (Minayo et al, 1994).

Buscou-se conhecer e compreender as representações de docentes de diferentes universidades públicas do país, assim como de docentes, estudantes de graduação e trabalhadores da saúde da APS, vinculados ao Programa de Educação pelo Trabalho para a Saúde (PET-Saúde) de uma universidade pública, mediante análise interpretativa, com base no referencial teórico dos estudos do processo de trabalho em saúde e enfermagem, educação interprofissional em saúde (EIP), profissões, teoria do agir comunicativo, prática colaborativa centrada no usuário, e a atenção primária á saúde.

A opção pela abordagem da EIP, junto a participantes do PETSaúde, justifica-se por consistir um espaço interprofissional privilegiado de uma política indutora de mudança da formação e das práticas de saúde. O PET-Saúde consiste na experiência mais próxima da EIP que ocorre no âmbito de diferentes cursos de graduação em saúde na universidade pública na qual o estudo foi realizado no município de São Paulo. 


\section{CENÁRIO DO ESTUDO}

São Paulo é um município populoso, com cerca de 11.821.873 milhões de habitantes, distribuídos em 1.521,101 km², com densidade demográfica de 7.398,26 hab $/ \mathrm{km}^{2}$. Possui 678 serviços de saúde, entre os quais 52 são serviços de saúde públicos estaduais e 482 estabelecimentos de saúde públicos municipais (São Paulo, 2011, 2013; IBGE, 2014).

Com a descentralização do município de São Paulo, suas 31 subprefeituras estão distribuídas juntamente com 25 supervisões técnicas de saúde e 96 distritos administrativos que abrangem diversos bairros da cidade, em cinco coordenadorias regionais de saúde - norte, centro-oeste, leste, sudeste e sul (São Paulo, 2013a).

A APS do município de São Paulo possui 116 serviços de Assistência Médica Ambulatorial (AMA), e 15 AMA Especialidades por Coordenadoria Regional de Saúde. Também possui 441 UBS, sendo que 270 estão estruturadas com o modelo da ESF que totalizam aproximadamente 1.277 equipes (São Paulo, 2013c, 2013e).

Desde 2005, prefeitura definiu que a gestão de alguns serviços como AMA, UBS com ESF e hospitais fossem realizados por Organizações Sociais de Saúde (OSS), com as quais a prefeitura pode firmar acordos/contratos de gestão. As OSS são entidades de interesse social e utilidade pública sem fins lucrativos, que estão distribuídas nas cinco coordenadorias de São Paulo. As unidades de ESF estão sob a gestão de 12 diferentes OSS: Associação Paulista para o Desenvolvimento da Medicina (SPDM), Associação Saúde da Família (ASF), Santa Casa, Fundação Faculdade de Medicina (FFM), Einstein, Santa Catarina, Instituto Adventista de Ensino, Associação Comunitária Monte Azul, Centro de Estudos e Pesquisas Dr. João Amorim (CEJAM) e Santa Marcelina (São Paulo, 2013c, 2013e).

Para ampliar a abrangência das ações e apoiar a inserção da ESF no município, foram implantados 88 Núcleos de Apoio à Estratégia de Saúde da Família (NASF) (São Paulo, 2013e). 
De acordo com o Plano Municipal de Saúde 2010-2013 Compromissos da Coordenação da Atenção Básica, as ações de atenção à saúde na APS, estão estruturadas em dois principais eixos estratégicos. O eixo um consiste na 'ampliação do acesso com redução de desigualdades regionais e aperfeiçoamento da qualidade das ações de saúde', e o eixo dois 'fortalecimento da atenção integral' (São Paulo, 2013e).

Os indicadores da ESF em São Paulo são: equipe da ESF completas, pessoas cadastradas, consultas médicas realizadas, visitas domiciliares (VD) médicas realizadas, atendimentos do enfermeiro, VD do enfermeiro, VD do auxiliar de enfermagem, VD do agente comunitário de saúde, gestantes acompanhadas, crianças menores de um ano com vacinação atualizada, gestantes maiores de 20 anos cadastradas, hipertensos acompanhados, diabéticos acompanhados, visitas de agentes comunitários de saúde para controle de Aedes aegypti, implantação de comissão de prontuários e atividades de Educação Permanente Continuada realizadas (São Paulo, 2013e).

Para atender a população vulnerável de habitantes residentes em cortiços, prédios desocupados e pessoas em situação rua, foram implantadas 27 equipes de ESF/Especial, com 9 consultórios instalados nas ruas da região central paulistana que apresentaram os maiores índices de vulnerabilidade social e de necessidades de saúde que resultaram em 13.012 usuários cadastrados em 2009 (São Paulo, 2013e).

A região de estudo tem uma rede de ações e serviços de saúde com resolutividade para o respectivo território, com suficiência em APS e de média complexidade, sob a responsabilidade de uma Supervisão Técnica de Saúde (STS), que responde à Coordenadoria Regional de Saúde na qual 44\% da população depende do SUS. Os 31 serviços de saúde da referida STS são: 13 UBS, um centro de saúde (CS) e 17 serviços especializados (SE), isto é, um Ambulatório de Especialidades, um serviço de assistência especializada DST/Aids (SAE - DST/Aids), um Centro de Atenção Psicossocial (CAPS) Álcool e Drogas Adulto e Infantil, quatro serviços de Assistência Médica Ambulatorial (AMA), um Centro de Convivência e Cooperativa (CECCO), um Centro de Especialidades Odontológicas (CEO), 
um Núcleo Integrado de Reabilitação (NIR), um Núcleo de Reabilitação e Saúde Auditiva (NISA), uma Unidade de Referência de Saúde do Idoso (URSI), dois serviços de saúde mental, um pronto-socorro, um hospital de ensino estadualizado e um hospital municipal e maternidade (São Paulo, 2013b, 2013f).

O foco deste estudo são unidades de APS que no município de São Paulo estão estruturadas em 18 áreas técnicas para atender as necessidades gerais da população, de acordo com a portaria $\mathrm{N}^{0}$ 1151/2008-SMS.G: Assistência Farmacêutica, Assistência Laboratorial, Cultura da Paz Cidadania e Saúde, Enfermagem, Estratégia Saúde da Família, Medicinas Tradicionais e Práticas Integrativas em Saúde, Pesquisa, Saúde Bucal, Saúde da Criança e do Adolescente, Saúde da Mulher, Saúde da Pessoa com Deficiência, Saúde da Pessoa Idosa, Saúde da População Indígena, Saúde da População Negra, Saúde do Adulto, Saúde do Trabalhador, Saúde Mental, Saúde Ocular. As referidas áreas técnicas estão presentes na portaria $\mathrm{N}^{0}$ 1151/2008-SMS.G (São Paulo, 2013d).

\section{UNIDADES BÁSICAS DE SAÚDE}

Foram escolhidas duas UBS para compor o cenário de estudo. A UBS A foi inaugurada na década de 1970 e funciona com modelo misto (tradicional e ESF). A população da área de abrangência é de 27.095 habitantes dos quais $8,9 \%$ possui 60 anos ou mais e 15,4\% de zero a nove anos. A unidade possui 129 trabalhadores da saúde, distribuídos em seis equipes de saúde da família, uma equipe de vigilância epidemiológica e conta com as especialidades de medicina de saúde da família, clínica geral, ginecologia, pediatria, odontologia e assistência social. Cada uma das equipes da ESF, atendem em média 3021 pessoas que totalizam 18.127 usuários cadastrados. Os profissionais da unidade realizam 3.570 consultas mensalmente, com a média diária de 178 consultas e cerca de 4.607 visitas domiciliares cuja média diária é de 230 (São Paulo, 2013g). 
A UBS B foi inaugurada na década de 1990 e funciona exclusivamente com o modelo da ESF. A população da área de abrangência é de 18.403 habitantes, sendo que $7,7 \%$ da população referida possui 60 anos ou mais e $15,4 \%$ de zero a nove anos. A unidade possui 95 trabalhadores da saúde, distribuídos em seis equipes de saúde da família, uma equipe de vigilância epidemiológica, e conta com as especialidades de medicina de saúde da família, clínica geral, odontologia, terapia ocupacional, psicologia, odontologia e assistência social. Cada uma das equipes da ESF atendem em média 3.248 pessoas, que totalizam 19.493 usuários cadastrados. Os profissionais da unidade realizam 4.572 consultas mensalmente, com a média diária de 228 consultas e cerca de 5.171 visitas domiciliares, cuja média diária é de 258 (São Paulo, 2013g).

Figura 2. Estabelecimentos e serviços de saúde da rede municipal por Coordenadoria Regional de Saúde, Subprefeitura e Distrito Administrativo. - Município de São Paulo. São Paulo, 2013. Fonte: http://intranet.saude.prefeitura.sp.gov.br/areas/ceinfo/divulgacao/crs_sp_sub _munic.pdf 
ESTABELECIMENTOS E SERVIÇOS DE SAÚDE DA REDE MUNICIPAL POR COORDENADORIA REGIONAL DE SAÚDE, SUBPREFEITURA E DISTRITO ADMINISTRATIVO. MUNICÍPIO DE SÃO PAULO

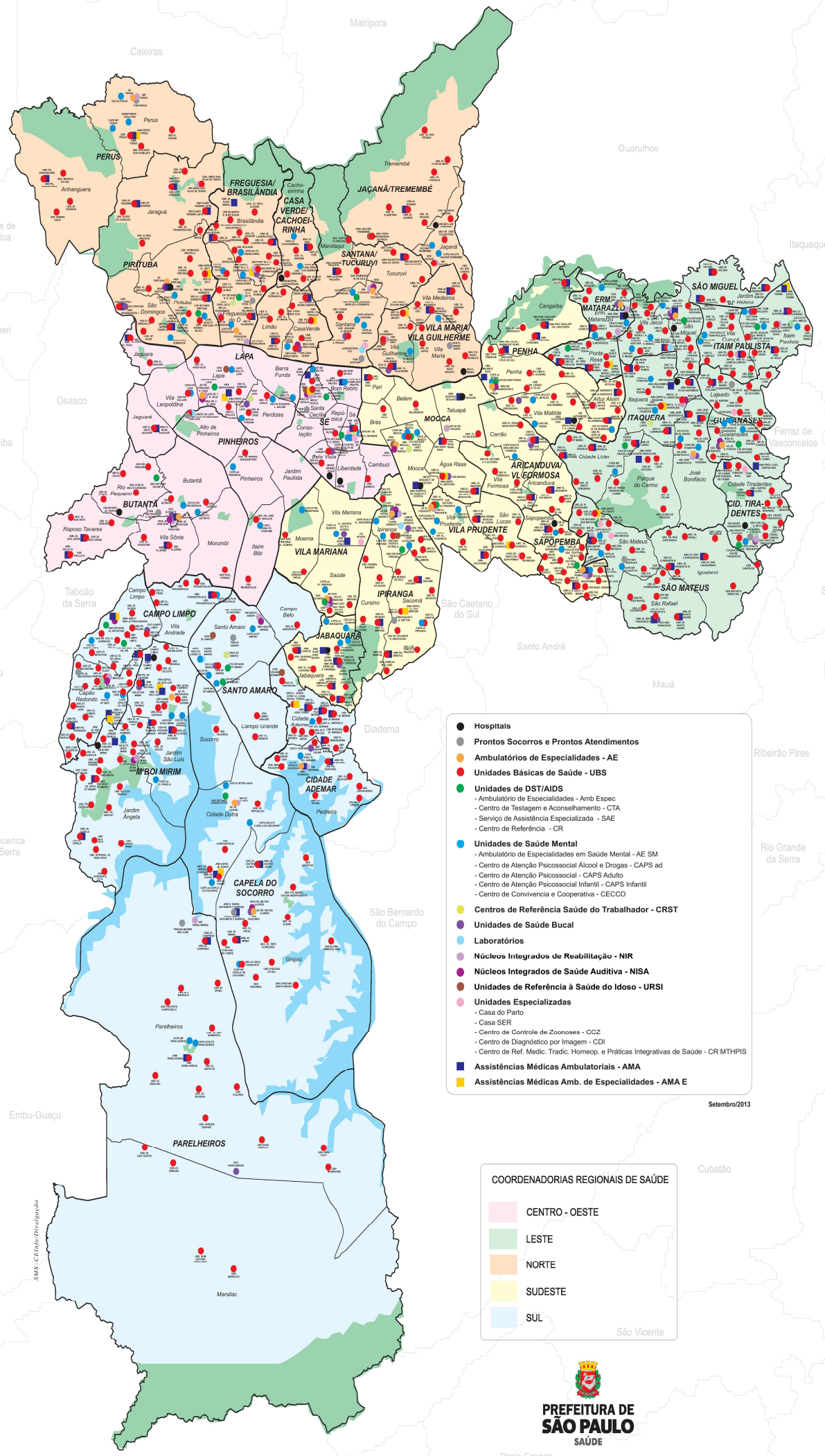




\section{O PET- SAÚDE}

O Programa de Educação pelo Trabalho para Saúde (PET-Saúde), vinculado a uma universidade do Estado de São Paulo foi escolhido como cenário privilegiado de atividades interprofissionais.

A referida universidade, participa das iniciativas de reorientação da formação em saúde desde 2005, por meio do Pró-Saúde, Telessaúde, PETSaúde da Família, PET-Saúde Mental e PET-Vigilância em Saúde. Atualmente desenvolve o PET com a participação de dez cursos de graduação e oito grupos tutoriais, experiências que fortalecem a articulação ensino-serviço no município de São Paulo (PET-Saúde, 2013).

Relatório recente das atividades do referido PET-Saúde em São Paulo, entre os anos de 2011 e 2012, aponta a participação de 110 estudantes não bolsistas, 96 alunos bolsistas, 48 preceptores trabalhadores e 8 tutores docentes. Os serviços de saúde da rede de atenção envolvidos nas atividades do projeto são: nove UBS, um CAPS, um Centro Saúde Escola (CSE) e um serviço Pró Saúde Mental (PROSAM). Destas UBS, cerca de seis possuem Estratégia de Saúde da Família, totalizando 27 equipes de ESF e três equipes de NASF (PET-Saúde, 2013).

No Brasil, até 2011, 379 cursos de graduação de 14 áreas profissionais diferentes, foram contemplados pelo PET-Saúde. Em 2012, foram incluídos 389 novos cursos, totalizando 709 cursos da saúde, dos quais predominam 110 cursos de enfermagem e 96 de medicina (Brasil, 2013).

A partir de 2013 foram incorporados 197 grupos de PET-Saúde Vigilância em Saúde (PET/VS) e PET-Saúde Redes de Atenção (PET/Redes). Sendo assim, atualmente existem 902 grupos PET-Saúde no Brasil, com participação de 902 tutores, 4.624 preceptores e 10.036 estudantes (Brasil, 2013). 


\section{PRIMEIRA FASE DA PESQUISA DE CAMPO: COLETA DE DADOS}

A primeira fase da pesquisa foi realizada por meio de entrevistas semiestruturadas. A entrevista é uma técnica de coleta de dados pautada na contribuição individual do entrevistado, em um espaço privilegiado de interação social, que permite captar a representação da realidade do ponto de vista dos atores sociais, grupos sociais, opiniões, condutas e atitudes. Nesse processo, o pesquisador realiza mediação entre marcos teóricometodológicos e a realidade empírica. A modalidade de entrevista semiestruturada possibilita a abordagem ampla e aprofundada de um tema, para compreensão do objetivo de estudo, a partir dos depoimentos coletados (Minayo, 2008).

O foco das entrevistas, geralmente está na experiência individual do participante, que é relevante para compreender a realidade de pessoas em situação semelhante. Possibilita uma representação da concepção existente sobre um tema, em um processo de interação social com o entrevistador (Flick, 2009).

Nas entrevistas foram abordadas as concepções sobre a EIP, experiências vivenciadas na formação compartilhada de estudantes de diferentes áreas, referências de práticas da EIP no contexto brasileiro, desafios para sua operacionalização no contexto educacional formal e nos serviços de saúde de atenção primária (Apêndice 1).

As entrevistas em profundidade foram realizadas em oito diferentes universidades públicas do país, cinco federais e três estaduais, dentre as quais duas são da região Nordeste, uma da região Sul e cinco da região Sudeste.

\section{Sujeitos participantes das entrevistas}

Participaram sujeitos-chave, de acordo com os seguintes critérios de inclusão: docentes, pesquisadores dos temas educação/formação em saúde e 
APS no Sistema Único de Saúde (SUS), que atuam na formação de estudantes de graduação em saúde no contexto da APS.

Entrevistaram-se 18 docentes universitários, no período de janeiro a dezembro de 2012, cujo convite para as entrevistas foi realizado mediante contato telefônico e envio de e-mail. Os participantes foram esclarecidos sobre os objetivos da pesquisa e participaram voluntariamente com a assinatura do Termo de Consentimento Livre e Esclarecido (TCLE) (Apêndice 3).

Todas as entrevistas foram realizadas pessoalmente pela própria pesquisadora e tiveram duração total de 31 horas e 48 minutos, com tempo médio de uma hora e 45 minutos de gravação por entrevista.

Para a apresentação dos resultados na discussão do material empírico, os docentes entrevistados foram identificados com a letra D, seguida de numeração aleatória e da categoria profissional à qual pertencem.

\section{SEGUNDA FASE DA PESQUISA DE CAMPO: COLETA DE DADOS}

$\mathrm{Na}$ segunda fase da pesquisa de campo foram realizadas quatro sessões de grupos focais homogêneos, compostos por trabalhadorespreceptores, docentes-tutores e estudantes vinculados ao PET-Saúde, no período de março a setembro de 2013.

A técnica de grupo focal é utilizada para estudar temas em contextos coletivos, baseando-se nas impressões de um conjunto de indivíduos em interação. O grupo possibilita a exploração do grau de consenso sobre determinado tema, compreender diferenças e contradições. Propicia a compreensão da realidade para o conhecimento das percepções e linguagens prevalentes no tema pesquisado (Gatti, 2005; Leopardi, 2001).

Nesse método ocorre uma interação peculiar, entre um conjunto de pessoas convidadas para debater um tema, no qual o pesquisador geralmente assume o papel de moderador da discussão (Mendes, Vaz, 2009). A ênfase nas ideias construídas coletivamente foi o que levou a pesquisadora a optar por este método de coleta de dados. 
O grupo focal deve ser estabelecido mediante interações intragrupais com certo grau de liberdade, para gerar uma cultura grupal e obter compreensões mais aprofundadas sobre o problema de estudo (Barbour, 2009; Gatti, 2005). Todos os comentários feitos durante os grupos focais, dependem do contexto e da dinâmica particular dos participantes e constituem uma possibilidade de entender porque e como pensam (Barbour, 2009).

O moderador do grupo focal é o facilitador da discussão grupal, mediante a interação com os participantes sem a intenção de elaborar perguntas e respostas. Com respeito ao princípio da não diretividade, realiza os encaminhamentos ao tema e faz intervenções para que o grupo se mantenha atento aos objetivos do trabalho e interaja (Barbour, 2009; Gatti, 2005).

A técnica de grupo focal foi utilizada para buscar o aperfeiçoamento e aprofundamento da compreensão dos dados provenientes das entrevistas realizadas. Nesse caso, o grupo foi importante para a triangulação ou validação dos dados coletados (Gatti, 2005).

O atraso na coleta de dados, cuja finalização estava prevista para julho de 2013 e estendeu-se até 15 de setembro de 2013, pode ser justificado, devido a dificuldade de agendamento dos grupos focais. Principalmente, com os trabalhadores das UBS e estudantes, que não demonstraram disponibilidade para participar de uma sessão de grupo focal em horário diferente do horário de aula ou trabalho, após sucessivas tentativas de contato pessoal, telefônico e por e-mail durante sete meses.

Os grupos dos trabalhadores-preceptores foram planejados em duas UBS com ESF de uma coordenadoria do Município de São Paulo. As UBS foram escolhidas devido à sua participação no PET- Saúde e sua tradição como unidades de ensino.

As reflexões obtidas nas entrevistas subsidiaram a elaboração do roteiro para as sessões dos grupos focais, pois indicaram a importância de aprofundar o debate sobre as articulações da EIP com as práticas de saúde no contexto da APS, para o alcance dos objetivos do estudo, considerando as experiências dos sujeitos vinculados ao PET-Saúde (Apêndice 2). 
A pesquisadora coordenou todos os grupos focais e contou com a colaboração de uma observadora em cada grupo. As quatro sessões de grupo focal resultaram no tempo de duração de oito horas, com duração média de duas horas.

\section{Sujeitos participantes dos grupos focais}

A seleção dos participantes do grupo focal seguiu alguns critérios: que tivessem características comuns que os qualificassem para o foco do trabalho interativo e da coleta do material empírico e que possuíssem vivência com o tema a ser discutido, de modo que trouxessem elementos para discussão (Gatti, 2005).

A composição do grupo baseou-se na homogeneidade das características dos participantes relacionados ao problema de estudo, cujo objetivo e o propósito da análise são o referencial das discussões realizadas, por facilitar a comunicação intragrupo (Gatti, 2005).

Cerca de 26 sujeitos participaram das sessões de grupo focal, cujo critério de inclusão foi a participação no PET-Saúde de uma universidade estadual do município de São Paulo no contexto da Atenção Primária. No tocante aos trabalhadores-preceptores, foram incluídos profissionais que atuam nas UBS com ESF, selecionadas para o estudo, devido sua experiência no acompanhamento de atividades educacionais teórico-práticas no ensino superior, na perspectiva da prática interprofissional em saúde.

No grupo focal estabelecido com estudantes, a participação de uma estudante de mestrado recém-formada em enfermagem, tornou sua configuração heterogênea, composição que pode ser justificada, devido à dificuldade de adesão dos estudantes para participar da sessão de grupo focal, cujas tentativas de agendamento foram realizadas durante o período de cinco meses.

Para apresentação dos resultados na discussão do material empírico dos grupos focais, os trabalhadores-preceptores do PET-Saúde foram identificados com a categoria profisssional seguida de numeração aleatória e 
indicação da unidade de referência $\mathrm{A}$ ou B. Os docentes-tutores foram identificados com a palavra docente, seguida da categoria profissional, e os estudantes com indicação do curso de formação e numeração aleatória. A numeração foi utilizada nos casos em que houve a presença de mais de um representante da mesma área profissional.

\section{ANÁLISE DOS DADOS}

$\mathrm{Na}$ fase de tratamento dos dados, realizou-se a análise vertical de cada entrevista e grupo focal separadamente e a construção de uma síntese para cada entrevista e grupo focal. Posteriormente, a leitura horizontal do conjunto das sínteses das entrevistas e dos grupos focais possibilitou análise referente a cada um dos dois objetivos do estudo e a produção de uma síntese geral do material das entrevistas e dos grupos focais. Em seguida, a análise transversal possibilitou o reconhecimento de semelhanças, contradições e antagonismos entre os relatos para estabelecer relações entre os depoimentos (Bardin, 2009; Minayo, 2008; Schraiber, 1995).

Os depoimentos foram lidos e analisados, em função do contexto em que se produziram, pois só podem ser entendidos dentro de sua dinâmica de relações sociais de produção e reprodução (Minayo, 2008). O contexto da pesquisa se refere à política de saúde e ao modelo de atenção em saúde, desenvolvido no âmbito da APS no cenário brasileiro, bem como o modelo de formação dos profissionais da saúde vigente no Brasil e a relação entre os profissionais da saúde no cotidiano das práticas.

Segundo Minayo (2008), uma boa análise depende da compreensão e interpretação dialética do material empírico que requer aplicar o referencial teórico que fundamenta a investigação. Esse processo envolve a experiência, vivência, senso comum e ação. A experiência do pesquisador e sua visão de mundo possibilitam a compreensão e interpretação. A vivência é fruto da reflexão sobre a experiência que sempre será única, por depender da personalidade do indivíduo e seu papel social, enquanto o senso comum expressa opiniões, valores e crenças que fundamentam o entendimento humano e configura a base dos estudos qualitativos. 
O resultado da análise dos grupos focais foi triangulado com o resultado das entrevistas. A triangulação prevê um método misto para a coleta de dados que possibilita a comparação das informações coletadas, a fim de confirmar ou contradizer os resultados. Na pesquisa qualitativa, geralmente as entrevistas individuais podem ser comparadas às evidências dos resultados do estudo nos grupos focais, que possibilitam um acesso privilegiado às construções sociais (Minayo, 2008; Barbour, 2009).

Para interpretação dos relatos das entrevistas e grupos focais foi adotada a abordagem hermenêutico-crítica, também chamada de crítica dialético-hermenêutica, cuja tarefa compreensiva visa fundamentar uma interpretação dos discursos em busca de seu significado histórico-social (Ayres, 2008, 2005).

\section{Abordagem hermenêutica}

No presente estudo foram consideradas as reflexões desenvolvidas por Jürgen Habermas e Paul Ricouer para o estudo da linguagem nas ciências sociais. No tocante à linguagem, Habermas considera a perspectiva de ação dos sujeitos, pois seu objeto central é a ação social, enquanto Paul Ricoeur, preocupa-se principalmente com os sistemas interpretativos, a partir da análise estrutural dos discursos, cujo aspecto central é a dialética da explicação e compreensão (Ayres, 2008).

A compreensão sempre é parcial, pois depende da consideração da singularidade e subjetividade dos sujeitos sociais, com análise das contradições entre as falas e as ações (Minayo, 2008).

Toda compreensão envolve a interpretação e uma visão de mundo que diz respeito ao modo como estamos nele. Por meio da linguagem, a perspectiva oculta, daquilo que não pode ser visto no mundo pode ser revelada. Essa linguagem simbólica, exprime a experiência fundamental do ser humano que precisa ser interpretada e compreendida por meio da linguagem interpretativa, que confere sentido na relação do homem com aquilo que o constitui. A hermenêutica busca decifrar o sentido oculto no comportamento do homem (Ricouer, 2011). 
A análise hermenêutica é de cunho interdisciplinar, pois ao considerar a atual fragmentação do saber e das linguagens pode ser construída à luz de outras disciplinas, para buscar a compreensão da variedade de linguagens utilizadas na descrição da realidade (Ricouer, 2011).

Ao considerar o contexto dos discursos na interpretação, é possível identificar a linguagem unívoca, num contexto de palavras polissêmicas. Nesse sentido, a crítica é utilizada para lutar contra a ausência de compreensão das coisas (Ricouer, 2011).

Paul Ricouer (2011), propõe procedimentos para lidar com a dialética da linguagem, para a decodificação interpretativa dos discursos que envolvem as seguintes etapas: relação entre texto e ação, fusão de horizontes, distanciamento crítico, dialética evento e significação, distinção entre sentido e referência.

Dialética evento e significação - consiste no distanciamento do discurso, que ocorre como um evento, pois acontece quando alguém fala, estabelecendo diálogo em tempo determinado. A unidade básica do discurso é a "frase", enquanto o "signo" é a unidade básica da língua. Nesse sentido, a linguística, ciência da linguagem articulada da frase, suporta a dialética do evento e do sentido. O evento consiste no fato de alguém falar, de modo que o discurso é considerado um evento, por ser realizado em tempo determinado. Além de constituir evento, o discurso tem significação que depende da clarificação do sentido e revela sua intencionalidade, afinal o discurso pode ser distribuído em três níveis de acordo, com a Teoria dos Atos da Fala de Austin e Searle, o locucionário (ato de dizer, enunciar), ilocucionário (aquilo que se faz ao dizer) e perlocucionário (aquilo que provoca no outro ao dizer, fazer pelo fato de falar, estimular) (Ricouer, 2011).

Relação entre texto e ação - o texto escrito, autonomiza a intenção do autor com liberdade em relação ao diálogo do discurso. O texto possibilita a autocompreensão do leitor, pois coloca sua subjetividade em pauta. 
Fusão de horizontes - propõe a possibilidade de se estreitar ou ampliar um horizonte, que remete à dialética da participação e do distanciamento. Gadamer desenvolve essa ideia, ao afirmar que a comunicação entre duas consciências diferentes pode ser desenvolvida por meio da fusão de horizontes, com produção de compartilhamentos, familiarização e apropriação mútua por meio do diálogo. Essa perspectiva exclui a diferença, ao considerar o comum entre os horizontes dos interlocutores, por meio da tensão entre o próprio e o estranho, o próximo e o longínquo. O texto não pertence ao leitor, nem ao autor, mas possibilita a comunicação à distância. Nesse sentido, a compreensão propõe a fusão entre o sujeito e o objeto, pois depende do sujeito se colocar no mundo do objeto que busca compreender (Ayres, 2009; Ricouer, 2011).

Distanciamento crítico - é uma condição do texto escrito que se torna necessária para a interpretação, pois a compreensão ocorre à distância. O texto é naturalmente produtor de distanciamento, pois mantem-se vinculado à historicidade humana. O distanciamento é possibilitado pela objetivação do texto, que se autonomiza após ser produzido, libertando-se do autor, condição essencial para interpretação (Ricouer, 2011).

Distinção entre sentido e referência - a referencia do texto envolve a pretensão do discurso de atingir a realidade. A referência do discurso cumpre o papel de revelar uma realidade comum aos interlocutores. Ao interpretar, o sujeito procura explicar o tipo de perspectiva de mundo que está manifesta diante do texto (Ricouer, 2011).

\section{ASPECTOS ÉTICOS}

A pesquisa foi aprovada pelo Comitê de Ética em Pesquisa da Escola de Enfermagem da USP e pelo ao Comitê de Ética em Pesquisa da Secretaria Municipal de Saúde de São Paulo, seguindo os preceitos éticos da resolução 466/12 de 12 de dezembro de 2012 (Brasil, 2012).

Os sujeitos do estudo foram esclarecidos sobre os objetivos da pesquisa e participaram mediante a assinatura do Termo de Consentimento Livre e Esclarecido, com a garantia de seu anonimato e sigilo sem nenhum tipo de prejuízo (Apêndice 3,4). Todos os participantes do estudo foram 
esclarecidos acerca da temática do estudo, e foram convidados a dialogar sobre aspectos conceituais e experiências da formação interprofissional. Neste contexto, o estudo não apresentou riscos e sim benefícios, tanto para os participantes como para a formação e atenção à saúde.

No tocante às Unidades Básicas de Saúde foi solicitada a autorização dos gerentes das unidades (Apêndice 5).

Ao término da pesquisa será realizada a devolutiva aos participantes do estudo nos locais da coleta de dados, incluindo as Unidades Básicas de Saúde A e B. A mesma ocorrerá por meio de oficinas, mediante diálogo acerca dos resultados encontrados no estudo, para reflexão do fortalecimento da educação e prática interprofissional em saúde, cujo benefício poderá propiciar a construção coletiva de estratégias para a prática interprofissional.

A devolutiva aos demais participantes entrevistados no estudo será realizada mediante o envio do arquivo da tese por e-mail. 


\section{RESULTADOS E DISCUSSÃO}

Neste capítulo apresentam-se os resultados e discussão da pesquisa com base no referencial teórico adotado e nos autores que abordam o objeto de investigação.

Considerando os objetivos e a metodologia da pesquisa, os resultados são apresentados em três partes. $\mathrm{Na}$ primeira, está a análise do material empírico das entrevistas realizadas com docentes de oito universidades públicas brasileiras. Na segunda, está a análise do material empírico dos grupos focais realizados com os atores sociais, docentes, trabalhadores de UBS e estudantes, que participam do PET-Saúde de uma universidade pública do estado de São Paulo. Na terceira está a triangulação dos resultados das entrevistas e grupos focais.

\section{PRIMEIRA PARTE: RESULTADOS E DISCUSSÃO DAS ENTREVISTAS}

A análise das entrevistas possibilitou a construção de três categorias empíricas, interpretadas como três diferentes sentidos, que compõem as concepções da EIP no contexto da APS e revelam a articulação da EIP com as práticas da saúde.

Figura 3. Concepções de educação interprofissional em saúde na APS na perspectiva dos docentes. São Paulo, 2014.

\begin{tabular}{|c|c|}
\hline & $\begin{array}{l}\text {-A educação interprofissional em saúde desloca a ênfase da } \\
\text { formação e práticas para integralidade do cuidado }\end{array}$ \\
\hline & $\begin{array}{l}\text {-A educação interprofissional em saúde contribui para a } \\
\text { reconfiguração das relações profissionais colaborativas }\end{array}$ \\
\hline & $\begin{array}{l}\text { - Preservação das competências complementares da especificidade } \\
\text { profissional, reconhecimento das competências comuns e } \\
\text { construção das competências colaborativas }\end{array}$ \\
\hline
\end{tabular}


A primeira categoria 'A educação interprofissional em saúde desloca a ênfase da formação e práticas para integralidade do cuidado' aborda que a EIP constitui uma proposta contra hegemônica que está relacionada com a mudança do modelo de atenção vigente e do modo de organização do processo de trabalho em saúde. A referida compreensão foi construída a partir de quatro subcategorias:

1.1 A formação orientada para atenção à complexidade das necessidades de saúde e a prática fragmentada predominante

1.2 Formação para o trabalho em equipe interprofissional nas redes de atenção à saúde

1.3 Comunicação interprofissional para o cuidado

1.4 Educação interprofissional em saúde: modelo de formação contra-hegemônico

A segunda categoria 'A educação interprofissional em saúde contribui para a reconfiguração das relações profisssionais colaborativas', mostra aspectos profissionais e interacionais que interferem em atividades da EIP, tal compreensão foi construída a partir de três subcategorias:

2.1 Influência dos estereótipos profissionais na interação

2.2 Interesses profissionais limitam a ampliação do escopo das práticas para atender as necessidades de saúde

2.3 As interações interprofissionais pressupõe o respeito mútuo

A terceira categoria 'Preservação das competências colaborativas da especificidade profissional, reconhecimento das competências comuns e construção das competências colaborativas', expressa a composição da formação em saúde por competências profissionais específicas, comuns e colaborativas, entendimento construído a partir de quatro subcategorias:

3.1 A formação em saúde com ênfase nas competências complementares/específicas e comuns

3.2 Preservação da especificidade da identidade profissional das competências complementares

3.3 Influências da educação interprofissional na construção da competência colaborativa: dinâmica de funcionamento das equipes de saúde 
3.4 A educação interprofissional em saúde possibilita o reconhecimento das competências comuns

Quadro 1. Perfil dos docentes entrevistados.

\begin{tabular}{|c|c|c|c|c|c|c|}
\hline $\begin{array}{c}\text { Código do } \\
\text { entrevistado }\end{array}$ & Sexo & Idade & Profissão & $\begin{array}{c}\text { Natureza da } \\
\text { Universidade }\end{array}$ & $\begin{array}{c}\text { Tempo } \\
\text { Região da } \\
\text { Universidade } \\
\text { trabalho } \\
\text { anos) }\end{array}$ \\
\hline D1 & M & 64 & Médico & Federal & Sudeste & 35 \\
\hline D2 & F & 62 & Médico & Federal & Sudeste & 40 \\
\hline D3 & F & 53 & Médico & Federal & Sudeste & 20 \\
\hline D4 & F & 47 & Psicólogo & Federal & Sudeste & 25 \\
\hline D5 & M & 59 & Médico & Estadual & Sudeste & 28 \\
\hline D6 & M & 63 & Médico & Federal & Nordeste & 43 \\
\hline D7 & M & 60 & Médico & Federal & Nordeste & 30 \\
\hline D8 & F & 57 & Médico & Federal & Nordeste & 32 \\
\hline D9 & F & 58 & Enfermeiro & Estadual & Sudeste & 23 \\
\hline D10 & F & 46 & Psicólogo & Estadual & Sudeste & 15 \\
\hline D11 & F & 52 & Enfermeiro & Estadual & Sudeste & 31 \\
\hline D12 & F & 55 & Médico & Estadual & Sudeste & 26 \\
\hline D13 & F & 48 & Fonoaudiólogo & Estadual & Sudeste & 22 \\
\hline D14 & F & 53 & Médico & Federal & Nordeste & 12 \\
\hline D15 & M & 52 & Enfermeiro & Federal & Sul & 19 \\
\hline D16 & F & 53 & Enfermeiro & Federal & Sudeste & 20 \\
\hline D17 & F & 56 & Psicólogo & Estadual & Sudeste & 11 \\
\hline D18 & F & 46 & Odontólogo & Estadual & Sudeste & 19 \\
\hline Fonter| & A & & & & \\
\hline
\end{tabular}

Fonte: Arquivo da pesquisadora.

Foram entrevistados 18 docentes, cinco do sexo masculino e 13 do sexo feminino, cujas idades variam de 46 a 64 anos, com média de 55 anos, entre os quais estão: nove médicos, quatro enfermeiros, três psicólogos, um fonoaudiólogo e um odontólogo. Todos possuem formação em nível de doutorado e o tempo de trabalho no ensino universitário, no contexto da APS, varia de 11 a 43 anos, com média de 25 anos.

No tocante ao vínculo de trabalho, cerca de 10 docentes estão vinculados a universidades públicas federais e oito a estaduais. Como alguns docentes estão vinculados à mesma universidade, os entrevistados representam oito diferentes universidades públicas do Brasil, cinco federais e três estaduais. 


\section{Categoria 1. A educação interprofissional em saúde desloca a ênfase da formação e das práticas para a integralidade do cuidado}

A análise dos relatos, com base no quadro teórico, resultou em subcategorias relacionadas à ênfase da formação em prol da integralidade do cuidado interprofissional, em substituição à primazia dominante da prática e formação especializada. As quatro subcategorias identificadas são:

Figura 4. Subcategorias da categoria 1. A EIP desloca a ênfase da formação e das práticas para integralidade do cuidado. São Paulo, 2014.

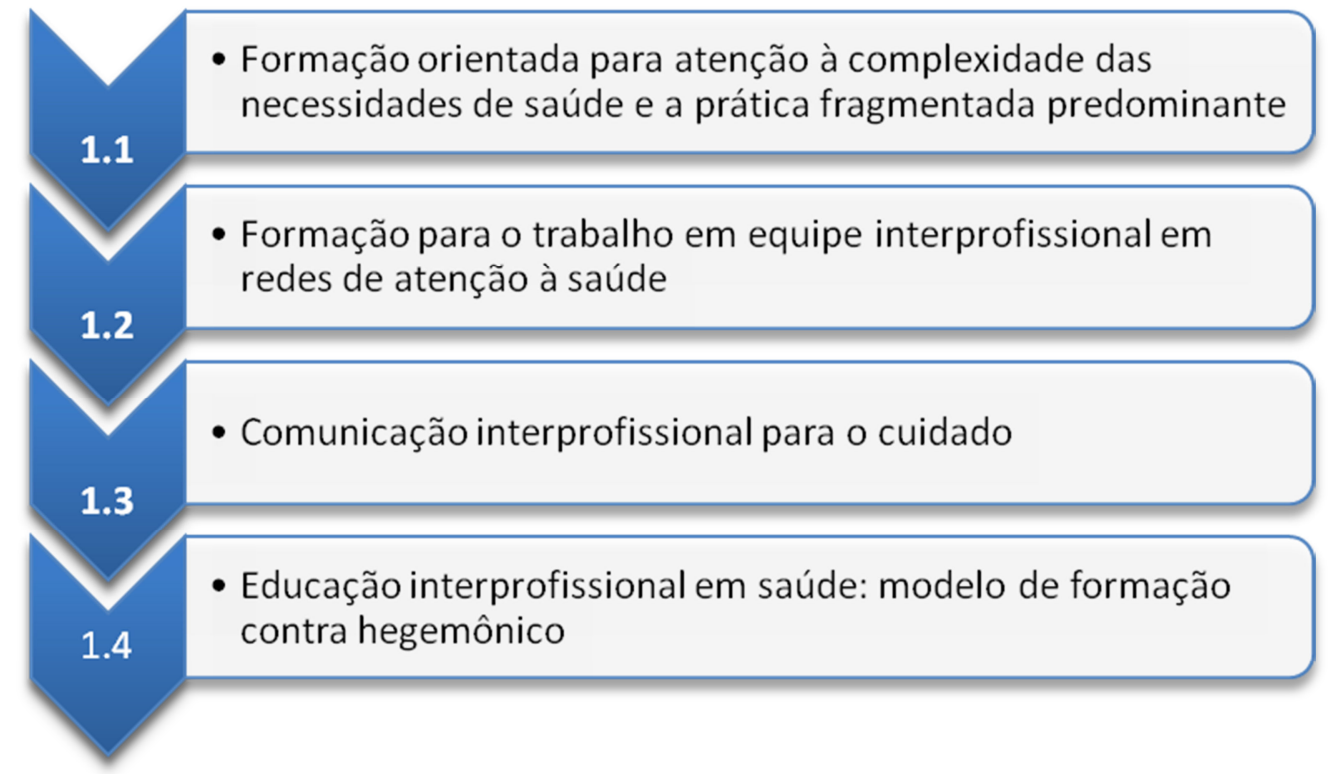

As subcategorias possibilitaram a construção da categoria empírica 'A educação interprofissional em saúde desloca a ênfase da formação e das práticas para a integralidade do cuidado'. Entende-se o cuidado em saúde como um processo de interação entre dois ou mais sujeitos, o usuário e o profissional da saúde, no qual, o primeiro busca a satisfação de suas necessidades de saúde e o segundo aplica saberes específicos a essa finalidade. Essa perspectiva supera a visão restrita do cuidado a um conjunto de recursos e medidas terapêuticas (Ayres, 2009). 


\section{Subcategoria 1.1 A formação orientada para atenção à complexidade das necessidades de saúde e a prática fragmentada predominante}

Os entrevistados consideram que a EIP favorece a aproximação do estudante das necessidades de saúde dos usuários para o cuidado na perspectiva da integralidade. Valorizam o encontro com os usuários e entre as diferentes áreas profissionais, com articulação dos saberes especializados, para abordar a complexidade das necessidades de saúde, em oposição à formação especializada isolada.

De acordo com o quadro teórico adotado neste estudo, o agir comunicativo, possibilita a unificação ou aproximação dos sujeitos aptos no falar e agir, que estão implicados nas relações de cuidado, em busca do entendimento. Habermas (2012) analisa que o comum acordo só ocorrerá quando houver convicções compartilhadas no mundo da vida.

Pensar em uma articulação entre conhecimentos que são especializados e
assim conseguir (...) não em uma pessoa, mas em um conjunto de pessoas
terem uma visão mais global do problema, uma abordagem, uma
aproximação das necessidades das pessoas de forma mais holística, de
forma mais global é preciso que a filosofia do aprendizado adquira um
valor que pense em fazer esse encontro, e não pense tanto ou esteja
centrada na qualificação muito especializada (D2- médico).

Uma das barreiras para a EIP na perspectiva do cuidado integral é o predomínio da formação especializada que acarreta na abordagem restrita das necessidades de saúde dos usuários.

$\mathrm{Na}$ perspectiva habermasiana o predomínio do saber técnico científico em detrimento à intersubjetividade necessária nas práticas de cuidado, pode sinalizar o avanço da racionalidade instrumental sobre a esfera comunicativa, denominado como um processo de colonização do mundo da vida.

A integralidade é uma imagem-objetivo que indica o que se deseja construir para atenção à saúde. A integralidade é um conceito polissêmico e um de seus sentidos refere-se à articulação da assistência com a prevenção, promoção e recuperação da saúde. Nesse sentido, a integralidade apresenta uma crítica ao modelo biomédico, no qual se adota uma postura fragmentada e reducionista, que privilegia as especialidades e o recorte anatomofisiológico, com enfoque na dimensão biológica em detrimento das sociais e psicológicas na atenção aos pacientes (Mattos, 2001). 
No próximo excerto, o entrevistado propõe desenvolver o plano terapêutico conjunto, ao invés de fragmentar o 'usuário em pedaços'. A articulação no cuidado possibilita que um profissional conheça a ação do outro e agregue novos saberes à sua prática. Para avançar na prática compartilhada sugere-se a importância de aprender a trabalhar juntos, durante o curso de graduação através da construção de planos terapêuticos.

Então eu acho que a gente teria que trabalhar nesse sentido, dos estudantes em treinamento já trabalharem junto, fechando diagnóstico, elaborando planos de atenção, o plano terapêutico conjuntamente. Acho que só assim, um vai entendendo a forma de pensar do outro, o conhecimento que vem daquela área. Porque que aquilo é importante, como é que se agrega ao conhecimento de outro profissional, do dentista, fonoaudiologia, fisioterapia, terapia ocupacional? $\mathrm{Eu}$ acho porque em função da prática compartilhada a gente vai aprendendo a trabalhar junto. Os ambulatórios separados não favorecem os alunos, você faz o paciente percorrer vários serviços e cada um olha o seu pedaço, isso é terrível, fica muito fragmentado para o paciente (D10 - psicólogo).

A produção de planos terapêuticos comuns, com abordagem integral das necessidades do usuário, remete à estratégia do projeto terapêutico singular (PTS), presente na Política Nacional de Humanização do SUS. O PTS coloca o usuário no centro das práticas de cuidado e resulta da discussão coletiva do caso do usuário pela equipe de saúde com a definição de intervenções. Tal proposta, se desenvolve por meio da interprofissionalidade, por depender da contribuição do saber específico de diversos profissionais para lidar com a complexidade dos casos. As etapas do PTS são: diagnóstico da situação vivenciada pelo usuário, definição de metas com a participação do usuário, divisão de responsabilidades entre os profissionais da equipe e reavaliação dos progressos obtidos no projeto, com elaboração de novas alternativas (Brasil, 2007a, Linassi et al, 2011).

Os próximos excertos mostram que o modelo biomédico hegemônico tem como desdobramento a atenção fragmentada, na qual o usuário é repartido 'em pedaços' que serão atribuição de diferentes profissionais de saúde.

E no caso é muito mais, você termina incorporando modelos, tecnologias, cuidados, para que cada um faça a sua parte. O sujeito doente que é inteiro, chega ao centro de saúde ou no hospital e ele é repartido em pedacinhos, porque cada pedaço vai ser visto por uma área, por uma profissão... é um recorte de formação de práticas (D7- médico).

Então quem estava responsável pela psicologia, tem conhecimento, tem uma formação, pode fazer isso, o enfermeiro pode fazer esse movimento 
de compartilhar e de ir complementando, de ir pontuando aspectos que são importantes e tal. Mas não acontece. E aí eu ficava olhando, gente, tem tudo para ser interessante! Mas não acontece por quê? Talvez porque as pessoas não saibam, não tenham clareza que esse é o seu papel e fazem do jeito que aprenderam, fragmentam, fragmentam o usuário e cada um vai fazer tal coisa. Eu sou assistente social e vou fazer tal coisa, a enfermeira vai marcar, agendar uma consulta de enfermagem parar ver como está a situação, colher Papanicolau (...) (D16 psicólogo).

Distante da lógica da integralidade, a educação dos profissionais de saúde na maioria dos países tem falhado devido fatores como: rigidez curricular, centralidade nas áreas profissionais, pedagogia tradicional, insuficiente adaptação ao contexto de formação e práticas da saúde e na organização das profissões orientadas para as demandas do mercado de trabalho. Esse modelo de formação, prejudica a atenção às necessidades de saúde dos usuários e comunidade, pois não desenvolve competências para o trabalho em equipe interprofissional (Frenk et al., 2010).

Segundo o entrevistado, o conhecimento fragmentado veiculado pela perspectiva uniprofissional do saber, provoca o isolamento e o recorte de frações do objeto de conhecimento, que prejudicam a resolução articulada dos problemas, dada à complexidade dos objetos de intervenção.

Quer dizer, a disciplinaridade te leva a um isolamento e a vários interditos. Porque você não se arrisca no quintal do vizinho. Você vai sabendo cada vez mais da sua área de conhecimento, vai se aprofundando e vai se fechando, naquele campo, naquela linguagem. E os problemas da realidade, e a educação nos preparam para isso, para solucionar os problemas da vida. Os problemas são multi facetados, eles são multi dimensionais, e o conhecimento tão fracionado, ele dá conta de frações do objeto conhecimento. Então, eu acho que é uma visão mesmo de mundo, e, portanto, de educação que pensa de um jeito mais integrado, em que ela volta com as preocupações que sempre teve de pensar por que nós estamos aqui, que vida é essa que vivemos? Que investimento é esse que a gente faz no conhecimento se ele não está voltado para melhorar a vida das pessoas? O que é isso? O que a gente está fazendo? (D9-enfermeiro)

O referido modelo predominante de educação e desenvolvimento dos trabalhadores da saúde é uniprofissional. Neste modelo, os profissionais de de cada área de atuação aprendem isolados das demais áreas da saúde, sobre determinada disciplina com ênfase na racionalidade biomédica, que é hegemônica, predominante e preconiza a dimensão biológica e o substrato anatomopatológico do processo saúde-doença (Barr et al., 2005; Almeida, Feuerwerker, 1999).

A integralidade como eixo norteador da formação em saúde, requer a articulação dos saberes e práticas numa lógica interprofissional a partir de 
um conceito ampliado de saúde, que reconhece e respeita a expressão da subjetividade do usuário, mediante o acolhimento e a responsabilização profissional, para superar as práticas centradas em procedimentos, com foco na doença (Ceccim, Feuerwerker 2004a).

A ação interprofissional requer o trabalho em equipe, articulado em torno do cuidado das necessidades de saúde do usuário, com participação e colaboração entre diferentes profissionais, que se dedicam a reconhecer a complexidade da situação trazida pelo usuário, no respectivo contexto de vida, ao invés de um 'pedaço do usuário' sobre o qual deverá intervir.

A prática articulada dos trabalhadores da equipe de saúde, possibilita a complementaridade das ações, com a troca de saberes especializados, que são indispensáveis na resolutividade da atenção. O depoimento destaca que o saber de um profissional é insuficiente para lidar com a complexidade do caso do usuário.

Então, eu sou enfermeira, posso estar cuidando de um paciente diabético descompensado, que tem problema de cuidar da sua alimentação, de fazer a sua insulina. Eu estou cuidando dele... Teve uma alteração, o médico está agindo... O nutricionista me ajudou a pensar e orientar o paciente, mas eu estou seguindo aquela dieta, peço apoio para o nutricionista se o paciente não está seguindo aquela dieta, como é que a gente vai repensar? Acho que para mim, seria uma ação interprofissional mais nesse sentido, de articulação do cuidado. E não picotar o paciente, cada um cuidar de um pedaço dele, mas ninguém sabe o todo desse paciente, ninguém dá o seguimento geral ou uma avaliação (D14 - enfermeiro).

A seguir, o entrevistado considera que o cuidado é o eixo comum entre as diferentes áreas da saúde, por isso é importante incorporar o cuidado na formação. Algumas estratégias podem ser desenvolvidas para o fortalecimento da formação, por meio de práticas de cuidado integradas entre as áreas profissionais como: estudo de caso e planejamento terapêutico compartilhado, como mencionado em relato anterior. O entrevistado sugere, que o cuidado seja organizado a partir do referencial de gestão da clínica, com a descentralização dos processos de tomada de decisão, mediante a participação de todos os trabalhadores da equipe interprofissional de saúde.

Porque a gente precisa encontrá-los para o cuidado. $\mathrm{O}$ médico, enfermeiro, terapeuta ocupacional, quer dizer, o que nós temos em comum no cuidado? Como fazemos essa clínica? E aí trabalhar com o referencial de gestão de clínica, de quem é o responsável por esse cuidado, uma ação interprofissional. Aí tem que construir um modelo de cuidado e trazer essas novas tecnologias para o campo. Para os alunos viverem essa experiência no campo e incorporarem na sua formação (D14 - enfermeiro). 
A gestão da clínica é um conceito adotado por Mendes (2012), relacionado à um sistema de tecnologias de microgestão, inspirado na gestão gerenciada norte-americana e na governança clínica britânica. Incorpora a educação permanente dos profissionais como aspecto central, a gestão de riscos, a auditoria clínica e a cultura de qualidade dos serviços de saúde. Fundamenta-se em cinco aspectos: diretrizes clínicas, gestão das condições de saúde, gestão de casos, auditoria clínica e listas de espera.

A gestão do caso geralmente é conduzida por um enfermeiro ou assistente social e também pode ser realizada pela equipe multiprofissional de saúde. O gestor do caso é responsável pela coordenação da atenção ao usuário, mobilização de recursos e monitoramento. Esse processo pode aumentar a satisfação dos usuários, contribuir para o acesso à serviços da rede de atenção, promover a continuidade do cuidado, contribuir para a comunicação e colaboração entre profissionais, usuários e famílias (Mendes, 2012).

A presença de elementos relacionados à organização do cuidado em saúde, podem ser entendidos como tecnologias que orientam as práticas da saúde e facilitam a implementação da educação interprofissional em saúde. As referidas tecnologias são denominadas por Mendes-Gonçalves (1994), como o saber operante, empregado no processo de trabalho em saúde, ou saberes tecnológicos que fundamentam distintos modelos tecnológicos de organização das práticas de saúde na APS.

As tecnologias referidas nesta subcategoria, podem ser entendidas como modelos de atenção que consistem em um dos elementos que mobilizam o desenvolvimento de práticas interprofissionais no contexto da formação em saúde. Os principais modelos tecnológicos mencionados pelos entrevistados são: o cuidado na perspectiva da integralidade, o biomédico, a clínica ampliada e a gestão da clínica. A seguir serão apresentados os relatos dos dois últimos modelos mencionados, pois o cuidado na perspectiva da integralidade e o modelo biomédico já foram abordados.

Ayres (2009), define que os modelos se referem aos modos de organização e operacionalização das tecnologias disponíveis para as práticas de atenção à saúde dos usuários/população. A relação entre os modelos e 
tecnologias é dialética, desse modo, sua aplicação pode evidenciar limites e tensões que desencadeiam a revisão das práticas.

No Brasil, eu uso, por exemplo, quando repenso as práticas, eu uso o
conceito de clínica ampliada e compartilhada. Nós fizemos um projeto
terapêutico singular. Então assim, quando alguém faz um atendimento e
diz 'fiz um atendimento integral', eu digo 'você medicalizou, você
psicologizou, você enfermerizou, você fez o que a pessoa precisava'.
Quando a gente vai atender um caso, ou de saúde coletiva ou clínica tem
que focar. Isso chama 'singular'. Tem um conhecimento transdisciplinar...
aí dependendo do problema você vai pegar pedaços daquilo lá, fazer uma
análise, uma compreensão singular e terapias singulares. Não tem que
abordar a subjetividade de todo mundo com a mesma intensidade (...) (D5
- médico).

A clínica ampliada compartilhada pode constituir uma alternativa para repensar as práticas de saúde. Este processo é estruturado por meio da construção de um projeto terapêutico singular, que requer conhecimento especializado do núcleo do saber e também envolve os diferentes saberes necessários para abordar a necessidade do cuidado.

Esse modelo de clínica, propõe a mudança do objeto de intervenção em saúde, ao considerar tanto as doenças, quanto problemas que aumentam o risco, a vulnerabilidade, articulação da promoção, prevenção, tratamento e reabilitação das condições de saúde e o estabelecimento da clínica do sujeito. Pode contribuir para a ampliação da autonomia dos usuários com o aumento da sua capacidade de autocuidado, compreensão de sua condição de saúde, tomada de decisão sobre sua própria vida e estabelecimento de contratos com os outros. A clínica ampliada aumenta a possibilidade de participação dos usuários e familiares no processo de gestão dos processos terapêuticos, visto que tende a fortalecer o vínculo entre os usuários e os profissionais das equipes de saúde (Campos, Amaral, 2007c).

A clínica ampliada indica a importância da análise da situação do usuário, para aplicação de um saber específico, relacionado à singularidade do caso. A singularização do cuidado é possível mediante a análise de cada caso específico pelo profissional. A autonomia do profissional no trabalho clínico tende a motivar a produção do cuidado em saúde, ao contrário do usual controle da conduta dos profissionais, contribui para a singularização dos casos na clínica (Campos, Amaral, 2007c).

A seguir, o mesmo entrevistado exemplifica a construção do projeto terapêutico singular, com a participação de estudantes de diferentes áreas e 
profissionais da saúde. Nesse processo, ocorre o aprendizado de lidar com diversas especialidades e interação na discussão do caso clínico. A complexidade dos casos requer a abordagem interprofissional na formação e nas práticas de saúde, contudo, como a referida experiência ocorreu no final do curso, o entrevistado destaca que o grau de inteprofissionalidade dos estudantes foi reduzido.

A equipe passa um caso super complexo para nós, em geral com mais de um nível de atenção, tem baixa adesão... que ela considera complexo, de difícil manejo. E nós vamos tentar, os alunos e o professor fazem um projeto terapêutico singular, em três semanas, quatro semanas... um ou dois casos só, de forma multiprofissional, com apoio matricial de equipe multiprofissional...aí entra enfermagem, fono... não são todos os grupos... mas são 120 alunos de medicina, 40 de enfermagem... e 40 de fono. Mas em vários grupos, a gente consegue mesclar a discussão do caso... a discussão do projeto terapêutico e eles vão lidar com a equipe. A regra é 'nós vamos levantar problemas', de conduta, de condução. E faz parte do curso o manejo de equipe, lidar com várias especialidades, lidar com o caso dos outros, discussão de caso clínico, levantar problemas de conduta, sem ofender os outros, sem fazer guerra civil... Então a gente enfoca tanto a parte clínica preventiva, digamos assim... quanto a parte de micro gestão do trabalho interprofissional. Então o conteúdo do curso é bem esse. É uma experiência interessante... Agora o grau de interdisciplinaridade, de interprofissionalidade dos alunos é baixo, porque já é no final do curso (D5 - médico).

Projetos terapêuticos singulares são indicados para casos complexos

de alta vulnerabilidade. O projeto terapêutico é uma construção coletiva com a contribuição de várias especialidades, para revisão do diagnóstico, avaliação de risco e intervenção terapêutica (Campos, Amaral, 2007c).

Os dois próximos excertos também remetem à concepção da clínica ampliada, projeto terapêutico singular e gestão do cuidado, aspectos fundamentais para o trabalho interprofissional. A gestão do cuidado ocorre com a atuação de um profissional de referência que acompanhará as necessidades do usuário. Os demais profissionais da equipe participarão do cuidado em colaboração e negociação com o profissional de referência do caso, contribuindo com seus saberes específicos.

Então, se eu pensar saúde da família... esse paciente ele é de alguém da saúde da família. Do dentista, do médico ou do enfermeiro, alguém disparou o cuidado ali e precisou de mais pessoas do que ele para cuidar. Então vejo que aí a gente precisaria entrar com essa noção de que quem vai fazer a gestão desse cuidado, quem é o gestor do cuidado desse paciente, que tem que ser uma pessoa... acompanhar e saber o que está acontecendo. E aí diversos profissionais podem ter interface para ajudar a cuidar. Pode ser em uma relação direta com o paciente ou só entre os profissionais. Não necessariamente o psicólogo precisa atender o paciente para achar que ele teve essa ação. Ele acompanhando a discussão do caso, orientando o enfermeiro, orientando a equipe de como cuidar daquele 
caso... isso para mim já é uma ação interprofissional. Então não é picotando o paciente... isso que precisa ser o nosso entendimento, né, hoje. O trabalho... em um conjunto de profissionais, eu tenho que ter alguém que está olhando para o todo, e cada um pode ir entrando com a sua especificidade, em momentos diferentes, de forma mais contínua ou de forma mais pontual, dependendo da necessidade (D14 - enfermeiro).

No próximo excerto, o entrevistado aponta algumas estratégias utilizadas para realizar o trabalho da equipe interdisciplinar na saúde da criança, como reuniões mensais para a discussão de casos, que possibilita a troca de saberes para a integralidade do cuidado. Entre as estratégias, também menciona a perspectiva da clínica ampliada e compartilhada, com o atendimento conjunto de profissionais e estudantes de diferentes áreas, docentes, residentes e aprimorandos.

Então a gente tem reuniões mensais onde participa toda a equipe e através da discussão de casos a gente tem um olhar de diferentes profissionais sobre situações que as crianças estão vivenciando no seu desenvolvimento, na integralidade do seu cuidado e nessa interface educação e saúde. Então há 26 anos nós temos reuniões mensais para discutir. A outra perspectiva que a gente trabalhou muito bem e continuamos trabalhando mas eu não diria para você que a gente está super forte nisso é a idéia da clínica ampliada e compartilhada. Então assim, a gente atende junto, tá?, eu como médica sou, digamos assim, a coordenadora da consulta, mas atende junto comigo em geral o residente da pediatria, ele fica um pouco comigo atendendo junto, o aprimorando que pode ser um enfermeiro, um pedagogo ou um assistente social (D12médico).

A consulta compartilhada é definida por Aguiar (2013) como ações clínicas realizadas por dois ou mais profissionais, simultaneamente, com objetivo de responder às demandas do usuário que propiciam troca de saberes e responsabilidades mútuas que podem se estabelecer de modo interprofissional, uniprofissional, entre profissionais da mesma equipe ou entre equipes diferentes.

O modelo hegemônico de atenção à saúde é curativo, mecanicista, procedimento centrado, hospitalocêntrico, superespecializado e responde de forma restrita às necessidades de saúde dos usuários dos serviços de saúde, tanto especializados como de atenção primária. Por isso, na busca de alternativas para mudanças na formação e nas práticas de saúde, a concepção de integralidade é indicada como princípio ordenador (Ceccim, Feuerwerker, 2004a; Pinheiro, Ceccim, 2005; González, Almeida 2010, Feuerwerker, Capozzolo, 2013). 
Os resultados da análise das entrevistas na subcategoria 'A formação orientada para atenção à complexidade das necessidades de saúde e a prática fragmentada predominante', mostram que a EIP é compreendida como uma abordagem educativa dos profissionais da saúde, que permite um deslocamento do modelo tradicional biomédico para integralidade da atenção à saúde. A mediação dessa passagem se faz por mudanças de concepção saúde-doença, que migra dos sinais e sintomas da doença para o foco no cuidado em saúde.

Esta mudança, pode ser facilitada pelo emprego de modelos tecnológicos de organização das práticas de saúde, em prol da integralidade na APS, como a gestão da clínica e a clínica ampliada.

\section{Subcategoria 1.2 Formação para o trabalho em equipe interprofissional em redes de atenção à saúde}

A formação em saúde para o trabalho em equipe é indicada pelos entrevistados, como um caminho para fortalecer as mudanças do modelo de atenção, com ênfase no trabalho colaborativo em equipe e articulação entre os serviços de saúde da rede.

O direcionamento da formação para o trabalho em equipe multiprofissional e interdisciplinar está presente nas DCN, por ser reconhecido como um aspecto necessário para o avanço da qualidade da atenção (Almeida Filho, 2010). Contudo, cabe destacar que a modalidade de articulação e integração dos profissionais esperada nas DCN, ainda é multiprofissional e não interprofissional.

É importante destacar, que a utilização dos termos com os sufixos multi e inter não ocorre ao acaso, pois expressam diferentes níveis de articulação entre os profissionais. A utilização do termo interprofissional se refere a uma integração maior entre as profissões.

Contudo, a predominância do modelo de atenção médico hegemônico, pautado em consultas, sem intervenções articuladas e interprofissionais, prejudica as possibilidades de avanço em direção à EIP. Por isso, o entrevistado aponta a importância de valorizar o trabalho em 
equipe na saúde da família e o apoio matricial para práticas de atenção à saúde articuladas, com abordagem ampliada das necessidades dos usuários. O espaço de formação no contexto da APS favorece o acompanhamento e desenvolvimento de ações interprofissionais

O modelo de atenção mudou mais na atenção básica, mais do que no secundário e no terciário, do que no restante da Rede. É muito tradicional ainda, tudo muito caixinha, tudo separado, muita consulta, referencia e contra referencia, só que você não tem intervenção articulada, projeto terapêutico articulado interprofissional, esse é o obstáculo. Porque a formação em saúde depende muito do cenário de práticas, se você vai formar o 'fisio' você tem que fazer supervisionado. Se o modelo é tradicional, é muito difícil você ter uma formação, por isso que a gente valorizou muito a atenção básica, as equipes de saúde da família são interprofissionais, mistura saúde coletiva com clínica, com as áreas clínicas, é obrigado a misturar. Na saúde coletiva tem que usar promoção, tem que usar vacina, tem que usar educação em saúde, tem que usar grupo, tem que escutar, tem que ir no território, tem que ir na escola, tem que ir na casa. Agora, o serviço de AIDS também faz isso, tem equipe multiprofissional, tem infectologista, tem terapeutas, tem apoio matricial. Também trabalha de forma ampliada, não vê só a infecção e o vírus, vê a sexualidade, vê o trabalho, vê a subjetividade. Então, algumas áreas, os CAPS mudaram. Mas você vai na 'dermato', na 'reumatologia', na 'traumatologia',mesmo a reabilitação física mudou muito pouco. Na cirurgia, na oncologia, gerontologia está mudando, agora tem trabalho em equipe. Então tem um movimento que precisa mudar o modelo ligado ao ensino (D5 - médico).

A centralidade da formação na perspectiva da integralidade considerando a determinação social do processo saúde-doença contribui para o desenvolvimento de saberes e práticas que superem a fragmentação do ensino tradicional e ações biomédicas centradas em procedimentos. Nesse sentido, para avançar na integralidade da formação em saúde é necessário investir em estratégias pedagógicas participativas e na educação permanente em saúde (EP), para promover o deslocamento de práticas centradas na identidade profissional de cada área, para dar espaço à construção compartilhada do saber interprofissional com a problematização das práticas de saúde (Pinheiro, Ceccim, 2005; Ceccim, Feuerwerker, 2004a; González, Almeida 2010).

Nessa perspectiva, as necessidades de saúde tornam-se o centro das intervenções e práticas, mediante a escuta qualificada dos usuários. Para a ampliação da integralidade é importante considerar tanto os saberes das equipes multiprofissionais dos serviços de saúde, como o encontro entre os usuários e a equipe, com seus múltiplos saberes, cuja preocupação está em 
realizar a melhor escuta possível da expressão individualizada das necessidades do usuário que procura o serviço (Cecílio, 2001).

Nesse encontro com os usuários, os diferentes profissionais devem contribuir com suas experiências e expertise para atender aos problemas de saúde em uma perspectiva ampliada, em oposição ao foco especializado da formação e das práticas de saúde (Propp et al., 2010; Orchard, Curran e Kabene, 2005).

No próximo excerto, o docente entrevistado enfatiza que a EIP tem como foco a formação para o trabalho em equipe e para a integralidade do cuidado.

A proposta é formar o futuro profissional para o trabalho em equipe na perspectiva da integralidade do cuidado. Eu acho que ainda falta uma decisão do Ministério da Saúde, se ele quer realmente mudar a política de atenção, se ele quer realmente assumir a integralidade que é trazer como os países lá de fora trouxeram, a educação interprofissional como estratégia de educação permanente dos profissionais já formados (D1médico).

No relato anterior, o entrevistado também considera a importância de assumir a educação interprofissional como estratégia da EP dos trabalhadores inseridos nos serviços. A EPS é uma construção brasileira que permanece restrita ao cenário nacional, enquanto a EIP é uma proposta internacional que se encontra em destaque entre as propostas de mudança na formação e práticas da saúde. Pode-se dizer que há convergências significativas entre a concepção da EP e da EIP. Ambas podem ocorrer durante a formação em cursos de graduação, pós-graduação e com profissionais que atuam serviços. Comparativamente, pode-se dizer que ambas envolvem usuários, docentes, trabalhadores de diferentes áreas e gestores. Contudo, uma possível interpretação da diferença teóricoconceitual entre a EP e EIP se refere ao modo de inserção do usuário nessas perspectivas formativas.

Os principais conceitos encontrados na literatura sobre a EIP sinalizam o debate sobre a inclusão dos usuários na perspectiva das práticas de cuidado centrada no paciente (Orchard et al., 2012; 2005), enquanto a EP voltada-se para a inserção do usuário no tocante ao controle social. Contudo, apesar do horizonte conceitual ampliado da EPS que considera a inclusão do 
usuário na participação social, há poucas experiências vivenciadas que são relatadas na literatura nacional.

A inclusão do usuário nas práticas de saúde também pode ocorrer no modelo de organização do trabalho interprofissional, com equipes de referência e apoio matricial, mencionada no próximo relato.

\begin{abstract}
A principal estratégia é a gente conseguir um cenário de práticas que o modelo seja centrado na interprofissionalidade, na interdisciplinaridade. Que os arranjos de cuidado, de atenção, sejam equipes de referência nos vários níveis, que tenha apoio matricial, a pessoa que entra e sai da equipe. Em uma equipe de saúde da família tem um psicólogo e de vez em quando ele sai, de vez em quando o fisioterapeuta sai, tem um sanitarista e de vez em quando sai. Então acho que esses arranjos facilitam a formação. Visita interdisciplinar de enfermaria, quem faz a medicina e a enfermagem? Se não tem a visita fica difícil. Então, acho que a primeira condição é o modelo. A segunda condição são reformas curriculares, precisamos rever, refazer, aprofundar, definir (...) (D5 médico).
\end{abstract}

De acordo com Campos e Domiti (2007a), o trabalho realizado pelas equipes e profissionais de referência é organizado a partir do vínculo entre os profissionais da equipe e os usuários. Os profissionais de referência são responsáveis pela condução longitudinal de casos de usuários, famílias e comunidades.

O trabalho em equipes de referencia é considerado pelo entrevistado, como uma possibilidade que contribui para a EIP. No mesmo relato, também aponta a importância de se considerar mudanças curriculares. Ao mencionar os dois aspectos para mudança em prol da EIP, um relacionado às práticas de saúde e outro à formação, pode-se inferir que o entrevistado sugere a indissociabilidade e o processo de mútua influência entre o sistema de formação e o sistema de saúde. Publicações recentes apontam que saúde e a educação constituem práticas sociais articuladas, com relações recíprocas (Pinto et al, 2013; Peduzzi, 2013), ou sistemas interdependentes pautados nas necessidades de saúde da população (Frenk et al, 2010).

As mudanças nas práticas de saúde em prol do trabalho em equipe, frente ao predomínio da formação tradicional centrada na prática hospitalar, podem ser estimuladas pela inclusão desse modelo de organização das práticas nos currículos de formação dos cursos da saúde.

Talvez isso... tendo esse enfermeiro que estou falando ele vai sair melhor ainda, mas os currículos tradicionais acabam dando conta de alguma forma desse cuidado que é feito no hospital. Mas para mim, para a atenção básica, se você não mudar o currículo, nós não vamos conseguir 
ter equipes que funcionam adequadamente. Nós vamos ter equipes ainda centradas no médico, o modelo que a gente está querendo romper, o modelo centrado no médico, para o modelo em equipe (D14 enfermeiro).

No próximo excerto o entrevistado destaca o potencial da APS em desenvolver o trabalho em equipes interprofissionais. Para tanto, aponta a contradição entre o modelo de formação focado na especialização dos saberes e a conformação de práticas que exigem a articulação entre as áreas por meio do trabalho em equipes integradas. Considera que no compromisso da formação e das práticas com as necessidades de saúde dos usuários está a articulação ensino-serviço.

Então, você veja também que essa ação indutora vai nessa direção que o MEC postula, que a formação tem que responder às necessidades concretas da prática profissional. E como fazer isso senão aproximando academia e serviço? Então o Ministério investe nessa direção e encontra, eu acho, na academia, pessoas que pensam também dessa forma. Que a formação adquire sentido e significado quando você olha para o que ela serve de fato, qual é o compromisso dela com a prática e com as necessidades das pessoas. Então, o grau de integração das equipes, até pelo nosso jeito brasileiro de ser, há um grau de integração desde esse ponto de vista, que são unidades orgânicas e tal, funcionam bem do ponto de vista relacional, mas avançam pouco no trabalho interprofissional, em um trabalho articulado, com todos os objetivos comuns, em que o seu trabalho tem a ver com o meu, ou seja, eles se complementam. Mas de qualquer forma, vendo positivamente, eu acho que tem mais condição de prosperar na atenção básica essa proposta de trabalho interprofissional do que em outros modelos de assistência mais fragmentados. Mas eu acho que é um desafio ainda para a gente. $\mathrm{O}$ que eu acho contraditório é formar disciplinarmente, em um formato muito rígido e depois pretender que o formado, o egresso, trabalhe em uma proposta interdisciplinar. Aí é esquizofrênico. Quer dizer, se a gente tem como horizonte esse trabalho interdisciplinar, a formação tem que ter um grau de integração, o máximo que a gente consegue dar em um mundo que valoriza muito a especialização (D9-enfermeiro).

A integração ensino-serviço tem sido perseguida ao considerar a experiência acumulada na formação em saúde e sua insuficiência diante dos desafios da atenção. No início dos anos 1990, a OPAS estimulou o avanço dos projetos UNI no contexto da América Latina e Brasil como uma estratégia para o fortalecimento da integração ensino-serviço, comunidade e da articulação docente-assistencial (Albuquerque et al., 2008). O projeto UNI teve desdobramentos significativos no contexto brasileiro, com mudanças no modelo de formação de universidades públicas e repercussões inclusive nas DCN que indicam a integração ensino-serviço. Contudo, o estudo de Alburquerque et al., (2008), aponta a persistência do distanciamento entre as universidades e os serviços públicos de saúde que 
dificultam mudanças no modelo de atenção, provocam conflitos decorrentes do distanciamento da universidade à dinâmica de trabalho e trabalhadores da saúde, com planejamento das atividades práticas de ensino desarticulado do contexto de trabalho dos serviços.

A seguir, destaca-se a importância de estimular os estudantes a se articularem com outros profissionais de saúde da equipe matricial, para discutir os casos e avaliar as necessidades de saúde dos usuários coletivamente, em um processo de EIP e prática colaborativa.

Nós trabalhamos muito com os alunos da medicina e com os outros profissionais... a gente estimula muito eles fazerem consultoria e fazer discussão dos casos com os outros profissionais da equipe matricial. Então, os pacientes hipertensos que estão com problema de dieta, então vamos estudar isso, vamos discutir com a nutricionista, o que ela propõe, chama ela para fazer avaliação junto. Então nós estamos tentando uma aproximação com os outros profissionais na formação da medicina, fazendo esse... essa ação com a equipe matricial ou com os alunos dos outros cursos que estão lá. Com a psicologia, que agora começa a ir para a atenção básica, que é inédito também na universidade. Aprender e ver outras formas de estar junto com o outro (D14 - enfermeiro).

A articulação de diferentes áreas, pressupõe a interação dos profissionais que contribuem para o cuidado com o seu saber específico, em espaços de discussão do caso clínico. O entrevistado acrescenta como componente do cuidado, a possibilidade de retaguarda e encaminhamento para atenção secundária, para realizar a atenção às necessidades de saúde em rede. Considera que a prática de discussão de casos clínicos na saúde da família, enfrenta a dificuldade de análise conjunta dos aspectos relacionados ao território e comunidade, que enriqueceriam a gestão do cuidado. Os territórios e os coletivos são características indissociáveis do cuidado no contexto da APS.

(...) de saúde da família e pega mais do que uma profissão. E a discussão do caso clínico, que eu também computo muito importante, é aquele momento então, em que todos interagem desde o seu ponto de vista e acho muito importante essa idéia, até acrescentando outros profissionais que não estão necessariamente no atendimento da atenção primária, mas na retaguarda. Quer dizer, eventualmente, diante da parte prática da discussão, no caso clínico, chamar a retaguarda especializada, chamar o radiologista é interessante também para fazer esse gancho com a atenção secundária e tal. Mas eu vejo pouco a discussão sobre o território e a sua comunidade. Como se ele fosse um caso também a ser pensado pelas pessoas. As pessoas no final da equipe, atuam na visita domiciliar, quase como um caso clínico, como se os domicílios não tivessem conexão entre si. O aluno vai ao território, mas como um conjunto de casos clínicos. Isso é um problema. Acho que tem que ter também essa visão de coletivo, de coletivos. E a atenção primária não pode sobreviver sem articular o seu território, senão ela deixa de ser atenção primária, que é a grande 
diferença, ao meu ver, com a unidade ambulatorial do hospital, que pensa em termos dos casos clínicos e... mas para soltar no território, o caso clínico ainda teria que passar de volta pela atenção primária, porque este que pensa a conexão individual, coletivo (D2- médico).

A proposta de gestão da clínica de Mendes (2012) orienta a organização da RAS a partir de diretrizes clínicas que se desdobram em linhas de cuidado. As linhas de cuidado, introduzidas nas propostas do Ministério da Saúde em 2010, devem se organizar a partir da APS, com a responsabilidade de ordenar o cuidado organizado em rede, a organização dos recursos necessários, a integração entre os serviços e equipes, a coresponsabilização e a pactuação de compromissos e resultados (Brasil, 2010).

A formação interprofissional com foco na integralidade da atenção à saúde, reforça o movimento de integração entre o território, serviços e práticas profissionais. Possibilita o desenvolvimento de conhecimentos e habilidades para realizar diferentes leituras integradoras das necessidades de saúde na perspectiva da integralidade, que segundo o entrevistado, também pode ser pensada a partir da articulação entre serviços da rede e não apenas nos limites de um único serviço.

Então quer dizer, da perspectiva teórica, a integralidade tem definições bastante interessantes e bastante completas já até certo ponto. Porque se você pensa na integralidade institucional, entre instituições ou equipamentos diversos, você pensa na integralidade médico sanitária, que tanto entre esses dois ramos, o território e o sanitário e o clínico, médico propriamente dito. Você pensa na integração entre profissões que são mais sociais, outras mais da saúde, outras mais das artes porque no território você vai encontrar isso também... esse é um aspecto interessante. Então, você pensa várias possibilidades de integração, né. E não uma só, lógico! As pessoas que conseguem fazer, que tem essa formação conseguirão fazer várias leituras integradoras sempre, né, tanto das necessidades quanto das suas respostas. Então eu acho que isso facilitaria muito nesse sentido, da integralidade (D2- médico).

A integralidade da atenção conduz à mudanças na formação em saúde, afim de preparar novos profissionais que abordem a complexidade das necessidades de saúde. As necessidades de saúde são polissêmicas históricas, sociais e carregadas de componentes de natureza subjetiva e individual (Cecílio, Matsumoto, 2006).

A articulação entre os serviços da rede mencionada pelo entrevistado remete à concepção das redes de atenção à saúde estruturadas com uma rede de serviços com diferentes potencialidades tecnológicas (Mendes, 2011). No Brasil, a portaria $\mathrm{N}^{\circ} 4.279$, de 30 de dezembro de 2010 estabeleceu as 
diretrizes para a implantação das redes de atenção à saúde (RAS) no SUS, em busca de superar a fragmentação entre as ações dos serviços de saúde, programas e práticas clínicas, considerando a transição do perfil epidemiológico brasileiro, com a prevalência de doenças infecciosas, parasitárias, desnutrição, intensificação da violência e das doenças crônicas (Brasil, 2010).

RAS constituem uma inovação na organização do sistema de saúde brasileiro para produzir impacto sobre os determinantes de saúde da população. A APS é indicada como coordenadora do cuidado nas RAS, em busca de responder aos desafios socioeconômicos, demográficos, epidemiológicos e sanitários (Brasil, 2010).

No próximo excerto, o entrevistado afirma que a colaboração interprofissional está relacionada com a colaboração interinstitucional, ressaltando a importância do trabalho em rede. Pode-se considerar que se aproxima da noção da integralidade em rede, afinal a prática interprofissional também remete à necessária articulação entre equipes e diferentes serviços de saúde. O entrevistado refere que a formação em EIP promove o aprendizado para o trabalho em equipe, assim como atitudes necessárias para esta modalidade de trabalho, como a escuta e a valorização do conhecimento do outro.

Então o que os estudantes fizeram, foi articular um processo de encontros dessas instituições e a partir dali que a colaboração interprofissional tem a ver também com a colaboração interinstitucional, com a colaboração com o trabalho deles. Enfim, é um pouco nessa visão... da importância do trabalho em rede... que as instituições precisam colaborar entre si... e isso passa a colaboração para os profissionais também. Não só dentro da mesma instituição, mas a colaboração com profissionais que estão em outras instituições também. Então, assim, o que mais marcou de todas as equipes foi o aprendizado dos estudantes, o aprendizado, a experiência que eles tiveram, das atividades que acharam fantásticas. Estar trabalhando com profissionais de outra área, aprendendo a trabalhar em equipe, a escutar o outro, a valorizar o conhecimento do outro profissional e a habilidade do outro profissional. E a partir disso, saber trabalhando em equipe, que a ação de um pode dar um maior impacto à ação do outro também. Então isso foi uma coisa que marcou (D15 - médico).

A integralidade da atenção depende da integração dos serviços de saúde com instituições de outros setores. Pode-se dizer, que a integralidade só pode ser realizada na rede de serviços de saúde e também ocorre com a integração intersetorial. Tal perspectiva, possibilita a compreensão do 
sistema de saúde organizado em rede, com múltiplos fluxos, entradas e articulação entre os serviços envolvidos (Cecílio, 2001).

Uma consulta médica por mais especializada que seja, não pode deixar de fazer uma certa escuta de outras necessidades do paciente que vão além da demanda referenciada que o traz ao consultório. A intervenção do especialista não pode alcançar sua eficácia plena se não tiver uma boa noção do modo de andar a vida do paciente, inclusive seu vínculo com outra equipe ou profissional, seu grau de autonomia e a interpretação que faz da sua doença (Cecílio, 2001, p. 119).

$\mathrm{O}$ reconhecimento da integralidade como princípio ordenador do SUS, pode contribuir para a ampliação da perspectiva das práticas e da formação, para o cuidado em saúde, contemplando princípios que visem à formação para atenção das necessidades de saúde conforme está previsto nas DCN (Henriques, Pinheiro, 2008). No próximo relato, o entrevistado afirma que a integralidade prevê a articulação entre serviços de saúde da rede e intersetorialidade, para dar conta das necessidades dos usuários. Requer a articulação interprofissional e intersetorial com a participação dos usuários. A operacionalização da integralidade expressa no depoimento, remete também à noção da prática interprofissional colaborativa centrada no paciente, que se refere ao processo de tomada de decisão compartilhada entre profissionais e usuários no tocante as necessidades de saúde.

A integralidade é você realmente e você nunca conseguir organizar o trabalho da unidade e isso implica que você nunca consegue olhar a unidade sozinha, porque você tem que pensar em coisas intersetoriais necessariamente e na articulação da unidade com o resto do sistema de saúde, porque para dar as respostas que precisa, ela precisa estar conectada com várias coisas, ela não vai conseguir ser autora sozinha para dar essas respostas, ela vai precisar construir isso junto com os usuários, tanto com outros profissionais, ela vai precisar fabricar essa coisa de um outro modo (D3 - médico).

As unidades de saúde são insuficientes para produzir as respostas necessárias aos problemas apresentados pelos usuários. Nesse sentido, a intersetorialidade é valorizada por possibilitar a ampliação da qualidade da atenção das necessidades de saúde dos usuários por meio da articulação com outros setores de prestação de serviços como a educação, assistência social e meio ambiente (Nascimento, 2010).

A análise do material empírico das entrevistas da subcategoria 'Formação para o trabalho em equipe interprofissional em redes de atenção', possibilitou a compreensão de que o trabalho em equipe consiste em um 
componente de organização das práticas de saúde que facilita o desenvolvimento de ações de EIP.

O papel da APS na coordenação do cuidado dos usuários nas RAS está presente nos depoimentos dos entrevistados, que indicam a importância da integralidade da atenção para o fortalecimento da EIP, por meio dos seguintes elementos: atenção da complexidade das necessidades de saúde dos usuários, integração ensino-serviço, intersetorialidade e prática colaborativa centrada no usuário.

\section{Subcategoria 1.3 Comunicação interprofissional para o cuidado}

Outro aspecto de fundamental importância para o desenvolvimento das práticas de saúde apontado pelos entrevistados é a comunicação interprofissional. Nesta subcategoria são analisados elementos que expressam recursos da comunicação, como a interação e a intersubjetividade argumentativa em prol do entendimento dos trabalhadores entre si e com os usuários, considerados protagonistas do cuidado.

A experiência comunicativa depende do posicionamento performativo dos sujeitos que agem comunicativamente, ao dizer algo e buscar compreender o que é dito pelo outro, a fim de que se compreenda o sentido da comunicação. O mundo da vida é o horizonte dos processos de entendimento e se expressa de acordo com o mundo objetivo, social ou subjetivo em particular. A estrutura dos processos de entendimento pode ser caracteriza por: referência ao mundo dos atores (mundo social, das relações interpessoais, mundo objetivo, do estado das coisas e mundo subjetivo, das vivências pessoais), pretensões de validade, comum acordo pautado no reconhecimento intersubjetivo de pretensões de validade, e concepção do entendimento como negociação cooperativa de situações comuns (Habermas, 2012).

A seguir, o entrevistado considera que para entender o cuidado é preciso entender as relações intersubjetivas entre os profissionais e como a informação circula e é necessária. 
Para entender o cuidado você tem que entender as relações entre os diversos profissionais, entre o farmacêutico que está no laboratório, enfermeira (...) como a informação circula. Independente de dizer que isso deve ser assim ou não (D8 - médico).

Recente revisão de literatura desenvolvida por Nancarrow (2013), identificou dez princípios para o bom trabalho em equipe interdisciplinar, também referida pelos autores como interprofissional. O primeiro princípio identificado foi a boa comunicação, definida como a habilidade para discutir e resolver problemas em equipe. Também reconhecida como uma das competências para o trabalho em equipe, as estratégias de comunicação contribuem para a tomada de decisão colaborativa e na efetividade das ações em equipe.

A comunicação é indicada pelos autores como um dos elementos que representam desafios para o trabalho em equipe interprofissional. Duas modalidades de comunicação foram indicadas: a primeira refere-se ao relacionamento externo com outros serviços, que afetam o trabalho em equipe e a segunda com o relacionamento geral da equipe, incluindo a integração entre os profissionais, o conhecimento claro sobre os papéis dos outros e os encontros entre profissionais e usuários.

No próximo excerto, o entrevistado defende que o compartilhamento e interação dependem da reciprocidade comunicativa, em um processo de interlocução, com a participação ativa dos sujeitos envolvidos, para que haja o entendimento. A interação intersubjetiva comunicativa tem como pano de fundo o mundo da vida partilhado, assim, o agir comunicativo se expressa por atos de fala simetricamente orientados para o entendimento (Habermas, 2012).

Olha, vou dizer uma coisa a você... eu acho que há um elemento básico aí, que eu não sei se as pessoas pensaram, mas sem o qual acho bastante difícil haver essa idéia da interação e da correspondência, do mútuo compartilhamento, a correspondência nesse sentido de comunicação mútua (D2- médico).

As relações intersubjetivas entre os profissionais e usuários dependem do reconhecimento do outro. Ao realizar uma analogia das esferas da teoria de reconhecimento de Honneth (2009) com as práticas de saúde, Miranda, Rivera e Artmann (2012), consideram que a primeira esfera das relações primárias de amor e amizade do reconhecimento, diz respeito às relações dos profissionais entre si e com os usuários, que envolve a base 
das interações sociais. A segunda esfera da Ordem Social ou relações jurídicas se refere à relação da equipe com o serviço e de ambos com os usuários, no tocante aos direitos que podem ser expressos em colegiados de gestão e processos participativos de decisão. A terceira esfera da Solidariedade ou estima social, se refere ao reconhecimento da individualidade/singularidade de cada sujeito, ou seja, das suas capacidades, competências, experiências e repertório, portanto, trata das relações da equipe com o serviço e comunidade, com o reconhecimento da contribuição da equipe, aspecto importante para a autorealização profissional.

$\mathrm{Na}$ esfera de reconhecimento da Solidariedade, as relações entre profissionais e usuários viabilizam o reconhecimento do saber dos profissionais e das qualidades e necessidades dos usuários. De modo que, além do saber técnico, ocorrerá o reconhecimento das singularidades de todos os envolvidos na relação de cuidado, tanto os profissionais, quanto os usuários (Miranda, Rivera e Artmann, 2012).

Ainda na esfera da Solidariedade, a escuta do usuário representa o reconhecimento do direito de expressar suas crenças e valores, interpretadas no contexto em que se realizam, sem imposição do poder profissional técnico-científico e suas contribuições no entendimento das necessidades de saúde, que espera-se, sejam reconhecidas na interação e negociação entre usuário e profissional.

A comunicação é uma das competências necessárias para a prática colaborativa centrada no paciente (IPEC, 2010; D'Amour et al., 2005; Martin Rodriguez et al., 2005, Suter et al., 2009). Um dos objetivos da comunicação é a habilidade de negociar em meio à diferentes pontos de vista, culturas profissionais e outras influências, como as diferenças de personalidade (Suter et al., 2009). A busca do entendimento por meio da negociação a partir das experiências vivenciadas é um elemento central na teoria do agir comunicativo.

Outro aspecto relevante no tocante à comunicação com os profissionais de saúde presente nos relatos é a participação do usuário como protagonista do cuidado. A clínica ampliada visa incluir o usuário no trabalho em saúde para que o cuidado em saúde seja realizado com sua 
participação ativa, mediante a ampliação da sua capacidade de análise sobre os determinantes e intervenções relacionadas aos problemas de saúde, considerando a singularidade do caso. Nesse processo haveria um desenvolvimento do agir comunicativo dos envolvidos, com a construção de novos padrões de interação intersubjetiva e vínculo, para assegurar a capacidade de escuta, compreensão e decisão dos envolvidos (Campos, 2007b; Campos 2011).

Também é importante retomar que no cenário internacional, a prática interprofissional colaborativa centrada no paciente, diz respeito à participação do usuário, em parceria com as equipes de saúde, nos processos de tomada de decisão sobre o cuidado (Orchard et a., 2012).

Depois foi se discutindo isso, o que é o cuidado de um paciente que não está em uma cama, paralisado a disposição da biomedicina e de todos os seus profissionais, mas aquele que se mantém na vida, está andando, volta para casa, volta para o trabalho. O que é este outro tipo de cuidado, de atenção, que não decorre daquele? Demorou-se para se perceber isso. Então, isso implicaria em uma mudança de paradigma pedagógico, portanto, para ensinar a patologia simples, mas com alta eficácia, efetividade do cuidado, eu preciso de uma outra forma de ensino, uma outra aproximação do adoecimento, da prevenção, da promoção, da reabilitação... preciso de uma outra filosofia de ensino (D2- médico).

A construção de vínculo envolve confiança, afeto e um processo de dependência mútua, no qual, o usuário precisa acreditar que a equipe de saúde pode ajudá-lo a superar suas dificuldades (Campos, 2007b).

A seguir o entrevistado indica possíveis desdobramentos da EIP, como o preparo para a colaboração no trabalho e mobilização para interação que não ocorre em espaços uniprofissionais. Também destaca o preparo para atuar na perspectiva da integralidade, frente a complexidade das necessidades de saúde, colocando o usuário como protagonista do cuidado, que pode participar ativamente da tomada de decisão sobre as intervenções terapêuticas a serem realizadas. Neste sentido, o saber do usuário será considerado e ele participará da construção do projeto terapêutico.

(...) sai com uma capacidade de, é claro, enfim eu acho que uma possibilidade de contribuir para construir dinâmicas de trabalho mais interessantes nos vários lugares, porque adquire ferramentas também nesse sentido, vivencia situações difíceis e tal, porque não é tudo um mar de rosas, muito pelo contrário. Eu acho que você consegue de uma maneira mais importante duas coisas. Uma é que o cara opere mesmo com um conceito mais amplo de saúde e faça essa separação. Segundo, para operar com um conceito ampliado de saúde lidando com a produção conjunta de várias profissões e com os usuários como protagonistas desse negócio também. Se não for assim também não vale a pena porque a 
única coisa que a gente faz com o usuário é educa-lo, porque muitas das experiências, vão para unidade e vai fazer o que? Vai fazer ações educativas, ensinar o usuário, muito chato e pouco produtivo, porque bota o usuário numa condição, num lugar, eu brinco assim... O SUS prevê a participação dos usuários na construção das políticas (D3- médico).

O protagonismo do usuário no cuidado modifica a relação com os profissionais da saúde, pois os usuários deixam de limitar-se a uma mera relação prescritiva, com a participação solidária e responsabilização pelo processo de cuidado. Nesse tipo de relação de cuidado como mediação são priorizadas a valorização do usuário, confiança e solidariedade. A corresponsabilidade, troca de saber e reconhecimento das diferenças favorecem o avanço na direção da integralidade do cuidado, direito de acesso e cidadania (Martins, 2011).

Os relatos da subcategoria 'Comunicação interprofissional para o cuidado' referem a importância da interação entre profissionais e usuários. Nessas relações intersubjetivas, o compartilhamento entre os atores depende do reconhecimento mútuo e da busca de entendimento por meio da negociação. Os usuários são considerados protagonistas do cuidado, noção presente na produção nacional sobre a clínica ampliada e internacional sobre a prática colaborativa centrada no paciente.

\section{Subcategoria 1.4 Educação interprofissional em saúde: modelo de formação contra-hegemônico}

A EIP é uma proposta contra hegemônica, pois está orientada por concepções e valores como a integralidade do cuidado, trabalho em equipe $\mathrm{e}$ prática interprofissional colaborativa centrada no usuário, que vão de encontro com o padrão de relações profissionais, orientado primordialmente pelo êxito técnico e produtivo estabelecido pelo mercado de trabalho.

Nesse sentido, o movimento da interprofissionalidade enfrenta dificuldades para se colocar como alternativa que compõe o leque de elementos/componentes de mudança da formação dos profissionais frente ao modelo médico hegemônico, centrado na doença que dificilmente dará abertura para proposta almejada da interprofissionalidade. 
A afirmação da entrevistada mostra uma força contrária à proposta de mudança do modelo de atenção à saúde, centrado no cuidado e na integralidade, pois afirma que os médicos não teriam abertura para esse modelo de práticas, assim como para inteprofissionalidade.

(...) não me parece que o mercado de trabalho... vai por aí não... Então é uma interprofissionalidade que vai padecer um pouco dessa ausência das profissões mais centrais da patologia. Dono, donos mesmo da patologia são só os médicos. Eles não vão abrir mão disso, não tem como pedir aos médicos que abram mão disso. Eles vão mais facilmente dizer - venha fazer medicina. É difícil porque é a profissão que historicamente montouse assim e não vai conseguir essa abertura... essa é a minha opinião, posso estar enganada. Os médicos oscilam entre serem mais genéticos, mais ambientalistas, mais clínicos, mais cirurgiões, mas é uma oscilação perfeitamente dentro de um certo geral dado pelo adoecimento. É o adoecimento que está sempre no horizonte (D2- médico).

O domínio do saber biomédico sobre o julgamento diagnóstico e terapêutico farmacológico na produção da atenção à saúde, confere ao profissional médico, uma posição dominante no modo de produção dos serviços de saúde. Esse status contribui para manter a hegemonia do modelo biomédico centrado na racionalidade instrumental. A dominação da profissão médica fica expressa na autoridade construída sóciohistoricamente de controlar e dirigir o trabalho dos outros profissionais da saúde com uma relação de subordinação, dependência técnica e social condicionada às decisões médicas (Lopes, 2001).

O entrevistado relata um exemplo de discussão de casos clínicos, considerando que a complexidade dos casos, requer o olhar de diferentes profissionais que podem contribuir para a qualidade do cuidado, com o seu saber técnico, sem hierarquias entre os profissionais. Contudo, considera a presença de relações de poder na interação social entre os diferentes profissionais, expressa no posicionamento do médico.

E eu acho que essa discussão entre... uma discussão de caso envolvendo vários profissionais, na qual não existe uma hierarquia, porque às vezes acontece do profissional médico intimidar um pouco os outros profissionais. Quando há um ambiente propício para trocas é extremamente rico, porque o psicólogo traz as alterações que ele observou na parte cognitiva. $\mathrm{O}$ médico fala das alterações clínicas, os exames, a neuro-imagem, exame neurológico, as coisas físicas que ele observou. $\mathrm{O}$ terapeuta, ou o terapeuta ocupacional, ou o fisioterapeuta, trazem informações específicas com as quais eles trabalham, funcionalidade de membros. E aí é tão rica a discussão, porque você consegue olhar o indivíduo de vários lados, sob vários aspectos, e o processo diagnóstico ele é mais confiável, porque você usa muito... uma quantidade maior de dados e eu acho que é um processo super rico para a equipe. Então é muito interessante quando a gente consegue ter discussão de caso clínico, 
definição de diagnóstico, definição de tratamento, com a participação de vários profissionais. Não é sempre que isso acontece (D10 - psicólogo).

As profissões constituem ocupações organizadas, com estatuto político que permite o delineamento dos papéis profissionais no trabalho. $\mathrm{O}$ diferencial da profissão médica está na autonomia e autoridade que possui sobre a doença e o tratamento, conquistada a partir da consolidação de sua base científica para o trabalho e formação no início do século XX (Freidson, 1978; Mendes-Gonçalves, 1994).

A hiperespecialização e a constituição de áreas profissionais específicas isoladas são consequências da racionalização da sociedade. A diferença dos saberes profissionais nas diversas categorias de trabalhadores da saúde, propicia a hierarquização dos diferentes trabalhos, de um lado, saberes complexos associados ao trabalho reflexivo de concepção e de outro, saberes práticos de execução das ações de saúde (Lopes, 2001).

De acordo com Habermas, o trabalho organizado dessa forma, revela a colonização da organização do trabalho e da saúde pela racionalidade instrumental, ou ação racional teleológica, com predomínio da técnica e ciência em detrimento da linguagem e interação.

O desenvolvimento da EIP depende da superação de barreiras presentes no mercado de trabalho, nas corporações profissionais, no modelo de formação e no conceito de disciplinaridade que reforça o processo de especialização dos saberes.

É evidente que tem contradições entre essas formas de superar as barreiras e as forças que reforçam as barreiras. Por exemplo, mercado de trabalho reforça barreiras. A conformação do Estado reforça barreiras, o modelo de formação reforça barreiras, a ponto, por exemplo de alguém com um talento clínico maravilhoso, mas com diploma de enfermeira, não poder diagnosticar por melhor que seja, não pode tratar. Por mais que demonstre competência não tem o respaldo legal, porque aqueles atos são protegidos. E nesse caso, como se trata de uma formação profissional que é muito... historicamente se constitui muito dominada pela referência médica, pela matriz médica, não há nem contestação. A formação da enfermagem é sempre subsidiária. $\mathrm{E}$ aí tem uma série de dificuldades que a gente sofre quando o projeto proposto é reconstituir a integralidade do cuidado. Até porque, a legitimidade científica da disciplinaridade é que resulta em especialização. A ideia de que o conhecimento é fragmentação contínua. A especialização é o que legitima um degrau superior, um nível superior (D7- médico).

Freidson (1978), realizou um estudo sociológico sobre a profissão médica e concluiu que o estado deveria intervir na regulação das profissões 
e exercer mais controle sobre o desempenho profissional para garantir que as necessidades de saúde sejam atendidas.

Os avanços da ciência com a bacteriologia e outras investigações, representam um corte qualitativo na prática clínica no tocante ao diagnóstico e controle das doenças. A prática médica se consolidou como uma prática individualizada, que exerce controle sobre o trabalho dos demais envolvidos com a assistência à saúde. Tanto as universidades medievais, quanto as corporações responsáveis pela relação profissional, contribuíram para a constituição de uma identidade pública, para a medicina e o monopólio profissional que assegura sua posição em relação às outras ocupações (Freidson, 1978).

O controle da medicina sobre o trabalho em saúde tem um caráter político, devido a colaboração do Estado na sua manutenção, bem como a autonomia do profissional médico é relativa devido a interferência do Estado (Freidson, 1978).

Freidson destaca a influência das associações profissionais no estabelecimento de normas para aprendizagem, registro e certificação profissional da medicina e de outras profissões, assim como, no controle da qualidade e do número de médicos que atuam no país (Freidson, 1978).

A ênfase da prática médica nas práticas da saúde remete ao conceito de medicalização da saúde. A medicalização pode ser compreendida como o processo no qual as condições humanas de vida e saúde são colocadas sob o domínio do diagnóstico médico e da patologia, com redução das possibilidades terapêuticas (Tesser et al., 2010).

No próximo excerto, o entrevistado questiona a prática medicalizada, ao ponderar que quando o médico fecha o diagnóstico clínico isoladamente, sem participar os demais profissionais do cuidado que coletaram informações sobre aspectos distintos da história do usuário, há uma perda muito grande na qualidade do cuidado e se inviabiliza a colaboração e o compartilhamento de saberes na tomada de decisão.

Todo mundo colhe os dados, o médico... não sei em qual momento, mas em algum momento, ele reúne os dados e fecha o diagnóstico. E alguns casos são trazidos para discussão. Mas os casos que são trazidos para discussão são os dificílimos, os complexos, que ninguém sabe qual é o diagnóstico. Mas o diagnóstico de rotina é fechado pelo médico. Então já 
acho que há uma perda aí, porque o médico acaba não ouvindo as diversas perspectivas dos outros profissionais (D10 - psicólogo).

Há muitas barreiras para o engajamento dos médicos na prática colaborativa relacionadas ao poder, status, socialização profissional e responsabilidade pela tomada de decisão. O status é um conceito complexo que pode ser entendido de modo simplificado como o nível de autoridade em uma sociedade. O aumento do status de outros profissionais da saúde representa uma consequente redução do status médico. A medicina ocupa o espaço da elite acadêmica na área da saúde, devido seus elevados níveis de formação. Um dos elementos centrais na educação médica é a formação da identidade profissional com o desenvolvimento da expertise e autoridade sobre a tomada de decisão, independente dos outros profissionais. Por isso é muito importante a inserção de estratégias de formação inteprofissional nos cursos da medicina (Whitehead, 2007).

Um estudo longitudinal que avaliou as atitudes de estudantes de graduação em saúde frente ao aprendizado compartilhado interprofissional, aponta que os estudantes de medicina do sexo masculino apresentam maior declínio na prontidão para a educação interprofissional, comparada a dos demais cursos da área da saúde (Coster et al., 2008).

Diferentemente, o enfermeiro é reconhecido como o profissional que faz articulação das ações realizadas pelos diferentes profissionais de saúde. No próximo excerto, o entrevistado considera que a enfermagem articula as diversas áreas, devido ao vínculo que tem com os usuários. O nível de colaboração entre as áreas é muito pequeno, pois cada profissional realiza uma pequena parcela das intervenções.

Na verdade no hospital não tem. Você convive lado a lado e tentando não se esbarrar nas várias profissões, com um nível muito pequeno de colaboração. Na verdade, eu acho que a enfermagem acaba fazendo uma certa articulação da intervenção das várias profissões. Então não quer dizer que existe uma articulação, ela organiza, e enfim, a enfermagem que tem mais contato no cotidiano dos usuários, ela cumpre esse papel bem forte (D3 - médico)

O estudo de Propp et. al., (2010), revela que as enfermeiras ocupam uma posição central nas equipes colaborativas de cuidado, por utilizarem estratégias de comunicação que articulam os profissionais da equipe e melhoram os resultados da tomada de decisão compartilhada no trabalho em equipe. 
Embora os enfermeiros estejam mais dispostos a colaborar e articular sua prática de cuidado com outros profissionais e isso contribua para a qualidade da tomada de decisão e sinergia das equipes de saúde (Propp et al., 2010), ainda são necessários alguns investimentos para fortalecer a prática colaborativa dos enfermeiros tais como: socializar para fazer parte do trabalho em equipe, entender para ser capaz de aplicar seu próprio papel conhecimentos e habilidades com os outros, entender os papéis conhecimentos e habilidades dos outros profissionais da saúde e aprender como trabalhar em equipes colaborativas (Orchard, 2010).

Abaixo, o entrevistado considera que a deficiência da formação clínica do enfermeiro, reforça o modelo de cuidado centrado no médico. O conhecimento técnico-científico presente no desenvolvimento de competências clínicas do enfermeiro, poderia contribuir para a mudança das relações de poder entre as diferentes áreas profissionais que compõem as equipes de saúde. Pode-se dizer que se torna necessária a ampliação do escopo da prática de enfermagem com maior aproveitamento de suas potencialidades. O mesmo processo, pode ocorrer em relação à outras profissões da área da saúde como: fisioterapeutas, cirurgiões dentistas e outros.

E trazer esse entendimento para a formação do enfermeiro, do que é o cuidado individual e para cuidar eu tenho um método que é o método clínico. E saber fazer exame físico, em um nível que não é para o diagnóstico diferencial, mas para que ele possa diferenciar do que está anormal. Então, isso dá uma capacidade de trabalho para o enfermeiro em uma unidade de saúde da família, uma capacidade de resolutividade... e aí de fato eu acredito que o modelo vai deixar de ser centrado no médico. A gente reclama, reclama, que montamos as equipes de saúde da família, e que o modelo continua centrado no médico. Mas para mim o problema disso... vamos discutir processo de trabalho, vamos discutir como é que está organizado, como é cada figura. Mas tudo para mim acontece por conta de uma deficiência da formação do enfermeiro. Porque se ele assume o cuidado das pessoas como o médico e como o dentista, que o dentista faz... cada um dentro da sua área, você ganharia mais poder de agilização, de decisão, de capacidade daquela equipe (D14 - enfermeiro).

A subcategoria 'Educação interprofissional em saúde: modelo de formação contra-hegemônico' mostra que a predominância do modelo biomédico, centrado no saber técnico-científico especializado, estabelecido por meio de práticas fragmentadas e medicalizadas, configura uma tensão significativa à EIP orientada pela integralidade do cuidado. 


\section{Categoria 2. A educação interprofissional em saúde contribui para a reconfiguração das relações profissionais colaborativas}

O material empírico das entrevistas possibilitou a construção de três subcategorias relacionadas à reconfiguração das profissões em prol da interprofissionalidade:

Figura 5. Subcategorias da categoria 2. A EIP contribui para a reconfiguração das relações profissionais colaborativas. São Paulo, 2014.

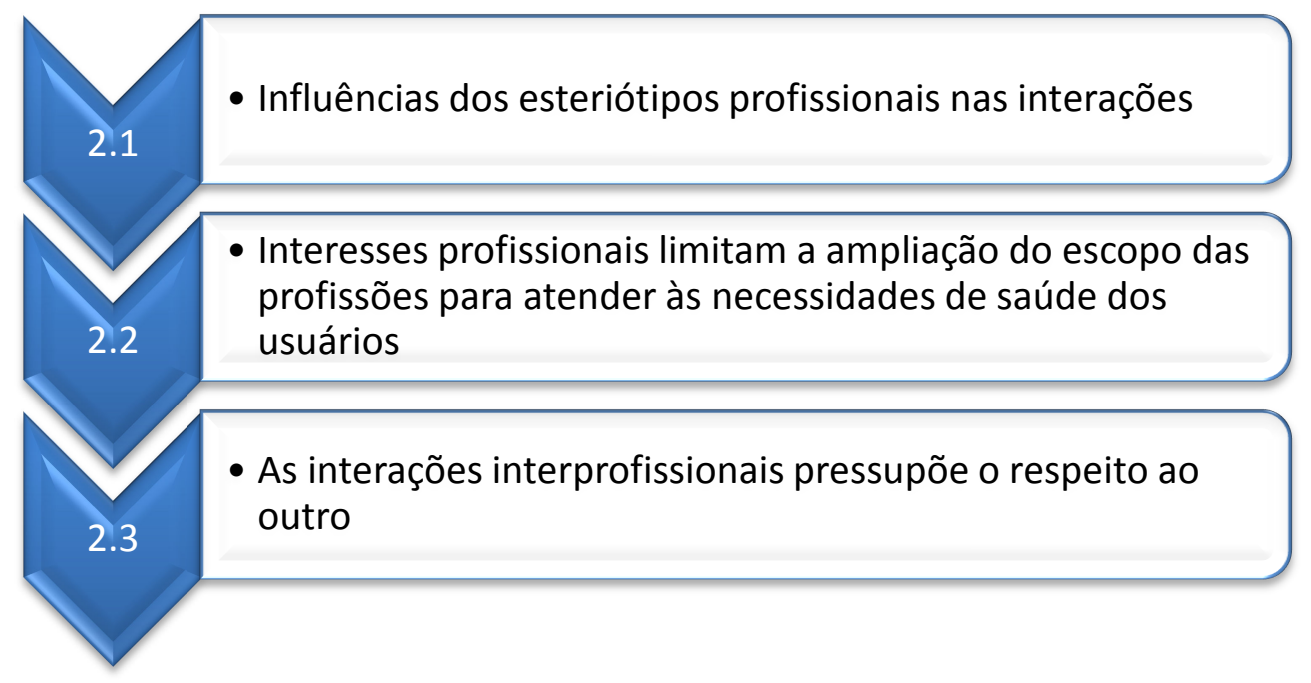

As três subcategorias possibilitaram a construção da categoria principal 'A educação interprofissional em saúde contribui para a reconfiguração das relações profissionais colaborativas'.

As profissões da saúde podem ser caracterizadas pela autorregulação que possibilita o controle de suas próprias práticas. Entretanto, o movimento da EIP representa uma possibilidade de refletir e construir alternativas para melhor integração entre os profissionais, por isso, a seguir apresentam-se relatos dos entrevistados que apontam caminhos e tensões relacionados à essa mudança. 


\title{
Subcategoria 2.1 Influência dos estereótipos profissionais na interação
}

Um dos aspectos que afetam as possibilidades da colaboração interprofissonal são os estereótipos profissionais. Estes podem ser definidos como percepções sociais ou julgamentos sobre determinado grupo de indivíduos que podem ser negativos ou positivos (Ateah et al., 2011).

O entrevistado considera que a EIP elimina estereótipos criados a partir do saber específico de cada profissão. A falta de experiência conjunta na formação e no trabalho, contribui para que um profissional não reconheça o papel do outro, gerando o desconhecimento da atividade que cada profissional realiza. A EIP seria uma alternativa de solução para propiciar o conhecimento sobre as atividades realizadas em cada área. A clareza dos papéis aumenta a articulação comunicativa em prol do cuidado eficiente na perspectiva da integralidade.

\begin{abstract}
Interprofissional eu acho interessante porque elimina um pouco os estereótipos criados a partir de um pressuposto do saber que será apropriado para cada profissão. Você supõe que o psicólogo... porque ele vai ouvir a história, ele também saiba falar para as pessoas. Então muita gente põe o psicólogo para falar e não para ouvir. Para comunicar as más notícias e não para ouvir. E ele - mas eu não sou um profissional de relações públicas, eu sou um profissional que escuta e não que fala. Mas todo mundo acha que porque ele escuta ele deve saber falar. Então esse desvirtuamento um pouco das imagens, do escopo profissional de cada profissão decorre muito dessa falta de experiência conjunta. Isso terminaria em uma formação interprofissional. Quer dizer, propiciaria às pessoas a experiência concreta do que de fato, cada um está atualmente fazendo. Isso não vai mudar, mas o que está atualmente fazendo. E como você poderia interagir com aquilo, aumenta a especialidade comunicativa, lógico, e aumenta a articulação objetiva de complementos de cuidado, lógico. Então, você começa a entender melhor o que está na sua frente. (D2- médico).
\end{abstract}

A mudança de estereótipos, com a redução da atribuição de características negativas a outros grupos profissionais pode ser influenciada por programas de EIP, que contribuem para compreensão dos conhecimentos, habilidades e papéis de outras profissões (Barnes, Capenter, Dickinson, 2000).

O entrevistado considera que os estereótipos profissionais se modificam na oportunidade de produzir o cuidado compartilhado, no qual cada estudante ou profissional de diferentes áreas contribui com o saber de sua especificidade, colabora e negocia com os parceiros da equipe em prol da qualidade do cuidado. 
(...) e o meu estudante da educação física verbaliza "pensam que a gente não pensa né professora", é só psicólogo que acha que pensa, meu estudante da TO diz assim "nós não somos aqueles artesão que só ficam costurando, botando botão, descosturando", trabalhar representações entre eles, porque eles tem que se confrontar e ver a parceria que nasce daí, e que essa parceria se consolida e se amplia, quando no eixo de trabalho e saúde eles vão produzir junto o cuidado, então essas são experiências para mim, essa é uma experiência com estudante que me tem chamado muita atenção (D4 - psicólogo).

A persistência de estereótipos negativos é um desafio para a efetividade das equipes de saúde. O estudo desenvolvido por Ateah et al. (2011), revela que a exposição de estudantes à experiências de formação interprofissional contribui para a melhora das percepções dos futuros profissionais das equipes de saúde.

Carpenter (2005), destaca que a interação das equipes de saúde é influenciada por estereótipos. Além disso, sempre que são iniciados programas de formação em saúde, os estudantes referem estereótipos.

O entrevistado considera que a aproximação precoce entre as áreas de formação em saúde, contribui para o interesse, valorização, constituição de espaços para diálogo e eliminação de jargões entre as áreas, assim como, elimina os estereótipos profissionais e preconceitos. A experiência prática nos serviços, por meio do aprendizado teórico-prático interativo é uma estratégia que favorece a desconstrução de estereótipos profissionais.

Então eu acho que eu você estudar junto e praticar junto desde cedo, acho que eu você reduz o preconceito e o estereótipo das profissões, acho que eu você cria um apreço uma aproximação e um carinho com as várias áreas, e acho que eu você faz com que eu o aluno passe a valorizar a contribuição das várias área. Eu tive uma oportunidade como eu te disse na psiquiatria quando um médico ou um fisioterapeuta trazia uma prospecção ou uma síntese sobre determinado caso, você passa a compreender olha que interessante, essa é uma contribuição importante de que eu não tinha visto ou eu não sei nada sobre isso, eu preciso aprender mais sobre isso, então acho que a gente passa a valorizar o saber que vem das outras áreas também e aprende a dialogar a usar os mesmos jargões, isso a gente aprende muito quando a gente trabalha numa equipe multiprofissional, a entender o jargão do outro , o critério diagnostico do outro o termo, é muito importante, é muito importante a gente aprende muito com isso, então se a gente tivesse um espaço compartilhado de aprendizagem a gente aprenderia muito sobre a área do outro também (D10 - psicólogo).

$\mathrm{Na}$ formação em saúde, o entrevistado destaca a riqueza de ter várias profissões articuladas e perceber as diferentes abordagens de formação e práticas entre elas, algumas mais voltadas para o saber técnico e outras mais dialógicas. Refere que os profissionais tem expectativas sobre o tipo de atuação do outro, e essas concepções se modificam com o tempo. 
No início a imagem das outras profissões está muito longe do real, por isso os residentes tem muitos espaços para interação entre si, para conhecer mais sobre o que o outro faz. Fora pouquíssimas exceções olha, acho que não há dúvida que é muito mais rico você ter vários profissionais, vários saberes, né, as diferenças, você percebe claramente cursos que são mais centrados nas técnicas, cursos mais pragmáticos. Aí você tem cursos que trazem outros tipos de conteúdos para a discussão, que não estão presentes. A expectativa da psicologia... isso na residência... de alguns profissionais terem uma expectativa em relação à psicóloga, o que o psicólogo vai fazer nesse lugar, né. Então aí no diálogo, na discussão isso vai se rompendo e eles vão percebendo que a psicologia vai muito além daquilo que eles imaginavam. É isso acontece com outras formações também. É isso acontece com outras formações também. Então há uma... quando eles chegam... independente do curso, a imagem que eles tem do outro está muito longe do real. E aí o contato que eles vão tendo... por isso que a gente na primeira semana, realmente, pegamos um tempo grande para que eles conversem, troquem, para que eles falem sobre o que eles fazem... o que é a profissão, o que seria estar nesse, que se fecham em si mesmos, tá? (D16 psicólogo).

A subcategoria 'Influência dos estereótipos profissionais na interação' possibilitou a apreensão de que a EIP pode contribuir para a eliminação de estereótipos profissionais negativos, mediante o reconhecimento dos papéis profissionais que favorece a interação intersubjetiva, a colaboração e o cuidado interprofissional que constituem elementos característicos da reconfiguração das relações profissionais.

\section{Subcategoria 2.2 Interesses profissionais limitam a ampliação do escopo das profissões para atender às necessidades de saúde dos usuários}

A prática e a EIP estão relacionadas com a convivência entre as diferentes categorias profissionais. Cabe considerar que o espaço de atuação profissional é delimitado pelas associações profissionais, que muitas vezes impedem atenção à saúde em regiões do país, nas quais não há profissionais com a formação adequada. Os profissionais disponíveis são impedidos de realizar procedimentos considerados privativos de outros profissionais, embora tenham a competência para tal.

Os entrevistados problematizam que o movimento da EIP poderia contribuir para ampliação do escopo das profissões, uma das possibilidades seria desenvolver protocolos clínicos para a realização de ações que contribuam para atenção das necessidades de saúde dos usuários do SUS. Postura que pode influenciar a mudança do marco regulatório das 
profissões, possibilitando o aproveitamento do potencial de conhecimentos e

habilidades dos profissionais de saúde, assim prevaleceria o direito à saúde

frente aos interesses corporativos.

(...) o termo 'interprofissional', porque tem a ver com a questão da convivência entre categorias profissionais diferentes. Tem a ver com a regulação do trabalho em saúde, né, e delimitação das diversas categorias. Isso é muito forte no mundo todo e no Brasil também é... Na própria experiência profissional, você tem regiões por exemplo, em que... uma carência enorme de profissionais e tem umas coisas que são irracionais, né. Essa questão do corporativismo é uma coisa muito séria dentro da saúde. Você ter uma enorme carência de profissionais, por exemplo... e alguém dizendo que um agente comunitário não pode verificar a pressão arterial, por exemplo... Acho um absurdo. A gente vai ter uma prevalência alta de pressão arterial. Essa prevalência vai aumentar nas populações .?., não é só o agente comunitário que tem que saber verificar, são todas as pessoas. O hipertenso tem profissionais que sabem verificar pressão. Então esse comportamento de querer... de algumas categorias profissionais, né, querer impedir que algumas coisas que são de necessidade, a regulamentação profissional não pode estar acima da necessidade de saúde da população. Principalmente curativos, alguns curativos simples a dona de casa tem que saber fazer. Aí você não querer que o agente comunitário saiba fazer... quer dizer... são coisas... São coisas... estou falando... da mesmo modo como eu convivi na região norte... a gente sabe que antibiótico só deve ser prescrito a maioria das vezes por um médico, mas na região norte você tem populações isoladas, tem uma carência enorme de profissionais... Se esse profissional por protocolos, por diretrizes clínicas que são internacionais, aceitas no mundo todo, como as ações integradas na infância, que eu trabalhei com um protocolo... que eu trabalhei... e esse trabalho interprofissional pode ser usado pelo médico... ele trabalha com síndrome... o diagnóstico a partir de síndromes... e a partir de sinais que você pode verificar com facilidade. Então, você ter... eu acho que isso talvez... sejam as situações mais marcantes para mim, que me marcam mais no sentido... porque fere o direito humano. É quando um interesse de uma corporação pode ferir o direito humano. Porque aí você ter uma criança, vamos supor na região norte... porque na região nordeste a gente enfrenta isso, mas muito menos, né... porque hoje o acesso ao profíssional de saúde, ao médico... hoje mesmo na região nordeste está melhor, mas mesmo aqui (...) você vai ter áreas isoladas, que no final de semana você não vai ter nenhum médico. E na região norte é pior. Vamos supor que você tenha uma criança que vive lá e esteja com apneia... que esteja dentro do critério de uma pneumonia, e aí você... só o médico deve prescrever aquele. A regulamentação profissional não pode estar acima do antibiótico? Isso pode... é um risco de das necessidades da população e à vida... Então são essas coisas que assim... eu acho muito fortes e que eu vejo que... e por isso também eu acho que a gente tem que trabalhar com o conceito de 'interprofissional' para a gente poder se situar dentro do campo da regulação profissional, da relação entre as profissões... para poder compreender e trabalhar com esses parâmetros (D15 - médico).

Uma barreira significativa para a EIP é a implementação de políticas

de formação destinadas à áreas específicas que não valorizam a articulação

do saber com outras áreas profissionais. As profissões se caracterizam pela

especificidade de um saber e por ações privativas, porém torna-se necessário 
a articulação entre as práticas. O entrevistado considera que esse tipo de perspectiva fragiliza as possibilidades de construção do saber interdisciplinar, reforça a fragmentação, a valorização das especialidades e das associações profissionais. $\mathrm{O}$ foco das práticas na especificidade profissional, representa um movimento de exclusão dos demais trabalhadores das intervenções que são privativas e reguladas pelas associações profissionais que cumprem o papel fiscalizatório sobre as ações. Nesse contexto, defende a importância dos trabalhadores transitarem entre as áreas do saber.

$\mathrm{O}$ que eu me lembro muito, que gostaria de... nessa oportunidade de registrar, foi um certo espanto da faculdade de medicina e muito especialmente do INAMPS, pelo menos o pessoal mais conservador do INAMPS, pelo fato de uma residência com o nome de medicina social e enfermeira participando. E ainda mais que no seu certificado de conclusão, que era o curso de especialização sob a forma de residência em medicina social, a enfermeira tivesse um título de residente em medicina social. Mas pior do que o espanto foi uma política que a partir de uma mudança que fizeram em uma resolução... da Comissão Nacional de Residência Médica, que praticamente inviabilizava a inclusão de pessoal não médico para participar da residência. Isso foi uma briga... foi uma das primeiras brigas da ABRASCO, da Associação Brasileira de Saúde Coletiva. Mas como o INAMPS financiava as bolsas e a direção do INAMPS, que era responsável por essa parte vetou o trabalho com profissional não médico, nós fomos obrigados nas próximas seleções não incluir o pessoal de enfermagem. Isso me marcou, foi uma briga política e a própria ABRASCO teve um certo papel nessa história. então essa foi uma experiência que para mim teve um... uma dimensão mais até política, institucional do que propriamente pedagógica você vê, a interação que a gente desenvolvia, a perspectiva de trabalhar com a questão do cuidado que a enfermagem trazia muito nas discussões, de aproximação com as dimensões sociais, porque o curso de enfermagem tinha muito mais envolvimento de trabalho comunitário do que o curso médico, que ainda era muito concentrado no hospital escola. Quer dizer, todas essas situações tornavam as discussões muito ricas. $\mathrm{E}$ isso era positivo na nossa avaliação. E a perda foi perder uma ação profissional, com possibilidades de desenvolver algumas discussões mais de caráter interdisciplinar. Eu, como minha vida toda foi muito centrada em estudantes de medicina, eles trazem a ideologia médica, que vem da família, que vem dos professores, e isso sempre eu sempre problematizei com eles. Mas mesmo assim a gente tem notícias assim... bem negativas, como por exemplo, alguém começa a perguntar - sim, mas se é uma profissão, qual é mesmo a especificidade dela? -, ou seja, o que ela vai excluir os outros? Eu aprendi quando era menino que propriedade privada é aquela com a que eu privo os outros. Corporação é isso. Essas regulações que vão fazendo sobre as profissões, depois que expropriaram os saberes e as práticas da comunidade em relação à saúde, nós queremos cada vez mais expropriar de outros profissionais intervenções sobre esse objeto complexo que é saúde e doença. Por isso... mais anfíbios ou beija flores por aí, né? (D6 - médico).

A comunicação interprofissional pode ser prejudicada pelos

interesses coorporativos presentes na relação entre os profissionais da saúde, 
especialmente no tocante aos médicos que tem dificuldade em compartilhar o trabalho entre sua própria categoria profissional. O entrevistado aponta que a falta de confiança nos outros profissionais e a tradição cultural podem ser motivos para atuação individualizada do médico. Outras categorias profissionais expressam o receio de perda da identidade profissional e de sua filiação coorporativa que representa a perda do campo de trabalho no mercado em áreas ainda pouco consolidadas.

Então, no interior das práticas profissionais você tem também os interesses coorporativos ali presentes, mas tem também dentro de cada profissão a cultura predominante do modo de atuação, né, e algumas como é o caso do médico é de uma tradição autonomista muito grande. Mesmo quando o médico trabalha em equipe de médico, ele não consegue interagir com o outro médico, ele atua 'solo', ele refaz o raciocínio, sempre tem mais confiança no seu próprio no que no do outro. É complicado essa... que seria a base de um compartilhamento, você dar crédito ao outro, o que o outro faz, o que o outro pensa, minimamente. Então a tradição cultural é muito forte, no sentido de um... do individual no caso da medicina. Pode ser que em outras áreas profissionais menos, mas no caso da medicina isso também é... Mas eu acho que a cultura de cada profissão, a identidade que faz... e agora com essa novidade do receio da perda da identidade, né, portanto da perda da filiação corporativa... eu imagino que se alguém tem medo de perder a identidade da sua profissão deve ser porque vai ficar sem lugar no mercado e não vai ter quem defenda seus interesses. Deve se sentir muito só no mercado, porque a gente sempre recorre aos órgãos de apoio da categoria quando você tem algum problema (D2- médico).

Nelson, King e Brodine (2008), realizaram um estudo sobre a colaboração entre médicos e enfermeiros e destacam que quando esses profissionais colaboram, há impacto positivo para a qualidade do cuidado do paciente. Por isso, consideram a importância do desenvolvimento de uma nova cultura de colaboração entre as áreas com o reconhecimento das contribuições de cada um, compartilhamento das responsabilidades e igualdade do poder nas relações interprofissionais para o fortalecimento da qualidade do cuidado ao paciente.

O padrão de comunicação estabelecido entre os profissionais da saúde é um reflexo de sua inserção social. Wagner et al (2011), analisa o desenvolvimento de habilidades de comunicação inteprofissionais e aponta que a comunicação entre médicos e enfermeiros é um reflexo do seu papel. Os médicos predominantemente do sexo masculino, pertencem a altas classes sociais e possuem um padrão educacional mais elevado. As enfermeiras predominantemente do sexo feminino, possuem oportunidades 
educacionais inferiores, menor valor social e geralmente seguem ordens. Dada as diferenças profissionais, a colaboração interprofissional em prol da tomada de decisão para o cuidado do paciente nem sempre é uma norma (Wagner, 2011).

(...) outro grande desafio que eu considero é ainda uma visão, não temos uma cultura de trabalho em equipe, onde se faça uma discussão aberta de liderança. Ainda temos uma forte tendência a achar que liderança é de uma profissão, de no máximo de mais uma, que por exemplo quem pode estar liderando a equipe é o médico ou a enfermagem e os outros...ainda a supremacia do trabalho medico sobre o restante da equipe, são todos pontos desafiadores para esse trabalho (D1 - médico).

A hegemonia médica reflete no comportamento dos docentes e estudantes no contexto da formação teórico-prática nos campos de estágio. A seguir, o entrevistado destaca que o comportamento coorporativo nas relações profissionais gera tensões e estimula a competição. Por isso é importante buscar alternativas que favoreçam a colaboração, com entendimento de que os saberes são complementares e podem ser compartilhados.

E aí você tem as reações, então assim... se os alunos da medicina e alguns professores da medicina são... vem com uma empáfia assim... com muito 'eu sei, eu sou melhor, sou eu que coordeno a equipe, eu que faço isso melhor que vocês enfermeiros', os enfermeiros também reagem, e tem aí um campo muito de tensão. De competição, de ver quem é melhor. E aí toda essa idéia de compartilhar, de ter uma ação muito mais de grupo... ela fica bastante comprometida. Esse sempre é um desafio para a gente. Como é que a gente trabalha para ser grupo, como é que a gente trabalha para entender que os saberes são para se completar, para compartilhar. Sempre a gente tem muitos obstáculos (D12-médico).

O controle do trabalho médico sobre outras ocupações da área da saúde se expressa de diferentes maneiras e influencia a atribuição de menos prestígio às outras profissões da saúde, do que o outorgado aos médicos. O médico tende a ser responsável pela ampliação ou aprovação do conhecimento técnico utilizado por outras áreas. A natureza das práticas de saúde dos outros profissionais está mais relacionada com a assistência, do que ao diagnóstico e tratamento, sendo que, os dois últimos configuram aspectos centrais do modelo biomédico hegemônico. Por fim, pode-se afirmar que o trabalho dos outros profissionais da saúde é subordinado às decisões médicas (Freidson, 1978).

A dificuldade de articulação entre os profissionais pode ocorrer em virtude da ausência de horizontalidade nas relações, devido ao diferente status social das profisssões, especialmente do medicina. As interações 
profissionais são influenciadas pelo conhecimento e relações de poder que fragmentam o cuidado a ser realizado e o usuário em 'pedaços' que serão delegados a diferentes profissionais.

A falta de compreensão... eh... de que... e mesmo as diferenças de status, as... a relação muitas vezes que não é horizontal entre os profissionais. Alguns... principalmente profissionais médicos... por ser uma profissão mais antiga, uma profissão com maior status social... muitas vezes... Mas entre os outros profissionais também acontece. Não vou dizer que é só o médico, não, porque eu já vi, por exemplo, já convivi com o fato do agente de saúde que eu citei para você em relação em relação à enfermagem, com relação à fisioterapia... que é muito da relação entre conhecimento e poder, né. É de você achar que o outro não pode conhecer nem pode fazer, para você não perder o poder, seja o poder individual, seja o poder da sua corporação. E o poder significa também dinheiro, significa várias outras coisas, né. Poder econômico, poder social, poder político... Então, por exemplo, outro fato que estava me lembrando agora também... que eu... quando trabalhava como pediatra ensinava a fazer 'tapotagem' nas crianças as mães... e aí um profissional veio e me disse - não, não ensina... porque isso aí é trabalho meu -, eu vi um comentário também, era um médico inclusive, um editorial... acho que no jornal... Jornal Americano de Saúde Pública, dizendo: a questão vai a um ponto que você vai ter que ter, para orientar uma mulher para amamentar, você vai ter que ter um enfermeiro para dizer a posição, como pega o bico, como o menino abre a boca, um nutricionista para ensinar para ela quais os benefícios que tem, o conteúdo protéico, de vitaminas que tem o leite materno... Um não sei o que para fazer outra coisa... quer dizer... é você... é a fragmentação de nosso objeto de trabalho que é a pessoa humana, né. Como a gente pode fragmentar dessa forma? Por isso que a gente tem que ter sempre as famílias..., profissionais (D15 médico).

De modo correlato às práticas, a aprendizagem ou formação em saúde segue e reproduz o prestígio, a independência e a responsabilidade atribuída ao trabalho. O controle e a autonomia sobre a educação conferido por ocupações de elite, influenciam a diferenciação das ocupações. A enfermagem foi designada como uma parte da divisão técnica do trabalho da medicina (Freidson, 1978).

O depoimento a seguir destaca que os estudantes de medicina representam uma elite na sociedade e reproduzem tal status social nas relações intersubjetivas. Contudo, acredita que o sucesso profissional dependerá de práticas compartilhadas.

Que a gente patina muito, como estou te falando, não é fácil isso. Você tem aqui uma elite de estudantes de medicina, eles acham melhores do que os outros. E a gente tem que estar trabalhando - você são melhores em algumas coisas, os enfermeiros são melhores em outras coisas, e obrigatoriamente o trabalho de vocês, o sucesso na profissão, vai dar muito mais certo se a gente tiver esse compartilhar das diferentes profissões (D12médico). 
Autonomia médica e isolamento na associação profissional, podem representar barreiras para a interprofissionalidade. O entrevistado afirma que a profissão médica é tradicionalmente solitária, com dificuldade de se imaginar em um processo de parceria com os demais, já que as principais parcerias estabelecidas nesta prática são exclusivamente entre médicos.

O fato de que trabalhar sozinho... como sempre digo, que a medicina é tipicamente uma profissão solitária. Consultório, porque ela nasce em um consultório, nasce como um médico e um paciente... um e um, e não tem mais ninguém. Então ela carrega, digamos, esse... é um fardo, é um certo fardo da solidão. Por isso sempre dentro da medicina em diferentes épocas históricas, os médicos buscaram exercitar certos coletivos de discussão. Assim, a junta médica, os conselhos, o médico mais velho trabalhar com o mais jovem, o mais jovem com o mais velho para poder ter essa referencia. Isso é muito comum, mesmo que não tenha nenhuma formalidade, isso sempre aconteceu. Porque é muito duro você estar completamente só para tomar uma decisão. Mas, tem essa característica, de ser uma profissão solo, solitária, né. E não se imaginar nunca com os demais (D2- médico).

O único critério capaz de diferenciar as profissões das ocupações é a autonomia, uma posição de legítimo controle sobre o trabalho. A autonomia é resultado da interação entre poder político, econômico e representação ocupacional, que pode ser facilitada por instituições educacionais que convencem o Estado sobre o valor do trabalho daquela ocupação (Freidson, 1978, p.93).

As profissões consistem em uma lógica de organização social do trabalho que na área da saúde se expressa com o controle da medicina sobre a definição do seu conteúdo e saber técnico-científico. O controle sobre o trabalho ou a autonomia técnica consiste no poder profissional. Desse modo, a medicina exerce um monopólio sobre o conhecimento da área da saúde que contribui para hierarquizar as outras ocupações (Bonelli, 1998).

Freidson considera que as relações interprofissionais consistem em uma organização social que condiciona o resultado das interações (Bonelli, 1998, p. 20). Contudo, o médico desenvolve seu trabalho predominantemente orientado para o individualismo profissional.

Apesar do conhecimento e autonomia garantirem o poder às profissões, Freidson destaca que a definição da doença deveria ser um atributo das famílias e dos pacientes, pois em uma sociedade caracterizada pela liberdade, o papel das profissões deve estar restrito à contribuição técnica para que os pacientes baseados em seus valores pessoais, possam 
tomar suas próprias decisões, sem o direcionamento ou constrangimento do profissional da saúde (Bonelli, 1998).

A profissão depende de uma formação específica para obter posições no mercado de trabalho e credenciamento profissional que possibilita uma reserva de oportunidades no mercado e excluem aqueles que não tem qualificação exigida (Freidson, 1998).

A profissionalização ocorre em decorrência do direito de executar o trabalho e controlar a formação para sua prática. Afinal, a organização na qual o profissional trabalha, pode controlar os recursos relacionados ao seu trabalho, mas não pode controlar o modo de realizar as atividades pela maior parte dos trabalhadores que exercem ocupações profissionalizadas (Freidson, 1998, p. 99). A administração pode controlar os termos e as condições do trabalho em virtude de um mercado de trabalho comprador, mas o trabalhador profissional controla o próprio trabalho, e o próprio trabalho é a chave da produção (Freidson, 1998, p.100).

O entrevistado considera a importância da formação médica articulada com outras áreas da saúde, a fim de estimular a mudança do modelo médico hegemônico para reconfiguração das relações profissionais e estabelecimento do trabalho em equipe. Ressalta que os docentes da área reforçam o status médico durante a formação.

Eu acho fundamental na formação do médico conviver durante a graduação com outros profissionais e com alunos de outras profissões. Não só os alunos, mas com os professores das outras carreiras, para a gente ter também uma mudança no modelo médico, que ele também esteja preparado para trabalhar em equipe, e não achar que ele é a equipe. Fazer o inverso. E infelizmente na escola médica poucos docentes tem essa clareza. A maioria dos docentes ainda forma o aluno e diz assim - o médico tem que ser arrogante e é ele que (D14 - enfermeiro).

Orchard (2010), destaca que há uma lacuna entre a prática interprofissional em equipe e o preparo para a mesma na maioria dos programas de formação, assim como na enfermagem. Essa falta de preparo pode resultar em dificuldades na compreensão da linguagem utilizada pelos profissionais, afinal, a comunicação ainda não está padronizada e a necessidade de informação que os enfermeiros possuem para realizar o cuidado pode ser irrelevante para outros profissionais da equipe. Desse modo as práticas de enfermagem, assim como a de outros profissionais, podem ter o potencial de gerar conflitos. É necessário o claro entendimento 
dos papeis profissionais, conhecimentos e habilidades na prática diária para evitar o tribalismo e aumentar as possibilidades de tomar decisões compartilhadas.

O entrevistado afirma que proporcionar espaços de encontro com outras áreas no contexto da formação provoca estranhamento e aproximação, porque tradicionalmente realizam atividades separadamente.

(...) de estar com os outros. Se eu estou só com enfermeiros, a gente tem... sei lá... né... tem professor da medicina que fala que a gente é uma maçonaria... Cada profissão tem... é, não deixa ninguém entrar... mas eles também fazem isso, os farmacêuticos também fazem... Quando a gente circula junto, por isso que eu falei para você que o fato da gente circular coloca a gente estranhando e se aproximando, faz isso de outro jeito, a conversa tem que ser em outro tom. Então, o programa... os programas hoje tem uma característica muito interessante. Somos mais enfermeiros, mas tem um grupo grande de outros profissionais que circulam com a gente. Então isso é muito legal, muito legal. Acho que isso dá um outro tom para a formação, para a produção também (D11 - enfermeiro).

Ocupar o mesmo ambiente não garante práticas interprofissionais, pois dependem do reconhecimento da importância do outro, o que ele faz e qual resolutividade terá. $\mathrm{O}$ entrevistado que representa uma categoria profissional diferente da medicina, considera que o encontro com estudantes de outras áreas contribui para promover articulação interprofissional.

Estar no mesmo espaço, conviver nesse espaço, não garante as práticas que sejam interprofissionais, ou não garante, na verdade, um espaço que seja multiprofissional propriamente dito no sentido assim... de compor para aqueles pacientes. Nitidamente a gente vê na área, mas elas (as fonoaudiólogas) tem uma sensibilidade eu acho para entender a importância do outro. Que é diferente do aluno de medicina, ele não sabe que o outro... o que outro faz, que o outro existe... a importância, a resolutividade que isso vai ter. No entanto, quando a gente começa no (...) desde cedo a falar disso e eu sou fono e dando aula para alunos de medicina, então isso cai como uma luva, não tem problema nenhum, né? (D13 - fonoaudiólogo).

Outro aspecto relacionado a influência das associações profissionais são as relações de poder, que também se expressam nos espaços de potencial desenvolvimento da formação inteprofissional, nas universidades e nos serviços de saúde e podem constituir barreiras para o avanço das práticas colaborativas intersubjetivas. Nos depoimentos, o poder está relacionado com: o saber instrumental técnico científico dos trabalhadores dos serviços e dos docentes, a gestão fragmentada dos serviços de saúde e a hierarquização das práticas de saúde.

$\mathrm{O}$ relato a seguir destaca que as relações de poder existentes nos serviços dificultam o desenvolvimento do processo de formação. O 
entrevistado refere que o profissional utiliza o conhecimento específico de sua área como um instrumento de poder, que inviabiliza a possibilidade de mudanças, pois o profissional se recusa a realizar uma atividade diferente daquela que está habituado a desenvolver.

(...) pode aparecer como resistência a compartilhar, então fico fechada no meu papel, que construí, que acho que é o que eu tenho que fazer e não arredo pé. Também lembrei de um relato ontem, de um aluno da graduação, de São João del Rei. Ele estava comentando que eles precisam da supervisão do psicólogo. O psicólogo do serviço é um supervisor direto do estágio deles ali na unidade básica, saúde da família. Essa psicóloga exige que eles ajudem a atender individualmente na unidade. E aí um debate se estabelece porque o Estágio é em psicologia comunitária e não em psicologia clínica, individual, tradicional... mas... mesmo que fosse clínica poderia ser de outro jeito. Então fica esse debate. A profissional vira e fala - bom, gente, se vocês não fazem isso eu não posso... não tenho nada a fazer com vocês -, ou seja, ela não vai supervisionar esses alunos porque eles não assumiram aquilo que ela espera que eles assumam. Porque fica nessa... é difícil ter diálogo quando você se fecha em um papel e não consegue... E isso se reflete na equipe, quando as pessoas sentam... os profissionais sentam para conversar, eu fico fechada no meu ponto, eu não consigo dialogar, não consigo compartilhar. Então tem várias situações desse tipo que acabam permeando... ela tem o poder de decidir o que ela pode e o que ela não pode na unidade. Nem o superior nem ninguém vai dizer para ela - esse lugar... não é isso que você tem que fazer - ou - não é só isso que você tem que fazer, tem que fazer outra coisa -. A gente vê isso em Botucatu também. Alguns profissionais que definem o que vão fazer e acabou... (D16-psicólogo).

O entrevistado aponta três diferentes maneiras de expressar o poder que têm impacto direto sobre a formação, tais como: o poder profissional da área médica, o poder de influência de um trabalhador sobre os colegas de trabalho e o poder do gestor que pode dificultar a criação de espaços de discussão coletiva com prejuízos sobre as relações interprofissionais.

(...) ninguém consegue... então assim... é uma expressão de poder. Tem as relações históricas de poder, o médico que acha que não tem que participar das reuniões... muitas vezes. Acho que na saúde da família isso diminuiu bastante mas ainda isso existe. Então ele fica muitas vezes à parte. Todo o resto da equipe se reúne, discute, mas... um profissional acha que não tem que estar naquele lugar. Não são todos, mas muitos ainda agem dessa forma. E não acontece nada com eles...é uma expressão de poder... é o serviço... é a Secretaria... precisa desse profissional de qualquer jeito, então melhor continuar assim do que não ter. E aí tem outros poderes internos assim... mais implícitos, né. De... então às vezes você tem situações em que a pessoa não tem nenhum cargo, não é coordenadora, não tem formação universitária e tal, mas é uma pessoa que junto com o grupo... no grupo tem um poder muito grande, uma influência muito grande. $E$ às vezes assim... é para o bem e para o mal... Para o bem e para o mal é modo de dizer, entre aspas aí, né, no sentido que pode boicotar tudo que é consensuado, discutido, compartilhado, como pode também colaborar para que a coisa caminhe. Então é... enfim... tem várias situações assim, que a relação de poder ela tem um impacto muito grande. Ou de gestão, saindo da gestão local e indo para a gestão municipal, por exemplo, a gente vê muitas situações em que a gestão municipal impõe um modo de agir internamente 
que é impeditivo... é impeditivo de se criar um espaço coletivo, de se criar possibilidades das relações interprofissionais ocorrer de uma forma mais... eh... vamos dizer assim, de construir mesmo o trabalho... de equipe... Então, têm várias formas (D16-psicólogo).

O entrevistado considera que para articular o conhecimento das áreas específicas e as competências comuns da área da saúde é fundamental humanizar a relação e reconhecer o outro. O saber estruturado inserido nas relações intersubjetivas é um mecanismo de expressão de poder que provoca o reconhecimento do outro em função do saber que ele domina.

(...) como equilibrar conhecimento produzido para áreas específicas e para áreas comuns, que é fundamental, porque senão você perde a interlocução, mas ao mesmo tempo ter o tempo necessário para o processamento do ensino. E não é o ensino de máquinas, porque eu acho que isso que diferencia. Ensino de gente que vai cuidar de gente. E aí tem que reconhecer o humano que está no outro. Independente de eu ser médica, enfermeira, dentista, terapeuta ocupacional e assim por diante. (...) porque eu acho que cada um tem o seu feudo difícil de quebrar. Acho que o próprio conhecimento ele está tão estruturado, a prática está tão estruturada, e o saber é tão...específico, tão específico... e que conforma um jeito mais endurecido. Não sei se é isso, mas a primeira impressão que me dá é isso. Essa conversa entre o que é específico meu e o que é geral de todos nós não é uma tarefa fácil. Eu acho que ela não é fácil por vários motivos. Porque quanto mais eu sei mais eu fico 'empoderado', e as pessoas vão... vão querer conversar comigo que sei muito daquilo... então eu acho que é uma forma também de expressão de poder. Tem um pouco isso (D11 - enfermeiro).

O entrevistado afirma que o movimento de compartilhar, fragiliza o

indivíduo e reduz as possibilidades de status e reconhecimento do saber acumulado individualmente. O compartilhamento é indispensável frente a complexidade dos problemas apresentados que exigem alternativas de solução desconhecidas e não estruturadas, desse modo, é necessária a análise de cada caso com a perspectiva de diferentes saberes. Situação que reforça a importância do trabalho em equipe, prática interprofissional e EIP, que buscam o reconhecimento da complexidade das necessidades de saúde, a partir da ampliação da concepção de saúde, do ensino e do direito à saúde.

Compartilhar coloca às vezes em uma situação de maior fragilidade e exposição. Estou falando isso mais geral, nem do trabalho em saúde, na vida é assim... quando mais eu retenho, mais as pessoas me procuram, que eu sou a sabida da história. Na medida também que eu disponho e capilarizo isso para um conjunto maior, há possibilidade mesmo de exposição do não saber, do não fazer do que quer que seja... e isso também coloca em uma situação mais frágil. E acho que a gente tem disputas, as disputas estão colocadas o tempo inteiro. Não só naquilo que eu sei, mas no que eu sei e que me possibilita fazer coisas. Então, área especializada, muito especializada acho que traz essa característica. Algumas áreas, acho que a área que você trabalha, que eu trabalho, que é da atenção primária, é uma área que a gente tem muita... vou usar o termo que a medicina tem usado, que é 'muita situação mal definida'. Hoje tem 
uma areazinha lá que é 'problemas mal definidos na saúde'. Tem até assim no referencial, tem gente estudando, tem gente buscando identificar... - eu não tenho dor no joelho, não tenho dor no tornozelo, eu tenho dor no meio da perna. Tem um problema assim... muito mal estruturado. E a hora que vem muito mal estruturado, como pode ser tudo, às vezes só o que eu sei não resolve, tem que ser o que eu sei, mais o que você sabe, mais o que outro sabe... Na área especializada, quando vai para um especialista a situação... ela vai muito estruturadinha. Então é a dor aqui, mas eu já fiz um exame, eu já vi que não é osso quebrado, eu já vi que não é músculo afetado, mas tem uma questão de transição nervosa, então vou para o neurologista com essa dor -. E quando chega lá já está muito estruturadinho, já fez esse exame, já fez isso... né... então ele chega com uma coisa bem recortadinha. A nossa área não. Desde a história da clínica com problemas mal definidos até com situações que exigem uma ação mais assim... transversalizada, de várias áreas. Então acho que é difícil por isso, porque eu acho que a gente é muito prescritivo. Então é mais fácil na especialidade ser prescritivo do que ser analista de contexto. Talvez por aí... (D11 - enfermeiro).

No modelo de produção industrial de bens e serviços que resulta na divisão técnica do trabalho como modo de organização das práticas (Pires, 2009), são estabelecidas tarefas definidas e supervisionadas hierarquicamente que contribuem para a alienação objetiva e subjetiva do trabalhador em relação ao trabalho por ele realizado (Freidson, 1998; Pires, 2009).

Este processo configura a autonomia profissional e a autorregulação como características da profissão médica, que no mesmo processo histórico de constituição das práticas de saúde na modernidade, configura a ação/intervenção do médico como ação nuclear em torno da qual se organiza o trabalho em saúde.

O entrevistado aponta a fragmentação das práticas, a partir da delimitação de diferentes áreas profissionais, cada uma buscando concentrar saberes e práticas específicas de sua atuação.

Ela é mesmo tão fragmentada ou existe uma comunicação... Por que ela não é mais articulada? Então tem a questão que dos espaços profissionais dos campos e dos sub campos... o campo médico, a hegemonia do campo médico... Mesmo se você for pensar a própria... o espaço da enfermagem, quer dizer, é um espaço que busca se delimitar, dizer o que é estar na enfermagem, qual a minha autonomia, o que não é... e delimita de outras profissões e de outros grupos profissionais, que é a idéia de campo de Bourdieu (D8- Médico).

O entrevistado defende que o conhecimento especializado confere status social ao profissional da saúde, especialmente no imaginário do profissional médico, que tende majoritariamente a se tornar um especialista para área hospitalar. 
Então, a opção do estudante de fazer... o médico, fazer uma especialidade médica na área hospitalar, em detrimento de optar pela medicina de família, também tem várias causas. Tem a questão do status que está envolvido nisso. E eu creio que não é só um problema financeiro. Primeiro também a atenção primária tem alguns desafios. Se você for trabalhar em uma cidade pequena, tem a questão do isolamento, o isolamento profissional, você trabalhar com nenhum ou com poucos colegas... você está afastado da produção do conhecimento, então isso é uma coisa que o médico sente muito. Eu acho que todos os profissionais, mas o médico como tem essa coisa da especialidade, tem um status, uma força dentro do imaginário do profissional médico muito grande, isso ainda é maior (D15 - médico).

A seguir, o entrevistado relata que as relações de poder entre as áreas

profissionais representam um impedimento para o avanço de propostas de

EIP. Indica que o poder se expressa no saber técnico-científico, desenvolvido na profisssão, reiterado na associação profissional e no status social proveniente da especialidade técnica e científica, processo de trabalho que resultará no comprometimento da atenção às necessidades de saúde dos usuários/comunidade.

(...) bom, impedimento é o preconceito, eu acho. Impedimento é a falta de compreensão sobre essa necessidade, eu acho. A falta de compreensão... eh... de que... e mesmo as diferenças de status, as... a relação muitas vezes que não é horizontal entre os profissionais. Alguns... principalmente profissionais médicos... por ser uma profissão mais antiga, uma profissão com maior status social... muitas vezes... Mas entre os outros profissionais também acontece. Não vou dizer que é só o médico, não, porque eu já vi, por exemplo, já convivi com o fato do agente de saúde que eu citei para você em relação em relação à enfermagem, com relação à físioterapia... que é muito da relação entre conhecimento e poder, né. É de você achar que o outro não pode conhecer nem pode fazer, para você não perder o poder, seja o poder individual, seja o poder da sua corporação. E o poder significa também dinheiro, significa várias outras coisas, né. Poder econômico, poder social, poder político... Então, por exemplo, outro fato que estava me lembrando agora também... que eu... quando trabalhava como pediatra ensinava a fazer 'tapotagem' nas crianças as mães... e aí um profissional veio e me disse - não, não ensina... porque isso aí é trabalho meu -, eu vi um comentário também, era um médico inclusive, um editorial... acho que no jornal... Jornal Americano de Saúde Pública, dizendo: a questão vai a um ponto que você vai ter que ter, para orientar uma mulher para amamentar, você vai ter que ter um enfermeiro para dizer a posição, como pega o bico, como o menino abre a boca, um nutricionista para ensinar para ela quais os benefícios que tem, o conteúdo protéico, de vitaminas que tem o leite materno... Um não sei o que para fazer outra coisa... quer dizer... é você... é a fragmentação de nosso objeto de trabalho que é a pessoa humana, né. Como a gente pode fragmentar dessa forma? Por isso que a gente tem que ter sempre as famílias..., e trabalhar sempre com sistemas. As pessoas fazem parte de famílias, fazem parte de comunidades, então, quer dizer, não faz sentido... você realmente precisa trabalhar em equipe... não é possível você trabalhar mais só. Não é que não seja possível, é que para muitas situações que a gente enfrenta hoje, principalmente no campo da saúde pública... um trabalho isolado não vai ter a repercussão necessária, para a saúde pública no país. Precisa do trabalho interprofissional. Quando você pensa no efeito do sistema de saúde, para a saúde da população (D15médico). 
No próximo relato, destaca-se que a competição entre as áreas profissionais provoca tensão e prejudica as possibilidades de compartilhamento e reconhecimento da complementaridade dos saberes.

E aí você tem as reações, então assim... se os alunos da medicina e alguns professores da medicina são... vem com uma empáfia assim... com muito 'eu sei, eu sou melhor, sou eu que coordeno a equipe, são eu que faço isso melhor que vocês enfermeiros', os enfermeiros também reagem, e tem aí um campo muito de tensão. De competição, de ver quem é melhor. E aí toda essa idéia de compartilhar, de ter uma ação muito mais de grupo... ela fica bastante comprometida. Esse sempre é um desafio para a gente. Como é que a gente trabalha para ser grupo, como é que a gente trabalha para entender que os saberes são para se completar, para compartilhar. Sempre a gente tem muitos obstáculos (D12-médico).

A seguir o entrevistado afirma que a medicina desenvolve uma

prática 'solo', isolada, marcada pela falta de confiança no saber dos demais

profissionais da saúde, característica fundamental para o compartilhamento.

No planejamento das instituições isso é óbvio também, quer dizer, os interesses que são de mercado, corporativos, quase sempre prevalecem na montagem de subsistemas de serviços, de redes, é muito .?., não estão voltados para a interação entre si, mas para interesses que são conflitantes do ponto de vista econômico, político, de autoridade profissional e prestígio, né... super complicado. Então ultrapassar isso não é muito simples. E no plano da prática propriamente profissional, que eu faço sempre essa divisão, que me ajuda muito, quer dizer, o que se passa na esfera das políticas, o que se passa na esfera da organização e distribuição dos serviços e redes de serviços para o conjunto da sociedade e o que se passa nas práticas profissionais no interior dos serviços. Então, no interior das práticas profissionais você tem também os interesses corporativos ali presentes, mas tem também dentro de cada profissão a cultura predominante do modo de atuação, né, e algumas como é o caso do médico é de uma tradição autonomista muito grande. Mesmo quando o médico trabalha em equipe de médico, ele não consegue interagir com o outro médico, ele atua 'solo', ele refaz o raciocínio, sempre tem mais confiança no seu próprio no que no do outro. É complicado essa... que seria a base de um compartilhamento, você dá crédito ao outro, o que o outro faz, o que o outro pensa, minimamente. Então a tradição cultural é muito forte, no sentido de um... do individual no caso da medicina (D2 - médico).

Outra barreira destacada no relato a seguir se refere à dificuldade dos

docentes transitarem entre áreas de formação diferentes das quais são especialistas, visto o desconforto frente ao não saber e à necessidade de aprender sobre outras área.

(...) insegurança daquilo que eu nunca fiz. Pessoas que fizeram o seu quadradinho há $10 \ldots 20$ anos e estão aqui no seu próprio quadradinho disciplinar. Então, de pensar que eu tenho que ir para a atenção básica, saúde da criança... 'eu sou da saúde da criança, mas eu só fui no hospital'... Então já cria uma resistência. Então eu acho que tem esse medo de viver o novo. De se sentir incapaz de pensar em uma metodologia mais inovadora. E uma outra coisa que do meu ponto de vista é a grande razão de tudo é porque fazer isso novo dá muito mais trabalho. Muito mais trabalho, então, eu prefiro ficar onde eu estou, que ninguém me mexe, eu faço isso há 20 anos, eu vou continuar fazendo. Então, o medo do novo, a insegurança e o 
medo de mais trabalho... essa é a análise que eu faço aqui nesses anos que estou aqui convivendo com os docentes da enfermagem, sou amiga de $80 \%$ delas, pessoas que já conhecia antes de vir para cá... que trabalhei em Marília. Silvia(?) e eu trabalhamos em Marília juntas... tem duas aí que fizeram mestrado comigo... então já conhecia. Então, não conseguem mudar. Então, o avanço aqui de pensar uma formação interprofissional, aqui vai ser muito lento (D14-enfermeiro).

Por um lado, a cultura profissional estimula a permanecer na zona de conforto, sem negociar e aprender com o outro, por outro, o movimento em prol da EIP, requer a habilidade de negociar e aprender com o outro, em um processo de convivência e respeito às diferenças e especificidades. Portanto, torna-se necessária a reconfiguração das relações profissionais com a ampliação do escopo das diferentes práticas profissionais, visto que as profissões continuarão a existir por um médio ou longo tempo.

O problema da cultura é um grande gargalo, a nossa cultura previa estabelecida né, os nossos preconceitos. Cultura...desafio mesmo não é fácil, é sair da comunidade, partir para uma outra proposta de formação interprofissional é sair do conforto, que é você com seu grupo. É sair deste conforto, é negociar, é partir para negociar, é partir para aprender com o outro e não achar que o nosso aprendizado é único ou mais importante. Então aí vai, é o desafio realmente do conviver, respeitar que somos diferentes, que temos especifidades mas que temos pontos comuns e podemos crescer juntos. Isso é desafiador, é muito mais fácil cada um ficar na sua casinha né, muito mais fácil. Isto não é uma coisa só nossa (...) sair da zona de conforto, do corporativismo, que existe entre as profissões da área da saúde. Então o desafio começa por aí, você acaba desembocando na falta de capacitação docente para um ensino diferente (D1 - médico).

As associações profissionais contribuem para o estabelecimento do poder profissional e dos limites profissionais de atuação das respectivas áreas, bem como o modo de interação com outros profissionais e os usuários (Freidson, 1998; Rivera, 1996, 2003).

A subcategoria 'Interesses profissionais limitam a ampliação do escopo das profissões para atender as necessidades de saúde dos usuários' mostra que a busca pela preservação de práticas privativas pelas associações profissionais, a fragmentação entre as práticas no processo de divisão técnica do trabalho, a prática especializada caracterizada por jargões comunicativos de determinada área profissional, o predomínio do saber médico sobre as ações dos demais profissionais da saúde, as relações de poder e a competitividade entre os profissionais, são elementos que representam os interesses segmentados das diferentes áreas profissionais, em detrimento ao foco nas necessidades de saúde dos usuários. 
Para a superação da ênfase das práticas de saúde organizadas em torno dos interesses de cada segmento profissional, torna-se necessário uma reconfiguração das relações profissionais em prol da comunicação, cujas ações estejam centradas nos usuários.

\section{Subcategoria 2.3 As interações interprofissionais pressupõe o respeito ao outro}

Nesta subcategoria são analisados relatos que indicam o respeito ao outro como um elemento que constitui as relações interprofissionais colaborativas centradas no usuário.

As interações sociais estão pautadas em uma ética que representa um conjunto de valores que remetem à manutenção do respeito ao outro e proporciona uma abertura que possibilita o estabelecimento do vínculo e confiança necessários no processo de interação interprofissional.

E não de uma ética mais interativa... se podemos falar assim, né, de uma ética assim, de uma ética assada... mas de fato são conjuntos de valores acerca das relações, interações, diferentes. Um eu interajo com um interesse, respeito ao outro, e abertura a esse outro. Outra eu interajo externamente a esse outro, então interajo porque sou obrigada a ter certas relações em comum, comerciais, de troca. De um certo ponto de vista filosófico isso não seria ético até... mas vamos imaginar que na agenda de valores são valores que foram sendo estruturados como éticas de relações sociais diferentes nesse sentido. $\mathrm{E}$ isso falta para todo mundo na sociedade contemporânea para poder interagir (D2- médico).

Os valores éticos fazem parte do conjunto de competências para a prática interprofissional colaborativa. Estão relacionados ao trabalho em cooperação com os usuários que recebem e participam do cuidado, aos profissionais e outros que contribuem para o tratamento e prevenção nos serviços de saúde. Tal competência se refere à construção de uma identidade profissional de dupla face, voltada tanto para identidade profissional, assim como a interprofissional (IPEC, 2011; Khalili et al., 2013). Em virtude do estabelecimento de práticas comuns, o grupo da IPEC definiu o profissionalismo interprofissional como:

Consistente demonstração de um conjunto de valores que evidenciam que os profissionais estão trabalhando juntos, aspirando e aplicando princípios de altruísmo, excelência, cuidado, ética, respeito, comunicação e responsabilização por manter a saúde dos indivíduos e comunidades (IPEC, 2011, p.17). 
Os valores presentes nos relacionamentos entre os profissionais, nas interações com os pacientes, na qualidade das trocas entre os envolvidos nas práticas de cuidado, fazem parte dos aspectos éticos interprofissionais para o desenvolvimento de políticas e programas de saúde (IPEC, 2011). As dez principais competências identificadas pela IPEC (2011) para o desenvolvimento do trabalho interprofissional com respeito mútuo e compartilhamento de valores envolvem o respeito às diferenças e aos interesses dos pacientes, sua cultura e dos profissionais, trabalho em cooperação e o desenvolvimento de relações de confiança entre pacientes, famílias e profissionais.

Vázquez (1982) aponta a existência de dois principais tipos de ética: a normativa e a teórica. A normativa tem como função elaborar recomendações, formular normas e prescrições. A ética teórica busca explicar a natureza, e condições da moral, relacionadas com as necessidades sociais.

O compartilhamento de um horizonte ético normativo é a base para o agir comunicativo, de acordo com Habermas (1989), a comunicação ocorre quando as pessoas se colocam em interação na busca de um acordo pelo reconhecimento intersubjetivo das pretensões de validez. Nos atos de fala ligados às normas, destacam-se as pretensões de validez das normas que constituem o fenômeno de uma ética filosófica explicativa. Quando ocorre a infração de uma expectativa normativa de comportamento reconhecida por um grupo social ou até mesmo, no tocante à normas estritas, a interação entre duas pessoas pode ser perturbada, com a manifestação de reações afetivas como indignação e ressentimento.

A verdade das proposições significa a existência de estados de coisas assim como, analogamente, a correção das ações significa o preenchimento de normas (Habermas, 1989, p. 80).

A ética do discurso pressupõe que uma norma pretenda validez, quando todos os sujeitos em interação chegarem a um acordo sobre a validez da norma, com o propósito de atingir o princípio de universalização. A universalização é uma regra que possibilita o acordo em discursos práticos (Habermas, 1989). 
O discurso prático ocorre quando os sujeitos reconhecem uma discordância por referência ao plano normativo e buscam reconstruir a ação comunicativa que se estabelece, quando convencidos argumentativamente de que a norma em pauta é igualmente boa para todos, ou seja, trata-se de uma norma justificada. Nesse processo, a argumentação deve evitar que alguns prescrevam aos outros 'o que é bom', pois se busca a imparcialidade da formação de opinião e a autonomia de formação da vontade, para que cada sujeito tome suas próprias decisões com liberdade (Habermas, 1989).

No próximo excerto, o entrevistado revela acreditar que a EIP pode contribuir para o desenvolvimento do respeito pelo fazer do outro, que repercute no respeito ao usuário. A cultura do respeito profissional, como expressão da dimensão ética da EIP, pode ser construída no movimento de parceria e colaboração proposto pela EIP mediante o exercício da empatia.

Olha, talvez o meu desejo, mais do que resultados, é que isso proporcionasse para cada um de nós, ao menos, o respeito pelo fazer do outro. Ao menos isso, do ponto de vista individual. E que isso pudesse traduzir também, ao menos, o respeito de quem a gente está cuidando. Porque hoje eu acho que os campos muito específicos de cada um de nós eles estão sendo marcados por um profundo desrespeito. E para com você e nós duas para com a garrafa. Sabe? Então isso... assim... tanto quando a gente se coloca no papel de usuário, quando a gente se coloca no papel de professor, como quando a gente se coloca no papel de parceiro de uma outra categoria profissional. Então assim, acho que meu grande desejo inicial era isso. A gente acho que consegue construir respeito um pelo outro quando a gente se coloca no lugar do outro. Então... alteridade, não ser bonzinho... Não, não é isso. Mas se eu me colocar no lugar do outro eu posso também, ao me colocar no lugar do outro, eu carrego para o lugar do outro desejos, o que eu espero, o que eu quero. Então, quando tem isso acho que eu não vou querer ser mal atendido, eu não vou querer ser mal tratado ou que façam alguma coisa do ponto de vista técnico para mim que seja ruim... né. Então, eu desejaria no mínimo isso, né. Que a gente tivesse respeito, a saúde tem falado que isso é (...) (D11 enfermeiro).

O trabalho colaborativo pautado na prática ética inclui o respeito às outras culturas, valores e crenças presentes na participação do usuário e na atenção aos limites impostos pelas normas (Suter et al., 2009).

A relação entre o profissional da saúde e o usuário deveria ser interativa. Contudo, geralmente considera-se que no plano social representam desiguais autoridades técnicas e científicas e se estabelece uma relação com interferência centrada no profissional (Schraiber, 1997). A desigual autoridade técnica e científica provoca assimetrias na comunicação entre profissionais e destes com os usuários. 
Às vezes a comunicação é separada dos atos físicos, cindida entre operação técnica e interação. A interação também pode ser separada entre dois tipos: conversa útil e aquela que não parece ser útil. Como resultado o profissional da saúde passa a disciplinar a vida dos usuários sem lhes conferir a possibilidade de escolha (Schraiber, 1997).

O complicado neste procedimento é que estamos separando o que é medicamente relevante para o raciocínio anatomopatológico, para o julgamento global do caso, pois nos inteirarmos do doente como um sujeito social global é muito importante para o sucesso de nossa proposição assistencial. Só que não percebemos isso logo de imediato! (Schraiber,1997, p.127)

No discurso prático do agir comunicativo entre o usuário e os trabalhadores da saúde, deveria ser preconizada a autonomia da vontade. Contudo, muitas vezes, predomina o comportamento prescritivo que é reforçado pela assimetria existente na relação entre profissional e usuário. Tal assimetria pode dificultar o estabelecimento do agir performativo, no qual, os sujeitos em interação falam e procuram entender o que é dito (Habermas, 1989; 2011).

A colaboração entre os profissionais, estudantes e entre profissionais e estudantes, pressupõe o mútuo respeito à diversidade, com a valorizarização da contribuição do outro (Barr et al, 2005).

A seguir, o entrevistado relata as principais características da prática interprofissional: o respeito ao outro, o reconhecimento do trabalho do outro, habilidades para interagir com o outro e a produção de equipes colaborativas.

O trabalho interprofissional permite discutir a regulação profissional e situar no campo entre as profissões eu acho que ela pode produzir equipes mais colaborativas, pode produzir profissionais de várias categorias que se respeitam entre si, que sabem o que o outro faz, que sabem qual é o conhecimento que o outro tem, que tipo de competências o outro tem, como ele pode interagir com o outro... e conseguir um melhor resultado no seu processo de trabalho nesse processo de interação. Então, e profissionais capazes de... trabalhando em equipe resolver problemas complexos (D15 - médico).

Conviver e respeitar são princípios éticos para o trabalho em equipe, considerar as diferenças e negociar para aprender com os outros profissionais ou estudantes de outras áreas são aspectos fundamentais da formação interprofisssional.

(...) partir para uma outra proposta de formação interprofissional é sair do conforto, que é você com seu grupo. É sair deste conforto, é negociar, é partir para negociar, é partir para aprender com o outro e não achar que o 
nosso aprendizado é único ou mais importante. Então aí vai, é o desafio realmente do conviver, respeitar que somos diferentes, que temos especificidades, mas que temos pontos comuns e podemos crescer juntos. Isso é desafiador, é muito mais fácil cada um ficar na sua casinha né, muito mais fácil (D1- médico)

A comunicação é um dos principais determinantes para a colaboração interprofissional. A comunicação efetiva possibilita a negociação entre os profissionais e constitui um veículo para outros determinantes da comunicação, tais como, o respeito mútuo, a confiança e o compartilhamento da verdade mútua (Martín-Rodriguez et al, 2005).

Martín-Rodriguez et al. (2005), consideram os determinantes da interação na EIP relacionados ao compartilhamento de conhecimentos e habilidades profissionais, a definição clara dos papéis dos membros da equipe para facilitar a delegação e reduzir a duplicação de ações, a educação coletiva para a decisão e execução das ações em equipe para o sucesso das práticas colaborativas.

Frenk et al (2010), referem que o reconhecimento da interdependência das ações e profissões é fundamental para a interação que promove a educação interprofissional, com a quebra das barreiras profissionais, estabelecendo práticas colaborativas e relações mais horizontalizadas nas equipes de saúde.

Estudantes de diferentes áreas geralmente desconhecem o papel dos outros. Em geral, os estudantes tem poucas experiências de aprendizagem com estudantes de outros programas ou áreas. A EIP pode proporcionar o conhecimento de outras áreas profissionais e o desenvolvimento de habilidades interpessoais, que facilitam a troca de informações e a comunicação (Zwarenstein, 2009; MacDonald et al., 2010; Orchard , 2010; Ateah et al.,2011; Barwell et al., 2013).

O conhecimento dos papéis dos outros é uma competência chave para a prática colaborativa interprofissional centrada no paciente. As características comportamentais relacionadas a esta competência contribuem para sua melhor compreensão. Estudo recente, aponta sete principais comportamentos como: a capacidade de descrever em que momento termina a sua prática profissional e começa a do outro, dar abertura para as contribuições dos outros, sinalizar estereótipos de membros das equipes, 
respeitar os papéis, expertise e contribuições dos membros da equipe, identificar habilidades comuns e valores benéficos para fortalecer a colaboração das equipes, descrever diferentes perspectivas de conhecimento de outras profissões (MacDocnald et al., 2010).

O entrevistado considera a necessidade de buscar a composição dos saberes e experiências com tolerância e estratégias de negociação para construir um estilo de comunicação.

A outra coisa é a gente ter assim... vou chamar de tolerância, ter uma certa tolerância para o trabalho. Não sei como constrói a tolerância. Mas acho que a tolerância é necessária, porque senão não escuta o outro. Então, não quer dizer que eu tenho que fazer composição de amigos, porque também trabalhando entre amigos a gente também não sai da mesmice. A diversidade acho que faz a gente compor de uma outra maneira (...) Então a tolerância talvez fosse criar mecanismos da gente negociar caminhos, negociar formas. (...) E eu acho que às vezes a gente tem no interior das profissões um ambiente mais coercitivo para as pessoas se colocarem. Não quer dizer a outra ponta, que eu tenho um ambiente extremamente liberal. Não, eu acho que a gente tem que ter uma composição. Por isso que eu falei da tolerância, negociação, porque eu acho que faz parte da gente ir construindo um jeito de se comunicar para isso. E de ir assinalando as diferenças. Então, tem a ver com a estrutura ou com uma opção pedagógica também (D11 - enfermeiro).

No próximo excerto, o entrevistado aborda a importância de

estimular o 'fazer junto', respeitando o saber do outro para ampliar a qualidade do cuidado. Ao reconhecer a necessidade de compartilhar com o outro para o trabalho em saúde, aumentam as possibilidades da integralidade do cuidado.

Mas o que dá para fazer junto? O que dá para compartilhar? Até uma consulta a gente pode atender junto, respeitando o saber do outro, e tentando introduzir novos campos para ampliar essa possibilidade, para qualificar esse atendimento individual. E também para pensar ações coletivas nos diferentes problemas que a gente vai enfrentando. (...)Vai desde esse campo de respeitar o outro, o saber e a importância do outro, e perceber que hoje na área da saúde eu não faço nada se eu não tiver esse compartilhar com o outro. Até você perceber, então, quanto engrandece a possibilidade da integralidade do cuidado se eu tiver esse compartilhar. Para mim essa é a grande questão que a gente tem que avançar. Fazer com que o aluno e o professor, porque eu acho que o (D12-médico).

A comunicação está apoiada em um norma ética, por isso a fim de manter os acordos éticos, alguns desafios relacionados às relações intersubjetivas entre os profissionais de saúde podem ser amenizados, com a interferência do coordenador da equipe. O coordenador pode favorecer a construção de espaços de diálogo, nos quais predomine o respeito, para promover um cuidado em saúde, articulado e integrado entre diferentes áreas. 
A gente fala tanto dessa coisa dos princípios... da escuta, do vínculo, para o usuário... e a gente às vezes esquece que esse movimento também tem que se dar...Então, esse exercício de ouvir o outro colega, que trabalha com você, que tem uma formação diferente, e tentar entender um pouco o que o outro faz, pensa e respeitar, não é uma situação tranqüila também quando a gente está em um trabalho de equipe. Eu acho que isso tem relação com questões de poder muito fortes, né, no trabalho. E isso vai minando de certo modo essa possibilidade também, dependendo de como isso foi construído, né. E um desafio... eu tenho defendido muito... Que assim... o papel de quem coordena nesse processo. De favorecer mesmo, favorecer que a equipe consiga dialogar, se ouvir, respeitar que o que um ou outro faz circule um pouco, e... eu vejo a dificuldade disso até no matriciamento, como função pedagógica. Então, é difícil o profissional ser capaz de explicar para a equipe como um todo, um procedimento que é necessário, na sua área, explicar por que é necessário... então essa conversa para poder facilitar a rede, um cuidado mais articulado, integral, que envolva os diferentes saberes. É difícil, então acho que é um desafio grande. O papel do coordenador é muito importante assim, no sentido de identificar as necessidades do grupo, identificar os emperramentos mesmo, que estão acontecendo, o que é preciso fazer... como potencializar essa... esse diálogo e essa inter-relação ali. Eu acho... eu defendo muito, esse papel é importante (D17- enfermeiro).

A ética consiste na ciência da moral, ou seja, expressa a teoria sobre comportamentos humanos, pautados nas normas morais vigentes na sociedade. O comportamento moral dos indivíduos está relacionado com a responsabilidade por seus atos. Pode-se dizer, que a ética envolve a análise teórica do comportamento, a partir da liberdade para a tomada de decisão e da responsabilidade moral que determinam os atos humanos no contexto histórico-social, individual e coletivo (Vázquez, 1982).

A abordagem científica da ética expressa a relação entre o comportamento moral, necessidades e interesses sociais. Nesse sentido, a moral é o objeto de estudo da ética, que cumpre o papel de expressar o melhor comportamento moral em dado contexto. A ética é definida como uma disciplina normativa que explica, esclarece ou investiga uma realidade teórica em busca da objetividade e racionalidade (Vázquez, 1982).

A ética não se limita a aspectos temporais, pois trata de situações universais válidas para qualquer moral. Considera os elementos históricosociais da moral e as mudanças nos valores, princípios e normas para compreender seu movimento e desenvolvimento (Vázquez, 1982).

Os depoimentos relacionados à dimensão ética necessária nas relações interprofissionais em prol da colaboração, também sinalizam a dimensão do reconhecimento do papel profissional das diferentes áreas, aspecto que consiste em um elemento muito importante para a EIP e merece 
destaque, por isso será abordado exclusivamente na terceira categoria que será discutida posteriormente.

A subcategoria 'As interações interprofissionais pressupõe o respeito ao outro' permite a compreensão de que o horizonte ético, pautado no compartilhamento do valor do respeito ao outro, consiste em um dos elementos necessários para o processo de reconfiguração das relações profissionais em prol da colaboração. $O$ respeito pressupõe $\mathrm{o}$ reconhecimento do outro, sua cultura, valores e interesses que se refletem tanto nas interações entre os profissionais, tanto com os usuários.

Categoria 3. Preservação das competências complementares da especificidade profissional, reconhecimento das competências comuns e construção das competências colaborativas

Os entrevistados consideram indispensável a preservação da especificidade profissional nos núcleos de atuação, para o estabelecimento do trabalho interprofissional colaborativo, com a definição clara dos papéis de cada profissional. Apontam a importância do reconhecimento das competências comuns do campo da saúde e também possibilidades de construção das competências colaborativas. As quatro subcategorias empíricas identificadas são:

Figura 6. Subcategorias da categoria 3 - Preservação da especificidade profissional, reconhecimento das competências comuns e construção das competências colaborativas. São Paulo, 2014.

\begin{tabular}{|l|l|}
\hline 3.1 & $\begin{array}{l}\text {-A formação em saúde com ênfase nas competências } \\
\text { complementares/específicas e comuns }\end{array}$ \\
\hline $\begin{array}{l}\text { - Preservação da especificidade da identidade profissional na } \\
\text { competência complementar/específica }\end{array}$ \\
\hline $\begin{array}{l}\text { - Influências da Educação Interprofissional na construção de } \\
\text { competências colaborativas: dinâmica de funcionamento das equipes } \\
\text { de saúde }\end{array}$ \\
\hline $\begin{array}{l}\text {-A Educação Interprofissional em Saúde possibilita o reconhecimento } \\
\text { de competências comuns }\end{array}$ \\
\hline 3.4
\end{tabular}


O conceito de campo e núcleo de competência e responsabilidade profissional proposto por Campos (2000), converge com a discussão da lógica profissional e da colaboração. $\mathrm{O}$ núcleo diz respeito às competências e responsabilidades específicas de cada área profissional e o campo envolve competências e responsabilidades comuns dos diferentes profissionais da saúde. Assim, pode-se afirmar que o campo se refere ao espaço comum do saber que é compartilhado entre os diferentes profissionais da saúde, enquanto o núcleo de competência diz respeito à especificidade de cada profissão.

A constituição de um campo comum de práticas, na área da saúde, requer o desenvolvimento de competências comuns entre os profissionais da saúde. Barr (1998), aponta três tipos de competências nos processos de interação interprofissional: competências comuns, complementares e colaborativas. As competências comuns envolvem ações que qualquer profissional qualificado no campo da saúde pode desempenhar, por isso podem contribuir para reduzir as tensões interprofissionais, favorecendo a colaboração. As competências complementares são desenvolvidas quando os profissionais identificam as atividades específicas que são capazes de realizar com a valorização das qualificações de cada profissão. As competências colaborativas se referem ao trabalho desenvolvido conjuntamente com outros profissionais, pacientes, famílias, voluntários, organizações e comunidades.

\section{Subcategoria 3.1 A formação em saúde com ênfase nas competências complementares/específicas e comuns}

Alguns entrevistados consideram que a formação interprofissional pode ser compreendida a partir de dois planos principais, competências profissionais complementares/específicas de cada profissão ou núcleo profissional e o campo comum de atuação permeado de valores e práticas compartilháveis. Este modelo de formação com ênfase na especificidade e 
nas competências comuns está estruturado de modo misto com momentos integrados e separados por área.

A seguir, apresentam-se relatos que consideram a importância da formação pautada em duas competências, complementares com ênfase na especificidade e comuns, ou seja, uma formação com duplo movimento com atividades integradas e momentos separados por área profissional.

Tem que ter uma parte da formação que tem que centrar no núcleo, não tem jeito. E aí eu acho que cada formação, cada núcleo é específico, você tem estratégias diferenciadas. O papel do enfermeiro é diferente do fisioterapeuta. A formação no núcleo ela tem que ser diferenciada. E a integralidade não é dada pela atenção primária, é dada pelo sistema. Nós precisamos de profissionais para o sistema (....). Precisa de uma supervisão do fisioterapeuta periodicamente, ainda que o generalista faça. Tem-se uma educação permanente, uma supervisão, uma formação, de alguém do núcleo daquilo, do fisiterapeuta, do educador físico. Então, o fisioterapeuta, mesmo na atenção primária, tem pessoas que falam - o que é campo nosso , com todas as profissões, e o que é uma coisa específica que nós fazemos-, fonoaudiologia é a mesma coisa. Por isso que no primeiro e no segundo ano tem coisas que a gente faz junto e tem coisas que a gente faz separado com a fonoaudiologia. Então, na verdade a formação ela não pode ser o tempo todo interprofissional, ainda que o cenário de práticas possa ser interprofissional, mas o papel, o aporte de conhecimento tem que ser específico. Tem coisa comum, mas tem coisa específica (D5 - médico).

Os momentos de formação interprofissional possibilitam a socialização dos papéis profissionais, necessária para o desenvolvimento de comportamentos e atitudes indispensáveis à cultura grupal, pois as barreiras assinaladas anteriormente são estabelecidas entre os membros das equipes e enfraquecem a integração entre profissionais de saúde e usuários.

A seguir, a entrevistada destaca que a formação deve seguir um duplo movimento, no qual a construção do saber comum não pode ser realizada separadamente do saber especifico. Afinal, o trabalho conjunto depende do saber específico das competências complementares e deve ser constituído na perspectiva da integralidade. Desse modo, acredita que o reconhecimento dos papéis depende da articulação nas discussões coletivas com as especificidades. O conhecimento das diferentes áreas durante a formação é muito valorizado pelos estudantes.

(...) feita apartado do especifico, não me pergunta como faz isso... porque se eu apartar eu tiro a motivação dos alunos de aprender o compartilhado. $\mathrm{O}$ projeto deles, eles tem que sair nutricionistas, mas eu tenho que produzir, juntos e subjetividade, juntos e subjetividade e dá um grande medo de que saia uma mistura que seja algo disforme, então há uma vigilância e uma tensão nossa, além da atenção há uma tensão. É preciso dimensionar possíveis equívocos nossos para que o trabalho conjunto seja 
entendido e pode ser entendido, porque eu quero que o SUS se mantenha, a população precisa de nutricionista de fisioterapeuta, numa perspectiva de integralidade, que isso seja apartado do especifico, acho que isso é um nó para mim, do ponto de vista da graduação. Então a gente esta cada vez mais no eixo comum abrindo mão do trabalho por curso, uma vez ou outra... uma discussão ou outa, porque não é isso que garante que eles se reconheçam é isso que a gente começou a perceber. Você está no grupo e você tem a sua especificidade, o que você tem é que articular nas discussões, o que é o difícil, se fosse fácil reunir todo mundo tudo bem, mas o grupo da fisio... não é isso que garante.... É interessante que o grupo de alunos fez essa avaliação, eles adoraram ouvir o outro e ouvir o seu, não é de abrir mão, mas eu tinha o meu professor lá, mas quando eles só ouviram os deles acharam pobre só a parte deles (D4 - psicólogo).

Como referido anteriormente na categoria 'A educação interprofissional em saúde contribui para a reconfiguração das relações profissionais colaborativas', o aprendizado dos papéis profissionais é influenciado pelo status de valorização de cada profissão na sociedade, assim como suas normas, valores e comportamentos.

A clareza do próprio papel profissional, o conhecimento e compreensão das habilidades e atitudes de outras profissões contribuem para aumentar a prontidão para aprendizagem interprofissional. Contudo, o modelo predominante de formação em saúde é uniprofissional, pois estimula os estudantes a priorizarem a prática profissional da sua área, sem valorizar o reconhecimento da complementaridade dos papéis e perspectivas de diferentes profissionais do cuidado em saúde (Khalili, et al., 2013).

As profissões se configuram de acordo com a história, status e condições sociais expressas nas relações intersubjetivas. As especificidades de cada área se expressam na formação, nas abordagens de aprendizado de cada área e de se relacionar com os estudantes, trabalhadores e usuários. A entrevistada também refere a experiência de formação com duplo movimento, na qual ocorre interação entre estudantes de diferentes cursos da saúde, com as competências comuns e competências complementares ou especificidades de cada profíssão.

Nessa relação interprofissional destaca-se o valor social de cada profissão no primeiro ano sempre é muito interessante, os estudantes tem características diferentes, os de enfermagem, medicina são diferentes... E aí apesar de eles estarem trabalhando sobre um território de competências comuns, as especificidades de cada um já se evidenciam de outro modo até pela forma como eles aprendiam na formação a já abordar as coisas de um modo diferente e também está relacionada com a condição social das profissões que já está presente ali no imaginário, nas relações, a história de vida dos estudantes, a origem social, tudo isso vai interferindo (D3 médico). 
Segundo, Khalili (2013), a adoção de uma dupla identidade profissional que contempla o campo e o núcleo de atuação, gera a possibilidade dos estudantes aprenderem o seu próprio papel profissional para compartilharem o entendimento da articulação dos papéis dos profissionais da saúde, em prol da prática colaborativa em equipe.

Os entrevistados destacam que a educação e a prática interprofissional, requerem o conhecimento e preservação da especificidade do saber de cada área profissional, para a atuação no campo comum das práticas da saúde, com a contribuição de profissionais de diferentes áreas. Consideram que a preservação da especificidade profissional nos núcleos de atuação é indispensável para o estabelecimento do trabalho interprofissional, com a definição clara dos papéis de cada profissional.

Se você pegar na atenção básica você tem os núcleos de conhecimento e saberes que são de cada profissão, e você tem o campo que muitas vezes perpassa, é comum a mais de uma ou a várias profissões, e que é um saber importante da atenção básica como um todo. Tem aí um rol de saberes que precisa ser comum a todos os profissionais que atuam na atenção básica e você tem um outro que é específico do núcleo de cada profissão. E a multiprofissionalidade ela vai ser construída por esse conjunto todo... vai envolver tudo isso (...) eu acho que em última instancia é uma... você oferecer para a população uma atenção à saúde mais resolutiva... mais capaz de atender as necessidades da população, não só do ponto de vista da saúde física, mas de uma maneira também mais global. Mas eu acho que o impacto que tem que acontecer é uma atenção à saúde mais resolutiva (D18- odontólogo).

No próximo excerto, o entrevistado também considera importante

desenvolver o campo comum de práticas e o núcleo de responsabilidades das competências profisssionais específicas. A composição de diferentes áreas de formação e práticas de saúde contemplando o núcleo específico de cada área, pode facilitar a convergência entre os saberes profissionais, e a identificação dos elementos que reforçam o ensino compartilhado.

Agora acho que o interprofissional ele tem desde a sua concepção... que também tem um processo de construção para eu ter essa ação e esse conhecimento conjunto. Porque aí eu tenho um campo que não é nada do que a gente conhece ainda. Então acho que talvez ele alarga um pouco o que a gente vinha usando aqui, de trabalhar com a idéia que é... de... roubo um pouquinho do Gastão Campos, que é trabalhar núcleo e campo, de competência e responsabilidade, mas ampliando um pouco isso (...) Então acho que para fazer o ensino compartilhado em outras áreas, eu preciso entender o que é específico e o que não é, e o que sustenta e ter isso demarcado, entendido. Porque a gente não vai precisar pensar igual. A gente vai precisar entender quais são as causas primeiras daquilo que te leva a pensar e agir e estruturar o conhecimento da sua área desse jeito e eu da minha. Acho que esse é um ponto(D11 - enfermeiro). 
O entrevistado considera que as profissões possuem conhecimentos especializados, então a formação não pode ser $\mathrm{o}$ tempo todo interprofissional, mesmo que o campo de práticas seja. Há um núcleo específico de saberes em cada área e um campo comum de ações, ambos espaços devem ser preservados.

Agora, é como se fosse... essa coisa de focar que estava te dizendo, de você... ter uma certa concepção ampliada, integral sobre o processo de saúde - doença, intervenção, mas as profissões, a formação, elas são específicas. Então, na verdade a formação ela não pode ser o tempo todo interprofissional, ainda que o cenário de práticas possa ser interprofissional, mas o papel, o aporte de conhecimento tem que ser específico. Tem coisa comum, mas tem coisa específica. Mesmo o estágio da atenção primária, o estágio do enfermeiro não pode ser igual ao do médico. A gente... se ensina muita clínica para o médico, muita clínica pediátrica, na atenção primária. A enfermagem tem que aprender também clínica, mas é clínica de enfermagem, outra coisa, é. Então, nessa hora o paciente é o mesmo, a equipe é a mesma, a discussão terapêutica é junto, mas tem que ter algum momento que os professores, que um aluno vai fazer uma coisa e outro vai fazer outra (D5 - médico).

Outro aspecto tematizado nas entrevistas é a confusão de papéis que pode ocorrer na prática interprofissional voltada para o campo ou competências comuns. No próximo excerto, o entrevistado relata uma experiência vivenciada durante a implantação do Centro de Atenção Psicossocial (CAPS) e da APS, quando profissionais de diferentes categorias profissionais passaram a atuar como psicólogos, deixando de cumprir os atendimentos específicos de sua área profissional. Afirma que houve confusão dos papéis profissionais e falta de atenção para o núcleo de saber das competência complementares ou específicas de cada área, por isso o núcleo do saber deve ser explorado e preservado.

Essa coisa da interprofissionalidade precisa ter cuidado... da interdisciplinaridade, da 'trans' ainda... Eu vi isso quando a gente começou com a atenção, equipe multiprofissional, interprofissional na atenção básica, na atenção primária e na saúde mental. Foi quando aqui começaram os CAPS. Eu vi mais radical na saúde mental, que os profissionais foram ficando todos iguais. Ficou um agente de saúde mental, terapia ocupacional perdeu a especificidade, o fisioterapeuta, o psicólogo, o psiquiatra, todo mundo ficou meio psicólogo, sabe? Psicólogo, assistente social, fazia cidadania, construção de cidadania, mobilização, luta pelos direitos e umas terapias tipo psicológicas... Um paciente lá estava perdendo a visão, precisava de capacitação para autonomia na vida diária, que a terapia ocupacional faz... e - não, isso eu não faço mais... -, virou meio psicóloga, sabe... Esse é um exemplo real (...) Daí que a gente começou a trabalhar isso do núcleo então... Tem um campo da saúde mental que é comum, a subjetividade, a determinação do social, da cidadania, construção da identidade... da discriminação.... Todos vão trabalhar isso, a relação com a família, com a rede social, com 
cuidadores. Agora o psicólogo tem umas coisas que ele faz... o psiquiatra... também... porque senão não precisa, senão a gente não precisa pôr (...) $\mathrm{Na}$ atenção primária foi todo mundo fazer promoção à saúde... e vai fazer clínica. Então o médico de saúde da família foi virando médico sanitarista, queria fazer só grupo, educação em saúde, politização, conscientização... e os hipertensos explodindo a cabeça com hipertensão... aí não dá. Não é essa a proposta. A proposta é que na equipe há um médico generalista, não é um médico especializado em saúde coletiva, que pode funcionar como apoio. $O$ enfermeiro é generalista, faz atendimento individual, de grupo... às vezes administração... faz educação em saúde, orienta vacina, faz consulta... faz grupo... faz prevenção, faz clínica... clínica de enfermagem. Essa discussão eu acho que amadureceu, mas no começo... de 90 a 2000 foi muito confusa, né. Até $2002 \ldots$ E eu acho que ajuda a gente a pensar isso... E isso teve reflexos na formação... Se isso está claro no modelo, na maneira de organizar a atenção... fica mais fácil o fisioterapeuta entrar lá com o núcleo em campo, eu acho. (D5 - médico).

não, agora como convivo com muita gente da odonto, eu virei dentista -. Não, não virou, você é enfermeira e ele é dentista. Porém, juntos... vocês podem fazer uma série de coisas compartilhadas (D9-enfermeiro).

No tocante às competências comuns, no próximo excerto, 0 entrevistado afirma que a construção do saber comum ocorrerá em situações de cuidado mais estruturadas, por exemplo: programas de saúde tradicionais como hipertensão e tuberculose. Nesses espaços o conhecimento é compartilhado e socializado com naturalidade, pois houve uma construção anterior de um comitê de especialistas, que socializou o saber por meio de um protocolo que orienta a execução de ações padronizadas que são comuns aos profissionais da saúde.

Então, é também...é uma tarefa pouco factível do ponto de vista pragmático, a não ser em situações, digamos, onde isso é possível coletivamente. Então, por exemplo, se pego alguns programas de saúde tradicionais, onde há um maior conhecimento porque hoje a gente tem um conhecimento mais consolidado. Você pega o programa de hipertensão, que se tem o que a enfermeira pode fazer no programa, o que o médico pode fazer, então já é uma coisa estabelecida, que esse conhecimento é compartilhado. Quer dizer, como se dá o diagnóstico de hipertenso, como se trata o tuberculoso. Não precisa ser médico para tratar o tuberculoso, porque o programa diz como se diagnostica, qual é a primeira indicação. A mesma coisa com o programa de hipertenso. Então esse conhecimento do ponto de vista foi socializado. Foi socializado através de um comitê de especialistas... (D8 - Médico).

Apesar da orientação das DCN para o trabalho em equipe, o entrevistado problematiza que a formação em saúde é predominantemente uniprofissional. Na maioria dos cursos, as competências comuns praticamente não são trabalhadas ao longo da formação ou ficam restritas à atividades da saúde coletiva, no primeiro ano dos cursos, sendo que posteriormente, fala-se de trabalho em equipe, mas não há articulação entre 
as diferentes áreas profissionais na formação. Assim, o entrevistado aponta um eixo comum para as profissões.

Eu diria que eu trabalharia as graduações apesar de elas terem as diretrizes elas tem sido trabalhadas de modo uniprofissional e elas têm sido feitas em cada profissão consigo mesma. O território das competências comuns praticamente não tem sido trabalhado e quando ele é trabalhado, esse era o âmbito da saúde coletiva no inicio do curso. Depois não anda, fala do trabalho em equipe, mas não articula. Essa não é uma coisa que entra na agenda, então eu acho que uma ideia como essa como a que tem (nesta universidade) de ter um eixo comum que é comum às varias profissões é importante (D3 - médico).

Um entrevistado refere que os estudantes reconhecem no PET-

Saúde a possibilidade de conhecer sobre a área dos outros nas experiências coletivas de construção de projetos terapêuticos integrados.

Uma outra questão é que no PET você às vezes ouve os estudantes conversando entre si e dizendo - puxa, eu não tinha ideia de que essa profissão também fazia tudo isso -, quer dizer, ao ter que construir um projeto terapêutico mais integrado, ele relê a própria atuação institucional da profissão dele e as dos demais. Acho que é um ganho muito grande nesse processo (D18- odontólogo).

É importante considerar que o PET-Saúde é desenvolvido como projeto de extensão nas universidades públicas, ou seja, consiste em uma atividade opcional à qual os estudantes podem estar vinculados. Então, apesar de possibilitar interessantes vivências interprofissionais com o reconhecimento do papel dos pares, seu alcance é limitado.

Atualmente, a formação em saúde é predominantemente uniprofissional, baseada no ensino por disciplinas e na racionalidade biomédica, com destaque para a flexinerização (Almeida Filho, 2010). Essa formação conduz à profissionalização e especialização precoce, fragmentação das práticas de saúde, utilização excessiva de tecnologias de diagnóstico, com a forte presença da ciência e da disciplinarização. Consequentemente, os estudantes priorizam a prática profissional da sua área de atuação profissional voltada para as competências complementares/específicas, sem valorizar o reconhecimento da complementaridade dos papéis e perspectivas dos diferentes profissionais do cuidado em saúde (Teixeira, Coelho, Rocha 2013; Feuerwerker, Capozzolo, 2013; Khalili, et al., 2013; Moraes, Manzini, 2006; Ceccim, Carvalho, 2005; Reeves et al, 2008; Barr et al, 2005).

$\mathrm{O}$ relato a seguir facilita o entendimento das competências complementares enunciadas por Barr (1998). O entrevistado indica o 
reconhecimento de que nenhum trabalho é centrado exclusivamente em uma única profissão. Todo conhecimento é parcial, pois as práticas são complementares. Complementar quer dizer que você precisa mais do que sabe, que precisa aprender com o outro, ou seja, com a especificidade do saber profissional que o outro possui. O entrevistado considera que para suprir lacunas de conhecimento é necessário desenvolver o trabalho interprofissional, interconsulta e matriciamento.

(...) primeira delas é o reconhecimento de que nenhum trabalho é centrado em uma profissão. Então o professor experimenta isso, o aluno experimenta isso e se dá conta de uma maneira mais contundente dessa realidade... que só falar é bem falso assim.. todo conhecimento é parcial..., todo mundo diz isso, mas não acredita que o seu conhecimento é parcial... quando de fato experimenta começa a ter mais clareza de quanto as coisas são complementares. Eu acho ruim quando pensa que o complementar é porque depende da inclusão da outra profissão... porque quando é complementar quer dizer que precisa saber mais do que sabia. Saber mais do que sabia então eu tenho que aprender com o outro... para mim saber....não para encaminhar. É para saber o que eu não sei, ver se eu posso resolver, se eu preciso de um trabalho interprofissional... uma interconsulta, um matriciamento, uma supervisão... então eu preciso saber quando preciso supervisão, quando preciso matriciamento, quando preciso interconsulta... quando preciso uma prática interprofissional e quando preciso(...) Então todo o tempo estive impregnado com a coisa de que não existem fronteiras entre as profissões, as profissões compartilham o que sabem, ou os profissionais... os profissionais compartilham o que sabem e quanto mais compartilham, mais sabem, e sabem o que não sabiam, portanto vão fazer outras coisas todo o tempo. (...) Então a gente tinha atendimento compartilhado, nós atendíamos de modo compartilhado os quatro, qualquer pessoa... quer dizer, eu aprendi muito de dermatologia, aprendi muito com ele, todos os impetigos... coisas de pele, quando via criança, eu aprendi muito com ele... porque atendíamos juntos, muitas coisas atendíamos juntos, compartilhávamos muita coisa (D17 enfermeiro).

A subcategoria 'A formação em saúde com ênfase nas competências complementares/específicas e comuns' possibilita a compreensão da importância da composição da formação em saúde pela especificidade profissional, com algumas práticas de saúde comuns. A construção da formação pautada nas competências complementares/específicas, pressupõe o reconhecimento da insuficiência do saber profissional individualizado frente as necessidades de saúde dos usuários. Enquanto as competências comuns se referem à habilidades e ações comuns que podem ser desenvolvidas por diferentes profissionais com ou sem colaboração.

Considera-se que a presença das duas competências referidas nos relatos, aponta possibilidades gradativas de aumento da integração 
profissional, nas quais inicialmente as estudantes de profissões isoladas enfocam competências complementares/específicas, avançam para competências comuns e posteriormente ou simultaneamente para competências colaborativas.

A formação uniprofissional predominante induz o desenvolvimento de práticas centradas em competências complementares específicas, que possibilitam o exercício da expertise profissional de cada área. Destaca-se que em alguns contextos de trabalho, como na APS, há possibilidades do desenvolvimento de competências comuns do campo de práticas, pautadas em protocolos de atendimento ou atividades comuns que são realizadas por diferentes profissionais, como por exemplo, acolhimento, visitas domiciliares e grupos educativos. Estas práticas podem estar pautadas também em competências colaborativas, consideradas mais 'sofisticadas' ou complexas, devido a dependência de ações ancoradas na competência da comunicação interprofissional com participação dos usuários/família e comunidade. As demais competências colaborativas sinalizadas pela CIHC (2010) são: clarificação de papéis profissionais, dinâmica de funcionamento da equipe, resolução de conflitos interprofissionais e liderança colaborativa.

Apesar dos entrevistados considerarem apenas duas competências mencionadas no contexto da formação na APS, considera-se que a competência colaborativa poderá ser desenvolvida no contexto do trabalho nos serviços.

\section{Subcategoria 3.2 Preservação da especificidade da identidade profissional na competência complementar/específica}

A preservação da especificidade é tematizada pelos entrevistados como um aspecto fundamental para a manutenção da identidade profissional. A educação interprofissional deve preservar as especificidades de cada área profissional, e com isso as possibilidades de contribuição das expertises profissionais na atenção integral às necessidades de saúde dos usuários e população. Este processo pode reduzir o temor que algumas áreas tem de perder ou fragilizar a respectiva identidade profissional. 
A seguir, o entrevistado afirma que a perda da identidade profissional, pode estar relacionada com a história da profissão e a fragilidade que possui em detrimento às demais no mercado de trabalho.

Se bem feito não deve apagar as especificidades, porque uma questão que apareceu em estudos dos psicólogos, que foi muito interessante, foi o medo de perder a identidade profissional, tão dificilmente conquistada, só na segunda metade do século XX no caso deles. Então assim, que escopo de atuação eu tenho e que se chama uma profissão? Eles tinham muito medo de vir para a área da saúde e transformar a clínica deles em uma outra coisa e perder a identidade de psicólogo. Interessante, né. Eu nunca vi nenhuma profissão tematizar isso desse jeito. Perder a identidade profissional. Então é importante ter clareza disso também. Ainda estamos no interprofissional, ainda estamos em que pessoas fazem quaisquer coisas. Mas eu acho que a cultura de cada profissão, a identidade que faz... e agora com essa novidade do receio da perda da identidade, né, portanto da perda da filiação corporativa... eu imagino que se alguém tem medo de perder a identidade da sua profissão deve ser porque vai ficar sem lugar no mercado e não vai ter quem defenda seus interesses. Deve se sentir muito só no mercado, porque a gente sempre recorre aos órgãos de apoio da categoria quando você tem algum problema (D2- médico).

Recente revisão de literatura realizada por Johnson et al., (2012),

revela que o termo identidade profissional nem sempre possui uma definição clara quando utilizado e pode estar associado à definição de autoconceito. Autoconceito pode ser definido como o entendimento sobre os atributos percebidos em alguém e pode ser relacionado aos conceitos de autoestima e autoconfiança. Por outro lado, a identidade profissional se refere a uma carreira ou uma ocupação e pode expressar a percepção sobre o trabalho realizado, com impacto sobre a inserção social, experiências e opiniões.

Mudanças no processo de trabalho podem influenciar a reconstrução da identidade profissional (Johnson et al., 2012). Por isso, a educação permanente em saúde pode contribuir para o preparo dos profissionais de saúde no tocante as constantes mudanças das práticas da saúde, relacionadas ao perfil epidemiológico da população com o envelhecimento e aumento das doenças crônicas, incorporação de novas tecnologias e saberes.

O entrevistado considera que a EIP, também deve centrar a formação no núcleo do saber específico de cada área, para a construção da identidade profissional do estudante, por meio de experiências nos diferentes cenários de práticas da rede de atenção do SUS.

(...) tem que ter uma parte da formação que tem que centrar no núcleo, não tem jeito. E aí eu acho que cada formação, cada núcleo é específico, você tem estratégias diferenciadas. O papel do enfermeiro é diferente do 
fisioterapeuta. A formação no núcleo ela tem que ser diferenciada. E a integralidade não é dada pela atenção primária, é dada pelo sistema. Nós precisamos de profissionais para o sistema. Se você formar um físioterapeuta generalista, com uma visão ampliada... ele não pode ser formado só na atenção primária... inclusive até mesmo na saúde coletiva. Tem que ter algum estágio em vigilância em saúde... em práticas de promoção, se bem que atenção primária às vezes não faz... E mesmo em outras práticas... Mas eu acho que tem que ter estratégias para cada curso. Ver o papel da atenção primária, o papel dos centros de referencia, das enfermarias, da prática hospitalar, das práticas territoriais, comunitárias, radicalmente territoriais e comunitárias... não só da atenção primária. E em cada um desses... e fazer uma balanço aí dessa... (D5 - médico).

Fatores relacionados ao macro espaço social e cultural, assim como

os aspectos do micro espaço, como expectativas individuais e experiências, contribuem para formação da identidade profissional. Programas curriculares influenciam o desenvolvimento da identidade nos espaços acadêmicos e das práticas assistenciais nos serviços de saúde. A formação e o treinamento são vitais para as mudanças na identidade profissional. Com a socialização e interação, o indivíduo adquire conhecimentos, habilidades e atributos da sua prática profissional (Johnson et al., 2012).

No próximo relato, o entrevistado afirma que o conceito de profissão implica na separação entre as áreas e induz às associações centralizadoras, como sindicatos que reforçam as disputas, conflitos e hierarquias que representam espaços de contradição em relação à EIP. Nesse sentido, qualquer movimento de articulação entre as áreas, representará uma negação da identidade profissional, e também, um viés aos estereótipos profissionais conhecidos e valorizados. Aspecto exemplificado pela noção de que a enfermagem é uma profissão dedicada ao cuidado ao invés da medicina.

Então, os recortes que você tem... em vez de ter uma associação de trabalhadores de saúde de um certo município, você tem sindicatos centralizados de profissionais de saúde, que faz com que os sujeitos que deveriam interagir com muito maior grau de harmonia do que fazem no local, no território em que as práticas de saúde ocorrem, eles se apresentam em conflito, divididos, em disputa, com formas de hierarquia muito demarcadas, fazendo com que o próprio conceito de interprofissionalidade pareça um outro símbolo, uma contradição em termos, porque a própria profissão implica em uma separação. Então, essa separação é uma separação tão demarcada que qualquer coisa que vincule uma identidade, uma definição profissional a outra, é muitas vezes vista como a negação da identidade profissional. Por exemplo, se um médico for cuidador demais, ele será visto de um modo diferente. Quem é mais cuidador é outra profissão, é a enfermagem, que deve ser mais cuidador. Se um farmacêutico se preocupa com o sistema de saúde aí ele pode ser até... é segregado entre os farmacêuticos, porque deveria estar mais preocupado com a farmacotécnica, com os aspectos... (D7-médico). 
O entrevistado defende que na saúde coletiva pode perder-se a identidade profissional ao assumir competências que não são específicas da sua profissão, mas necessárias no contexto de práticas em especial na APS. Para ele, a formação integrada depende da organização dos serviços de saúde. Com facilitação da comunicação entre os profissionais para potencializar o cuidado. Mesmo que haja uma integração diferenciada na formação, se os estudantes se depararem com uma prática compartimentalizada nos serviços, onde desenvolvem suas experiências de estágio ou aprendizado teórico-prático, fica difícil avançar na EIP.

Quando você entra em uma disciplina você começa a perder a anterior. Quer dizer, na área de saúde coletiva as pessoas acabam perdendo a sua identidade, você não é mais médico, não é mais enfermeira, não é mais odontóloga... você é um epidemiologista, planejamento de gestão, quer dizer, você assume outras competências que não são mais aquelas da sua profissão de origem. Então, da mesma forma esse trabalho... a idéia de uma formação integrada é, ao meu ver, dependeria da organização dos serviços de saúde, onde a comunicação que já existe entre os profissionais, fosse facilitada. Estimulada, incentivada, para potencializar o cuidado (D8 - Médico).

A subcategoria 'Preservação da especificidade da identidade profissional na competência complementar/específica' mostra que os entrevistados consideram que a constituição da identidade profíssional, depende da formação pautada na especifidade do saber de cada profissional ou competência complementar/específica. A valorização da preservação das especifidades, no desenvolvimento das competências complementares da formação é um componente necessário para o avanço da formação interprofissional. Afinal, a interprofissionalidade pressupõe o reconhecimento da insuficiência do saber profissional individualizado, por isso requer a composição simultânea por competências complementares e colaborativas.

\section{Subcategoria 3.3 Influências da Educação Interprofissional na construção da competência colaborativa: dinâmica de funcionamento das equipes de saúde}

$\mathrm{Na}$ reflexão sobre a composição dialética entre a dimensão profissional específica e a colaborativa na EIP, os depoimentos também apontam algumas características relacionadas ao desdobramento desse tipo 
de EIP nas práticas de saúde, no tocante à dinâmica de funcionamento das equipes, tais como: estabelecimento de objetivos comuns para o trabalho em equipe, avaliação do trabalho com reconhecimento dos limites do saber e possibilidade de complementaridade com o saber do outro.

O reconhecimento do 'funcionamento da equipe' é identificado como uma das competências colaborativas desenvolvidas pelo grupo de trabalho canadense CIHC. Trata-se do conhecimento e habilidades que os estudantes e trabalhadores da saúde deveriam desenvolver a respeito da dinâmica da equipe e do processo grupal para a efetiva colaboração interprofissional em equipe (CIHC, 2010).

Desse modo, requer o entendimento sobre o desenvolvimento do processo de trabalho em equipe, respeito aos valores éticos dos membros da equipe, interações e discussões efetivas, respeito à participação e tomada de decisão compartilhada. Essas características de funcionamento da equipe terão impacto sobre a interação e aprendizado da equipe de trabalhadores, estudantes, pacientes e famílias (CIHC, 2010).

O reconhecimento do trabalho do outro nas equipes de saúde e da articulação do trabalho em uma relação de complementaridade são apontados por diversos estudos que abordam o trabalho em equipe (Pereira, Rivera, Artmann, 2013).

O estabelecimento de um projeto assistencial comum, com objetivos de intervenção comum é uma prática frequente das equipes de saúde integradas, que procuram estabelecer acordos intersubjetivos (Pereira, Rivera, Artmann, 2013; Fortuna et al., 2005; Peduzzi, 2001, 2007b, 2009b).

A perspectiva interprofissional possibilita o compartilhamento das práticas de saúde, ao trabalhar junto com a contribuição dos diferentes saberes implicados na ação conjunta. Responsabilidades compartilhadas e objetivos comuns são elementos fundamentais para o funcionamento das equipes de saúde, conforme apresentado no relato a seguir.

A inter traz a perspectiva da equipe de saúde com aquelas três premissas: vamos juntos equacionar, vamos juntos propor, vamos juntos avaliar. Tenhamos contribuições diferentes a dar. A junção dos diferentes olhares vai se ampliar e nós teremos mais sucesso (...) Equipe para mim significa responsabilidades compartilhadas, objetivos comuns a serem seguidos, avaliação compartilhada, essas três coisas é equipe, frente a uma situação a ser explorada (D1- médico). 
A proposta de realizar o trabalho junto com o outro, remete à concepção do trabalho em equipe relacionada à cooperação, colaboração e divisão de responsabilidades (Pereira, Rivera, Artmann, 2013). A construção da cultura do trabalho em equipe depende da tomada de decisão compartilhada, construção conjunta de objetivos e plano de cuidados, coresponsabilização, efetiva comunicação, resolução de conflitos e constante diálogo entre profissionais e comunidade (WHO, 2010).

Para atender a complexidade das necessidades de saúde dos usuários é importante reconhecer a contribuição do trabalho em equipe interprofissional, caracterizado pela interdependência e complementaridade das ações profissionais (Peduzzi, 2009b; Peduzzi, 2001; Pereira, Rivera, Artmann, 2013).

Os principais indicadores da colaboração ativa propostos por D'Amour et al. (2008) em um modelo de tipologia da colaboração entre os profissionais da saúde, posteriormente destacados por Souza (2011) são: objetivos comuns consensuais, prática centrada no paciente, oportunidade frequente de encontro e atividades conjuntas, forte confiança, presença ativa do supervisor que fomenta os consensos, liderança compartilhada consensual, mecanismos comuns de troca de informações, experiências que estimulam a colaboração e inovação, espaços de discussão e participação.

O entrevistado afirma que o conceito interprofissional está relacionado com a lógica do trabalho, quando um profissional não sabe fazer algo, a sua equipe poderá realizar por ele. Cabe ao profissional o comportamento ético para reconhecer o que não sabe fazer.

Então as coisas... eu nunca vi ninguém dizendo isso... de maneira
explícita, assumindo isso. Então para mim o interprofissional chega a esse
ponto, de que... qual é o trabalho que se põe para mim... e como me
relaciono com o meu trabalho... eu não sei certas coisas então não posso
fazer. Sei essas coisas, posso fazer. A medida do que eu sei, do que eu
não sei, é a minha equipe, então tem que existir a equipe, e o meu usuário
e a minha ética para comigo mesmo, para com saberes. Ser exposto pelo
próprio usuário e os colegas dizendo - não, isso não pode fazer, não sabe,
porque falta isso, falta aquilo -, então isso tudo eu ponho no conceito de
interprofissional. É uma lógica muito mais relativa ao trabalho. No
trabalho deveríamos ter este comportamento, o trabalho interprofissional,
o trabalho das áreas interdisciplinar... (D17 - enfermeiro).
revistado exemplifica uma atividade interprofissional que tem como objetivo avaliar um programa de atenção à saúde. Nesse processo de 
análise dos indicadores de avaliação, reforça a necessidade do reconhecimento do papel de todos os profissionais que participam do cuidado e da comunicação interprofissional, pois a fragmentação das ações impede a clarificação de papéis. Refere também, que a avaliação do trabalho é um aspecto indispensável para o aprimoramento do trabalho em equipe, que necessita ser repactuado constantemente com a gestão do cuidado.

(...) pensar junto como é que a gente ia avaliar. E ao fazer isso a gente foi rediscutindo de novo o programa e qual que era o papel do médico, do enfermeiro, do agente comunitário... da equipe do dentista... qual era o papel deles naquele cuidado, né, na puericultura durante 2 anos com bebê de risco. Então foi uma experiência bacana, mas o mote era a avaliação de um programa, mas ao fazer isso a gente foi fazendo uma revisão do que era o papel de cada um nesse programa de bebê de risco, porque se cada um não fazia o seu papel o programa não avançava, né?! Apesar de ter alguns indicadores até melhores, menos internação, menos intercorrências... com esse bebê, o ganho de peso seguiu, mas a gente pode avaliar, então foi uma experiência bem bacana, né... a partir da avaliação de um programa... você vê a participação de cada um. E eu acho que entre eles também... que muitas vezes a gente divide muitas tarefas e eles pouco vêem a implicação de um trabalho no outro, né. Se o médico faz a consulta dele e não comunica os problemas que tem com aquele paciente para a enfermeira, para o agente comunitário... ele... tem que dar seguimento. Não adianta esse bebê de risco voltar dali a dois meses, se tem uma intercorrência (...) acho que o desdobramento é uma repactuação do trabalho, que eu vi ali acontecer. E que eu acho que a equipe acaba fazendo pouco na sua gestão. Implementa as coisas e deixa, implementa e deixa... implementa e deixa... Pouco avalia, pouco combina... pouco repactua... Tudo que a gente planeja, lógico que não vai dar certo tudo... mas como que a gente trabalha, né, reavaliando, repensando, repactuando... Então com poucas coisas a gente pode fazer essa avaliação e perceber que as equipes poucos trabalham em conjunto na gestão do cuidado. Cada um trabalha no seu pedaço no cuidado. Então foi uma experiência bacana, não sei se eles incorporaram isso depois, né... de pensar que qualquer ação que a gente vai planejar e executar, como eu faço a acompanhamento para não se perder, né (D14 - enfermeiro).

Segundo Orchard et al. (2012), Olenick et al. (2010) e Zwarenstein et al. (2009), Martín-Rodriguéz et al. (2005), a prática interprofissional colaborativa requer a parceria entre a equipe de saúde, os profissionais da saúde e os usuários, para a tomada de decisão compartilhada sobre as necessidades de saúde no cuidado do paciente.

Desse modo, a presença de vários profissionais, não é uma condição suficiente para que ocorra o trabalho em equipe, pois a colaboração dependerá dos fatores mencionados acima, assim como do envolvimento e reflexão sobre o processo de trabalho e coprodução.

A equipe precisa ser fabricada, precisa ser produzida, só o fato de ter muitos profissionais lá dentro não adianta se não tem uma posição ativa a ser feita e ainda mais no cotidiano porque tem que pensar sobre o 
trabalho, refletir construir e reconstruir junto sempre, nas UBS e nos outros lugares, tem que produzir relação diferente sempre (D3 - médico).

A presença de diferentes profissionais que atuem lado a lado, não é suficiente para a prática em equipe interprofissional, pois espera-se que produzam bons resultados na atenção às necessidades de saúde dos usuários (Batista, 2012; Peduzzi et al, 2013).

A interação da equipe de saúde é um processo que precisa ser construído, pois envolve lidar com diferenças, contradições, relações de poder e expectativas que implicarão na atuação conjunta (Fortuna et al., 2005).

A EIP envolve a teoria e a prática em espaços de aprendizagem e trabalho colaborativo de profissionais que se colocam em discussão para a construção de um projeto com objetivos comuns.

Você vê que realmente há educação interprofissional quando os profissionais tem a possibilidade de trabalhar e estudar juntos. De realizar projetos em comum, que eles discutam, que eles sentem e discutam os objetivos do projeto, as atividades, as funções, as responsabilidades e realmente coloquem aquela atividade em prática. Aí que você realmente consolida um processo. Tanto de aprendizagem como de trabalho colaborativo. Então eu creio que uma educação interprofissional realmente só é efetiva se ela envolve as duas coisas. Teoria e a prática. E se ela envolve o trabalho comum. Isso eu já sentia da minha... e depois com a literatura... tem um livro até... acho que é do CAIPE, e ele coloca isso no livro. Se você for falar só na teoria realmente não vai conseguir consolidar um trabalho interprofissional, só vai conseguir se você... se os profissionais... se os diferentes profissionais estiverem envolvidos em um projeto comum. Então é isso que eu tenho experimentado (...) E a gente vê muito isso, na área de saúde pública, na gestão a gente vê que encontra equipes bem afinadas, que conseguem trabalhar na prática o conhecimento... efetivamente tem uma boa experiência de construção de projetos comuns, de trabalho interprofissional (D15 - médico).

Entre as características das equipes de sucesso estão os propósitos comuns, que devem ser definidos com clareza pelos membros da equipe, incluindo o interesse coletivo (WHO, 2011).

Tradicionalmente, a organização parcelada do processo de trabalho em saúde, contribui para o aumento da fragmentação do saber com a valorização do saber especializado em detrimento do campo comum. De acordo com o próximo excerto, a EIP representa uma nova possibilidade de composição da formação, que deveria ser desenvolvida em dois planos, as competências complementares do núcleo de saber específico da área profissional, e as competências comuns. 
Porque isso é bastante interessante como a repartição dos trabalhos, a repartição dos conhecimentos deu muito valor ao que é específico e pouco valor ao que é comum. Ou seja, ao que faz de fato a recostura das especificidades, em valores e práticas, que fazem sentido são comuns, são compartilháveis. Então, acho que esse princípio de dar conta da especificidade e dar conta do que é comum ajudaria muito a formação interprofissional. Para isso toda formação teria que estar sempre voltada para esses dois planos, né. E buscando articulá-los, quer dizer, o que é específico da medicina, o que o médico vai fazer, mas o que é comum com os demais na assistência, no cuidado que ele vai prestar ao paciente? $\mathrm{E}$ isso que é comum, às vezes é comum com a gerencia, que é mais delicado, porque parece longe do paciente, como sistemas de informação ou a vigilância epidemiológica, parece longe do paciente. Então... mas... essa articulação é muito importante. No fundo, exceto dentro de algumas... dentro de especialidades médicas, isso já há na escola médica (D2- médico).

No próximo excerto, o entrevistado fala sobre os desdobramentos da formação interprofissional, destaca a preservação das especificidades de cada área, assim como as possibilidades de interação proporcionadas nesse espaço de formação, como um caminho para desenvolver novas estratégias nas práticas e o reconhecimento de que a atuação profissional isolada é insuficiente para responder as necessidades de saúde dos usuários.

Primeiro os caras saem com uma caixa de ferramentas mais ampla inegavelmente, ninguém vai deixar de ter a sua profissão, mas aprende coisas com as outras, com interação e juntos produzem estratégias que sozinhos não tem a menor possibilidade de ver. Segundo ter uma noção mais clara dos limites da atuação isolada de cada profissão (D3- médico).

Tradicionalmente as equipes de saúde eram uniprofissionais, com conhecimentos, funções e tarefas similares. Todavia, estão aumentando o número de equipes, compostas por membros com diferentes funções e especialidades, que compartilham objetivos comuns no cuidado ao paciente (West, 2013).

As principais características das equipes, segundo West (2013), são: interdependência, objetivos compartilhados, liderança e reflexividade. A interdependência pode ser entendida como a manutenção do trabalho coordenado em equipe. Os objetivos compartilhados devem ser claros e definidos em comum acordo com os membros da equipe, pois definirão seu comportamento. A liderança influenciará a definição do trabalho em equipe, a participação dos seus membros, o foco do trabalho e a performance. Por fim, a reflexividade envolve a revisão sistemática do desempenho da equipe a fim de analisar como o trabalho é desenvolvido e adaptar seus objetivos, de acordo com as necessidades do paciente e demandas organizacionais. 
Poulton, West (1999), destacam que os melhores preditores para o trabalho em equipe na atenção primária são objetivos compartilhados, ênfase na qualidade, participação, e suporte para inovação, enquanto a efetividade do trabalho em equipe depende da prática centrada no paciente, da eficiência organizacional e das práticas de cuidado em saúde. Desse modo, seus achados sugerem que quanto mais participativas e colaborativas forem as equipes, sua prática será mais centrada no paciente e, portanto, o trabalho em equipe terá melhores resultados.

A subcategoria 'Influências da EIP na construção da competência colaborativa: dinâmica de funcionamento das equipes de saúde' mostra que a educação interprofissional em saúde contribui para o desenvolvimento de características necessárias para o trabalho em equipe colaborativo como: o compartilhamento do saber, processos de tomada de decisão coletivos e o estabelecimento de objetivos comuns que compõe as competências colaborativas.

\section{Subcategoria 3.4 A Educação Interprofissional em Saúde possibilita o reconhecimento de competências comuns}

A composição das práticas por meio de diferentes saberes profissionais, representados pelos núcleos profissionais no processo de trabalho em saúde, possibilita a interação e o compartilhamento de saberes, em um movimento de borrar as fronteiras entre as profissões. Esse movimento, pode dar origem a novos saberes do campo de prática comum das diferentes áreas de atuação profissional que podem ser denominados como competências comuns.

A seguir, o entrevistado considera que as competências comuns do campo comum de saber e práticas da saúde possibilita o aprimoramento do saber e de conhecimentos recíprocos. A interprofissionalidade provoca o 'borramento' das identidades profissionais e reconfigura uma nova prática construída em uma dinâmica de trocas de saberes. Esta nova prática, pode ser entendida como um rol de habilidades necessárias para o desenvolvimento do trabalho interprofissional. 
Não quer dizer, portanto, que uma assistente social vai se tornar uma enfermeira... que uma enfermeira vai se tornar psicóloga, não quer dizer. Mas de qualquer forma... um pouco vai, né, um pouco o interagir vai dando espaço para aquele outro conhecimento, vai acolhendo, vai compartilhando, um pouco vai borrando... pessoas são chamadas a atuar sem nenhuma licença profissionalizante. Isso acontece efetivamente. Então pode ser um caminho possível. Pode ser o caminho... Por isso que eu digo, isso borra um pouco as fronteiras e por onde escoa essa capacidade pragmática de resposta? Pela tecnologia informatizada, porque ela permite acessar pessoas que você nunca nem entendeu onde estão, mas que sabem fazer coisas que ou nenhuma profissão sabe ou que mistura ramos de profissões que sabem (...) Eles não interagem necessariamente em equipe, são identidades borradas na prática, porque ninguém mais faz o que originalmente era, e faz o pilates, mas não é o mesmo pilates para eles... sequer tem comunicação das diferenças ou das semelhanças... Porque podia ter... ser diferente, mas eles fazerem trocas entre si. Aprimorar um ao outro pelos conhecimentos recíprocos... suponho que seja essa a idéia da interprofissionalidade (D2- médico).

D’Amour et al., (2008) desenvolveu um modelo para a colaboração pautado na premissa de que os trabalhadores da saúde querem desenvolver as práticas de cuidado juntos, porém com a presença de interesses próprios e de uma esfera de autonomia. A necessidade de construção de objetivos comuns no trabalho em equipe expressa os interesses dos usuários relacionados às necessidades de saúde e também os interesses profissionais dos serviços e corporações.

A autora sugere que as ações dos profissionais sejam analisadas a partir de quatro dimensões, entre as quais está o suporte para inovação. Este indicador sinaliza novas atividades que podem ser construídas coletivamente em decorrência da prática colaborativa no campo comum de práticas.

Os novos saberes decorrentes da prática colaborativa, ampliam a responsabilização das equipes, conferem flexibilidade à dinâmica do trabalho em equipe e a resposta às necessidades de saúde dos usuários.

Outro aspecto interessante é que alguns depoimentos afirmam a existência de algumas áreas de atuação construídas como espaços interprofissionais caracterizados por competências comuns como: saúde mental, saúde coletiva, saúde pública e educação em saúde. No próximo excerto, o entrevistado aponta que a atividade específica de uma profissão, pode ser realizada por diferentes áreas, desde que haja uma formação específica para a atividade. 
Acho razoável o conceito de interprofissionalidade porque se ajustaria talvez a alguma coisa como a que eu faço, que são as várias ocupações... mas não importa qual é a profissão, é interdisciplinar, mas não faz a menor diferença qual é a profissão... Saúde mental é interprofissional... Eu acho que uma cirurgia não é interprofissional, mas a saúde mental é interprofissional. E muitas práticas são interprofissionais... mas eu chego ao ponto de dizer que tudo aquilo que a gente acaba localizando em uma determinada profíssão pode ser de várias profissões, desde que eu trabalhe com a formação necessária para aquilo (D17 - enfermeiro).

$\mathrm{Na}$ EIP há um campo comum de saberes e práticas, por isso na

formação em saúde, busca-se discutir o espaço do trabalho comum entre as diferentes áreas como a promoção, a prevenção da saúde e as relações intersubjetivas com a equipe e comunidade.

IPE trabalha com o campo do comum, educação interprofissional, porque ele era justamente quem fazia... que trabalhava com os residentes os objetivos comuns, do campo de atividades da saúde da família, o planejamento de atividades da equipe de saúde da família, no campo dentro da própria unidade... as atividades de educação, as atividades de assistência... então esse preceptor de território tem um papel muito importante nisso, mas... e paralelo ao preceptor do território a gente também tinha preceptores na área clínica. E esse preceptor na área clínica era específico. Então para o médico a gente trabalhou com três especialidades pelo menos, ginecologia, pediatria e obstetrícia, clínica médica. E com a enfermagem a gente trabalhava com os enfermeiros que tinham mais experiência como preceptores, tinha algum reforço na área de saúde da mulher, outros na área da saúde da criança... Mas a gente procurava também com os preceptores da clínica discutir o trabalho que é comum, né... Por exemplo, o pediatra, tudo bem, está trabalhando o atendimento clínico de pediatria, mas no que tivesse relação com a saúde pública, como imunização, como alimentação e promoção à saúde de uma forma geral, alimentação e nutrição... acompanhamento do desenvolvimento, e outros aspectos que pudessem envolver outros profissionais, a própria dentição... quer dizer, toda a parte de promoção e prevenção, isso era trabalhado... e mesmo a parte de acompanhamento dos pacientes... o que não fosse especificamente do médico. Preceptor que trabalhava a relação intra equipe e com a comunidade que é diagnóstico e tratamento medicamentoso, era trabalhado o tempo todo na residência... a idéia era que fosse trabalhado com toda a equipe (D15 - médico).

O campo comum das práticas entre as áreas não se refere às atividades específicas de categorias profissionais. No próximo relato, o entrevistado refere que o conhecimento comum permite trabalhar com grupos educativos, famílias e escolares.

$\mathrm{Na}$ residência era multiprofissional, que incluía médico, enfermeiro, psicólogo e como foco da residência... não era uma residência em psiquiatria, então era como trabalhar com grupos, como compreender cultura e sociedade, cultura e saúde, cultura e sociedade... como era multiprofissional não fazia a menor diferença a formação de ninguém, porque não era nenhuma pergunta específica de profissão nenhuma. A gente entendia que esse componente que nos agregava, que era trabalhar com grupos, trabalhar com acompanhamento de família, trabalhar com acompanhamentos escolares e coisas desse tipo, qualquer de um podia fazer e fazíamos (D17 - enfermeiro) 
A subcategoria 'A educação interprofissional em saúde possibilita o reconhecimento de competências comuns' mostra que há uma esfera de competências comuns no campo da saúde e outras também comuns que são desenvolvidas pelos profissionais de saúde nas práticas de cuidado. O reconhecimento das competências comuns são uma consequência do desenvolvimento da EIP e das práticas interprofissionais.

A partir do conjunto de relatos desta categoria, pode-se concluir que a educação e a prática interprofissional requerem o conhecimento e preservação da especificidade do saber de cada área profissional para o reconhecimento e atuação no campo comum das práticas da saúde, com a contribuição de profissionais de diferentes áreas e construção de novos saberes comuns, decorrentes das vivências compartilhadas no trabalho. 


\section{BARREIRAS PARA EDUCAÇÃO INTERPROFISSIONAL EM SAÚDE}

Ainda na primeira parte dos resultados e discussão apresentam-se aspectos referidos pelos docentes entrevistados, como barreiras para o avanço da operacionalização da EIP, no cenário brasileiro. Destaca-se que os referidos resultados não serão analisados em profundidade, pois não se trata do objetivo do presente estudo.

Os docentes entrevistados apontaram as seguintes barreiras à EIP:

Figura 7. Barreiras para EIP na perspectiva dos docentes. São Paulo, 2014.

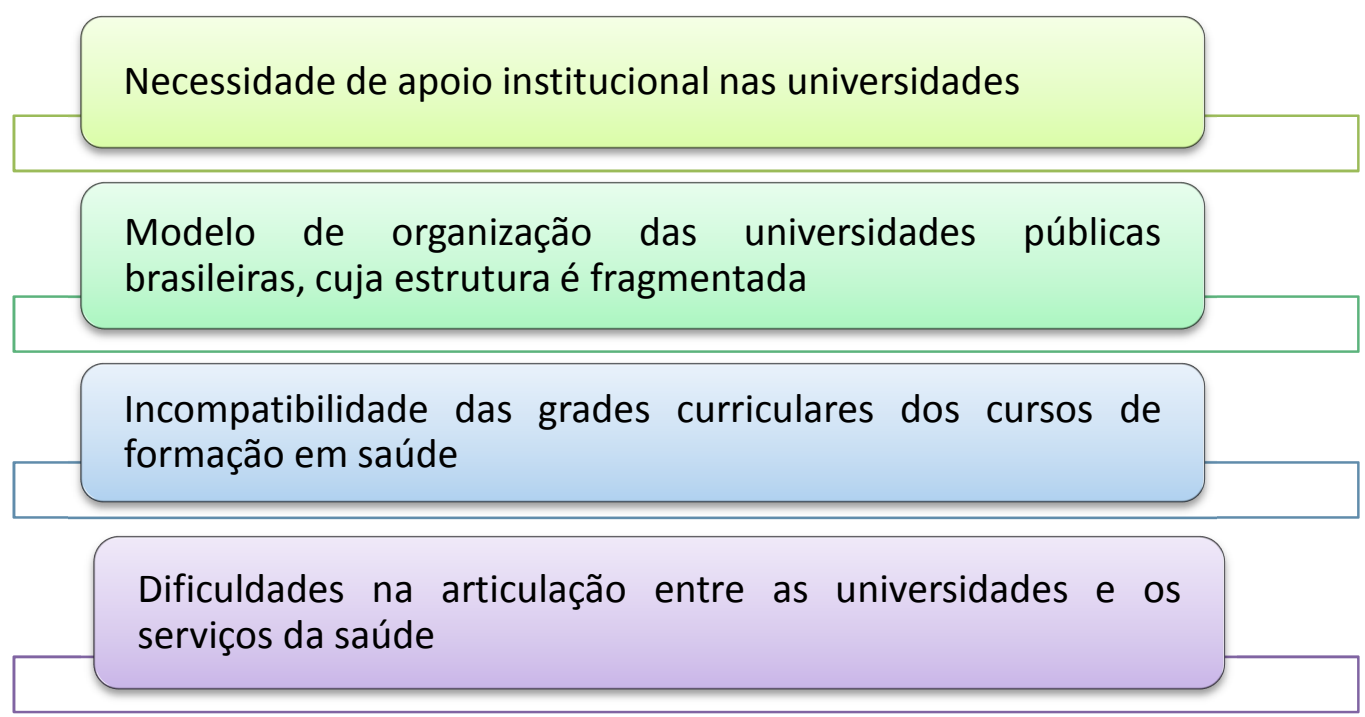

Os depoimentos apontam a necessidade do apoio institucional para avançar nas propostas de mudança na formação em saúde. No próximo excerto, o entrevistado destaca que a valorização desse processo pela universidade, dirigentes e docentes pode ser um caminho para avançar na flexibilidade das grades curriculares com possibilidades de articular propostas de formação entre diferentes áreas profissionais.

Do lado da universidade, acho que o comprometimento nos diversos níveis também, político institucionais, de apoio também, para a direção das faculdades, dos docentes, para que esse processo seja valorizado, e para que, por exemplo, o próprio processo de planejamento das atividades curriculares, possa se flexibilizar e favorecer o trabalho multiprofissional. A ida ao serviço, que muitas vezes cada curso monta o seu horário de forma isolada e quando eles vão tentar trabalhar juntos não bate o horário de cada 
um. Então isso é um problema. A gente precisa ter abertura e flexibilidade para poder construir juntos isso (D18 - odontólogo).

Costa et al., (2014), realizou um estudo sobre a EIP para a reorientação da formação em saúde e considera que o apoio institucional é um dos elementos que pode favorecer a implementação da EIP nas universidades. Segundo Clark (2013), o apoio institucional está relacionado com a visão de mundo e as intencionalidades que conduzem à reorientação da formação, por isso, deve reforçar a necessidade de mudança e responsabilidade social da universidade, em busca de alcançar maior coerência entre à formação e as necessidades de saúde.

A estrutura universitária fragmentada entre as áreas dos diferentes cursos, com um corpo docente específico, índices de produção departamentais e controle de carga horária docente individual, dificulta o processo de articulação do ensino entre os cursos.

A organização da universidade pública brasileira, pode ser compreendida por meio dos modelos clássicos das universidades, pode ser considerada um misto do modelo napoleônico e do humboldtiano. O modelo francês napoleônico, confere a universidade o papel de formar os quadros profissionais necessários para o Estado, caracterizada pelo profissionalismo e especialização na formação. Por outro lado, o modelo alemão humbolditiano, está pautado na liberdade de pesquisar, aprender e ensinar (Sguissardi, 2011).

Apesar do modelo misto, a ênfase da formação universitária brasileira ainda está no modelo técnico-profissional. A Lei 5.540/68 da Reforma Universitária, estimulou o desenvolvimento da universidade de pesquisa neo-humboldtiana, que se intensificou nos anos $1980 \mathrm{em}$ torno da indissociabilidade, ensino-pesquisa-extensão e se fortaleceu com a Coordenação de Aperfeiçoamento do Pessoal de Nível Superior (CAPES) e do Conselho Nacional de Pesquisa (CNPq) criados em 1951. A CAPES foi criada com o objetivo de assegurar a formação de pessoal qualificado, assim promoveu a formação docente no exterior nos anos de 1960 e assumiu o papel de coordenar, elaborar, avaliar e acompanhar a pós-graduação no país (Sguissardi, 2011). 
Outro desdobramento da Lei da Reforma Universitária é a lógica da racionalização e eficiência, com organização departamentalizada que privilegia a especialização do saber, para o avanço da pesquisa associada ao ensino (Sguissardi, 2011).

Nos últimos 40 anos, o crescimento da pós-graduação tornou-se uma política de ensino superior, no qual a produção científica é considerada como critério de avaliação da CAPES, para o credenciamento dos programas de pós-graduação (Sguissardi, 2011). Os docentes universitários que atuam no ensino de graduação e pós são pressionados pela necessidade de manter padrões quantitativos e qualitativos de produção científica, a partir de pesquisas realizadas.

O entrevistado refere que as mudanças na formação dependem da valorização da graduação em relação às outras frentes de atuação da universidade, pesquisa e pós-graduação. Também considera que as possibilidades de compartilhamento dos espaços de formação, pelos docentes de diferentes áreas é limitada pela estrutura departamental da universidade, que dificulta o registro formal da carga horária e o cadastro de disciplinas.

Então esse é um desafio, dar mais valor para a graduação, dar mais valor para os processos interdisciplinares, para as trocas interdepartamentais, para sumir a fronteira entre departamentos. Compartilhar na sala de aula, professor que é de diferente curso, de diferente unidade academia. Porque a mesma disciplina pode ter um professor que veio da sociologia, que veio da informática, que veio da educação física. Tem que ver entre eles, ver o conteúdo que cada um vai abordar e trabalhar juntos! (D-17-enfermeiro).

O movimento de mudança na formação em prol da EIP é contrahegemônico, quando considerada a lógica produtivista da universidade atualmente, que de acordo com Marilena Chaui (2003), pode ser fruto da mudança na concepção de universidade como instituição social, para a universidade como organização prestadora de serviços.

A universidade como instituição social expressa a estrutura e o modo de funciomento da sociedade. Desenvolve uma prática social fundamentada na autonomia intelectual do saber, frente ao Estado e religião, que permite manifestar contradições no tocante aos rumos da sociedade e sua função, frente à luta de classes sociais (Chaui, 2003). 
Enquanto, organização social, a universidade passa a ser incluída no setor dos serviços não exclusivo do Estado, o que significa que a educação deixa de ser um direito, então, a universidade pode ser um serviço privado. Assim, a prática social da organização tem como finalidade, vencer a competição com outras universidades, estruturada por normas e padrões alheios ao conhecimento intelectual (Chaui, 2003).

A perspectiva organizacional, segundo Freitag, produziu a universidade operacional, caracterizada pela fragmentação competitiva, avaliada por índices de produtividade e estruturada por estratégias e programas de eficácia organizacional, que avaliam o tempo custo e quantidade produzida (Chaui, 2003).

O entrevistado afirma a seguir, que diante das pressões pela produção que os docentes enfrentam, há dificuldades para dispor do tempo de trabalho para espaços de construção coletiva e formativa de mudanças curriculares.

Agora, cá para nós, a universidade pública atual, está exigindo outra coisa da gente... não é... ela está extremamente produtivista, pressionando para ter um tipo de coisa que eu acho que a maior parte dos docentes fogem de projetos que deêm trabalho. Garantindo que vários profissionais estejam juntos, participando de ações onde vários profissionais estejam juntos, isso implica uma disponibilidade para... não adianta só juntar as pessoas, tem que... o processo formativo exige sentar juntos, discutir juntos... Você precisa aprender a fazer isso, fazendo, tem que haver um processo formativo... senão como é que vai posteriormente ter uma prática? $\mathrm{Na}$ verdade a gente está vivendo um momento extremamente produtivista na universidade, como em outros setores? Então a exigência é muito assim da produção... produção artigo. Então, um projeto de extensão que exija, ou um grupo de estudos... que pode vir a produzir artigos, sim, mas... exige de você um tempo de trabalho, de trabalho com o grupo. Não é impeditivo da produção mas ao mesmo tempo implica que a produção não vai ser tão rápida quanto se pede. Então acho que tem um descompasso nesse sentido (D16-psicólogo).

A seguir o entrevistado problematiza uma possível mudança do papel da universidade. Anteriormente, a universidade estava voltada ao ensino, pesquisa e extensão, mas atualmente com a primazia da lógica produtiva, secundarizou a extensão e graduação priorizando as atividades de pesquisa.

(...) então, na verdade na década de 80 teve um debate grande, importante, sobre a função da universidade, e aí se definiu pelo 'tripé'. Então assim, a universidade não era só ensino, mas não era só pesquisa... então a extensão entrou... era o outro pé. E esse princípio, para a universidade pública, era fundamental. Então durante um período longo, quem estava dentro da universidade de modo geral, não todo mundo, mas enfim... de modo geral, 
tinha esse entendimento e defendia isso como super importante. E não havia um apelo muito grande ao produtivismo, que isso vem com os acordos, na década de $90 \ldots$ do neoliberalismo para cá. Então o papel da universidade é produzir, produzir... é, o foco. E a extensão ela foi secundarizada nesse processo. Então ensino e graduação, dependendo do lugar, da universidade, você sente uma certa secundarização, que é um absurdo... um absurdo... é muito grande. Então, muitos professores acabam priorizando o ensino da pós graduação e a graduação fica em segundo plano e projetos de extensão então... em terceiro, quarto plano... E a pesquisa então... é iniciação científica, é mestrado, doutorado... e vai... nessa linha. Eu acho que é uma questão meio de princípio da função da universidade. A hora que isso se desmontou de certo modo, desmobilizou, cada um está cuidando de si, de seu lápis...(D16-psicólogo).

O tripé ensino, pesquisa e extensão constitui o eixo de trabalho da universidade e não deveria ser compartimentalizado. O artigo 207 da Constituição Brasileira de 1988, dispõe sobre a indissociabilidade dos elementos do tripé (Brasil, 1988). Afinal, a atividade de ensino é enriquecida pelas oportunidades de pesquisa e extensão que expressam o compromentimento social da universidade (Moita, Andrade, 2009).

Os depoimentos apontam dificuldades para implementar propostas interprofissionais devido a incompatibilidade entre as grades curriculares de diferentes cursos. Tais atividades são desenvolvidas, principalmente por meio de projetos de extensão como o PET-Saúde.

E essa dificuldade que a gente vê nos estudantes hoje, em projetos, que existe hoje, em termos de educação interprofissional, são atividades de projetos de extensão ou do PET Saúde, no caso, né. E a grande dificuldade é com a incompatibilidade das agendas, porque cada currículo tem agendas diferentes... enfermagem e médico tem um horário... agendas muito sobrecarregadas dos estudantes, e praticamente não tem tempo para reservar um tempo de fazer um trabalho de... da... interprofissional. [..] o desafio é a gente avançar, a gente avançar dentro da universidade, avançar para a gente construir esses espaços (de aprendizagem compartilhada) (D15-médico).

Recente revisão sistemática realizada por Sunguya et al. (2014), aponta que a estrutura e a rigidez curricular estão entre as barreiras para implementação de programas da IPE. Como alternativas para a falta de integração curricular nos currículos acadêmicos tradicionais que mostram algumas possibilidades, como a implantação de currículos flexíveis, o desenvolvimento de disciplinas de IPE comuns para os cursos e o estabelecimento de currículos comuns entre os cursos.

$\mathrm{O}$ entrevistado declara que mesmo uma proposta indutora de mudança na formação como o PET-Saúde, enfrenta dificuldades no contexto atual da universidade, devido à incompatibilidade de horários das 
grades curriculares entre os cursos, a ausência de práticas articuladas nos serviços e de trabalhos articulados entre os cursos e os docentes.

Aí o ano que vem a gente vai tentar que esses cursos mudem... por exemplo, quando a gente decidiu fazer isso no PET, os dias da semana não batem entre os alunos... então nós temos que deixar no calendário que dia da semana nós vamos para as unidades... terça e sexta... Então terça e sexta todos os cursos precisam ter livre nos seus calendários para que os alunos possam se encontrar, porque senão faço um PET de novo cada aluno indo em um dia, mesmo sendo um projeto, cada um indo em um dia. Então aqui os desafios são imensos. A impressão que eu tenho, a gente comentou, foi a nossa primeira conversa, não havia nenhum tipo de trabalho articulado entre os cursos. Pior, nem entre os professores. Nem entre os cursos nem nos cenários de trabalho. A fisioterapia sempre trabalhou com a questão da especialidade. Então, nunca foi para a atenção básica, então tinha a 'UBS dela, os ambulatórios que não era espaços onde encontrava enfermagem. Nem com a terapia ocupacional, que era um curso do mesmo departamento, nunca conseguiram fazer nada junto. E a enfermagem isolada no canto dela e a educação física muito menos ainda integrada. Então, as possibilidades de integração aqui na são muito recentes, é coisa de $2 \ldots 3$ anos para cá. Então vai ter que construir. Acho que o PET vai ser fundamental nesse sentido, como acho que está sendo em São Paulo (D14-enfermeiro).

Um conjunto de relatos dos docentes entrevistados aponta barreiras

relacionadas à dificuldades para articulação entre as universidades e serviços da saúde, ou seja, ensino-serviço, por reconhecer a relação de interdependência entre os processos de formação e práticas da saúde que depende da valorização de todos os sujeitos envolvidos, trabalhadores, gestores, docentes estudantes.

O depoimento a seguir, expressa a importância de articular as propostas de formação com as políticas públicas de saúde, mediante a articulação ensino-serviço. Considera, que há interdependência entre formação e práticas de saúde, por isso, defende a importância de marcos regulatórios, vinculados à legislação para a formação em saúde que considerem o papel ativo a ser assumido pelos serviços de saúde e universidades, para que sejam corresponsáveis pelo processo de formação. A articulação ensino-serviço depende de mudanças infraestruturais nos serviços da saúde e no processo de trabalho para constituir uma rede de ensino aprendizado no SUS.

E acho que a formação precisa estar contextualizada nas políticas públicas, no processo... no que é necessidade de cada comunidade para que esses profissionais possam estar sempre prontos a entender que é um processo muito dinâmico e em constante mudança (...) Eu falei bastante do lado da... instituição de ensino, talvez tenha enfatizado mais o lado da instituição de ensino, mas eu acho que do lado dos serviços de saúde... eu acho que é importante também que os gestores dos diferentes níveis, os próprios trabalhadores de saúde também incorporem essa questão da importância da 
integração ensino - serviço, universidade - sistema de saúde -, a valorização precisa vir de lado a lado. E talvez a gente, para evoluir dos estágios que a gente está hoje, nós precisemos de marcos regulatórios, para que possam dar no longo prazo maior sustentabilidade para todos os processos de mudança que estão em curso... marcos legais, que deixem claro, diretrizes do processo de integração ensino - serviço, talvez legislações em diversos níveis, federal, estadual, municipal... que tragam um processo de integração ensino - serviço. Quais são os direitos e obrigações da instituição de ensino? Quais são os direitos e obrigações... o que precisa do serviço? Como a gente institucionaliza isso?, não parte só de ter um programa federal com recursos, com pessoas mobilizadas para fazer aquilo... quer dizer, como é que a gente introjeta isso como um... deixa ser necessário um programa... para ser...política ... então nós temos tanto o desafio de fazer o processo de ensino - aprendizagem quanto de promover uma série de mudanças, desde infraestrutura, de gestão, de processo de trabalho no serviço de saúde, para darem conta desse ideal (D18 - odontólogo).

A integração ensino-serviço, pode ser definida como o trabalho coletivo pactuado entre estudantes, docentes e trabalhadores do campo de práticas em prol da qualidade da atenção às necessidades de saúde dos usuários, qualidade da formação e satisfação dos trabalhadores do serviço (Albuquerque et al., 2008), que pode ter como desdobramento o enfoque no ensino, serviço, na gestão setorial, controle social e respeito aos usuários (Cavalheiro, Guimarães, 2011). Nessa direção, algumas propostas indutoras foram implementadas pela OPAS como a IDA e o projeto UNI, sendo que na última década o MS lançou o Aprender-SUS, o Pró-Saúde e a estratégia do PET-Saúde (Feuerwerker, Sena, 2002; Almeida, Feuerwerker, Llanos, 1999; Ceccim, Carvalho, 2005; Brasil 2007b, 2008a; Cavalheiro, Guimarães, 2011).

No estudo de Cavalheiro e Guimarães (2011), os resultados de uma oficina desenvolvida com o objetivo de contribuir para o fortalecimento da integração ensino-serviço, apontam a necessidade das instituições de ensino superior compreenderem que os serviços também produzem conhecimento e que a parceria com a universidade qualifica essa produção, assim como, pode contribuir nos processos de implementação de mudanças curriculares.

O compartilhamento de responsabilidades entre a universidade e os serviços da saúde, pelo processo de formação é tematizado no próximo relato, ao destacar que a formação articulada depende do tipo de prática da universidade, dos gestores e trabalhadores dos serviços.

Acho que esses núcleos de desenvolvimento docente, de capacitação docente, da maneira que ela aconteça ela tem que fazer... mas também a gente entende que a gente tem que estar dentro do serviço. Então, essa formação compartilhada ela também tem que ser uma contrapartida da 
universidade para o preceptor, mas ela também tem que ser dividida com o gestor do serviço, para ele entender que não é só pôr o aluno lá e ficar lá... como com o preceptor e com as pessoas que estão lá da equipe (D13fonoaudiólogo).

O distrito docente assistencial, representa uma boa alternativa para a formação quando os docentes participam da gestão e do trabalho assistencial desenvolvido. Segundo o entrevistado, em geral os docentes permanecem na universidade sem realizar um trabalho articulado no sentido referido de distrito docente assistencial e os trabalhadores dos serviços, não tem disponibilidade para contribuir no processo de formação com ausência de incentivos financeiros que mobilizem sua participação.

(...) eu acho que os desafios dependem do cenário e da organização concreta de organização do serviço de saúde. Se o cenário é desfavorável, e aí eu estou considerando cenário desfavorável um cenário onde a atenção básica ela é organizada de forma tradicional, com os trabalhos parcelados, não tem trabalho em equipe, não tem trabalho no território, o modelo assistencial é o da demanda espontânea... então o que você pode... a possibilidade é do professor mostrar ao aluno como é que está acontecendo e discutir como deveria ser. Essa é a pior situação. Aí tem uma situação intermediária que é o distrito docente assistencial, que é uma estratégia intermediária, é você ter um lugar de ensino. Mas o distrito docente assistencial só funciona quando ele é gerenciado por docentes e tem docentes trabalhando lá, como no hospital escola....Quando você tem que negociar para o aluno ficar lá e o docente não está participando do trabalho... então esse é o modelo pouco eficaz. Então o distrito docente assistencial, quando o docente assume tarefas assistenciais também e os profissionais assumem tarefas docentes, esse é o modelo ideal, mas muito difícil. Porque os docentes não querem sair da faculdade para ir para o serviço. Nem os profissionais querem ensinar, se não forem pagos por isso. O mundo social se estrutura dessa forma, né? São campos, sub campos, que tem conflitos, que tem disputas. Então, a superação disso não é algo que dependa só da nossa vontade, depende de transformações estruturais, da configuração desses espaços sociais. Então aí eu não tenho bola de cristal, não. A minha... eu acho que a única possibilidade é com a transformação dos espaços práticos. Quando você transforma os espaços práticos você cria uma demanda para a universidade (D8-médico).

Um estudo realizado por Olschowsky e Silva (2000), problematiza que a desarticulação entre o docente e os serviços da saúde desencadeia conflitos expressos em um processo de divisão do trabalho, no qual o docente se responsabiliza pela coordenação do ensino, ou seja, a parte mais intelectual da formação, enquanto o trabalhador do campo realizará o trabalho operacional ao qual é atribuído menos prestígio.

Outro aspecto tematizado por um entrevistado expressa que a desarticulação ensino serviço pode estar relacionada com a intencionalidade da universidade brasileira, em formar profissionais especializados. A ênfase na especialização da formação, provoca a rejeição ao modelo de formação 
compartilhada, constituído por meio de troncos comuns de formação como ocorre nos bacharelados interdisciplinares. Esta proposta possibilita a convivência entre os estudantes, afasta-se da centralidade técnico-científica e da profissionalização precoce. No próximo excerto, o docente comenta que a educação brasileira foi organizada em instituições tradicionais que influenciam a ideologia popular, voltada para a valorização das faculdades, que representam espaços de formação profissional específica, ao invés de valorizarem as universidades.

(...) a trajetória que a organização da educação no Brasil tomou... foi de sucessivas rejeições a modelos de educação compartilhada. Mesmo quando tivemos algumas experiências de integração, essas experiências, por mais energia institucional que tenha se investido, mais capacidade de mobilização política, tão logo o investimento na implantação cessa, o sistema conservador recua, faz recuar... Um exemplo ali, a idéia dos troncos comuns de formação. A própria reforma que os militares promoveram no Brasil, a reforma de 68, tinha um elemento positivo, que era colocar todos os aspirantes à formação profissional em um tronco comum de formação. E o lado mais positivo disso tudo é que faz com que os sujeitos tenham uma convivência durante seu período de formação (D7-médico).

A valorização da proposta contra-hegemônica do ensino universitário com troncos comuns de formação nas universidades brasileiras ficou evidente na Universidade Federal da Bahia (UFBA) em 2008, com a criação de quatro cursos de Bacharelado Interdisciplinar (BI): Ciência e Tecnologia, Humanidades, Artes e Saúde. Sendo que em 2009 foi implantado o BI Saúde (BIS), cujos eixos estruturantes são a determinação social do processo saúde-doença e os níveis de organização das práticas de saúde (Teixeira, Coelho, Rocha, 2013).

De acordo com os autores, no processo de implantação dos BIS muitos desafios precisam ser superados. Na perspectiva dos estudantes, os problemas estão no ingresso posterior aos cursos de graduação de progressão linear e na insegurança sobre a inserção no mercado de trabalho. Para os docentes, as questões estão relacionados à sobrecarga de trabalho, ao escasso número de docentes e a implantação concomitante do projeto dos BIS que está em elaboração. A maior tensão entre o modelo de formação superior hegemônico e o modelo do BI está na ênfase da interdisciplinaridade e ausência da fragmentação inicial por área profissional. 
As barreiras para o avanço da EIP, apontadas pelos entrevistados, remetem à aspectos organizacionais das universidades e dos cursos de formação em saúde. Entre os quais estão o modelo de organização das universidades públicas brasileiras, cuja estrutura é fragmentada, incompatibilidade das grades curriculares dos cursos de formação em saúde, dificuldades na articulação entre as universidades e os serviços de saúde e a necessidade de apoio institucional nas universidades.

As barreiras mencionadas, remetem a aspectos definidos por Martin Rodriguez et al. (2005) como determinantes organizacionais da colaboração, que podem ser considerados 'meso' determinantes, compreendidos como fatores dos processos organizacionais internos às instituições, entre os quais estão a estrutura organizacional e o suporte administrativo. A estrutura organizacional pode ser hierárquica ou horizontal, com potencial para compartilhar a tomada de decisão e a abertura de comunicação. O suporte administrativo, remete ao apoio dos administradores às atividades de colaboração interprofissional.

A partir dos determinantes organizacionais da colaboração elencados pelos autores, nota-se que o conjunto de depoimentos mostra que o movimento da EIP nas universidades brasileiras deste estudo ainda é incipiente, por isso, são necessários inventimentos em prol do desenvolvimento de condições organizacionais para implementar a EIP. A estrutura hierarquizada e fragmentada das universidades, não favorece a tomada de decisão compartilhada e também se identificou a ausência de apoio institucional para o avanço das propostas de EIP. 


\section{SÍNTESE DOS RESULTADOS DAS ENTREVISTAS}

Os relatos dos docentes nas entrevistas mostram que suas concepções da EIP na APS estão relacionadas com a reconfiguração das relações profissionais para o estabelecimento de práticas de saúde na perspectiva da integralidade centrada no usuário.

A categoria I, 'A educação interprofissional em saúde, desloca a ênfase da formação e das práticas para a integralidade do cuidado', foi construída a partir de subcategorias relacionadas com mudanças na formação em saúde em prol da integralidade, do cuidado interprofissional, em substituição ao predomínio da formação e prática fragmentada por disciplinas, com ênfase na especialização profissional. Perspectiva de formação que se aproxima dos pressupostos do SUS, como responsável pela orientação da formação em saúde e das DCN.

As quatro subcategorias identificadas na categoria I são: a formação orientada para atenção à complexidade das necessidades de saúde e a prática fragmentada predominante, formação para o trabalho em equipe interprofissional em redes de atenção à saúde, comunicação interprofissional para o cuidado e educação interprofissional em saúde: modelo de formação contra-hegemônico.

A percepção dos docentes, evidencia que a implementação da EIP está relacionada com a mudança do modelo de atenção, por meio da organização do trabalho estabelecido, com equipes integradas e colaborativas na rede de atenção, cuja prática está ancorada em relações intersubjetivas/interativas com foco no usuário.

Nesse sentido, os relatos mostram a importância da articulação dos saberes dos profissionais entre si e com os usuários, desde o curso de graduação, para constituir práticas voltadas para abordagem integral da complexidade das necessidades de saúde, com a construção de planos terapêuticos compartilhados.

Contudo, apontam que a proposta de integralidade do cuidado almejada, está tensionada pelo modelo biomédico hegemônico, expresso na 
fragmentação e especialização das práticas profissionais, com abordagem restrita das doenças para remissão de sinais e sintomas.

É importante considerar, que o modelo biomédico trouxe contribuições significativas para o tratamento de doenças, contudo a crítica realizada pelos entrevistados, sinaliza a necessidade de ampliação da abordagem das necessidades de saúde, tomando a subjetividade, aspectos sociais e culturais do contexto de vida dos usuários, em uma prática de cuidado interativa com a colaboração de profissionais de diferentes áreas.

A formação disciplinar uniprofissional é apontada como um componente que reforça a fragmentação dos saberes e práticas e revela o preparo insuficiente do estudante, frente à multidimensionalidade das necessidades de saúde.

O cuidado é reconhecido como um eixo comum das práticas de diferentes profissionais da saúde, por isso os entrevistados recomendam que seja incorporado na formação por meio da sugestão de diferentes modelos tecnoassistenciais, para organização das práticas de saúde na APS como: clínica ampliada e gestão da clínica que estão pautadas na diretriz da integralidade do SUS, que representa um horizonte para a reorganização do processo de trabalho em saúde. Indicam também estratégias/dispositivos de de intervenção relacionadas com os referidos modelos tecnoassistenciais, como o projeto terapêutico singular e consultas compartilhadas.

A inclusão da formação para o trabalho em equipe interprofissional, em redes de atenção à saúde, nos currículos dos cursos de graduação é indicada pelos docentes como um caminho para articulação interprofissional interativa colaborativa, por promover a integração entre o território, serviços, equipes, práticas profissionais e também a articulação intersetorial.

A comunicação para educação interprofissional é mencionada para o estabelecimento de práticas intersubjetivas entre trabalhadores e usuários por meio do agir comunicativo em prol do entendimento. De acordo com o relato de um entrevistado, os usuários devem ser considerados protagonistas do cuidado, por isso devem participar ativamente dos processos de tomada de decisão, juntamente com os trabalhadores da saúde, como discutido nas 
produções sobre clínica ampliada e também na prática interprofissional colaborativa centrada no paciente.

Os docentes apontam que a EIP consiste em um modelo de formação contra-hegemônico, tensionado pelo fato da formação e práticas de saúde estarem estruturadas sob a lógica biomédica disciplinar, medicalizada, especializada, caracterizada pela fragmentação e ênfase no agir instrumental, em detrimento ao agir comunicativo. Nesse contexto, destacam o papel do enfermeiro como articulador das ações profissionais em prol do cuidado.

A categoria II 'A educação interprofissional em saúde contribui para a reconfiguração das relações profissionais colaborativas', volta-se para as relações profissionais no tocante aos aspectos que tensionam e influenciam o estabelecimento de práticas colaborativas interativas necessárias na EIP. Esta compreensão foi elaborada a partir das seguintes subcategorias: influência dos estereótipos profissionais na interação, interesses profissionais limitam a ampliação do escopo das práticas para atender as necessidades de saúde, as interações interprofissionais pressupõe o respeito mútuo.

Os estereótipos profissionais são apontados pelos docentes, como uma consequência da ausência de reconhecimento do trabalho e papel profissional dos outros, situação que pode ser modificada com a EIP, que pressupõe a formação articulada entre duas ou mais áreas profissionais.

As práticas de cuidado também são sinalizadas como espaços potentes para desconstrução de esteriótipos negativos, com avanços no reconhecimento dos papéis profissionais e compartilhamento de um horizonte ético comum, necessário no agir comunicativo.

Os interesses profissionais, consistem em uma tensão para a EIP, pela competição, cerceamento da ação profissional dos outros para manutenção do escopo de práticas privativas de cada profissão e relações de poder. Nessas relações, os docentes destacam a fragmentação das práticas decorrente da divisão técnica do trabalho, a ausência de articulação entre os profissionais, devido o diferenciado status social entre as profissões, e o individualismo profissional, especialmente da medicina. Os docentes 
mencionam que em alguns casos, para as profissões não médicas, esta postura pode estar relacionada com o receio da perda da identidade profissional e do campo de trabalho no mercado. O reconhecimento profissional ocorre pelo domínio de determinado saber, que muitas vezes é utilizado como um mecanismo de expressão do poder profissional. Por isso, os entrevistados consideram a necessidade de colocar o direito à saúde e a ampliação da concepção sobre o processo saúde-doença, como aspectos centrais para reconfiguração das relações profissionais, a fim de constituir práticas interprofissionais colaborativas, com interação, compartilhamento e reconhecimento da complementaridade dos saberes para a qualidade da atenção aos usuários.

Os docentes apontam, que o respeito ao outro, constitui as relações interprofissionais colaborativas centradas no usuário, com reconhecimento do papel profissional dos outros. O compartilhamento de valores éticos comuns no mundo da vida, no tocante ao respeito ao outro é um requisito necessário para o agir comunicativo. Os relatos mostram que a EIP pode contribuir para desenvolver o respeito aos outros profissionais e usuários, contudo, a assimetria presente na relação entre profissional e usuário pode prejudicar o desenvolvimento do agir comunicativo e as possibilidades de negociação para tomada de decisão e aprendizado com os outros.

A categoria III 'Preservação da especificidade profissional das competências complementares, reconhecimento das competências comuns e

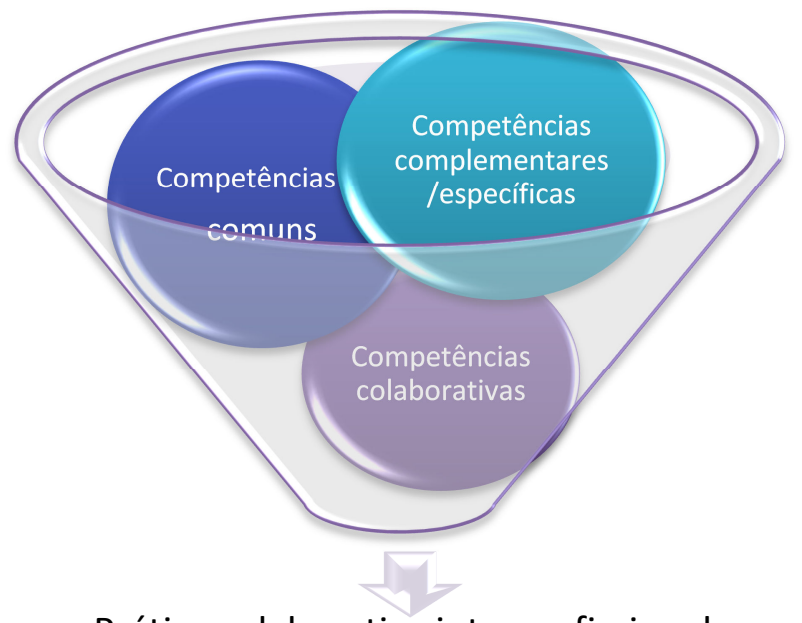

Prática colaborativa interprofissional

Figura 8. Três tipos de competências profissionais de Barr (1998), adaptado de IPEC (2011). 
construção das competências colaborativas', mostra que a EIP deve articular a construção de competências profissionais específicas, comuns e colaborativas para avançar em direção à prática colaborativa.

As subcategorias relacionadas ao tema são: 'a formação em saúde com ênfase nas competências complementares/específicas e comuns', 'preservação da especificidade da identidade profissional na competência complementar/específica', 'influências da educação interprofissional em saúde na construção da competência colaborativa: dinâmica de funcionamento das equipes de saúde', 'a educação interprofissional em saúde possibilita o reconhecimento das competências comuns'.

Os docentes concordam que a formação em saúde requer a articulação de momentos voltados para a especifidade profissional das competências complementares e também para competências comuns do campo das práticas de saúde. Esta proposta de formação articulada, possibilita a socialização dos papéis profissionais e sinaliza a complementariadade e interdependência entre os saberes profissionais, características necessárias para a construção da prática colaborativa em equipe, com o compartilhamento dos saberes.

No contexto da prática interprofissional, um entrevistado defende que o núcleo profissional específico, deve ser explorado e preservado ao apontar o receio pela confusão de papéis, pelo fato de diferentes categorias profissionais desenvolverem as mesmas ações, deixando de lado a especificidade de sua atuação.

Um aspecto que pode tensionar o crescimento da EIP é a preocupação com a preservação da especificidade da identidade profissional tematizada pelos entrevistados devido o receio em perde-la. Afirmam que a articulação interprofissional pode provocar a negação da identidade profissional, por isso propõe a formação centrada no núcleo profissional específico. Um entrevistado exemplifica esta questão, ao mencionar a perda da identidade profissional quando assume competências profissionais específicas de outra profissão. Nesse sentido, os relatos reforçam a 
importância das competências complementares, específicas de cada área para a EIP.

Como uma das finalidades da EIP é promover a formação para o trabalho em equipes integradas colaborativas, os relatos evidenciam a relevância do debate sobre o funcionamento das equipes de saúde. Mencionam características das equipes como: objetivos comuns e avaliação do trabalho, com reconhecimento dos limites do saber e possibilidades de complementaridade com o saber dos outros, para processos de tomada de decisão compartilhada.

A EIP possibilita o reconhecimenro das competências comuns do campo da saúde, mediante a interação, compartilhamento de saberes e transição entre as fronteiras profissionais. Os entrevistados indicam que as competências comuns do campo de práticas, ampliam a responsabilização dos profissionais e das equipes, com flexibilidade na dinâmica de trabalho. Mencionam alguns espaços de trabalho na saúde que se constituíram como campos interprofissionais, com práticas comuns: saúde mental, saúde coletiva, saúde pública. Também apontam saberes e ações interprofissionais relacionados à promoção, prevenção e educação em saúde.

Os relatos dos docentes também mostram barreiras para EIP relacionadas ao: modelo de organização da universidades públicas brasileiras cuja estrutura é fragmentada, incompatibilidade das grades curriculares dos cursos de graduação em saúde, dificuldades na articulação entre as universidades e os serviços da saúde e a necessidade de apoio institucional nas universidades.

A estrutura fragmentada e departamentalizada das universidades, reforça a ênfase na especialização do saber técnico-profissional, que dificulta a articulação entre os cursos de graduação. Nesse contexto, os entrevistados apontam a lógica produtivista das universidades, como um limite para a construção de mudanças curriculares em direção à EIP, pelo fato das atividades de pós-graduaçao, serem privilegiadas em detrimento às ações na graduação. 
A necessidade da articulação ensino-serviço é reconhecida pelos entrevistados, que indicam a interdependência entre a formação e as práticas da saúde, para atenção às necessidades dos usuários.

As barreiras apontadas pelos entrevistados não foram analisadas em profundidade, mas indicam que o movimento da EIP depende de investimentos na organização das universidades estudadas, para implementar estratégias de mudança na formação em saúde. 


\section{SEGUNDA PARTE: RESULTADOS E DISCUSSÃO DOS GRUPOS FOCAIS}

Foram realizados quatro grupos focais homogêneos, compostos por diferentes atores sociais, trabalhadores de duas UBS diferentes, docentes e estudantes, envolvidos na formação de profissionais da saúde no contexto do PET-Saúde em cenários da APS.

Os resultados representam a voz de cada um desses atores sociais, suas concepções sobre a EIP, as perspectivas de articulação da EIP com as práticas de saúde da APS e possibilidades de engajamento no tocante ao avanço da EIP. $\quad \mathrm{Na}$ análise dos relatos, identificaram-se diferenças significativas entre os GF, por isso os resultados estão apresentados individualmente para cada grupo focal.

\section{GRUPO FOCAL DE TRABALHADORES DA UNIDADE A}

O grupo focal de trabalhadores da unidade A, contou com nove participantes, entre os quais, um cirurgião dentista, um farmacêutico, três enfermeiros de equipe da ESF, um enfermeiro da equipe de vigilância, um médico de equipe da ESF, um assistente social e o gerente da UBS, com idades entre 28 e 57 anos e média de 40,6 anos. Cerca de oito participantes possuem especialização lato sensu e um tem formação em nível de mestrado. O tempo de trabalho com a formação em serviços de saúde varia de 3 a 25 anos, com média de 9,7 anos, sendo que o tempo médio de trabalho no SUS é de 11, 2 anos (Quadro 2). 
Quadro 2 - Perfil dos trabalhadores participantes do grupo focal da unidade A.

\begin{tabular}{|l|c|c|c|c|c|}
\hline $\begin{array}{c}\text { Código do } \\
\text { participante do } \\
\text { GF / Categoria } \\
\text { profissional }\end{array}$ & Sexo & Idade & Pós-graduação & $\begin{array}{c}\text { Tempo } \\
\text { trabalho } \\
\text { educação } \\
\text { (anos) }\end{array}$ & $\begin{array}{c}\text { Tempo } \\
\text { no SUS } \\
\text { (anos) }\end{array}$ \\
\hline Assistente social & $\mathrm{F}$ & 44 & $\mathrm{M}$ & 6 & 11 \\
\hline Enfermeiro 1 & $\mathrm{M}$ & 30 & $\begin{array}{c}\text { Lato-sensu } \\
\text { Mestrado } \\
\text { cursando }\end{array}$ & 6 \\
\hline Enfermeiro 2 & $\mathrm{F}$ & 57 & Lato-sensu & 25 & 25 \\
\hline Enfermeiro 3 & $\mathrm{F}$ & 42 & Lato-sensu & 11 & 20 \\
\hline Enfermeiro 4 & $\mathrm{F}$ & 57 & Lato-sensu & 17 & 14 \\
\hline Farmacêutico & $\mathrm{F}$ & 40 & Lato-sensu & 3 & 6 \\
\hline $\begin{array}{l}\text { Gerente/ } \\
\text { enfermeiro }\end{array}$ & $\mathrm{F}$ & 33 & $\begin{array}{c}\text { Lato-sensu } \\
\text { Mestrado }\end{array}$ & 7 & 10 \\
\hline Médico & $\mathrm{M}$ & 35 & Lato-sensu & 4 & 6 \\
\hline Odontólogo & $\mathrm{F}$ & 28 & Lato-sensu & 5 & 3 \\
\hline
\end{tabular}

Fonte: Arquivo da pesquisadora.

Os trabalhadores da unidade A, tematizam os seguintes elementos relacionados à implementação da EIP:

Figura 9. Resultados do grupo focal dos trabalhadores da unidade A. São Paulo, 2014.

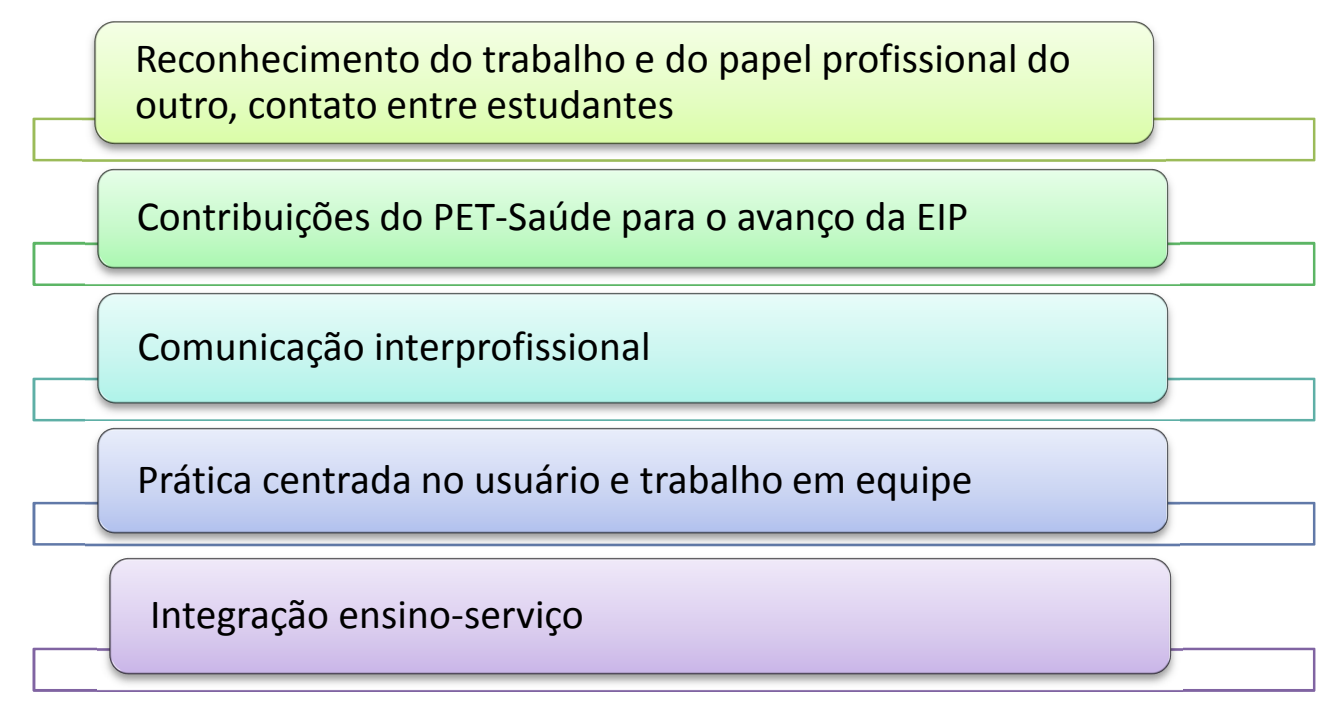

O reconhecimento do trabalho e do papel profissional dos novos parceiros de trabalho é tematizado pelos participantes, como uma característica da prática compartilhada. O próximo relato, mostra que a presença de novas profissões no contexto da formação e das práticas com a 
introdução do NASF, estimulou o reconhecimento dos papéis profissionais das profissões que não são consideradas nucleares na área da saúde, em virtude da oportunidade de trabalho compartilhado

(...) em reunião técnica, que a gente estava com dificuldade que os alunos da terapia ocupacional... que elas foram fazer oficina para falar o que era a terapia ocupacional... lembra?... foi... foi muito marcante para a gente e me remeteu agora quando eu estava falando, com essa vivência da entrada dos alunos de outros cursos de graduação, assim, que não os mais nucleares na saúde, foi um impacto que a gente teve, que é o mesmo que acontece quando chega o NASF (....) (Gerente - Unidade A).

Eu acho que o maior impacto de outros profissionais foi a chegada do NASF. Eu acho, porque assim... na minha opinião, o impacto de novos profissionais, das novas categorias. Eu lembro que no segundo dia que o NASF estava aqui a vigilância já comprou uma briga com ele, porque ele... não queria ver na área posto uma pessoa... não entendia o que era NASF na verdade, não tinha essa questão do entendimento do que realmente tinha que fazer, nunca tinha nem ouvido falar em NASF, na verdade, nessa época, logo que chegou. Então, para mim foi um pouco impactante, até você apreender o que realmente a equipe veio fazer, o que pode fazer, o que eles são destinados a fazer. Eles recebem ordens também, eles tem regras também, igual à gente. Mas a gente meio que queria um... queria tudo para a gente assim... A gente achava que vinha .? (Enfermeiro 1 - Unidade A).

O reconhecimento do trabalho e do papel profissional do outro é um atributos da EIP e da prática colaborativa (Khalili et al., 2013; Pereira, Rivera, Artmann, 2013; Orchard et al., 2012; MacDonald et al., 2010; Martin Rodriguez et al, 2005; CIHC, 2010; IPEC, 2011). A seguir o trabalhador refere a necessidade de que esse reconhecimento aconteça durante a formação da graduação.

(...) é, quer dizer, é um reflexo mesmo da... acho que a gente volta naquela questão do começo da discussão, de que é uma falha de formação mesmo. As pessoas... assim... eu fui descobrir o trabalho do terapeuta ocupacional... realmente o que essas pessoas fazem? elas vão até onde?... até onde que engloba o trabalho?, o que vai agregar para o meu trabalho?, depois de muito tempo de prática conjunta (Médico - Unidade A).

As escassas oportunidades de aprendizado compartilhado entre estudantes de diferentes cursos, prejudica o reconhecimento dos papéis profissionais (Zwarenstein, 2009; MacDonald et al., 2010; Orchard, 2010; Ateah et al., 2011; Jackobsen et al., 2011; Barwell et al., 2013).

O reconhecimento do papel profissional dos outros, contribui para evitar o isolamento profissional, característico da prática médica, mediante a compreensão da insuficiência do saber, de uma única profissão, para responder a complexidade das necessidades de saúde dos 
usuários/população. A seguir, o participante refere que a composição da prática com estudantes e outros profissionais amplia as possibilidades de intervenção com a contribuição de outros conhecimentos específicos.

(...) eu acho que o impacto é o reflexo da falta de conhecimento sobre o papel das pessoas... ... um saber isolado... e a gente... nós médicos... a gente tem bastante dificuldade de respeitar saberes diferentes... porque a gente foi treinado dentro do raciocínio clínico e como se só a gente conseguisse fazer isso... como se a gente só pudesse fazer isso... e às vezes as pessoas perdem oportunidades... não sabem quanto que estão perdendo... às vezes o paciente perde, nosso cliente principal, por... pela gente não dividir saberes com as outras pessoas, né. A gente tem tido essa experiência com outras equipes, com alunos também... às vezes de você estar tão focado naquele caso por tanto tempo... e vem o aluno e te abre outra porta que você diz - nossa, sabe que não tinha olhado por esse ângulo ainda, ou vem um outro profissional que tem um outro conhecimento específico que pode agregar para caramba naquele contexto... (Médico - Unidade A).

O entendimento sobre o trabalho e papel dos outros profissionais é uma competência necessária para a EIP e prática colaborativa. Indica onde começa e termina o escopo de práticas de um profissional, a abertura para contribuições de outros membros da equipe, envolve a superação de estereótipos profissionais, o respeito ao papel e conhecimento dos outros, assim como, constitui um caminho para a valorização das contribuições dos outros membros da equipe (Mc Donald et al., 2010; CIHC, 2010).

Outro aspecto mencionado pelos participantes do GF da unidade A é a necessidade do trabalho em equipes colaborativas, para atenção das necessidades do usuário, aspecto que remete à mudança no modelo de atenção biomédico para a perspectiva da integralidade. A seguir, o trabalhador afirma, que sem articulação com os outros profissionais da equipe, não será possível resolver os problemas dos usuários.

(...) você não consegue oferecer uma atenção integral focada exclusivamente no seu nicho de saber, para mim é simples assim. Ou você abre... atualmente, né, eu trabalho como médico de família, já dá trabalho você ter que atender criança, ter que atender gestante, atender idoso, atender saúde mental... um monte de coisas... e a gente? O interessante nesse processo é que assim... se provou, se sabe que não é o médico o detentor absoluto do saber. Ou você vai pesquisar e conversar com outros profissionais e vai resolver junto ou você não vai resolver (Médico Unidade A).

No relato anterior o trabalhador também questiona a medicalização, ao considerar que os problemas de saúde dos usuários não são exclusivos do profissional médico (Zorzanelli, Ortega, Bezerra Junior, 2014), por isso é 
necessário que haja articulação com outros trabalhadores da equipe de saúde no processo de trabalho

A articulação das equipes e profissionais do serviço, por meio do reconhecimento dos papéis, desencadeia a corresponsabilização pelas necessidades dos usuários que devem orientar as práticas de saúde. A atenção centrada no usuário é reconhecida como uma mudança necessária para fortalecer o trabalho em equipe. A seguir, o depoimento mostra que a articulação entre os profissionais da equipe do serviço, desencadeou o consenso de que os problemas dos usuários são responsabilidade de todos os trabalhadores da UBS.

(...) o que trouxe após essa decisão... Antes era assim... surgia um problema, - ah, esse problema é relacionado a farmácia? Ah, então não é meu, veja com a enfermagem, esse problema é de vigilância? Ah, então o problema é da farmácia. Agora não, quando você passa a conhecer o processo do outro, você entende... você começa a enxergar que o problema chega... pode não ser da farmácia... chega uma demanda que é da enfermagem ou da vigilância... mas a gente já não trabalha mais assim: ah, isso não é um problema meu, é do outro. Esse problema é nosso porque o usuário é nosso. Então, aguarde um momentinho, se não for comigo vou encaminhar o senhor corretamente para o setor correto ou alguém que vá realmente prestar esclarecimentos adequados sobre o seu caso. E eu sinto que é feito da mesma forma com a farmácia, assim... não é algo que ah, isso não é um problema meu, é da farmácia, e joga lá. Não, é nosso. O problema passa a ser comum e não mais - isso não é meu, é do outro -. Então isso foi muito... (Enfermeiro 2 - Unidade A).

A responsabilização dos profissionais pelos resultados do cuidado aos usuários é uma característica da proposta nacional de clínica ampliada (Campos, 2007a) e também consiste em um dos atributos do trabalho em equipe na prática interprofissional colaborativa e da EIP (Silva, 2014; Pelzang, 2010; Orchard, 2010; CIHC, 2010; Baindridge, Nasmith, Orchard, 2010; Carpenter, Dickinson, 2008; Curran, Kabene, 2005; Oandansan, 2004).

O estabelecimento do trabalho coletivo em equipes colaborativas, possibilita a construção de uma nova cultura de trabalho com responsabilidades e interesses coletivos. Segundo o relato a seguir, os resultados do trabalho são atribuídos à equipe e não a uma categoria profissional específica. Também refere, que o trabalho colaborativo estabelecido favorece o compartilhamento do foco das práticas de saúde, em torno do tripé: necessidades dos usuários, ensino de estudantes nas UBS e pesquisa para o aprimoramento das práticas e da formação. 
(...) e isso tem que ser fortalecido, cada vez mais, até pelo ‘empoderamento' e pelo resultado também, né. A gente não... quando o resultado é bom a gente dilui isso com a equipe toda... e quando o resultado é ruim também... Quando o desempenho é ruim, os nossos indicadores são ruins porque a equipe não ajudou. E não simplesmente porque uma categoria não desempenhou o seu papel corretamente. Então, essa proximidade possibilita isso também, da gente compartilhar os nossos resultados e o nosso foco... que muitas vezes fica meio obscuro, né?, mas se o nosso foco realmente está no usuário, se o nosso foco está na pesquisa... está na educação... a gente tem que se conversar muito para que isso ande. Esses diferentes focos eles se... para que um não atrapalhe o outro. Se a gente não se fala, essas coisas não fluem... (Médico Unidade A).

O comprometimento do trabalho das UBS com o tripé, ensino, pesquisa e assistência, resulta em uma necessária reorganização das demandas de trabalho e da articulação ensino-serviço. Os depoimentos mostram que os gestores da prefeitura e da universidade, responsáveis pelas UBS, tem prioridades diferentes que deveriam ser consideradas por ambos, como as metas de produtividade da assistência e o ensino, a fim de evitar prejuízos nos resultados das práticas e na avaliação dos serviços.

Engraçado que nós temos gestores que são envolvidos... são docentes da universidade e temos docentes que são da Prefeitura. E eles nos cobram coisas diferentes... os gestores da Prefeitura não estão muito interessados em saber se tem aluno... se a educação está boa... (Médico - Unidade A).

Eles querem números... querem produtividade (Odontólogo - Unidade A).

(...) e isso para o gestor vinculado à universidade... esse foco também muda. Tanto é que as nossas metas e prioridades elas são diferentes do restantes das UBS, mas é muito difícil lidar com esse equilíbrio, né. Você... fala - tá, a nossa meta não é $100 \%$, não é uma meta cheia, mas é uma meta qual? Preciso fazer o que para não comprometer a assistência... (Médico - Unidade A).

A perspectiva de articulação do ensino, pesquisa e assistência corrobora com a indissociabilidade entre ensino, pesquisa e extensão no contexto da formação universitária em saúde. O tripé preconizado pela universidade e UBS, contribui para a integração entre a ciência e a realidade social, que pode ressignificar as práticas de saúde e qualificar a atenção ao usuário.

A ampla articulação ensino-serviço, com o envolvimento da pesquisa, pode ser considerada um recurso pedagógico que contribui para a formação e educação permanente dos trabalhadores inseridos nos serviços (Ellery, Bosi, Loiola, 2013), assim como para a sustentabilidade de inovações tecnoassistenciais inseridas nos serviços, na medida em que os profissionais sentem-se co-participantes dos processos de mudança. 
O ensino nos serviços, também requer investimentos na comunicação com a gestão do serviço e do ensino, para avançar na qualidade do trabalho. No próximo excerto, o trabalhador refere a necessidade de comunicação e pactuação das metas para o trabalho com gestores do SUS da região, representados pela OSS e docentes da universidade. $\mathrm{O}$ trabalhador considera, que a comunicação com a macrogestão, pode contribuir para a necessária reorganização do processo de trabalho na UBS, frente às demandas por metas de produção. Aponta, que após quatro anos, os trabalhadores avançaram no trabalho em equipe colaborativo e construíram um processo de corresponsabilização pelo trabalho desenvolvido na unidade.

(...) a gente está em um processo de tensionamento agora, que eu acho que a gente conseguiu aqui dentro da unidade... mudar bastante os nossos fluxos de comunicação. Muito. A gente evoluiu absurdamente... e a gente está em um momento de tensionar mesmo para melhorar essa comunicação com a 'macro gestão'. Está na hora assim... não dá... essas dificuldades de comunicação... desde o docente lá da cadeira da universidade com a gente... tem que se estreitar, e isso passando pela gestão da OS também. Então é um momento assim... você está fazendo a sua pesquisa dentro do foco do nosso tensionamento com essa... O nosso embate atual é com comunicação, com a 'macro gestão'. Mas o fato de nós nos termos fortalecido em esses anos... nesses $3 \ldots 4$ anos passados... faz com que a nossa conversa mude de tom nesse momento. Eu não sou mais o médico agora falando que eu estou cheio de alunos para resolver... nós somos um grupo, somos uma unidade... temos unidades escola, e a gente precisa se conversar, porque senão o trabalho não flui (Médico Unidade A).

A comunicação é um dos indicadores da prática colaborativa interprofissional, que tem como desdobramento a capacidade de negociar frente à diferentes opiniões (IPEC, 2010; D'Amour et al., 2005; Martin Rodriguez et al., 2005, Suter et al., 2009).

O cuidado centrado no usuário, também é tematizado a partir do foco nos resultados do cuidado. Essa prática requer a articulação interprofissional, para responder as necessidades do usuário, antes que seja realizado o encaminhamento para especialistas.

A efetividade da EIP, pode ter como desdobramento a prática centrada no usuário e sua satisfação, devido a ampliação da qualidade das práticas de saúde (Reeves et al., 2013).

(...) eu acho que a gente teve pressões também da própria rede, da própria estruturação da rede, sendo que se você for marcar uma fisioterapia para um paciente, ou ela não vai acontecer nunca, ou você vai procurar os recursos que você tem dentro da unidade. Desde estágios, 'fisio' do 
NASF, a gente tem que 'sambar' para conseguir. Então, a partir do momento que o foco está no resultado, o foco está na satisfação do usuário, na nossa própria resolutividade como profissional, a gente tem que 'sambar' entre as categorias para conseguir resolver (Médico Unidade A).

A mudança do modelo de atenção à saúde, com deslocamento da ênfase das práticas da saúde, pautadas no modelo biomédico, para a integralidade do cuidado, no qual o objeto de intervenção deixa de ser a doença para atender as necessidades de saúde dos usuários, está relacionada à prática centrada no usuário. Nesse processo, como o trabalhador acima menciona, o foco está na satisfação do usuário e depende da dedicação do profissional, em abordar as necessitadas do usuário frente aos limites da rede de atenção para os encaminhamentos. A opção de centrar o processo de trabalho nas necessidades dos usuários, significa produzir melhores resultados no tocante às necessidades identificadas.

$\mathrm{Na}$ prática centrada no usuário, a comunicação é um elemento central, assim como, para o trabalho em equipes integradas. Nos próximos relatos os trabalhadores referem que a comunicação com troca de saberes é uma condição necessária para atenção ao usuário.

(...) quer dizer... para o nosso cliente, o nosso usuário... isso é um aspecto positivo para ele, enfim, toda essa troca em questão entre os profissionais, isso vai ser voltado para o atendimento ao cliente (...) (Assistente Social Unidade A).

(...) se isso acontece não funcionaria... porque na atenção básica, se não existir a comunicação entre os profissionais é igual a uma orquestra, se alguém tocar errado já vai acabar com tudo. Então isso é impossível que venha acontecer aqui, porque não existe essa... é uma continuidade e a comunicação ela tem que existir sempre (Enfermeiro 1 - Unidade A).

Falhas na comunicação interprofissional tem como consequência erros clínicos, prejuízos à segurança do paciente e à qualidade da atenção (Brock et al., 2013; Reeves et al., 2013). A EIP pode ser uma alternativa para o aprendizado dos elementos críticos para comunicação no trabalho em equipe.

A comunicação para o trabalho em equipe é definida como o aprendizado de habilidades que fortalecem os trabalhadores para a prática colaborativa. Consiste em uma competência para a prática segura, que requer efetiva comunicação com pacientes e parceiros de trabalho mediante a escuta ativa e respeito ao outro. Falhas ocorrem, quando informações vitais não são comunicadas ou analisadas conjuntamente, devido as 
dificuldades de interação, problemas de relacionamento interpessoal e falta na clareza da definição dos papéis profissionais (Brock et al., 2013).

A EIP prepara para o trabalho coletivo em equipe, pois favorece que o estudante desenvolva habilidades de comunicação e interação grupal. Nesse sentido, a seguir o trabalhador considera a importância da formação interprofissional, no preparo dos estudantes para escuta com abertura para o diálogo e discussão grupal com a busca de entendimento e consensos.

$\mathrm{Eu}$ acho que se ele tiver isso na formação dele, esse contato com outras categorias, após formação dele e inserção nos serviços como profissional, ele não encontrará dificuldades. Acho que se for uma formação que é muito centrada só em um grupo, sem interagir com os demais, esse profissional vai ter muita dificuldade de troca com as demais categorias (...). Porque foram muitos anos focado só em um grupo, em que ele acaba não enxergando o outro, as outras categorias. Então, na formação dele, ele é preparado só para discussões no próprio grupo, quando ele sair e tiver que interagir com outros grupos, ele vai ter uma cabeça, vai ter muita dificuldade, vai ter muito choque de comunicação, de se colocar, ou de aceitar a colocação do outro, o que é pior. Que muitas vezes a pessoa vai se colocar mais não aceita que você não está habituada a ouvir... mesmo que as visões sejam diferentes, que ela pense 'a', que eu pense ' $b$ ', que o ele pense 'c'... nessa formação (...) você aprende a... a enxergar o que? Não importa que pense $a, b$ ou c,de três formas diferentes, qual é o consenso do grupo? Vai ser o a? Vai ser o b? Ou vai ser o c? Ou de repente a solução vai ser o $d$. De repente eu enxergo o b porque ele me mostrou, ao ouvi-lo ele me mostrou um lado que eu não tinha enxergado, ou vice-versa. Pode ser que o meu modo de me expressar faça os demais enxergarem algo que não estavam enxergando antes (Farmacêutico Unidade A).

A ênfase colocada na comunicação para EIP, refere-se ao compartilhamento do mundo da vida, desde a formação com o compartilhamento de um horizonte ético na constituição das práticas profissionais. No agir comunicativo em busca do entendimento, os atores sociais em interação, expressam sua opinião para a construção de consensos e também podem utilizar o agir estratégico, a fim de convencer os interlocutores.

A experiência interprofissional do PET-Saúde promove o aprendizado compartilhado do trabalho em equipe, com a troca de saberes. Os trabalhadores referem que o PET, possibilita o aprendizado mútuo de trabalhadores e estudantes.

Eu senti que com o PET os alunos vêm para a sua sala... e você fala puxa, o que eu vou ensinar para eles, eu percebi que a gente acaba tendo mais dúvidas do que eles... porque eu acabo perguntando mais coisas para o aluno do que.. que você faz... quando você faz... o que está fazendo agora... acho que acaba aprendendo mais do que os alunos... dependendo das vezes... é super legal... (Odontólogo - Unidade A). 
A interação com troca de conhecimentos entre áreas profissionais contribui no preparo para o trabalho em equipe. Os trabalhadores relatam que o PET-Saúde, favorece a compreensão da importância da prática compartilhada com a composição do saber de outros profissionais para o desenvolvimento do trabalho em equipes colaborativas.

A EIP tem como desdobramento o preparo para o trabalho em equipe, mediante à interação dos estudantes de diferentes cursos durante a formação (Reeves et al., 2013, 2008; Thistlethwaite et al., 2010; WHO, 2010; Barr et al., 2005).

(...) se graduou...na atenção primária o contato... pelo menos no PET, nos proporcionou que...você enxergar que você... é necessária essa troca de conhecimentos com outras profissões também... e o quanto isso dá retorno para as instituições que estão formando os alunos... a necessidade de preparar esses novos profissionais aí do futuro... a saber trabalharem em uma equipe 'multi' (Farmacêutico - Unidade A).

(...) mas eu também percebo assim... que esse... entrosamento, toda essa troca trouxe uma coisa que é a transdisciplinaridade... que eu acho que um... acaba aprendendo com o outro e às vezes, cada profissional lógico, na sua competência, mas tem umas certas interfaces entre os profissionais, entre as graduações... eu percebo isso também (Enfermeiro 4 - Unidade A).

Outra contribuição do PET-Saúde referida pelos trabalhadores é a integração entre os profissionais dos serviços da APS. Como referido em outros relatos, essa integração pode estar relacionada com a compreensão compartilhada sobre o objeto de trabalho, as necessidade de saúde dos usuários, que estimulam o reconhecimento dos papéis profissionais e a construção da prática compartilhada para atenção à saúde.

As oportunidades de encontro e realização de atividades conjuntas por meio do trabalho compartilhado, caracterizado pela interação entre os profissionais faz parte da colaboração efetiva (D’Amour et al.,2008).

O resultado mencionado mostra o processo de mútua influência entre as mudanças ocorridas na formação em saúde e no processo de trabalho (Capozollo, Feuerwerker, 2013; Frenk et al. 2010; Oandansan et al., 2005; Feuerwerker, Sena, 2002), pois o PET constitui uma atividade de ensino que desencadeia a ressignificação das práticas de saúde em prol da prática interprofissional colaborativa.

(...) aqui na UBS: a gente tinha... vamos dizer assim... uma relação de composição, mas não inter-relação nas categorias profissionais. Era bem 
separado assim...o grupo dos médicos, o grupo dos enfermeiros e os outros. Eu venho percebendo assim... a gente tem forçado o encontro e o PET favoreceu para isso, acho que até a nossa dificuldade estrutural de dividir espaço, para todo mundo fazer a sua parte... e saber que o seu é importante... o seu também é importante para o meu e a construção das agendas (...) (Gerente - Unidade A).

Os relatos mostram que o contato entre estudantes de diferentes áreas não é planejado no contexto da universidade. O contato acontece espontaneamente nos serviços, durante os estágios e após a formação na prática profissional. O PET-Saúde possibilita a participação dos estudantes no planejamento das atividades, em conjunto com os trabalhadores do serviço, diferentemente do que geralmente ocorre com a fragmentação do ensino, no qual as atividades de planejamento são realizadas pelos docentes da universidade e a execução pelos trabalhadores dos serviços.

A dificuldade de articulação ensino-serviço, também foi tematizada anteriormente nos resultados relacionados às barreiras para EIP. De modo correlato, a fragmentação do ensino mencionada pelos trabalhadores no próximo relato, os docentes entrevistados, também apontaram a divisão do trabalho entre a universidade, que planeja o ensino, enquanto os serviços de saúde executam (Olschowsky, Silva, 2000).

(...) a gente que força esse diálogo... (Gerente - Unidade A).

(...) ela não existe dentro da universidade... Engraçado que isso também não mudou. Que eu venho de uma formação que foi exatamente dessa forma... a gente só via os outros cursos ou nas festas ou na extensão... e a gente não tem contato. Só vê em estágios que coincide de você estar na mesma enfermaria com os outros alunos, mas que também... eu do meu ponto de vista de aluno de medicina... ele da enfermagem... sem pensar nada em conjunto. E a vantagem é que a extensão, pelo menos nesses dois últimos anos tem ganhado aqui, é que a gente tem responsabilizado bastante os alunos pela criação das coisas...dos trabalhos. E não simplesmente pela reprodução, pela execução de um trabalho que foi pensado pela universidade. Os alunos no PET pelo menos eles tem a possibilidade de criar as coisas, conjuntamente... (Médico - Unidade A).

(...) eu estou há 7 anos na atenção básica... e só aqui eu fui ter essa vivência da interdisciplinaridade, da questão do convívio múltiplo de todas as áreas, né. Antes, quando a gente pensava em atenção básica, pensava-se apenas em medicina e enfermagem é, no máximo odonto. E quando você consegue ter essa vivência com todas as áreas juntas assim... e os alunos eles sentem esse impacto, eles se surpreendem, exatamente... com essa troca de... conhecimentos de diversas áreas. Tipo a terapia ocupacional, se envolve com a odonto, a odonto se envolve com a enfermagem, a enfermagem se envolve com a nutrição. Então, como essa... e a gente também se surpreende... e quando tive esse primeiro contato aqui, que foi a primeira unidade escola que eu vim trabalhar, então... então esse contato também me deixou surpreendido assim... Porque você aprende muita coisa... (Enfermeiro 1 - Unidade A). 


\section{SÍNTESE DOS RESULTADOS DO GRUPO FOCAL DA UNIDADE A}

Os trabalhadores da unidade $\mathrm{A}$, consideram que a articulação das equipes e profissionais, por meio do reconhecimento dos papéis, desencadeia a desconstrução dos estereótipos profissionais e a corresponsabilização pelas necessidades de saúde dos usuários. Os participantes do grupo, reconhecem que a articulação entre os profissionais é fundamental para atender a complexidade das necessidades de saúde.

Apontam a fragilidade da integração ensino-serviço, devido a ausência do planejamento articulado das atividades de ensino entre a universidade e o serviço. A fragmentação do ensino está expressa no planejamento de atividades pelos docentes da universidade e execução pelos trabalhadores dos serviços

Nesse sentido, o PET-Saúde cumpre o papel de política indutora para o fortalecimento da articulação ensino-serviço. Os relatos apontam que o PET contribui para a participação dos trabalhadores e estudantes no planejamento conjunto das atividades a serem desenvolvidas.

O PET-Saúde foi sinalizado como um elemento que pode contribuir para o avanço da EIP pois: possibilita a convivência entre diferentes áreas profissionais durante a formação, contribui para o reconhecimento dos papéis profissionais tanto de estudantes como de trabalhadores do serviço, promove a integração entre os trabalhadores do serviço, a construção da prática compartilhada e prepara os estudantes para o trabalho em equipe.

O deslocamento da ênfase das práticas para as necessidades de saúde do usuário, remete à prática centrada no usuário, que segundo os participantes do GF tem como desdobramentos, o fortalecimento da comunicação, do vínculo com o usuário e o estabelecimento do trabalho em equipes colaborativas.

O processo de trabalho da UBS de ensino está pautado no tripé: assistência à saúde, pesquisa e ensino. Os depoentes consideram a necessidade de equacionar as referidas demandas do tripé que intensificam o 
ritmo de trabalho e o tornam mais complexo. As contradições entre as expectativas dos gestores da prefeitura e da universidade, tensionam o cotidiano de trabalho nas UBS, pois a produtividade da assistência é influenciada pela presença das demandas de ensino que muitas vezes não são consideradas pelos gestores. Por isso, os trabalhadores da unidade A, ressaltam a necessidade de comunicação com os gestores para equacionar as demandas.

Na perspectiva dos trabalhadores da unidade A, a EIP corresponde à formação integrada com interação entre diferentes áreas profissionais que depende do reconhecimento do trabalho e do papel profissional do outro com respeito e disponibilidade em colaborar em prol da prática centrada no usuário.

É importante destacar que os depoimentos apresentam a utilização indiscriminada dos termos multiprofissional, transdisciplinar e interdisciplinar, mas em geral não mencionam o termo interprofissional. Este aspecto não foi analisado no conjunto de relatos, por isso indica-se a necessidade de desenvolver pesquisas sobre o tema.

\section{GRUPO FOCAL DE TRABALHADORES UNIDADE B}

No grupo de trabalhadores da Unidade B, houve seis participantes, com idades entre 29 e 49 anos, cuja média é de 36 anos, entre os quais quatro enfermeiros de equipe da ESF, um farmacêutico e um gerente. No tocante à formação, cinco possuem especialização lato sensu, um mestrado e um doutorado. O tempo de trabalho com a formação em saúde varia entre dois e 27 anos, com média de 11,6 anos, sendo que, o tempo médio de trabalho no SUS é de 10,3 anos (Quadro 3). 
Quadro 3 - Perfil dos trabalhadores participantes do grupo focal da unidade B.

\begin{tabular}{|c|c|c|c|c|c|}
\hline $\begin{array}{c}\text { Código do } \\
\text { participante do } \\
\text { GF/ Categoria } \\
\text { profissional }\end{array}$ & Sexo & Idade & Pós-graduação & $\begin{array}{c}\text { Tempo } \\
\text { trabalho } \\
\text { educação } \\
\text { (anos) }\end{array}$ & $\begin{array}{c}\text { Tempo de } \\
\text { trabalho no SUS } \\
\text { e antes do SUS } \\
\text { (anos) }\end{array}$ \\
\hline Enfermeiro 1 & $\mathrm{F}$ & 30 & - & 5 & 4 \\
\hline Enfermeiro 2 & $\mathrm{F}$ & 35 & $\begin{array}{c}\text { Lato-sensu } \\
\text { Mestrado e } \\
\text { Doutorado }\end{array}$ & 9 & 5 \\
\hline Enfermeiro 3 & $\mathrm{F}$ & 49 & Lato-sensu & 27 & 6 \\
\hline Enfermeiro 4 & $\mathrm{F}$ & 33 & Lato-sensu & 6 & 6 \\
\hline Farmacêutico & $\mathrm{F}$ & 29 & Lato-sensu & 2 & 16 \\
\hline Gerente/Enfermeiro & $\mathrm{F}$ & 40 & Lato-sensu & 16 & 6 \\
\hline
\end{tabular}

Fonte: Arquivo da pesquisadora.

Os trabalhadores da unidade B tematizam sobre:

Figura 10. Resultados do grupo focal dos trabalhadores da unidade B. São Paulo, 2014.

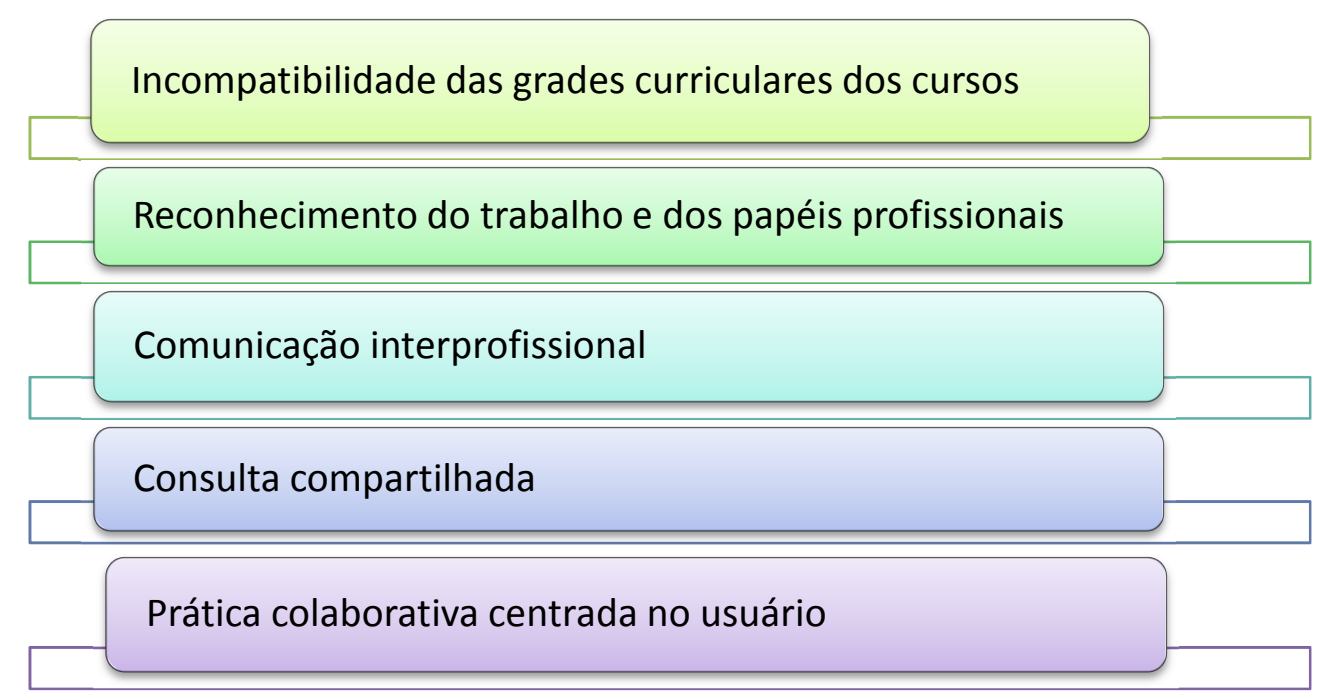

A incompatilbilidade das grades curriculares prejudica o encontro entre os estudantes do PET-Saúde, pois cada curso possui uma disponibilidade diferente para as atividades práticas nos serviços. A ausência de espaços comuns em virtude da incompatibilidade das grades 
curriculares dos cursos, pode ser entendida como um reflexo do planejamento fragmentado e individualizado, sem articulação entre os cursos de graduação de uma mesma universidade.

A incompatibilidade curricular e a rigidez curricular são barreiras que prejudicam a implementação de atividades interprofissionais (Sunguya et al., 2014), assim como dificultam as ações do PET-Saúde (Leite et al., 2012).

(...) é um pouco mais complicado, porque aí depende das grades dos alunos... e é isso que simplesmente atrapalha totalmente a interação dos alunos de diversos cursos. São as grades muito engessadas. Então se não acontece uma relação maior... uma inter... uma comunicação, uma articulação maior... é exatamente por causa das grades (Enfermeiro 2 Unidade B).

tem uma questão que é bem organizacional, que eu acho que é contra. Como a gente precisa se adequar às grades de todas as disciplinas, fica praticamente impossível a gente achar uma data para fazer atividades comuns... (...)já passamos por vários tutores. Eu acho que do mesmo jeito que a grade dos alunos... a dos professores idem, né... Então eu sinto que a carga maior fica para os preceptores... os professores também não conseguem... eh... fazer... eu acho que está aquém da minha expectativa o envolvimento deles (...) Acontece porque eles não conseguem mesmo, porque eles também não tem uma grade... eles também não tem um período para fazer isso... o projeto perde na consistência... está solto. é, eu acho que a solução mais simples era ser uma disciplina optativa (Gerente - Unidade B).

(...) acho que o que é mais crucial, que a gente começou a conversa... colocando isso... é a questão da grade curricular. Essencialmente na formação tentar integrar... os diferentes cursos nos diferentes espaços. Acho que quando eles vêm para estágio no PET... que aí já... desde a formação a gente já introduzir esse objetivo e facilitar mesmo o andamento das coisas... (Enfermeiro 1 - Unidade B).

Frente às grades curriculares, os participantes tematizam que os

projetos de extensão como o PET-Saúde e os estágios, favorecem o reconhecimento do trabalho e dos papéis profissionais. O referido reconhecimento é um dos atributos da EIP e da prática colaborativa, pois é preciso conhecer as possíveis contribuições de cada profissional envolvido nas práticas de saúde para buscar a composição dos saberes e intervenções com a participação de outros profissionais.

Acho que ninguém sabe qual é o papel da farmácia na unidade. Não tem essa questão abrangente, só tem a questão pensando em medicamento. Todos os alunos do PET passam, né, pela farmácia. O nosso instrumento de trabalho é... no PET eles passam na farmácia. Então para mim assim... quase todos nunca tinham visto, nem sabiam o que poderiam estar tirando ou como utilizando o serviço. Não sabiam como funcionava assim... Então eles ficam super curiosos, perguntam um monte... (Farmacêutico Unidade B).

Com a gente, que eles também não entendem o que a gente faz, qual é o papel da enfermeira, né. Então principalmente quando eles acompanham 
consultas... eles ficam - ah, vocês podem fazer isso? -, não tem muita noção do trabalho da enfermeira na atenção básica. Acho que eles vem com uma visão hospitalar mesmo. No acolhimento o primeiro ano fica muito comigo, porque eles vêm de segunda-feira, ficam no acolhimento, na consulta, então eles também não têm idéia do que a gente faz (Enfermeiro 4 - Unidade B).

(...) isso é o mais importante, no PET, para mim, poder ter a oportunidade de... atuar com outras áreas... Meu melhor ano do PET, o ano que eu mais gostei... que eu fiquei com duas alunas que faziam odontologia. E conversando com elas eu tive a oportunidade de aprender várias coisas sobre o universo do... dentista (Gerente - Unidade B).

O reconhecimento do trabalho e dos papéis profissionais dos outros é uma característica necessária para estabelecer ações articuladas e complementares na prática colaborativa (Khalili et al., 2013; Pereira, Rivera, Artmann, 2013; Orchard et al., 2012; MacDonald et al., 2010; Martin Rodriguez et al, 2005), também é considerada uma das competências da prática colaborativa (CIHC, 2010; IPEC, 2011).

O campo de práticas favorece o encontro dos estudantes e trabalhadores de diferentes áreas, para o desenvolvimento de práticas compartilhadas com a troca de saberes, característica da interação intersubjetiva. A troca de informações é um dos indicadores da colaboração interprofissional segundo D'Amour et al. (2008), mas precisa ser diferenciada da interação necessária, para as práticas de saúde.

A troca de informações pode ser definida como conversa útil, na qual o sentido da interação é reduzido à informação que precisa ser transmitida. A interação pode ocorrer por meio da troca de experiências entre profissionais em reuniões de discussão de caso, ou encontros informais. Trata-se de uma forma de trabalhar intersubjetivamente, que contribui para a reflexão sobre as práticas, ao reviver experiências acumuladas, compartilhar acertos e dúvidas (Schraiber, 1997).

Então no meu caso é a integração das áreas... e como tem residente na minha equipe fica fácil de ter essa integração, com aluno de enfermagem. Já aconteceu diversas vezes de VD com aluno de enfermagem. Eu, aluno de enfermagem com o residente (da medicina). Então tem esses momentos importantes que estão acontecendo. Em reunião de equipe... então acaba trabalhando junto, né?, como um todo, a equipe como um todo... (Enfermeiro 3 - Unidade B).

Outro elemento referido pelo gerente, que possibilita a troca de saberes no sentido interativo, entre as áreas profissionais, é a organização das práticas no serviço, pois considera que na unidade $\mathrm{B}$, o trabalho não está centrado no núcleo profissional específico. As práticas estão organizadas em 
prol do campo comum da saúde, no qual ocorre a contribuição de cada área profissional. Nesse contexto, o ensino prático do trabalho em equipe, potencializa o desenvolvimento da prática colaborativa.

O campo comum de práticas, articulado ao núcleo profissional específico é um elemento imprescindível para o desenvolvimento da prática, centrada nas necessidades de saúde dos usuários (Campos, 2000, 2007a) de acordo com a perspectiva interprofissional colaborativa.

E acho que para eles estar aqui e a gente não é um serviço muito fechadinho nas categorias, também? Que todas as profissões tem um núcleo de competência delas, mas a gente tem um campo da atuação em saúde. E nesse campo tem muita intersecção de atuação, então eu acho que o aluno percebe na prática essa intersecção das várias áreas de atuação. Então eu acho que uma das potencias que tem no estágio, na área de trabalho em equipe e atuação multidisciplinar é ver que isso acontece mesmo, em algumas áreas mais limitadas, em outras menos. Por exemplo, a odonto é uma área que é super fechada. É um setor fechado praticamente (...) mas tem uma dentista que participa do PET. Ela adorou, porque começou a entender um pouco mais as outras profissões, e se não fosse o PET ela não teria essa oportunidade. E o estágio idem, dá muita oportunidade de ampliar conhecimento (Gerente - Unidade B).

Apesar das práticas de saúde na unidade B, estarem organizadas em torno do campo comum de práticas, os estudantes de cursos, cujo modelo de formação é biomédico, apresentam dificuldade em compreender e transitar entre as áreas profissionais. Estes estudantes voltam-se à especificidade do seu saber profissional, devido à valorização do saber instrumental que é predominante no contexto da formação.

(...) é... eu identifico... como a colega falou, como existem alunos que tem uma formação maior em saúde coletiva e atenção primária, que seria no caso a enfermagem, a terapia ocupacional, fonoaudiologia, esses tem uma facilidade maior de transitar, compreender os outros grupos. O que é difícil com os alunos da medicina...da nutrição... (Enfermeiro 2 - Unidade B).

O predominante modelo de formação uniprofissional (Costa et al., 2014; Reeves et al., 2008; Barr et al., 2005) está voltado para a lógica biomédica que reforça a fragmentação das práticas de saúde (Teixeira, Coelho, Rocha, 2013; Feuerwerker, Capozzolo, 2013; Khalili et al., 2013).

No próximo excerto, o trabalhador refere que as atividades interprofissionais do PET-Saúde, possibilitam a troca de saberes, experiências, reconhecimento do trabalho e papéis profissionais e do objeto comum de intervenção das práticas de saúde. 
O reconhecimento do trabalho e papel profissional dos outros está relacionado com os instrumentos ou meios utilizados no processo de trabalho, pois envolvem o emprego do saber especializado de cada profissional, para manipular os instrumentos e implementar as intervenções. O estabelecimento de práticas de saúde sob um objeto comum de intervenção, com a utilização de diferentes instrumentos de trabalho, remete à noção do trabalho inteprofissional, para o qual torna-se necessária a reconfiguração das profissões em prol do objeto comum, as necessidades de saúde dos usuários.

Questiona-se sobre as similaridades ou aproximações entre o objeto comum de intervenção no processo de trabalho e os objetivos comuns de trabalho das equipes de saúde. Embora a literatura nacional e internacional indique que os objetivos comuns são um dos atributos das equipes (West, 2013; Poulton West, 1999; Anderson, West, 1998; Peduzzi, 2007b; Queiróz, Penna, 2011; Lancman, Barros, 2011), não aponta evidências da correspondência entre ambos objetos referidos. Contudo, acredita-se que o objeto comum de trabalho, pode orientar a definição do objetivo comum das equipes integradas e comprometidas com a qualidade da atenção à saúde.

O objeto de trabalho do campo da saúde são as necessidades de saúde, sentidas e trazidas aos serviços pelos usuários, ou até mesmo geradas pelo serviço. Afinal, o processo de trabalho em saúde, pode transformar as necessidades que são social e historicamente construídas (MendesGonçalves, 1994; Peduzzi, Schraiber, 2009).

Nos próximos relatos, os trabalhadores apontam objetos de trabalho diferentes, ao tomar como referência diferentes contextos de prática. No primeiro relato, o trabalhador aborda o objeto de trabalho da atividade do PET-Saúde, as necessidades de saúde no território. No segundo relato, o gerente considera que o paciente é o objeto comum de trabalho na UBS.

Agora acho que os 'pros' todos, troca de conhecimentos, troca de experiências... compreender os instrumentos dos outros. Por que a gente trabalha muito no PET... é que o objeto de trabalho é o mesmo para todo mundo. Todos trabalham para a mesma questão. O que vai mudar são os instrumentos de cada um. Então eles acabam conhecendo os instrumentos... muito diferentes e sabendo lidar a mesma questão... como que eu vou acessar esse caso aqui?, eu preciso disso, disso e disso... Eu acho que eles aprendem muito isso no PET. Eles não estão acostumados que existe um objeto comum por detrás disso... o que aconteceu?, a gente 
desde o começo... a gente foi construindo com os alunos que o objeto ia ser as necessidades de saúde do território. Então que a gente ia tentar ver o que estava por trás do adoecimento (Enfermeiro 2 - Unidade B).

Eu acho que é ter visão das outras áreas, conhecer um pouco a atuação das outras áreas... conseguir perceber como as pessoas podem contribuir, considerando o mesmo objeto, né, o paciente, como as diversas áreas podem contribuir e como elas podem se orquestrar de forma a que cada área faça a sua contribuição dentro das suas competências e das suas habilidades, né. Eu acho que é trabalhando assim em todas as áreas, não só na saúde coletiva (Gerente - Unidade B).

$\mathrm{Na}$ reconfiguração das relações profissionais, a articulação com outras categorias profissionais é uma característica necessária para o trabalho colaborativo em saúde. No relato a seguir, o trabalhador considera que o enfermeiro é um dos profissionais reconhecido como articulador das práticas de saúde entre todos os demais profissionais, por contribuir para a convergência e distribuição das informações, inclusive aos usuários, aspecto presente nos estudos de Orchard (2010), Proop et al. (2010), Rossi, Lima (2005) e Willig, Lenardt (2002).

Eu acho que não fica difícil para a gente fazer isso, porque no nosso trabalho no dia a dia a gente já faz isso. Acho que é a categoria (enfermeiro) que mais faz no trabalho, articular com as outras categorias. Então quando a gente recebe aluno... acho que para a gente é automático, é natural, né, ter essa conversa com os alunos do PET. (Enfermeiro 4 Unidade B).

A reflexão sobre a articulação entre as áreas profissionais, característica do processo de trabalho do profissional enfermeiro, presente no debate do GF da unidade $\mathrm{B}$, pode ser uma consequência da composição do grupo, no qual participaram cinco enfermeiros.

A articulação entre os profissionais ocorre em consultas compartilhadas, realizadas para atender a complexidade das necessidades de saúde dos usuários. Nos depoimentos a seguir, além da consulta compartilhada, os trabalhadores referem a existência da reunião 'trans', que funciona como um espaço de apoio matricial. A criação da reunião 'trans' na unidade $\mathrm{B}$, pode ser uma alternativa encontrada pelo serviço para a construção compartilhada da análise de casos complexos, pois, diferentemente da unidade $A$, a unidade $B$ não dispõe de uma equipe de NASF para realizar este trabalho conjunto.

A reunião 'trans' recebeu essa denominação, por ser compreendida pelos trabalhadores do serviço, como um espaço transdisciplinar ou transprofissional. Esta reunião envolve os profissionais de saúde que 
compõe a equipe mínima da ESF, médicos, enfermeiros, auxiliares de enfermagem e agentes comunitários de saúde, que apresentam casos complexos para serem discutidos em busca de propostas terapêuticas a serem construídas coletivamente, com apoio de outros profissionais da UBS como: terapeuta ocupacional, assistente social, psicólogo, odontólogo e farmacêutico.

A nomenclatura utilizada para denominar a reunião 'trans'ou transdisciplinar, pode ser considerada coerente aos objetivos da reunião, pois indica a construção de um espaço caracterizado por saberes compartilhados, com tendência à horizontalizar as relações interdisciplinares (Almeida Filho, 2000; Irribarry, 2003).

Outro diferencial que a gente tem aqui no serviço é a reunião 'trans', que é um espaço oficial... assim... se a gente está atendendo um paciente e a gente identifica uma necessidade para aquele paciente, a gente vai atrás do médico, vai atrás do assistente social, a gente vai atrás do enfermeiro, do médico da equipe. As coisas do dia a dia, essas coisas mais pontuais... a gente resolve isso de certa forma bem tranqüila. E quando são coisas que a gente precisa organizar melhor, (...) fazer um plano terapêutico para aquele paciente, que é um caso mais complicado, que é um acompanhamento que a gente vai ter que ter por um tempo maior, a gente observa na reunião 'trans', que é o espaço que a gente tem como enfermeiro... Uma reunião mensal com assistente social, farmacêutico... terapeuta ocupacional, dentista, psicólogo, o enfermeiro da vigilância e a equipe de saúde da família... médico, agentes, auxiliares e enfermeiro (Enfermeiro 1 - Unidade B).

(...) e aí nesse espaço a gente discute alguns pacientes mais... que demandam um pouco mais de cuidados(...) e os alunos participam. Vai residente, vão os alunos de graduação que estiver com a gente, os alunos de TO... (Enfermeiro 4 - Unidade B).

A consulta compartilhada é referida como uma prática que qualifica o cuidado, por possibilitar a resposta à casos mais complexos mediante a articulação entre profissionais, também é considerada como uma possibilidade de otimizar as práticas e racionalizar os custos do trabalho em saúde.

Aguiar (2014), considera que a consulta compartilhada é uma alternativa encontrada, por médicos e enfermeiros, para ampliar o espectro de abordagem das necessidades de saúde dos usuários e agilizar os atendimentos na ESF. Assim, os profissionais atendem a dupla intencionalidade de organização dos serviços e racionalização das práticas de saúde, que expressa a tensão entre a recomposição do processo de 
trabalho na lógica da atenção integral e a redução de custos com maior eficiência das práticas.

Indo à raiz você pode ampliar o cuidado na verdade... então você tem possibilidade de dar articulação, de atender... e a equipe... a gente faz muito atendimento a equipe mesmo, assim, médico, enfermeira junto... junto com a família... para o cuidado é muito importante. Acho que essa articulação do cuidado é mais importante (Enfermeiro 2 - Unidade B).

Eu também tenho uma visão de gestão, que, por exemplo, um médico talvez consiga atender... sei lá... um paciente a cada 20 minutos. Mas quando ele atende junto com a enfermeira, talvez ele consiga atender dois pacientes a cada 20 minutos. E a enfermeira idem. As pessoas trabalhando em equipe elas atendem mais pessoas. Se aumenta a potencia de atendimento. Você aumenta a potencia. Então, você chega para o atendimento do enfermeiro, aí o auxiliar de enfermagem já verificou a temperatura, já verificou a intercorrência, ele já fez uma série de coisas dentro da competência dele, quando chega no enfermeiro aquilo ajuda a tomar uma decisão mais rápido. Então, considerando que a gente tem que atender uma população muito grande, a gente... estando bem articulado entre as diversas pessoas, bem organizado, a gente aumenta muito a nossa potencia de atendimento, do que se a gente atendesse sozinho, isolado... cada um no seu consultório, a gente atenderia menos... (Gerente Unidade B).

Outro aspecto tematizado pelos trabalhadores, é o desenvolvimento

da prática centrada no usuário, na qual o mesmo e a família tem a oportunidade de participar da tomada de decisão, sobre o plano de cuidados.

A gente sempre tenta envolver o paciente no cuidado. Se não for possível devido a alguma limitação, aí a gente parte para a família. Mas compartilha o plano (...) e é comum a gente fazer reunião familiar, é bem comum. Nós marcamos reuniões com as nossas famílias, junto com os profissionais e fazemos. Isso já é uma prática comum mesmo (...) (Enfermeiro 2 - Unidade B).

As práticas interprofissionais centradas nos usuários, promovem a

troca de informações e a corresponsabilização dos membros da equipe, pelos casos que deixam de ser responsabilidade de um único profissional (Silva, 2014; Pelzang, 2010; Orchard, 2010; CIHC, 2010; Baindridge, Nasmith, Orchard, 2010; Carpenter, Dickinson, 2008; Curran, Kabene, 2005; Oandansan, 2004).

Novamente, a referida prática colaborativa, remete à reconfiguração das relações profissionais que compõe o trabalho colaborativamente, em detrimento à competição, que ainda prevalece nos espaços profissionais.

Ou até a resolução. Se o médico não está aqui e o paciente vem e se o médico não está não resolve? Não. Conversa com o enfermeiro, com a terapeuta ocupacional, assistente social, com quem quer que seja, porque como os casos são discutidos com todos, todos... muitas vezes conhecem aquele caso e podem resolver. Não fica só em uma pessoa... (Enfermeiro 2 - Unidade B).

Eu acho que a gente também compartilhar os problemas que a gente identifica, além de ter toda essa questão de integrar o cuidado, acho que a 
gente se sente mais fortalecida e a gente sofre menos. Porque quando a gente compartilha o caso a gente fala e conversa sobre aqueles casos que são tão difíceis... traz um conforto muito grande para a gente. E a gente tem um outro olhar, tem outras coisas que a gente vai identificando e vai conseguindo... eh... acompanhar de uma forma que é mais resolutiva (Enfermeiro 1 - Unidade B).

\section{SÍNTESE DOS RESULTADOS DO GRUPO FOCAL DE TRABALHADORES DA UNIDADE B}

Os trabalhadores da unidade B consideram que a incompatibilidade das grades curriculares dos cursos, prejudicam os encontros entre as áreas, inclusive de estudantes participantes do PET-Saúde. As grades constituem uma das barreiras organizacionais características da fragmentação do ensino entre áreas profissionais praticada nas universidades

O PET-Saúde é referido como uma política indutora da EIP, pois promove a troca de saberes, experiências, reconhecimento do trabalho, dos papéis profissionais e do objeto comum de intervenção das práticas de saúde. Nesse sentido, contribui para o desenvolvimento de atributos, que influenciam a reconfiguração das relações profissionais em prol da colaboração.

Como o grupo foi predominantemente composto por enfermeiros, els tematizaram o papel do enfermeiro em articular as demais áreas profissionais, em prol do cuidado em saúde, aspecto que também é apontado nos relatos das entrevistas.

Dois aspectos se destacam na fala do gerente do serviço, sinaliza que o modelo de organização do trabalho favorece a troca de saber entre os profissionais e que a consulta interprofissional compartilhada, representa uma possibilidade de otimizar as práticas e racionalizar os custos do trabalho em saúde.

A consulta compartilhada é uma prática comum no serviço para atender a complexidade das necessidades de saúde dos usuários. Mais uma vez o deslocamento das práticas especializadas para ações compartilhadas representa uma possibilidade de reconfiguração das relações profissionais. 
$\mathrm{Na}$ mesma direção, os trabalhadores tematizam a orientação das ações para a prática centrada no usuário, com a participação das famílias e usuários na construção do plano de cuidados.

Abordam o reconhecimento do trabalho e dos papéis profissionais, para indicar as possibilidades de contribuição de cada um, frente aos objetivos comuns da equipes de trabalho e do objeto comum das práticas de saúde, as necessidades de saúde dos usuários.

Consideram que a prática colaborativa centrada no usuário, com a participação dos mesmos e seus familiares, no processo de tomada de decisão compartilhada com o profissional, para o planejamento terapêutico e melhora dos resultados da atenção.

Os relatos dos trabalhadores da Unidade $\mathrm{B}$ possibilitam a compreensão da concepção da EIP dependente do reconhecimento dos papéis profissionais de cada um, para o estabelecimento da prática interprofissional colaborativa, no cotidiano de trabalho voltado às necessidades de saúde dos usuários.

\section{GRUPO FOCAL DOS ESTUDANTES}

No grupo focal realizado com estudantes, houve cinco participantes com idades entre 18 e 25 anos e média de 22,6 anos, entre os quais, três estudantes de graduação em enfermagem, um estudante de graduação de medicina, um estudante de mestrado recém-formado em enfermagem. Todos participaram do PET-Saúde e além disso, um participou do Projeto Xingu, um da Jornada Universitária da Saúde (JUS) e um do Curso/Atendimento de Clowns.

O perfil dos estudantes que participaram do grupo focal expressa seu interesse pelo tema da interprofissionalidade, em virtude de sua inserção voluntária em atividades extracurriculares interprofissionais.

A participação de um estudante de mestrado recém-formado em enfermagem, justificada na metodologia deste estudo, alterou sua conformação para um grupo focal heterogêneo. 
Quadro 4 - Perfil dos estudantes participantes do grupo focal.

\begin{tabular}{|l|c|c|c|c|l|}
\hline $\begin{array}{c}\text { Código do } \\
\text { participante } \\
\text { do GF }\end{array}$ & Sexo & Idade & $\begin{array}{c}\text { Curso de } \\
\text { Graduação }\end{array}$ & $\begin{array}{c}\text { Semestre do } \\
\text { Curso }\end{array}$ & $\begin{array}{l}\text { Participação em } \\
\text { Projetos Extensão }\end{array}$ \\
\hline $\begin{array}{l}\text { Estudante de } \\
\text { enfermagem 1 }\end{array}$ & $\mathrm{F}$ & 22 & Enfermagem & Quinto & $\begin{array}{l}\text { PET-Saúde Jornada } \\
\text { Universitária da } \\
\text { Saúde (JUS) }\end{array}$ \\
\hline $\begin{array}{l}\text { Estudante de } \\
\text { enfermagem 2 }\end{array}$ & $\mathrm{F}$ & 18 & Enfermagem & Terceiro & PET-Saúde \\
\hline $\begin{array}{l}\text { Estudante de } \\
\text { enfermagem 3 }\end{array}$ & $\mathrm{F}$ & 25 & Enfermagem & Sétimo & $\begin{array}{l}\text { PET-Saúde } \\
\text { Atendimento de } \\
\text { Clowns }\end{array}$ \\
\hline $\begin{array}{l}\text { Enfermeiro } \\
\text { recém- } \\
\text { formado }\end{array}$ & $\mathrm{F}$ & 24 & Enfermagem & $\begin{array}{l}\text { Recém- } \\
\text { formado }\end{array}$ & PET- Saúde \\
\hline $\begin{array}{l}\text { Estudante de } \\
\text { medicina }\end{array}$ & $\mathrm{M}$ & 22 & Medicina & Quinto & $\begin{array}{l}\text { PET-Saúde Projeto } \\
\text { Xingu }\end{array}$ \\
\hline
\end{tabular}

Fonte: Arquivo da pesquisadora.

Os estudantes tematizam os seguintes aspectos:

Figura 11. Resultados do grupo focal dos estudantes. São Paulo, 2014.

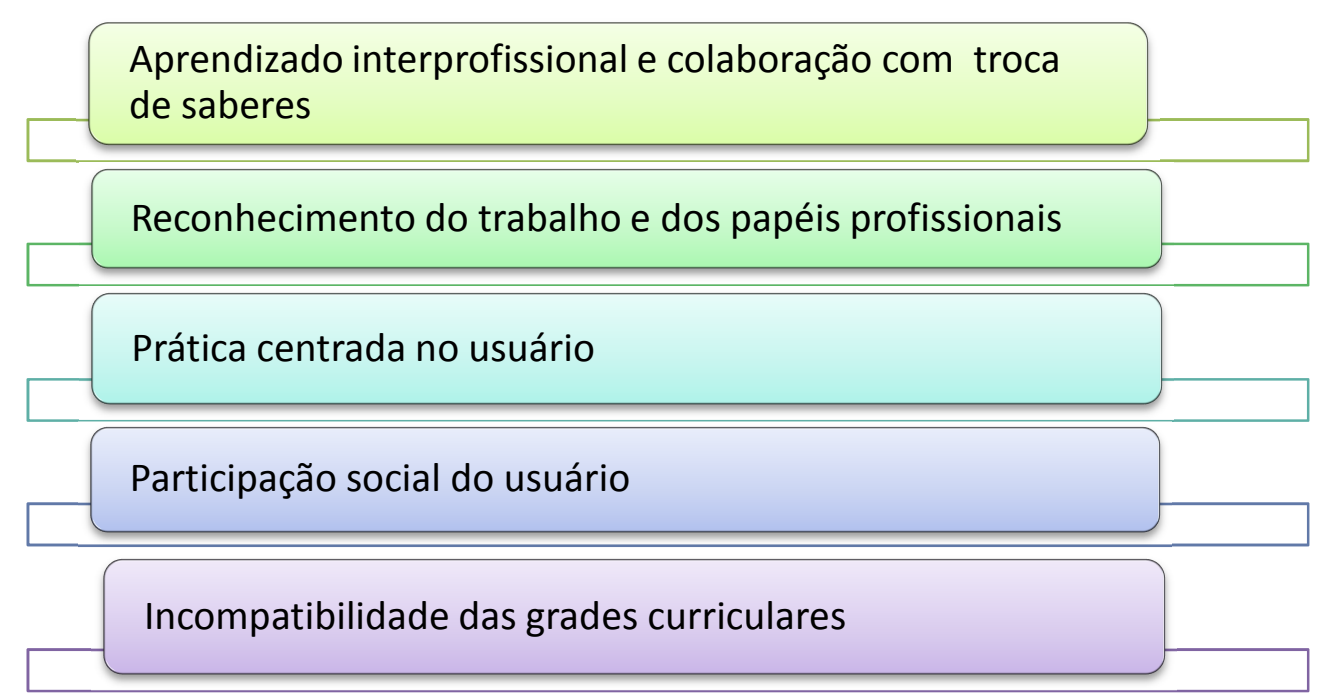

As experiências interprofissionais possibilitam a integração do saber de diferentes áreas, com análise coletiva dos problemas, ao contrário da prática usual, na qual os profissionais atuam isoladamente. No próximo 
depoimento, está referida uma experiência que remete ao conceito de EIP, definido por Barr et al., (2005), no qual os estudantes aprendem de forma interativa sobre si e os outros profissionais em prol da colaboração e da qualidade do cuidado.

O aprendizado interativo pressupõe a comunicação intersubjetiva em prol do entendimento, na qual, os sujeitos implicados expressam diferentes opiniões, em busca da produção de consenso (Habermas, 2012).

(...) porque a gente está sempre muito focado na nossa área. Então... foi legal ver que cada um trouxe um olhar diferente para a mesma situação e a gente junto montou... leu o estudo de caso de uma maneira diferente. Então, ficou bem rica a situação e nesse sentido foi muito rico assim... e foi bom também porque são áreas que no final... apesar que o foco é o mesmo, acabam trabalhando separado? Então vou lá, faço a minha evolução... os meninos vão lá, fazem a parte médica deles... e aí a farmácia... a gente quase nunca vê o farmacêutico... só se for para buscar alguma coisa... E as meninas da 'nutri' também, só quando tem alguma demanda...procura a 'nutri'. Então, foi interessante ver, sentamos juntos, Olhando a mesma situação, e como aquilo desenvolveu. Porque cada um levantava um ponto sobre aquele estudo e cada um tinha uma maneira de enxergar e de trazer uma contribuição diferente, então foi bem rico (...) Porque, bom a enfermagem tem aquela visão do cuidado. Aí o psicólogo trouxe toda a questão do desenvolvimento do recém nascido e também uma visão mais psicológica da mãe. Aí a gente foi complementando. A farmacêutica trouxe a questão farmacológica mesmo. Ela apresentou que tinha uma medicação que ela estava tomando que ia inibir a produção de leite... então assim... foram coisas que foram somando de verdade e levou a uma discussão bem ampla da situação. Uma coisa que... normalmente quem pega a mãe na consulta de retorno é uma enfermeira... e realmente foi legal, porque deu para ter essa visão de como seria essa consulta de retorno, o que poderia ser levantado (Estudante de mestrado e enfermeiro recém-formado).

A formação interprofissional possibilita o reconhecimento dos papéis, dos limites de atuação de cada área e o preparo para desenvolver atendimentos compartilhados em equipe (Zwarenstein et al., 2009; MacDonald et al., 2010; Orchard, 2010; Ateah et al., 2011; Jackobsen et al., 2011; Barwell et al., 2013). Nos relatos a seguir, os estudantes consideram que o aprendizado interprofissional, prepara para a interação entre as áreas profissionais, mediante o reconhecimento da especificidade do saber de cada um, contribuindo para a construção do trabalho em equipes colaborativas.

Eu acho que é interessante já treinar o estudante para a vida profissional, no sentido de saber consultar os outros profissionais. Que... para fazer de fato $o$ atendimento integrado. E... assim... é difícil, porque muitas vezes uma área não sabe até aonde a outra área vai, o que a outra área faz e é importante que todas as áreas se conheçam para saber o que dá para casar, o que não casa... e assim... a graduação é o treino para isso. Você está 
para aprender mesmo, literalmente, como que vai ser. E... levar isso para a vida profissional acho que é muito enriquecedor (Estudante de mestrado e enfermeiro recém-formado).

Acho que acaba sendo positivo para todos os lados, né, para a pessoa que vai prestar assistência, porque tem uma contribuição maior, tem essa visão integral... para a gente treinar, trabalhar realmente em equipe e para... não direcionar, porque acaba sendo uma... automaticamente cada um foca na sua área e esquece... acaba sendo um estímulo para a gente não se prender a isso, para perceber vários horizontes. Abre a nossa visão para o trabalho dos outros cursos. Acho que acaba sendo positivo para todos os lados (Estudante de enfermagem 1).

A troca dos saberes e a necessidade de complementaridade são aspectos que constituem a prática colaborativa da EIP. No próximo excerto, o estudante relata uma experiência interprofissional, na qual, os estudantes de diferentes cursos reconhecem a importância da prática compartilhada com outros profissionais, e cada um pode contribuir com a especificidade de seu saber.

A gente selecionou alguns temas e a gente tentou fazer... para ficar mais fácil, teve a ideia de fazer por curso. Então cada curso fez um tema. E aí foram selecionados alguns temas, vacinação, deixa com a enfermagem. A parte de exames de rotina que tem que fazer deixa com a medicina (...) Teve alimentação saudável, deixou com a nutrição, e aleitamento materno. Aí a parte da nutrição foram os alunos da nutrição, (...) Aí logo uma da fono falou - não, mas o aleitamento materno não é só os componentes do leite, mas tem também a posição do bebê que é importante. Aqui a enfermagem também entra, mas tem o cuidado com o ambiente, com a mãe, então assim, deixou bem claro um tema só cada olhar diferente de todos os cursos. Então no fim deixou bem claro que não adianta a gente tentar dividir por curso para deixar mais fácil, sendo que em uma parte cada um tem um pouco para contribuir. Então no fim a gente começou a fazer o folder, foi passando por todos os cursos, para cada um poder dar a sua contribuição. Assim, deixou bem claro, quando começou a discussão, praticamente, não sobre quem ia fazer esse tema. Uma coisa que todos tinham a contribuir para... Então foi isso (Estudante de enfermagem 1).

A seguir, o estudante relata a experiência vivenciada em um grupo educativo interprofissional, no qual cada profissional possui uma atribuição relacionada à sua expertise de formação técnica. Todos os saberes e ações são indispensáveis para a realização do grupo, para lidar com a complexidade dos casos.

Estudos mostram, que a prática inteprofissional colaborativa produz bons resultados para os usuários, contudo, apontam a importância de profundar investigações sobre o tema (Reeves et al., 2013; Thistlethwaite et al., 2010).

Então a minha atividade foi no PET mesmo, na UBS. Acho que quase em todas existem grupos, né... acompanhamento dos pacientes de acordo com a necessidade de cada região. Mas lá tinha muitos usuários... dependentes 
do tabaco. E eles fizeram um grupo sobre o tema e a gente teve oportunidade de participar e o grupo é dirigido pelo enfermeiro, pelo médico, dentista e farmacêutico. E aí você tem a oportunidade de escutar... não só os profissionais falando como também os usuários. Cada um expondo a sua dificuldade e a sua vontade de largar e não conseguem. Ou então exemplo de motivação, que conseguiu, superação... mesmo os que não conseguiam, de frustração... Então toda essa parte e aí entra todo o cuidado do médico explicando, a ocorrência de certos sintomas na abstinência, explicando a parte fisiológica... os receptores no cérebro... essas coisas todas... E a parte do enfermeiro também, sobre os cuidados. A parte de farmácia, alguns medicamentos que podem ser tomados, ministrados para ajudar. Os adesivos e tal... E também a parte do dentista, sobre o câncer que gera na boca de quem fuma... e todos os aspectos. E foi bem legal também, enriquecedor essa parte. Porque você vê as pessoas super interessadas e o tema sendo abordado de uma forma bem abrangente... também porque um profissional não dá conta de olhar o paciente inteiro, entendeu? O médico, por exemplo, não tem como avaliar coisas que no caso envolvem um dentista... já é um serviço muito mais específico. E que a integração do trabalho, a contribuição de cada um enriquece muito? (Estudante de enfermagem 2)

A EIP pode contribuir para a qualidade do cuidado em saúde, por estimular o desenvolvimento da prática interprofissional colaborativa. No próximo excerto, o estudante considera que a especialização e a fragmentação do saber, limitam as possibilidades de intervenção no cuidado, que pode ser ampliado com a contribuição de diferentes profissionais.

Eu acho que ia mudar totalmente o jeito de você... de você pensar o seu cuidado. Porque acho que você incluindo o outro, você acha que pode melhorar. Eu penso que você melhora o cuidado se você integra... se você faz o seu raciocínio levando em conta a opinião de um outro profissional. Eu acho que você cuida bem melhor, porque... é como ela estava falando... hoje todo mundo é tão especialista, tão especialista... que todo mundo vê um pedacinho... e se você vai e você já sabe que o outro pode fazer... ir até tal lugar... você já pensa com ele... já pensa nessa área e até a discussão pessoal, você ter a iniciativa de ir e falar, de ir e discutir, de ir e defender o seu ponto de vista. Por exemplo, eu não tenho segurança nenhuma de discutir alguma coisa com o outro profissional, com exceção de médico, por exemplo. De discutir alguma coisa de fono, fisio, não tenho segurança. Isso para mim vai ser muito novo na minha prática para a atenção básica, por exemplo, de ir por exemplo, ver um caso com o NASF ou com um outro profissional, até dentista (Estudante de enfermagem 3).

A seguir, o estudante considera que a boa prática depende do aprendizado interprofissional, mas sugere que ocorra fora da graduação, na especialização ou residência por exemplo. Compreende que a universidade é um espaço de construção da ciência e produção científica, que possui excessivas demandas de formação específicas para cada área, assim, considera que não há espaço para a formação interprofissional no contexto da universidade atual.

Eu acho que esse aprendizado (interprofissional) tem que existir, mas eu não sei assim... um pouco diferente assim... eu acho que ele vai ter que 
existir porque é a prática... a boa prática depende dele, né? Agora não sei se você define a universidade, a graduação, como um espaço para ter esse aprendizado. Você pode pensar na universidade como uma coisa mais para o aprendizado teórico e a parte prática você tem como se fosse... vai... uma especialização, a residência, o internato e tal. Eu não sei se você define a universidade como o lugar para coisa prática assim... não sei se eu defino a universidade como... uma capacitação técnica ou uma formação teórica para depois você pegar a parte técnica. Então... depende do momento, depende do que você entende por universidade. Eu penso isso, porque eu... olho a universidade como um negócio mais teórico, mais de ciência e de produção científica e tal. Não que esteja alienado do resto, mas... eu não sei assim qual a importância disso na graduação. Mas eu vejo a importância disso... absoluta... para o trabalho, para a assistência à saúde, para tudo. porque eu acho que é muita carga, fica o dia inteiro aqui, não tenho nem tempo de parar e fazer uma coisa diferente... que eu acho que também é importante, ou me aprofundar mais na teoria, porque depois vou fazer só prática durante não sei quantos anos... Eu já vou ter espaço na residência para me aprimorar na prática e com outras profissões, e às vezes eu sinto que eu perco o aprendizado teórico, que eu acho que é importante, em detrimento de outras coisas. Mas é a minha opinião assim, não sei se enxergam isso... (Estudante de medicina)

A literatura internacional não revela consenso sobre o melhor momento para implementar a EIP, se durante a formação nos cursos de graduação ou na pós-graduação, contudo revela mudanças significativas no comportamento do estudantes de graduação durante a formação e indica possíveis desdobramentos desse modelo de formação, no prepapro para o trabalho em equipe, tanto na graduação, quanto na pós, incluindo o aprendizado de conhecimentos, habilidades, atitudes e comportamentos que contribuem para a melhora dos resultados da atenção ao usuário (Thistlethwaite et al., 2010; Coster et al., 2008; Reeves et al., 2008; Hind et al., 2003).

A interação interprofissional colaborativa no trabalho em equipe, possibilita a abordagem integral das necessidades de saúde do usuário, deslocando a ênfase da abordagem restrita à doença, para a integralidade da atenção, que contempla ações de prevenção, promoção e recuperação da saúde como exemplificado acima.

Apesar da referência à perspectiva da integralidade na atenção à saúde, os estudantes consideram que o usuário ainda não participa das decisões sobre o plano de cuidados, mas tem a possibilidade de participação social no conselho gestor das unidades de saúde.

Nas experiências que eu tive o usuário não participa ativamente do que vai acontecer assim. É mais uma reunião da equipe que vai decidir qual vai ser a conduta e a equipe se engaja naquela conduta (...) Eu já presenciei algumas vezes da equipe falar - não, simplesmente não 
colabora - não sabe o que fazer, e ter aquela frustração, aquela coisa... mas assim... em nenhum momento chamar o usuário e dar esse... empoderar ele para que ele possa decidir ou não pelo que vai acontecer ali naquela situação (Estudante de mestrado e enfermeiro recém-formado).

Eu acho que apesar das situações do dia a dia que acontecem, acho que existe o conselho gestor atualmente. $\mathrm{E}$ acho que as pessoas que representam a comunidade e participam realmente, no que eu vi assim..., que a gente estava e nas lideranças indígenas, eles participam mesmo, participam muito. Achei até mais do que imaginava. Assim, não nessas coisas do dia a dia, que às vezes acontece, uma discussão, uma coisa ou outra. Mas a diretriz de como vai ser o serviço e eu achei que o conselho gestor ... nas que eu vi, né, não sei em todas, mas achei que é importante e talvez seja novo até. Da última Constituição da implantação do SUS... eu achei que era importante... a gente até conversou com uma liderança assim... Mas assim, claro, que não representa a todos, sempre tem alguns usuários que não se sentem representados ali, ou não participam, ou não sabem, ou sei lá... Então sempre tem os que participam mais e acabam representando os outros. Mas eu achei que está presente isso (Estudante de medicina).

A participação do usuário no plano de cuidados pode beneficiá-lo significativamente, por influenciar sua adesão ao tratamento de doenças, contudo, pode ser prejudicada pela abordagem que o profissional de saúde utiliza no processo de interação. Um estudo empírico realizado na Holanda para avaliar a participação do usuário na consulta médica, aponta que quando o profissional realiza reflexões sobre as emoções dos usuários, pode estimular sua participação, contudo a tendência do profissional em interromper o usuário ou mudar o foco do diálogo pode prejudicar a participação ativa (Zandbelt et al, 2007).

Outro tipo de participação mencionado pelo estudante no relato é a participação social do usuário, que consiste em uma das diretrizes operacionais do SUS, prevista na Lei Orgânica da Saúde, nº 8080/90. A regulamentação da participação da população por meio de duas instâncias colegiadas, Conselhos de Saúde (Local, Municipal, Estadual e Nacional) e as Conferências de Saúd é tratada na Lei Complementar n⿳o 8.142/90 (Brasil, 1990).

O sentido de participação social mencionado, diz respeito ao controle social, que corresponde à vigilância da sociedade às ações realizadas pelo Estado. De acordo com Stotz (2006), a sociedade pode participar da formulação, acompanhamento e avaliação das políticas públicas (Oliveira et al., 2013). 
O usuário é um dos atores sociais, que podem interferir no fortalecimento do trabalho em equipes interprofissionais colaborativas. No próximo relato, o estudante refere que os usuários também precisam ser preparados para aceitar o trabalho interprofissional nos serviços de saúde. Pois, geralmente as expectativas dos usuários estão voltadas ao atendimento médico, como consequência da medicalização que acarreta na falta de compreensão do papel dos outros profissionais e de seu potencial no cuidado estabelecido.

A minha opinião é algo parecido com isso. Porque não adianta também ter só essa consciência da importância do trabalho em equipe, da divisão de tarefas e de olhares entre os profissionais, se o paciente também não tem consciência disso. O paciente tem que ter consciência disso. Ás vezes ela acha que se ela for atendida por um enfermeiro... às vezes por ela ser atendida por enfermeira acha que não vai ser tão bem atendida como e ela fosse por um médico. E a coisa que acho que a gente viu até quando... o paciente tinha muitas coisas que eu falava - não, consulta de enfermagem -, - nossa, mas enfermeira também faz consulta? -. Então acho que as pessoas ainda não conhecem, não tem essa noção da importância... (Estudante de enfermagem 1)

A inclusão social do usuário em espaços de participação social, assim como, a participação do usuário no plano de cuidados, segundo a lógica da prática centrada no usuário, requer investimentos no empoderamento dos usuários. $\mathrm{O}$ depoimento mostra que o empoderamento envolve o desenvolvimento da capacidade de tomada de decisão sobre seu plano de cuidados e o estímulo à participação social nos conselhos gestores.

Acho que isso faz parte do empoderamento assim. Foi uma coisa muita tirada assim... no sentido de, ah, não vai saber o que é melhor para ele. Quem sabe é a equipe. Então, tirou ele da questão de quem decide o que vai acontecer na conduta e ele também, obviamente, não se preocupou em saber quem faz o que... teoricamente. Mas eu acho que assim, tem a questão do conselho gestor. Aonde você tem um conselho gestor mais ativo obviamente você tem uma comunidade que participa mais, logo uma comunidade que entende o funcionamento do sistema melhor. E essas comunidades que você chega e a pessoa fala - não vou passar em consulta de enfermagem! -, você vê realmente que é uma população que não faz o uso da ferramenta que está disposta lá, do jeito que teoricamente deveria ser feito, como entrada... porta de entrada para o sistema de saúde, que... teoricamente vai usar, mas ou para vacina ou para uma receita, uma coisa ali... de uma medicação... um crônico, por exemplo... mas assim... acho que são todas situações que vão se complementando dentro de essa situação, desse panorama (...) acho que no sentido...começa pelo empoderamento do usuário. Se você tem uma equipe coesa... aquele usuário vai ser orientado em todas as áreas, então ele vai ter mais segurança e mais... vai se sentir mais incentivado a participar ele mesmo do próprio cuidado (Estudante de mestrado e enfermeiro recém-formado).

O empoderamento envolve um maior controle dos indivíduos sobre

suas próprias vidas e pode se manifestar a partir da influencia dos usuários e 
coletivos, no contexto de políticas e práticas macrossociais, com a discussão de alternativas para mudança do status quo. Empoderar-se implica em desenvolver habilidade reflexiva, dialógica, argumentativa e de tomada de decisão, para assumir postura de participação política ativa, frente às determinações sociais e possibilidade de mudanças das condições socioculturais (Carvalho, 2004).

A seguir, o estudante considera que participação dos usuários no plano terapêutico, contribui para qualificar as práticas de saúde, pois ele pode contribuir para a adaptação da terapêutica às suas necessidades de saúde, compartilhando a responsabilidade pelos resultados do cuidado, juntamente com os trabalhadores da saúde.

Na minha visão acho que no tratamento tem que ter a participação do
usuário. Porque se você vai colocar, por exemplo, um tratamento e ele
não aceita, ele não tem participação nisso... ele não vai, vai recusar,
entendeu? Então eu acho que tem que ter a participação dele o tempo
todo... não tem como prescrever um medicamento e pedir para ele... só
orientar, ele tem que estar disposto a seguir né, as normas e tal... acho que
tem que ter sempre a participação. Acho que a participação dele é um dos
fatores relevantes para a qualificação da assistência. Porque não adianta
só o profissional fazendo o papel dele. O usuário também tem que
desempenhar... (Estudante de enfermagem 2). A responsabilização do usuário, no tocante aos resultados do cuidado é um aspecto presente na produção sobre a clínica ampliada (Campos, 2007a), e na prática colaborativa centrada no usuário (Orchard et al., 2012; CIHC, 2010).

Um elemento que pode interferir e dificultar a participação do usuário no plano de cuidados é a assimetria do saber entre o usuário e os profissionais. Os estudantes referem que a assimetria prejudica a comunicação entre os profissionais e usuários, contudo, um estudante ressalta que apesar do comportamento dominante da prescrição do cuidado que reserva as decisões aos profissionais, em detrimento da opinião do usuário, pode haver espaços de negociação entre as partes para a tomada de decisão.

Eu acho que depende... um pouco assim... acho que exista uma certa assimetria às vezes assim, cultural até, educacional entre o profissional e a pessoa que está sendo... o usuário... e às vezes não existe a comunicação adequada, de linguagem até, paciência... ou tempo necessário para que seja explicado... ver que a pessoa entenda, que ambas as partes estejam falando a mesma coisa, que elas saiam de lá com o mesmo entendimento do assunto? Aí... também não é só culpa do profissional também. Mas aí... acho que é difícil? Mas talvez exista, sim, não consigo... não consigo 
generalizar e falar - não, a maior parte dos casos é assim, não sei, não sei ainda, para ser sincero (Estudante de mestrado e enfermeiro recémformado)

Mas eu acho que tende a ser que é muito assimétrico e às vezes não existe tempo nem disposição suficiente das partes para que seja efetivo essa negociação. E acaba sendo que a parte que tem o conhecimento... do que vai ser feito, manda e a outra obedece. Ou sei lá, tenta pelo menos convencer... (Estudante de medicina).

Eu acho que acaba se misturando um pouco. Lógico, um pouco mais voltado para a prescrição, mas ao mesmo tempo que prescreve vai explicando... mas não existe essa parte do contrato com o paciente, se ele aceita a medicação... se vai aceitar aquele plano terapêutico. Acho que não existe essa coisa formal. Acaba sendo meio que automático a prescrição... a prescrição já é vista como o 'aceitamento'(!) do paciente... aceitação... (Estudante de enfermagem 1)

Eu acho que é relativo, de cada paciente e o atendente também, o profissional que está. Já vi profissional que só prescreve, o que prescreve orienta... e que conversa sobre o que seria melhor, para adequar às condições do paciente... Para mim é relativo, não tenho uma opinião formada, se sim ou não (Estudante de enfermagem 2).

A predominante assimetria na relação entre os profissionais de saúde e usuários é uma consequência da comunicação estabelecida. O estudo de Caprara e Rodrigues (2004), sobre a assimetria na relação médico paciente, com a finalidade de repensar o vínculo terapêutico, indica que alguns médicos não explicam de forma compreensível os problemas e também não verificam o grau de entendimento do paciente sobre o diagnóstico dado.

$\mathrm{Na}$ relação entre usuários e profissionais da saúde, marcada pela assimetria e ausência de entendimento, pode-se dizer que prevalece a ação instrumental ou estratégica, em detrimento à prática comunicativa intersubjetiva dialógica.

Os estudantes também tematizam, que a incompatibilidade das grades curriculares dos cursos pode constituir uma barreira para EIP. A seguir, o estudante considera que mesmo no PET-Saúde, que tem como pressuposto a formação interprofissional, as grades curriculares impedem o encontro dos estudantes de diferentes cursos.

Só no PET... Mal e mal... só no PET, porque as amigas minhas que fazem comigo no mesmo dia, no mesmo horário, também são da enfermagem, então... com a enfermeira, e as meninas que fazem comigo são da enfermagem, então, está bem concentrado ali.Aí às vezes, às vezes... a gente tem... a gente encontra as meninas da farmácia e de odonto... (Estudante de enfermagem 2).

Uma expressão das dificuldades do planejamento articulado na universidade, devido as diferentes grades curriculares pode ser identificada nos campos de estágio. No relato a seguir, o estudante refere que os estudantes de diferentes cursos, geralmente se encontram em alguns dias de 
estágio, realizado nos mesmos serviços, mas não têm possibilidades de interação e desenvolvimento de atividades conjuntas para o avanço da EIP.

$\mathrm{Na}$ experiência que eu tenho da graduação, tirando o PET e a JUS, acontece até de em estágio na UBS cruzar nos corredores com os cursos. Um dia tem um montão de gente, tem o pessoal da enfermagem, pessoal da medicina, no mesmo lugar, estão fazendo estágio no mesmo ambiente, mas não tem essa interação entre os cursos (Estudante de enfermagem 1).

\section{SÍNTESE DOS RESULTADOS DO GRUPO FOCAL DE ESTUDANTES}

O conjunto de relatos dos estudantes, diferentemente dos outros grupos focais revela a sensibilidade e preocupação com a participação do usuário no plano terapêutico. Tematizam que sua participação pode contribuir para a qualificação das práticas de saúde, contudo nem sempre é efetiva, devido a assimetria do saber entre o usuário e o profissional, sendo necessário seu preparo e empoderamento para ocupar tal espaço. Ressaltam que a participação do usuário pode ser notada, com mais facilidade nas instâncias de participação social dos conselhos gestores dos serviços de saúde.

A participação do usuário, tematizada pelos estudantes remete à atenção centrada no usuário, atributo central para o fortalecimento do trabalho em equipe apontado pela literatura recente.

Também consideram, que a EIP pode contribuir para a qualidade do cuidado em saúde, por estimular o desenvolvimento da prática interprofissional colaborativa em equipes com a composição integrada do saber de diferentes profissionais. Assim, reconhecem que o predomínio da especialização e a fragmentação do saber, limitam as possibilidades de intervenção no cuidado.

Referem que as grades curriculares dos diferentes cursos dificultam as possibilidades de encontro entre os estudantes constituindo uma barreira para o avanço da EIP.

Nesse sentido, compreende-se que na perspectiva dos estudantes a EIP consiste em uma experiência de formação articulada e interativa entre 
diferentes áreas profissionais que prepara futuros profissionais para o desempenho do trabalho em equipe colaborativo centrado nos usuários.

\section{GRUPO FOCAL DOS DOCENTES}

No grupo focal de docentes, houve seis participantes, com idades entre 36 e 56 anos e média de 48,8 anos, entre os quais dois enfermeiros, um odontólogo, um terapeuta ocupacional, um educador físico e um fisioterapeuta. No tocante à formação, todos possuem mestrado e doutorado sendo que cinco, possuem pós-graduação lato sensu. O tempo de trabalho com a formação em saúde, varia de 13 a 29 anos, cuja média é de 19,6 anos. Apenas três docentes possuem experiência de trabalho nos serviços de saúde, anterior ao vínculo profissional com a universidade, a referida experiência varia de dois a 12 anos, cuja média entre os três docentes mencionados é de 7,3 anos.

Quadro 5 - Perfil dos docentes participantes do grupo focal.

\begin{tabular}{|c|c|c|c|c|c|}
\hline $\begin{array}{c}\text { Código do } \\
\text { participante do } \\
\text { GF/ Categoria } \\
\text { profissional }\end{array}$ & Sexo & Idade & Pós-Graduação & $\begin{array}{c}\text { Tempo } \\
\text { trabalho na } \\
\text { educação } \\
\text { (anos) }\end{array}$ & $\begin{array}{c}\text { Tempo de } \\
\text { trabalho no SUS } \\
\text { e antes do SUS } \\
\text { (anos) }\end{array}$ \\
\hline $\begin{array}{l}\text { Docente } 1- \\
\text { Enfermeiro }\end{array}$ & $\mathrm{F}$ & 54 & $\begin{array}{l}\text { Lato-sensu } \\
\text { Mestrado } \\
\text { Doutorado }\end{array}$ & 12 & 12 \\
\hline $\begin{array}{l}\text { Docente } 2- \\
\text { Enfermeiro }\end{array}$ & $\mathrm{F}$ & 52 & $\begin{array}{l}\text { Lato-sensu } \\
\text { Mestrado } \\
\text { Doutorado } \\
\end{array}$ & 22 & 2 \\
\hline $\begin{array}{c}\text { Docente } 3- \\
\text { Farmacêutico }\end{array}$ & $\mathrm{F}$ & 50 & $\begin{array}{c}\text { Mestrado } \\
\text { Doutorado }\end{array}$ & 29 & - \\
\hline $\begin{array}{c}\text { Docente } 4- \\
\text { Fisioterapeuta }\end{array}$ & $\mathrm{F}$ & 36 & $\begin{array}{l}\text { Lato-sensu } \\
\text { Mestrado } \\
\text { Doutorado }\end{array}$ & 13 & 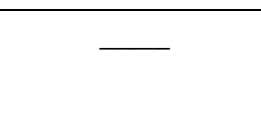 \\
\hline $\begin{array}{c}\text { Docente } 5- \\
\text { Terapeuta } \\
\text { Ocupacional }\end{array}$ & $\mathrm{F}$ & 56 & $\begin{array}{l}\text { Lato-sensu } \\
\text { Mestrado } \\
\text { Doutorado } \\
\end{array}$ & 29 & 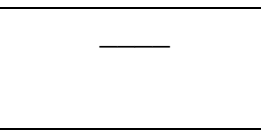 \\
\hline $\begin{array}{l}\text { Docente } 6- \\
\text { Odontólogo }\end{array}$ & $\mathrm{F}$ & 45 & $\begin{array}{l}\text { Lato-sensu } \\
\text { Mestrado } \\
\text { Doutorado }\end{array}$ & 13 & 8 \\
\hline
\end{tabular}

Fonte: Arquivo da pesquisadora.

Os depoimentos dos docentes abordam: 
Figura 12. Resultados do grupo focal dos docentes. São Paulo, 2014

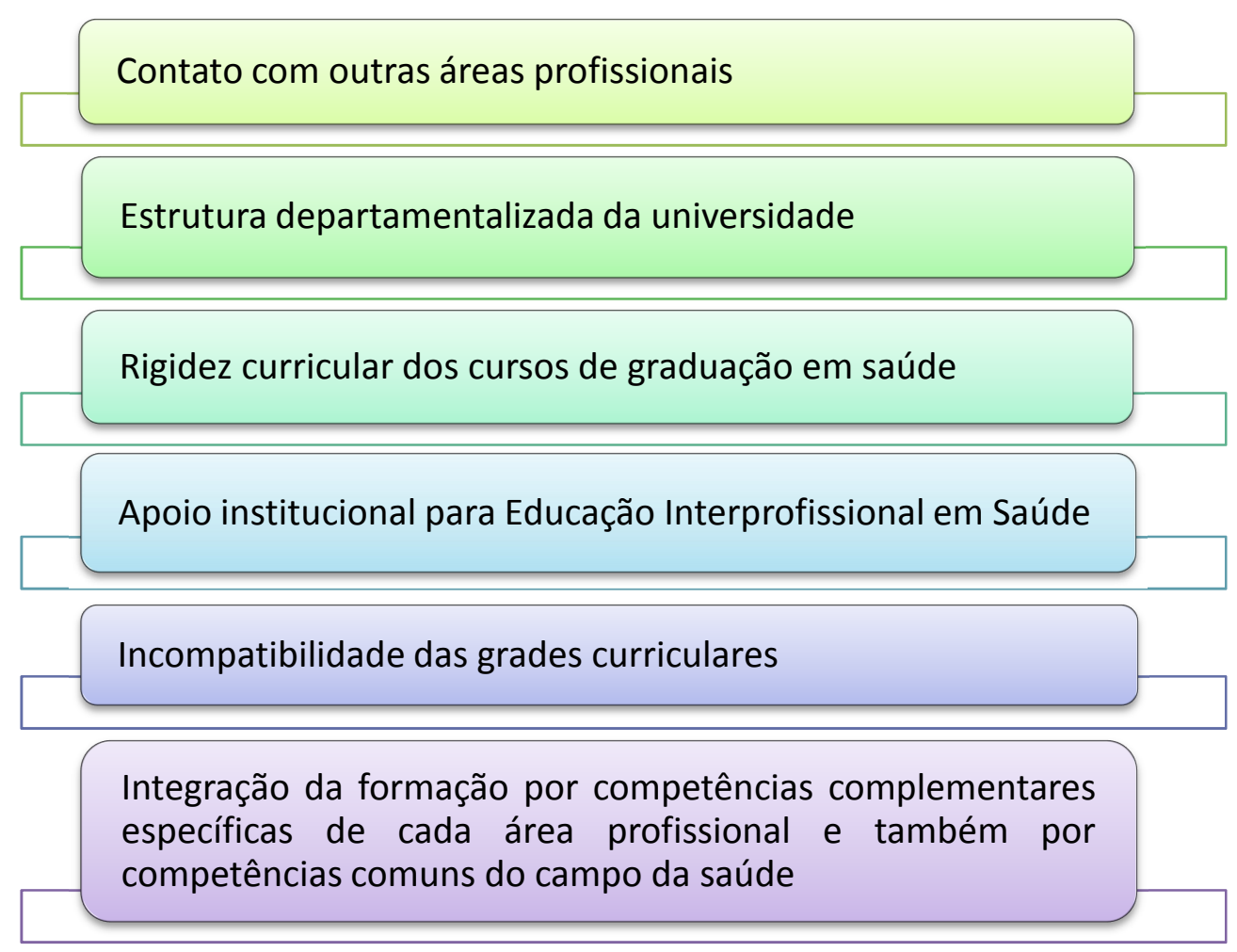

Os contatos com outras áreas são ocasionais, geralmente ocorrem nos campos de estágio, em reuniões de equipe, nas quais participam profissionais e estudantes de outros cursos. O contato interprofissional, prevalece entre estudantes e profissionais nas atividades de formação nos campos de práticas, ao invés de contatos com estudantes de outros cursos.

Eu acho que enquanto espaço de formação e graduação em nutrição, os alunos só vão ter contato mesmo com os profissionais na prática de estágio. Nós temos 8 alunos do curso de nutrição no PET. Eu acho que ali nesse espaço que está tendo mais essa discussão de formação interprofissional. Eu não sei se isso conta, mas eu tive prática de ser enfermeira (de uma unidade escola), e aí lá eu tinha alunos de medicina, tinha internos, residentes... alunos de enfermagem também, que faziam as suas atividades lá dentro da UBS e aí a gente tinha um espaço diferente, que era de reuniões de equipes técnicas, reuniões de equipe que a gente realmente fazia toda uma discussão de todos os profissionais juntos (Docente 2 - Enfermeiro). 
Nas visitas técnicas da disciplina, de graduação, e tanto nos estágios, a gente programa de tal forma para o aluno vivenciar com outros... com outros profissionais e não somente físioterapeutas no serviço. Então, a gente programa muito mais pelas ações acontecem no serviço... Então, mais com o trabalhador do que com os outros cursos. E aí sim tem com os enfermeiros, com terapeutas ocupacionais, com a educadora física, com a nutricionista de lá também. Então, de alguma forma tem uma interlocução, tanto no estágio quanto na disciplina (Docente 4 Fisioterapeuta).

Estudos apontam que há pouco contato entre os estudantes durante a formação no contexto da graduação (Coster et al., 2008, Hind et al., 2003; Horshburg, Landim, Wiliamson, 2001). O contato ou presença de estudantes e profissionais de diferentes áreas, em um mesmo espaço físico, lado a lado, não é suficiente para a construção de atividades da EIP e suas características como o respeito ao outro e mudança de estereótipos profissionais (Sargeant J, Loney E, Murphy, 2008; Carpenter, Dickinson, 2005). A EIP pressupõe a aprendizagem interativa, por meio da troca de saberes e opiniões, que pode ocorrer em espaços de interação informal no contexto das práticas de saúde nos serviços (Sargeant J, Loney E, Murphy, 2008).

A participação dos estudantes no PET-Saúde, também é prejudicada pelas grades curriculares. Nos próximos relatos, os docentes consideram que o PET ainda não consiste em um espaço de formação interprofissional na universidade, pois possibilita poucos encontros entre os estudantes de diferentes cursos de graduação.

(...) por exemplo, eles tem um período semanal que eles precisam ir para a UBS... É muito comum você ver dupla de estudantes de enfermagem, porque a janela... ou a área... o dia que não tem aula é de sexta feira à tarde... Outro curso é terça feira de manhã... Outro é segunda... então é difícil imaginar para conseguir fazê-los se encontrar mesmo no PET que tem essa meta... digamos assim... (Docente 1 - Enfermeiro).

(...) não tem um projeto institucional que diga 'olha, a atenção primária é importante, como é que a gente vai configurar isso dentro dos currículos dos quatro cursos aqui da faculdade'. Não estou falando nem da universidade, que eu acho que até o desejo do PET é esse, fazer uma articulação um pouco maior dessa discussão. Mas a gente não consegue fazer, porque a gente está de tal maneira preso na estrutura da grade... (Docente 5 - Terapeuta Ocupacional).

Como mencionado anteriormente, a incompatibilidade das grades curriculares consiste em uma barreira para EIP (Sungaya et al., 2014) e prejudica ações interprofissionais no PET-Saúde (Leite et al., 2012).

A dificuldade de contato e interação entre os estudantes de diferentes áreas, pode ser considerada uma consequência da estrutura 
departamentalizada da universidade e da rigidez curricular, que prejudicam o desenvolvimento de atividades interprofissionais. Nos próximos relatos, um docente menciona a impossibilidade de orientar um aluno de iniciação científica de outro curso de graduação e o outro aborda a dificuldade em desenvolver a EIP, devido a incompatibilidade nas agendas.

(...) na extensão tinha só fono e fisio trabalhando junto, um trabalho de referencia e contra referencia... Aí esse trabalho a gente tentou passar para a iniciação, só que daí o Departamento não deixou que os alunos de outros cursos fossem orientados... por docente que não era do próprio curso... (Docente 4 - Fisioterapeuta).

E tem um desejo dos alunos grande, em relação ao trabalho interprofissional, que às vezes as disciplinas não dão conta, apesar de colocar como objetivo. Então a gente percebe que a gente tem um caminho grande ainda nesse... a gente não consegue agendar horário comum, para as disciplinas (Docente 5 - Terapeuta Ocupacional).

A estrutura fragmentada da universidade reflete no modelo tradicional de ensino fragmentado, voltado à especialização do saber por campos disciplinares. A interdisciplinaridade no contexto da formação universitária consiste em um movimento de reação à fragmentação da ciência e do conhecimento. De acordo com Japiassu (1976), o positivismo científico influenciou a compartimentalização das disciplinas, para delimitar os objetos do saber.

Para Almeida Filho e Coutinho (2011), a universidade e a educação superior, possuem diferentes funções que precisam ser especificadas. A função da universidade está na formação de intelectuais produtores de conhecimento, pesquisadores, aspecto que reforça a manutenção o modelo de formação disciplinar. Por outro lado, a função das instituições de ensino superior é a formação técnico-profissional que resulta na habilitação para carreiras profissionais.

Como mencionado pelo docente, no relato anterior, cada orientador de inciação científica, deveria trabalhar com alunos vinculados exclusivamente à sua área profissional e disciplinar, delimitada pela estrutura departamental da universidade que reforça a fragmentação entre as disciplinas.

No Brasil, o enfoque da formação desenvolvida pelas universidades, está na formação técnico-profissional, com caráter multidisciplinar, ou seja, com sobreprosição entre as áreas disciplinares e ausência de articulação. Por 
isso, a partir de 2008, iniciou-se um processo de reforma universitária, com a implantação do regime de ciclos predominante na Europa, por influência do Tratado de Bolonha, implantado em 1934 na Universidade do Distrito Federal e em 1961 na Universidade de Brasília (Almeida, Coutinho, 2011).

No contexto da reforma universitária, destacam-se modelos de formação por ciclos em 18 universidades brasileiras, e 16 Bacharelados Interdisciplinares (BI). O BI está pautado na inter/transdisciplinaridade e na pedagogia emancipatória para a formação de sujeitos autônomos e criativos (Almeida, Coutinho, 2011), cujas experiências existosas estão na Universidade Federal da Bahia, Universidade do Sul da Bahia e Universidade do Recôcavo Baiano.

Devido à dificuldade em desenvolver atividades curriculares interprofissionais nos currículos dos cursos de graduação, nos relatos os docentes consideram a importância do desenvolvimento de projetos de extensão, como a Jornada Universitária da Saúde (JUS) e o PET-Saúde. No próximo depoimento, o entrevistado afirma que a participação nos referidos projetos é uma alternativa frente às limitadas oportunidades de implementar outros projetos interprofissionais, devido às exigências de vincular as propostas às unidades ou departamentos da universidade. Nesse sentido, o modo de organização das universidades, cuja estrutura é hierarquizada e fragmentada por áreas, unidades e departamentos, dificulta o avanço da EIP.

E aí, o que nós temos de espaço formal para experiência interprofissional tem sido via ou projetos ligados a cultura e extensão, como Bandeira Científica ou agora com o PET Saúde. Com relação à formação dos alunos seria isso. E ainda (...) tem essa limitação que outra docente comentou do projeto... de cultura e extensão, que não é só lá, aqui também... ainda que a gente faça inscrição de projetos que possam ser interprofissionais, pelo fato de você precisar... aqui na universidade tudo tem que estar atrelado a uma das unidades, e isso acaba limitando as nossas possibilidades de integração e são sempre via disciplinas, o que também então limita bastante qualquer experiência fora as disciplinas. O que for fora disciplina pode ser não interessante para o reconhecimento do nosso trabalho interno inclusive (...) todos nós identificamos o fator limitador grande, que a gente tem para qualquer experiência integradora... é a estrutura curricular... e a questão das disciplinas.. A existência das disciplinas com os seus créditos, que é o que define o poder dentro das relações inter departamentais... eu tenho a disciplina ' $x$ ', com ' $\mathrm{x}$ ' créditos, e essa situação não pode ser mudada porque isso pode dar prejuízo... né... enfim... (Docente 6 - Odontólogo).

(...) tivemos uma experiência de reformulação do currículo, então teve um esforço grande, não para articular diferentes áreas de formação (...) mas fizemos uma experiência para pelo menos integrar com alguns 
conhecimentos específicos de departamentos diferentes (...) sempre tem um movimento para redividir... (Docente 1 - Enfermeiro).

Apesar da dificuldade de integração entre os cursos na estrutura universitária, alguns docentes estão mobilizados para discutir e buscar alternativas de integração. No próximo relato, o docente menciona a experiência de reflexão, em um fórum de discussão que propõe alternativas de integração na universidade, como por exemplo, o oferecimento de disciplinas de graduação abertas para todos os cursos.

(...) gente chegou a discutir no nosso primeiro simpósio de integração ensino-serviço, quando estiveram presentes nesse simpósio os representantes das comissões de graduação dos nossos cursos... e o quanto também eles estão amarrados também a essa estrutura universitária... e o quão difícil é para a universidade imaginar espaços verdes, digamos assim, que a gente viu a experiência de outros cursos que conseguiram mexer nas estruturas curriculares dos cursos da área da saúde e arrumar um espaço comum. Que aí sim... na dependência da vontade dos docentes... pensar nesses espaços para conseguir juntar alunos de cursos diferentes (...) E aí uma das estratégias até que surgiu desse encontro, como uma alternativa incipiente, inicial, mas que pode acontecer... é inicialmente que inclusive as próprias disciplinas que existam ofereçam essas disciplinas para todos os cursos. Então assim, é incipiente, é muito pequeno ainda, mas é a possibilidade então de que alunos de qualquer área da saúde se inscrevam nas minhas disciplinas, na medida que tenham interesse. E aí sim... isso passa a ser uma experiência interprofissional. Mas eu identifico como um fator limitador para essas experiências... é achar um espaço comum nas estruturas curriculares dos alunos, que permita isso. Que não seja a hora do almoço... que ele vai no bandejão, né? Existem esses espaços que são ricos, mas... na estrutura curricular dos cursos a gente não consegue fazer essa articulação... (Docente 6 Odontólogo).

Os cursos de graduação tem estrutura disciplinar, com enfoque técnico-científico específico de cada área profissional. $\mathrm{O}$ docente refere, que as disciplinas das ciências básicas, constituem um conteúdo comum a todos os cursos da saúde, contudo é necessário que as especificidades necessárias para a construção do saber técnico de cada área profissional sejam abordadas.

Aqui todos os cursos daqui da área da saúde passam pelo Instituto de Ciências Biológicas (ICB), então esse talvez seria um exemplo de um espaço formal para a formação interprofissional, mas ali também ele acontece de maneira estanque. Então tem fisiologia para os alunos da medicina, para os alunos da enfermagem e assim sucessivamente. E uma das queixas dos alunos foi inclusive reclamando com relação a isso, porque os dentistas, professores, né, com formação de dentistas, que atuavam no ICBs, estão se aposentando... enfim... estão sumindo, e eles estão se sentindo muito prejudicados porque existem algumas especificidades... Bom, a única talvez especificidade seja anatomia dental, mas fora isso, acho que não teria tanta especificidade. Mas os alunos reconhecem isso, e estão tendo dificuldade e foi uma das queixas. E citaram, por exemplo, precisam aprender articulação, e o exemplo que foi dado... que eles queriam que articulação fosse 'temporo mandibular', que 
é a principal... mas os slides eram de uma articulação do joelho. Então a gente tem essas dificuldades de... essa limitação de formação interprofissional que vem já desde as básicas. E essa promessa de integração, mas a própria formação acaba sendo estanque pelos cursos. E aí o nosso curso em particular é extremamente técnico e específico, e não existe nenhuma experiência interprofissional (Docente 6 - Odontólogo).

$\mathrm{Na}$ concepção dos docentes, a formação interprofissional deve ser composta por competências complementares/específicas de cada área profissional e também por competências comuns do campo da saúde. Aspecto que remete ao conceito de campo comum e núcleo profissional específico, elaborado por Campos (2000, 2007a) e também às três competências para a formação interprofissional elaboradas por Barr et al. (2005).

No próximo excerto, o docente reafirma a ênfase da formação em saúde, na construção do saber específico de cada área profissional. Contudo, destaca a importância da concepção do processo saúde-doença e da complexidade das necessidades de saúde que são multidimencionais, e portanto, exigem a colaboração interprofissional, por meio da composição entre os saberes das áreas profissionais. Tal postura, aponta para uma possível mudança na lógica da formação, com ênfase nas disciplinas necessárias e no desempenho profissional, para um modelo de formação que tenha como foco as necessidades de saúde dos usuários/população. Assim, requer que a formação esteja voltada, tanto para a construção do núcleo profissional específico, quanto para o campo comum.

Eu acho que é porque os cursos focam o domínio, a prática, do instrumento específico, de cada curso. Ponto. Não se discute aonde que está inserido esse instrumento. Como é que você utiliza os seus instrumentos específicos no conjunto com outros instrumentos para, então, transformar em um objeto mais ampliado. Que é a possibilidade de você ampliar a prática... é você juntar, que cada curso tem o seu conjunto de instrumentos específicos. Quando eu falo do processo de saúde e doença para os estudantes, eu sempre uso a figura do chaveirinho... multifacetadinho assim..que batia luz e eu digo para eles que o objeto é aquele... eu acho que o processo de saúde-doença o objeto é aquele, das necessidades de saúde. E cada um utiliza o seu... o cuidado ele não é específico, não é só enfermagem que faz o cuidado, por exemplo. Embora seja um instrumento específico da enfermagem o cuidado, mas não é só da enfermagem. Então, no entanto, acho que cada profissão tem o seu conjunto de instrumentos específicos que tem possibilidade de incidir em uma ou várias fases dessa bolinha. Então, eu só consigo ampliar a prática do cuidado quando junto com outros instrumentos específicos de outras áreas. Mas cada curso, eu acho, foca na destreza com os instrumentos. Seja manual da enfermagem, que é bem técnico, manual... Seja na área mais... estou pensando na área das ciências humanas, por exemplo... aí não é específico da saúde. Mas eu tenho a impressão, assim, a minha 
opinião é essa, que a gente fica... o curso inteiro, enfim, discutindo mais as perspectivas do instrumento específico de cada área e não da utilização em conjunto. Então, você não olha para o objeto, como você quer ampliar o objeto... é seu pedacinho com seus instrumentos... E aí você prescinde de outras áreas, fica estanque o curso... (Docente 1 - Enfermeiro).

A construção da prática interprofissional compartilhada, depende do reconhecimento do saber de cada área profissional e das especificidades de sua atuação. Nesse sentido, o próximo relato ressalta que no processo de trabalho em saúde, torna-se fundamental compreender o objeto de intervenção e os instrumentos ou meios de trabalho disponíveis para transformá-lo. Desse modo, é possível reconhecer os limites dos seus instrumentos de trabalho e buscar a contribuição de outros profissionais e seus respectivos instrumentos.

Acho que por isso que é importante conhecer o que é específico do seu trabalho... do outro, e se ter muita clareza do que a gente quer transformar no trabalho. O trabalho quer transformar uma coisa em outra coisa. Porque aí é que você vai ver o limite que tem o seu instrumento sozinho... eu acho que essa é a questão... que se junta com os instrumentos do outro... mas não é só domínio do instrumento, você tem que ter clareza do que é a transformação... (Docente 1 - Enfermeiro).

$\mathrm{Na}$ verdade eu acho que esse tipo de compartilhar... é justamente isso, você está em um espaço compartilhado, ensinando, aprendendo, e você começa a perceber as especificidades da profissão do outro (Docente 3 Farmacêutico).

No próximo excerto, o docente afirma que o sucesso do movimento interprofissional na universidade, depende de uma macro política institucional. Tal reflexão, pode ser comparada ao movimento desencadeado pelas DCN, que estimularam o fortalecimento da integração ensino-serviço e o deslocamento do modelo hospitalocêntrico para a formação voltada para a APS com ênfase nas necessidades de saúde dos usuários.

Como é que vai se mudar isso? Como você estava apontando da nutrição... Coloca as disciplinas de humanas e aí vem um protesto... Se for uma coisa isolada e focada de cada curso... se não for uma coisa de todos os cursos como um todo... a gente pode conseguir algumas coisas, mas também pode morrer na praia. Então é uma discussão bem delicada essa... O interprofissional precisaria de uma política institucional macro... (Docente 5 - Terapeuta Ocupacional).

A presença de uma política governamental, que suporte os programas da EIP é considerada um dos macro fatores ou sistêmicos, necessários para interprofissionalidade. Está relacionada com o compromisso dos sistemas de educação e saúde em apoiar a EIP, com políticas e estratégias que possam minimizar a segregação profissional entre 
as áreas e estimular a articulação entre profissionais da saúde, usuários, docentes e estudantes para a elaboração de reformas na legislação e regulação profissional (D’Amour, Oandansan, 2005; Oandansan, Reeves, 2005). Nesse sentido, destacam-se as experiências do National Health Service do Reino Unido e o apoio do governo canadense e norte-americano no estímulo à mudanças curriculares, elaboração de competências para a formação interprofissional colaborativa centrada no usuário, criação de programas de acreditação para EIP e fortalecimento da integração ensinoserviço (CIHC, 2010, EIPC, 2011).

A perspectiva interprofissional, consiste em um movimento de troca de saberes e composição com os outros. Por isso, depende do reconhecimento dos limites da atuação de cada profissional e da atitude de lidar com a insuficiência do saber e a imprevisibilidade, característica do processo de trabalho em saúde.

(...) eu acho que da experiência também do inusitado, do imponderado, do imprevisível... que a realidade traz, mas principalmente quando você está em um conjunto de olhares, que você estava falando, olhar prismático, né, quer dizer, esse prismático ele não se encerrar nele mesmo. Ele não é um juntado de coisas. O 'inter' ele não é um juntado. Então ele tem que ser uma troca. E para ser uma troca ele tem que se transformar, ele tem que deixar de ser específico para ser uma coisa que não é nem esse, nem aquele... é um outro que está fora, que é o próprio conceito de grupo... é...que quando você está junto não é um juntado de... individualidades e particularidades, mas é um conceito que ele se sobrepõe a isso, ele vem a se configurar de outra maneira. Então acho que isso é o mais interessante. Mas principalmente essa coisa assim, de sair do previsível, que é o que a estrutura bem tradicional dá para o aluno, que aí o agarramento do aluno nas técnicas, na especialidade...porque é tudo previsível. Tudo está ali dado e você sabe como é que vai proceder. Quer dizer, o interprofissional ele te lança em uma experiência diferente, quer dizer, existe o imprevisível, e a gente tem que poder lidar com o imprevisível... o imponderável, sei lá o que... (Docente 5 - Terapeuta Ocupacional).

A preservação de procedimentos privativos à determinada categoria

profissional pelas associações profissionais, representa uma das tensões no movimento em prol da EIP, que deveria estar voltado para às possibilidades de troca de saberes na construção da prática colaborativa. No próximo depoimento, o docente relata a respeito de profissionais que buscam apoio jurídico para estabelecer práticas privativas e considera que a identidade profissional não está relacionada à procedimentos técnicos.

Tem agora uma coisa que está acontecendo na terapia ocupacional (TO), que os médicos estão interpelando um ato terapêutico ocupacional e as fonos também. $\mathrm{E}$ as fonos começaram a interpelar que a TO não pode 
atender bebê em unidade de terapia intensiva (UTI), que o bebê em UTI é da fono, não é da TO. Vejam vocês... como essa coisa da profissão... a discussão ia ser amanhã na câmara dos deputados... em Brasília... para definir o quadrado... Então está uma discussão jurídica... que é isso, gente! $\mathrm{O}$ trabalho da gente às vezes é fazer do apoio... é a discussão do matriciamento também, quer dizer, você instrumentalizar o outro... Mas para fazer isso você tem que se despojar um pouco dessa coisa também de que a tua identidade está... colada no procedimento... (Docente 5 Terapeuta Ocupacional).

As associações profissionais estabelecem critérios os para as práticas de profissões específicas e procuram garantir autonomia e respeito para os seus membros. Exercem influencias sobre as propostas curriculares e articulação entre as profissões. Contudo, podem provocar a fragmentação entre as profissões com a imposição de limites ao escopo de práticas profissionais de outras áreas (Gilbert, 2005).

O modelo de formação da EIP, enfrenta tensões constantes dentro e fora da universidade, pois o contexto dos serviços da saúde também pode obstaculizar a prática interprofissional. A seguir, o docente considera que os egressos da formação interprofissional podem contribuir na produção de rupturas com as práticas de saúde fragmentadas predominantes nos serviços da saúde.

E que dá a perspectiva disso, de que a realidade não está dada... de que o indivíduo que aprendeu em um espaço compartilhado, de âmbitos diferentes do diálogo, tem tensões... na hora que ele chegar no espaço profissional, que hoje não permite a interprofissionalidade, talvez permita. Porque a realidade do futuro não está dada, e a gente tem essa expectativa de que tudo continuará como está... e não é. Então, acho que é essa possibilidade de criar ruptura que é interessante, do interprofissional (Docente 3 - Farmacêutico).

No próximo excerto, o docente aponta uma contradição do modelo de atenção à saúde, cujo foco ainda é biomédico e está em constante embate com a lógica de organização dos serviços de APS, pautados na Estratégia de Saúde da Família. Tal situação, revela a tensão entre a ênfase das práticas no objeto de intervenção, que pode ser compreendido exclusivamente na doença ou nas necessidades de saúde dos indivíduos e famílias.

E eu acho que... uma das coisas que alguém falou aqui... acho que foi você... sobre tempo...o tempo é um negócio fundamental. Não termos tempo para conviver mais, dificulta a troca, então acho que esse é um problema. Porque é tudo espremido... Mesmo os nossos encontros são à noite com os alunos, preceptores... então isso é uma coisa que está prendendo um pouco o projeto. Agora, você falou de avanços. Eu acho que os avanços que eu vejo são mais dessa possibilidade de ir abrindo essa conversa, de ir... inclusive de abrir uma discussão sobre o que é a própria atenção primária... gente... porque eu acho que a gente ainda está nessa discussão... não é nem no 'interprofissional', é no que é a atenção 
primária. Instigá-los e os profissionais também, porque uma das coisas que eu tenho discutido muito com os grupos é: nós temos uma contradição fortíssima na atenção primária, que a gente tem que discutir, que é: o objeto da atenção primária hoje, se diz que é a família... pela Estratégia Saúde da Família, no entanto se organiza todo o sistema em serviço, acima de uma estrutura que é procedimental, e encima da doença. Não é a família nem é o indivíduo. É na doença, na patologia, no tuberculoso, no hipertenso, no diabético. $\mathrm{Na}$ gestante que não é doente, mas é um grupo dos programas, mas são biomédicos. E eles ficam premidos por isso, porque tem que registrar, tem que fazer um monte de coisas... Mas aí diz que não, aí diz que o objeto é a família. Aí ninguém sabe o que é família, porque aí a família não é a família esperada. Aí tem a família que colabora e a família que não colabora, que é aquela que não abre a porta. Então... e aí depois se fala do trabalho intersetorial e a gente não tem nada dessa discussão, sobre o que é o intersetorial, o que são as trocas com a comunidade... ninguém sabe nem o que fazer em relação a isso. Então, essa discussão, eu acho que ela é uma das mais complicadas, agora hoje até acho que me deu um pouco de luz essa discussão da gente... porque eu acho também que essa discussão da solidão das profissões... é que dificulta também pensar um pouco no trabalho coletivo... (Docente 5 - Terapeuta Ocupacional)

\section{SÍNTESE DOS RESULTADOS DO GRUPO FOCAL DE DOCENTES}

Os relatos dos docentes evidenciam que as atividades de EIP não correspondem ao modo de organização das universidades, cuja estrutura é hierarquizada, fragmentada por áreas, unidades, departamentos e disciplinas. A universidade está organizada para a construção do saber especializado de cada área profissional. Por isso, os docentes enfrentam a falta de reconhecimento institucional das atividades de graduação que ocorrem fora de disciplinas.

Nesse sentido, apontam a busca de alternativas para compor propostas interprofissionais, como oferecimento de disciplinas abertas para todos os cursos e projetos de extensão. Destacam, que os estudantes interessados no contato com outros cursos, procuram projetos de extensão como JUS e programas indutores de mudança, como o PET-Saúde, por inciativa própria.

A ausência do apoio institucional para a EIP nas universidades, pode ser considerada um dos limites para integração interprofissional entre os cursos. Por isso, um docente ressalta a necessidade de uma macro política institucional, que incentive e apoie as atividades da EIP nas universidades. 
Pode-se dizer, que o movimento da EIP na universidade estudada ainda é incipiente e que devido a estrutura fragmentada da universidade e a ausência do apoio institucional, depende de esforços individuais de grupos de docentes e estudantes interessados na construção de espaços de vivências interprofissionais.

No tocante às práticas de saúde, a principal tensão para a EIP se refere à preservação de procedimentos privativos pelas associações profissionais.

A concepção da EIP apresentada pelo grupo de docentes, expressa o reconhecimento das competências colaborativas da especificidade profissional e das competências comuns, para constituir espaços de troca de saberes para atenção da complexidade das necessidades de saúde, considerando os limites de cada área profissional e a imprevisibilidade dos problemas de saúde que na maioria dos casos são pouco estruturados. 


\section{SÍNTESE DAS CONVERGÊNCIAS E CONTRADIÇÕES DOS GUPOS FOCAIS}

É consenso para os participantes dos GF, que a experiência interprofissional promove a clarificação, ou reconhecimento do trabalho e dos diferentes papéis profissionais e dos limites entre as práticas, a eliminação dos estereótipos e o reconhecimento da importância da contribuição dos saberes das diferentes áreas profissionais e sua complementaridade para atenção à complexidade das necessidades de saúde dos usuários. Estes resultados reafirmam a necessária reconfiguração das relações profissionais em prol da colaboração interprofissional, com ênfase nas necessidades de saúde dos usuários ou da prática centrada no usuário.

Os relatos dos GF apontam que a EIP pode desencadear a corresponsabilização dos trabalhadores e usuários, com o deslocamento do foco das práticas para as necessidades de saúde dos usuários, contribuindo para o desenvolvimento da prática interprofissional e do trabalho em equipes colaborativas, em detrimento à usual fragmentação do processo de trabalho em saúde.

O PET-Saúde é reconhecido como uma política indutora da EIP que promove o trabalho em equipe, com articulação interprofissional, o reconhecimento dos papéis profissionais e a integração ensino-serviço.

Embora os resultados dos GF sejam convergentes, destacam-se alguns aspectos que foram tematizados diferentemente pelos participantes dos GF. Os estudantes revelam a importância da participação do usuário no planejamento terapêutico e nos espaços de participação social do conselho gestor de saúde. Os trabalhadores das UBS apontam a ausência do planejamento articulado entre os cursos da universidade para a realização das atividades práticas nos serviços, ou seja, a desarticulação ensinoserviço, em virtude do planejamento das atividades de formação sem integração com serviços, que são considerados executores do planejamento realizado pela universidade. Os docentes e estudantes ressaltam que as atividades de EIP não correspondem ao modo de organização das 
universidades, cuja estrutura é hierarquizada, fragmentada por áreas, unidades, departamentos e disciplinas.

Ainda na perspectiva dos docentes tutores, a universidade está organizada para a construção do saber especializado de cada área profissional, cuja ênfase está no agir instrumental pautado no conhecimento técnico-científico. A ausência do apoio institucional para a EIP nas universidades, pode ser considerada um dos limites para integração interprofissional entre os cursos.

Pode-se dizer, que o movimento da EIP na universidade, ainda é incipiente e que devido a ausência do apoio institucional depende de esforços individuais de grupos de docentes e estudantes, interessados na construção de espaços de vivências inteprofissionais. Nesse contexto, um docente menciona a importância de uma macro política para estimular o desenvolvimento da EIP.

Outro aspecto tematizado pelos docentes e trabalhadores nos GF que corrobora com os resultados das entrevistas é o reconhecimento de que a busca da preservação dos espaços profissionais pelas associações e corporações, consiste em uma tensão para o fortalecimento da EIP. Tal resultado, também aponta na direção da reconfiguração das relações profissionais em saúde, no tocante à regulação profissional, em prol da colaboração interprofissional.

A principal concepção de EIP apresentada nos GF, expressa a importância do reconhecimento e preservação da especificidade profissional de cada área e a construção de uma prática colaborativa com a troca de saberes, para atenção da complexidade das necessidades de saúde dos usuários/população 


\section{SÍNTESE FINAL: TRIANGULAÇÃO DOS RESULTADOS}

Os resultados das duas fases de pesquisa de campo, entrevistas com docentes e grupos focais com trabalhadores, docentes e estudantes, permitiram identificar convergências que dizem respeito ao reconhecimento do trabalho, dos diferentes papéis profissionais e dos limites entre as práticas, que constitui o aspecto central das concepções da EIP expressa pelos participantes. Estes resultados evidenciam que a concepção da EIP indica a necessidade da reconfiguração das relações profissionais para colaboração interprofissional em saúde, centrada no usuário, na perspectiva da integralidade.

As entrevistas apresentam resultados que corroboram com os dos GF, pois ambos apontam que a EIP pode desencadear o deslocamento do foco das práticas para as necessidades de saúde dos usuários, contribuindo para o desenvolvimento da prática interprofissional e do trabalho em equipes colaborativas, em detrimento à usual fragmentação do processo de trabalho em saúde.

A ênfase nas necessidades de saúde dos usuários é mencionada por todos os participantes, docentes, trabalhadores e estudantes, entretanto, é importante destacar que os estudantes, tematizam a participação do usuário no planejamento terapêutico do cuidado, com a tomada de decisão compartilhada, como um aspecto central de sua preocupação no tocante à formação interprofissional.

Tanto nas entrevistas quanto nos GF, referem o papel do profissional enfermeiro na articulação das práticas profissionais da saúde, devido contato frequente com trabalhadores e usuários, e sua atuação como agente de convergência e distribuição de informações.

É importante destacar, que a orientação da formação para o trabalho em equipe é tematizada principalmente pelos docentes e trabalhadores que falam sobre essa modalidade de organização do trabalho na rede de atenção 
para fortalecer o trabalho de equipes integradas, a comunicação interprofissional, prática colaborativa entre diferentes equipes e a colaboração entre equipes de outros serviços, assim como a articulação intersetorial. Também abordam que preditores do trabalho em equipe podem ser desenvolvidos por meio da EIP, como o estabelecimento de objetivos comuns, o reconhecimento dos limites do saber e a possibilidade de complementaridade com os saberes dos outros.

Considera-se que a triangulação dos resultados, da primeira e segunda fases da pesquisa corrobora as três categorias empíricas identificadas a partir da análise das entrevistas: 'A educação interprofissional em saúde, desloca a ênfase da formação e das práticas para a integralidade do cuidado', 'A educação interprofissional em saúde contribui para a reconfiguração das relações profissionais colaborativas', 'Preservação da especificidade profissional das competências complementares, reconhecimento das competências comuns e construção das competências colaborativas'.

Quanto a terminologia relacionada à EIP nos depoimentos, comparativamente, pode-se dizer que os docentes entrevistados e dos grupos focais, utilizam com mais frequência o termo interprofissional diferentemente dos trabalhadores e estudantes. Contudo, embora esse aspecto não tenha sido analisado em profundidade, notou-se a utilização de termos correlatos como multiprofissional, interdisciplinar, multidisciplinar, transdisciplinar. Aspecto que aponta a necessidade de estudos sobre as terminologias relacionadas à EIP.

No tocante as barreiras identificadas para o avanço da EIP, os docentes entrevistados apontam o modelo de organização das universidades públicas brasileiras, cuja estrutura é fragmentada e também a incompatibilidade das grades curriculares dos cursos de formação em saúde, dificuldades na articulação entre as universidades e os serviços de saúde e necessidade de apoio institucional nas universidades.

Contudo as principais barreiras da EIP apontadas nos GF são as grades curriculares que impedem o encontro entre os estudantes de diferentes cursos. Nesse contexto, o PET-Saúde consiste em um espaço 
potente para esse encontro, embora também seja prejudicado pelas grades curriculares.

Nos depoimentos dos GF o PET é indicado como uma proposta indutora da EIP, que proporciona oportunidades de convivência com outras áreas, reconhecimento dos papéis profissionais, eliminação de estereótipos, práticas compartilhadas e integração ensino-serviço.

Frente as barreiras identificadas tornam-se necessários investimentos nas instituições formadoras, para implantação de propostas de flexibilização curricular, articulação entre as unidades de ensino da universidade e também o desenvolvimento de planejamento conjunto entre as universidades e serviços de saúde para as práticas em campos de estágio.

As principais tensões identificadas frente ao avanço da EIP, se referem às relações de trabalho organizadas a partir dos interesses profissionais, em detrimento às necessidades de saúde dos usuários e do direito à saúde e ao modelo de organização de trabalho biomédico que é hegemônico, frente à outros modelos tecnoassistenciais, voltados aos usuários com destaque para a clínica ampliada orientada para a diretriz da integralidade da atenção à saúde.

Ao buscar compreender as concepções e articulação da EIP com as práticas de APS no contexto brasileiro ficou evidente a circularidade e a mútua dependência entre formação e trabalho em saúde como pode ser visualizado a seguir. 
Figura 13. Diagrama dos resultados com circularidade entre trabalho/formação em saúde. São Paulo, 2014.

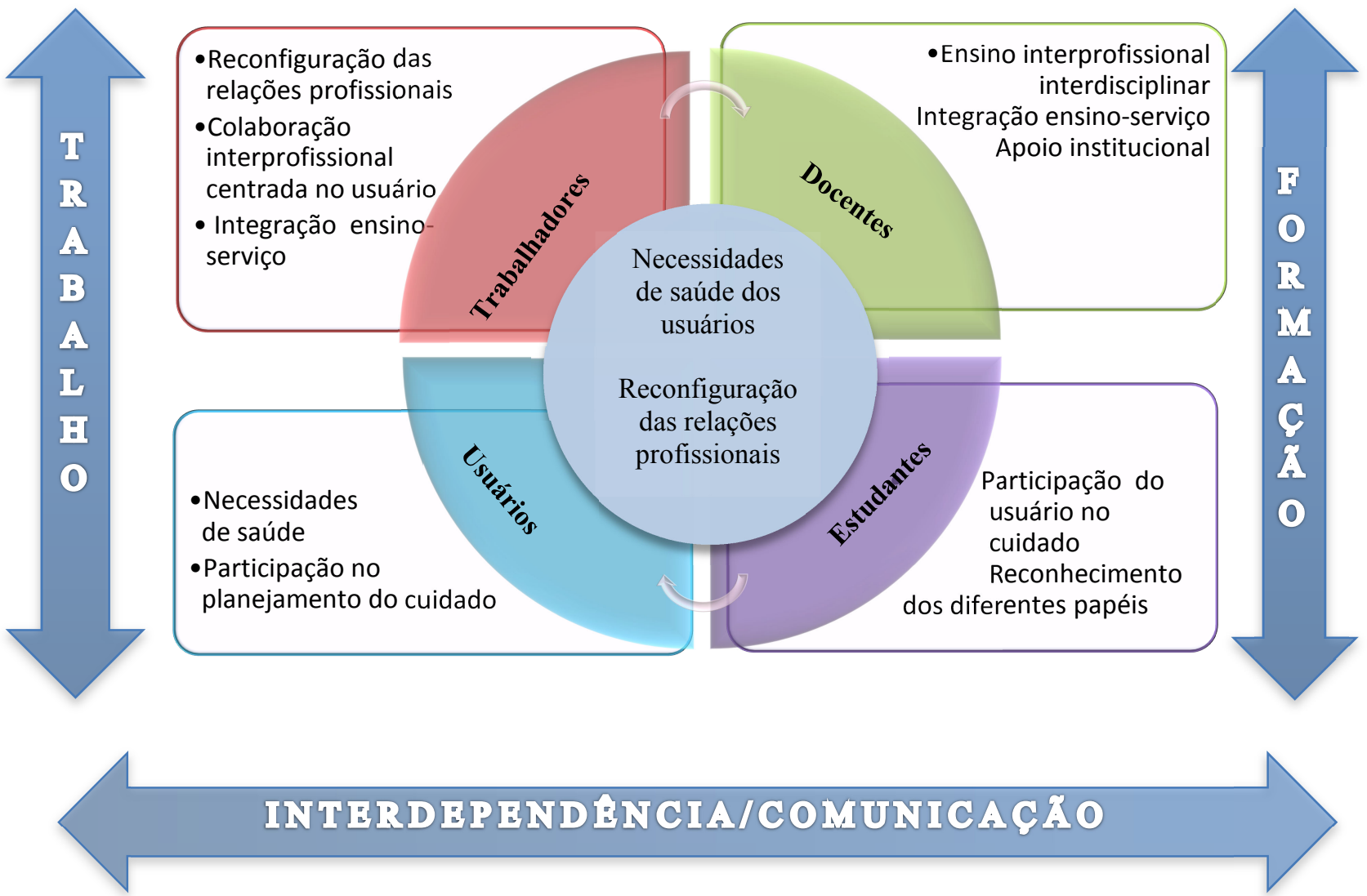




\section{CONSIDERAÇÕES FINAIS}

$\mathrm{Na}$ busca de compreender possibilidades para o avanço da EIP no cenário brasileiro, realizou-se este estudo para analisar as concepções da EIP e sua articulação com as práticas de saúde no contexto da APS, na perspectiva de trabalhadores, docentes e estudantes vinculados ao PETSaúde.

Apresentam-se considerações finais, relacionadas às fortalezas e limitações do estudo, bem como possíveis desdobramentos de pesquisas futuras.

A complexidade do objeto de estudo, a EIP e a prática interprofissional na APS, foi contemplada com a utilização do referencial teórico adotado à luz dos conceitos do processo de trabalho em saúde e enfermagem, profissões, profissionalismo, teoria do agir comunicativo, interdisciplinaridade e prática centrada no usuário. Embora, seja necessário dar continuidade à exploração do potencial desse quadro teórico em outros estudos, dada a sua complexidade e a ousadia de articular referenciais teóricos conceituais distintos, como utilizado nesta pesquisa, na abordagem de temas do campo da saúde na área da enfermagem.

A escolha do recorte de estudo no contexto da APS, mostrou-se acertada, à medida em que os resultados mostram o potencial da APS para interprofissionalidade, devido o intenso debate pela mudança do modelo de atenção em direção à integralidade, que requer o trabalho em equipes integradas e colaborativas na rede de atenção. A estratégia preconizada para a reorganização da APS é o trabalho em equipes da ESF, aspecto que favorece a integração entre distintos saberes profissionais, em uma relação de interdependência e complementaridade, que constitui um terreno fértil para reconfiguração das relações profissionais, apontado como um aspecto de consenso apresentado nesta pesquisa.

A opção pelo desenho de estudo em duas fases, possibilitou a triangulação e maior consistência dos resultados obtidos e a inclusão das 
vozes de diferentes atores sociais, estudantes, trabalhadores e docentes contribuiu para uma compreensão mais abrangente do fenômeno de estudo, que no entanto, deverá ser ampliada em próximas pesquisas com a inserção de usuários e população no desenho de estudo.

Os grupos focais enriqueceram as possibilidades de análise das concepções da EIP e sua articulação com as práticas no contexto da APS, que constituem os objetivos do estudo, pois representam os atores sociais envolvidos na formação e permitiram a expressão de diferentes aspectos da operacionalização da interprofissionalidade, mas convergem no tocante às concepções da EIP.

As concepções da EIP identificadas nos relatos, indicam a necessidade da reconfiguração das relações profissionais, para a perspectiva da colaboração interprofissional em saúde, centrada no usuário, na perspectiva da integralidade.

As limitações do estudo se referem ao longo período de realização da coleta de dados, que se estendeu por um ano e sete meses, devido a necessidade da pesquisadora realizar viagens para entrevistar docentes de oito universidades das regiões nordeste, sudeste e sul do país, na primeira fase da pesquisa. Na segunda fase, para a composição dos grupos focais, muitas tentativas de agendamento de horários comuns para o encontro dos participantes foram realizadas sucessivamente. Notou-se a baixa disponibilidade dos estudantes em participarem do grupo focal, tanto durante o período das aulas, devido a incompatibilidade das grades curriculares tanto durante o período letivo, como durante as férias escolares. Por isso, foi incluído um estudante recém-formado, o que configurou a constituição de um grupo focal heterogêneo, diferentemente do que estava previsto inicialmente no projeto de pesquisa.

A pesquisa traz contribuições, no que se refere às concepções e tensões presentes na operacionalização da interprofissionalidade na APS brasileira. Possibilitou também a identificação de lacunas do conhecimento sobre a EIP no Brasil, que apontam a necessidade do desenvolvimento de novos estudos sobre as barreiras para operacionalização da EIP, estratégias 
pedagógicas, avaliação do impacto de programas de EIP na formação dos estudantes e nas práticas da saúde.

Espera-se que os resultados desse estudo, contribuam para subsidiar novas pesquisas sobre EIP e sensibilizar os agentes docentes, trabalhadores, estudantes e usuários, envolvidos nos possíveis processos de mudança, para o avanço da EIP no cenário nacional. 


\section{REFERÊNCIAS}

Aguiar C. Atuação do enfermeiro na atenção básica no âmbito da articulação interprofissional [dissertação]. São Paulo: Escola de Enfermagem, Universidade de São Paulo; 2013.

Aguilar-da-Silva RH, Teixeira SL, Batista NA. Avaliação da formação interprofissional no ensino superior em saúde: aspectos da colaboração e do trabalho em equipe. Avaliação, Campinas; Sorocaba, SP. 2011;16(1):16582.

Albuquerque VS., et al. A Integração Ensino-serviço no Contexto dos Processos de Mudança na Formação Superior dos Profissionais da Saúde. Revista Brasileira de Educação Médica. 2008;32(3):356-362.

Almeida Filho N. A ciência da saúde. Editora Hucitec: São Paulo; 2000.

Almeida Filho N. Reconhecer Flexner: inquérito sobre produção de mitos na educação médica no Brasil contemporâneo. Cad. Saúde Pública. 2010; 26(12):2234-49.

Almeida Filho N, Coutinho D. Nova arquitetura curricular na universidade Brasileira. Cienc Cult. 2011 [citado 2014 Junho 24] ;63(1): 4-5. Disponível em :http://cienciaecultura.bvs.br/scielo.php?script=sci arttext\&pid=S0009-67252011000100002\&lng=en.

Almeida MJ, Feuerwerker L, Llanos M. A educação dos profissionais de saúde na América Latina: teoria e prática de um movimento de mudança. Tomo 1: um olhar analítico. São Paulo: Hucitec; 1999.

Almeida MCP, Rocha JSY. O saber da enfermagem e sua dimensãoo prática. São Paulo: Cortez; 1986.

Anderson NR, West MA. Measuring climate for work group innovation: development and validation of the team climate inventory. J Organiz Behav. 1998;19:235-258.

Antunes R. O caracol e sua concha: ensaios sobre a nova morfologia do trabalho. São Paulo: Boitempo Editorial; 2005. 136 p.

Aragão L. Habermas: filósofo e sociólogo do nosso tempo. Rio de Janeiro: Tempo Brasileiro; 2002.

Artmann E, Rivera FJU. Humanização no atendimento em saúde e gestão comunicativa. In: Deslandes SF. (organizadores). Humanização dos cuidados em saúde: conceitos, dilemas e práticas. Rio de Janeiro: Editora Fiocruz; 2006. p.205-231. 
Artmann, E. Interdisciplinaridade no enfoque intersubjetivo habermasiano: reflexões sobre planejamento e Aids. Ciência \& Saúde Coletiva. 2001; 6(1):183-195.

Ateaha CA., et al. Stereotyping as a barrier to collaboration: Does interprofessional education make a difference? Nurse Education Today 31 (2011) 208-213.

Ayres JRCM. Organização das ações de atenção à saúde: modelos e práticas. Saúde e Sociedade. 2009;18(supl.2):11-23.

Ayres, JRCM. Cuidado: trabalho e interação nas práticas de saúde. Rio de Janeiro: CEPESC: UERJ/IMS: ABRASCO, 2009.

Ayres, JRCM. Hermenêutica e humanização das práticas de saúde. Ciência \& Saúde Coletiva, 2005; 10(3):549-60.

Ayres, JRCM. Para comprender el sentido práctico de las acciones de salud: contribuciones de la hermenéutica filosófica. Salud Colectiva. 2008; 4(2): 159-72.

Ayres, JRCM. Sujeito, intersubjetividade e práticas de saúde. Ciência \& Saúde Coletiva. 2001; 6(1):63-72.

Bainbridge L, Nasmith L, Orchard C, Wood V. Competencies for interprofessional coillaboration. Journal of Physical Therapy Education. 2010;24(1):6-11.

Barbour R. Grupos Focais. Porto Alegre: Artmed; 2009.

Bardin L. Análise de conteúdo. Lisboa: Edições 70; 2009.

Barnes D, Carpenter J, Dickinson C. Interprofessional education for community mental health: attitudes to community care and professional stereotypes. Social Work Education. 2000;19(6):565-583.

Barr H, Koppel I, Reeves S, Hammick M, Freeth D. Effective interprofessional education: arguments, assumption \& evidence. London: Blackwell, CAIPE; 2005.

Barr H. Competent to collaborate: Towards a competency-based model for interprofessional education. Journal of Interprofessional Care. 1998;12:181187.

Barreto ICHC, Loiola FA, Andrade LOM, Moreira AEMM, Cavalcanti CGC de Sá, Arruda CAM et al. Development of interprofessional collaborative practices within undergraduate programs on healthcare: case 
study on the Family Health Alliance in Fortaleza (Ceará, Brazil). Interface. 2011;15(36):199-212.

Barwell J., et al. How interprofessional learning improves care. Nursing Times. 2013;9(21):14-6.

Batista N. A. Educação interprofisssional em saúde: concepções e práticas. Caderno FNEPAS. 2012:2; 25-28.

Belisário AS. Implantação do curso de graduação em saúde coletiva: a visão dos coordenadores. Ciência \& Saúde Coletiva. 2013:18(6); 625-34.

Berardinelli LMM, Santos MLSC. Repensando a interdisciplinaridade e o ensino de enfermagem. Repensando a interdisciplinaridade e o ensino de enfermagem. Texto Contexto Enferm. 2005.14(3):419-26.

Berridge EJ, Mackintosh N, Freeth D. Supporting patienty safety: examing communication within delivery suíte teams through contrsting approaches to research observation. Midwifery 2010; 26:512-9.

Bonelli MG. Origem social, trajetória de vida, influencias intelectuais, carreira e contribuições sociológicas de Eliot Freidisson. In: Freidson E. Renascimento do profissionalismo: teoria, profecia e política. São Paulo: Edusp, 1998. p.11-30

Bourgeaultt IL. Mesa redonda: Experiências de regulação do trabalho e das profissões em saúde. O papel do estado nas políticas reguladoras das ocupações profissionais na area da Saúde. 2013.

Bourgeaultt IL, Grignon M. A comparison of the regulation of health professional boundaries across OECD countries. The European Journal of Comparative Economics. 2013;10(2):199-223.

Brasil. Ministério da Educação e Cultura. Secretaria do Ensino Superior. Programa de Integração Docente-Assistencial (IDA). Brasília, MEC/SESU/CCS, 1981. 32p. Cadernos da Ciência da Saúde, n.3.

Brasil. Constituição, 1988. Constituição da República Federativa do Brasil. Brasília: Senado; 1988.

Brasil. Lei n. 8080, de 19 de setembro de 1990. Disõe sobre as condições para a promoção, proteção e recuperação da saúde, a organização e o funcionamento dos serviços correspondentes e dá outras providências. [legislação na Internet]. Brasília; 1990 [citado 2013 jun30]. Disponível em: http://portal.saude.gov.br/portal/arquivos/pdf/lei8080.pdf

Brasil. Ministério da Saúde. Conselho Nacional de Saúde. Resolução n. 52, de 6 de maio de 1993. Diário Oficial da União, 26 de maio de 1993. 
Brasil. Diretrizes Curriculares Nacionais dos Cursos de Graduação em Enfermagem, Medicina e Nutrição. Despacho do Ministro em 1/10/2001, publicado no Diário Oficial da União de 3/10/2001, Seção 1E, p. 131. Ministério da Educação. Conselho Nacional de Educação; 2001.

Brasil. Ministério da Saúde. Secretaria de Gestão do Trabalho e da Educação na Saúde. Conselho Nacional de Saúde. Mesa Nacional de Negociação Permanente do SUS: democratização das relações de trabalho no Sistema Único de Saúde. Brasília; 2003

Brasil. Ministério da Saúde. Pró-Saúde: programa nacional de reorientação da formação profissional em saúde / Ministério da Saúde, Ministério da Educação. Brasília: Ministério da Saúde; 2005a. 80p. (Série C - Projeto, Programas e Relatórios).

Brasil. Ministério da Saúde. Conselho Nacional de Saúde. Princípios e diretrizes para a gestão do trabalho no SUS (NOB/RH-SUS). 3 ed. Brasília, $2005 b$.

Brasil. Ministério da Saúde. Secretaria de Gestão do Trabalho e da Educação na Saúde. Departamento de Gestão e Regulação do trabalho em Saúde. Câmara de Regulação do Trabalho em Saúde. Brasília; 2006a.

Brasil. Ministério da Saúde. Residência Multiprofissional em Saúde: experiências, avanços e desafios [Internet]. Brasília, 2006b [citado 2013 dez. 10]. Disponível em: http://bvms.saude.gov.br/bvs/publicacoes/ residencia_multiprofissional.pdf

Brasil. Ministério da Saúde. Portaria interministerial $\mathrm{n}^{\circ}$. 1.802, de 26 de agosto de 2008. Institui o Programa de Educação pelo Trabalho para a Saúde - PET - Saúde. Diário Oficial da União. Brasília, DF, 27 ago. 2008.

Brasil. Ministério da Saúde. Programa Nacional de Reorientação da Formação Profissional em Saúde - Pró-Saúde: objetivos, implementação e desenvolvimento potencial. Brasília; 2007c.

Brasil. Ministério da Saúde Política Nacional de Atenção Básica. Ministério da Saúde: Brasília, 2012. [citado 05 dez. 2013]. Disponível em: http://189.28.128.100/dab/docs/publicacoes/geral/pnab.pdf

Brasil. Ministério da Saúde. Ato Portaria GM n. 1.996, de 20 de agosto de 2007. Dispõe sobre as diretrizes para a implementação da Política Nacional de Educação Permanente em Saúde e dá outras providências [legislação na Internet]. Brasília; 2007a. [citado 2011 set. 5] Disponível em: http://portal.saude.gov.br/portal/arquivos/pdf/Portaria_1996_de_20

_de_agosto-de-2007.pdf

Brasil. Ministério da Saúde. Ato Portaria GM n.198, de 13 de fevereiro de 2004. Institui a Política Nacional de Educação Permanente em Saúde como 
estratégia do Sistema Único de Saúde para a formação e o desenvolvimento de trabalhadores para o setor e dá outras providências [legislação na Internet]. Brasília; 2004. [citado 2008 set. 13] Disponível em: http://www.saude.mg.gov.br/institucional/cib/legislacoes-e-materais-deapoio -1/Portaria\%20n.\%20198.pdf

Brasil. Ministério da Saúde. Conselho Nacional de Saúde. Resolução no 466, de 12 de dezembro de 2012. [Internet]. Brasília; 2012. [citado 2014 fev. 10]. Disponível em: http://conselho.saude.gov.br/resolucoes/2012/Reso466.pdf

Brasil. Ministério da Saúde. Ministério da Educação. Programa Nacional de Reorientação da Formação Profissional em Saúde - Pró-Saúde: objetivos, implementação e desenvolvimento potencial. Brasília: Ministério da Saúde, $2007 b$.

Brasil. Ministério da Saúde. Portaria No 154, de 24 de janeiro de 2008. Cria os Núcleos de atenção à Saúde da Família (NASF). Brasília: Ministério da Saúde; 2008a.

Brasil. Ministério da Saúde. Portaria no 4.279 de 30 de dezembro de 2010. Estabelece diretrizes para a organização da Rede de Atenção à Saúde no âmbito do Sistema Único de Saúde. Brasil: Ministério da Saúde; 2010.

Brasil. Ministério da Saúde. Pró-Saúde: programa nacional de reorientação da formação profissional em saúde. Ministério da Saúde, Ministério da Educação. Brasília: Ministério da Saúde; 2005. (Série C - Projeto, Programas e Relatórios).

Brasil. Ministério da Saúde. Secretaria de Atenção à Saúde. Núcleo Técnico da Política Nacional de Humanização. Clínica ampliada, Equipe de referência e projeto terapêutico singular. 2. ${ }^{a}$ edição. Série B. Textos Básicos de Saúde. Brasília: Ministério da Saúde, 2007.

Brasil. Portaria interministerial $\mathrm{n}^{\mathrm{o}} 1.802$, de 26 de agosto de 2008. Institui o Programa de Educação pelo Trabalho para a Saúde (PET - Saúde). Ministério da Educação; 2008b.

Brasil. Programa de Educação pelo Trabalho para Saúde (PET-Saúde). PRÓ-Saúde. Ministério da Saúde, SGTES: Brasília; 2013. [citado 2014 fev. 10]. Disponível em: http://bvms.saude.gov.br/bvs/folder/pro saude pet saude.pdf

Brasil. Reunião regional dos observatórios de recursos humanos em saúde. Chamado à ação de Toronto: 2006-2015 rumo a uma década de recursos humanos em saúde nas Américas. Brasília: Ministério da Saúde; 2006. (Série D. Reuniões e Conferências).

Brock D, Abu-Rish E, Chiu CR, Hammer D, Wilson S, Vorvick L, Blondon K, Schaad D, Liner D, Zierler B. Interprofessional education in team 
communication: working together to improve patient safety. BMJ Qual Saf. 2013; 22(5):414-23.

Campion-Smith C, Austin H, Criswick S, Dowling B, Francis G. Can sharing stories practice? A qualitative study of an interprofessional narrative-based palliative care course. Journal of Interprofessional Care. 2011; 25:105-111.

Campos GWS, Amaral MA. A clínica ampliada e compartilhada, a gestão democrática e redes de atenção como referenciais teórico-operacionais para a reforma do hospital. Ciênc Saúde Coletiva . 2007;12(4):849-59.

Campos GWS, Domitti AC. Apoio matricial e equipe de referência: uma metodologia para gestão do trabalho interdisciplinar em saúde. Cad Saúde Pública. 2007a; 23:2399-407.

Campos GWS. A mediação entre conhecimento e práticas sociais: a racionalidade da tecnologia leve, da práxis e da arte. Ciênc. Saúde Coletiva. 2011:16(7);3033-40.

Campos GWS. Saude Paidéia. 3 ed. Editora Hucitec: São Paulo, 2007b.

Campos GWS. Saúde pública e saúde coletiva: campo e núcleo de saberes e práticas. Ciênc. Saude Colet. 2000; 5(2):219-30.

Canadian Interprofessional Health Collaborative (CIHC). Interprofessional Education \& Core Competences. Literature Review. Canada: University of British Columbia; 2007.

Canadian Interprofessional Health Collaborative (CIHC). A national interprofessional competence framework. Vancouver: Canadian Interprofessional Health Collaborative; 2010.

Caprara A, Rodrigues J. A relação assimétrica medico-paciente repensando o vincula terapêutico. Ciência \& Saúde Coletiva. 2004;9(1):139-46.

Carpenter J, Dickinson H. Interprofessional education and training. Bristol: The Policy Press; 2008.

Cavalheiro MTP, Guimarães AL. Formação para o SUS e os desafios da integração ensino-serviço. Caderno FNEPAS. 2011;1:19-27.

Carapinheiro G. Saberes e poderes no hospital: uma sociologia dos serviços hospitalares. Porto: Edições Afrontamento, 1993

Carvalho SR. Os múltiplos sentidos da categoria empowerment no projeto de promoção à saúde. Cad Saúde Pública. 2004;20(4):1088-95.

Carvalho BG, Peduzzi M, Mandú EDT, Ayres JRCM. Trabalho e intersubjetividade: reflexão teórica sobre sua dialética no campo da saúde e 
enfermagem. 2012; 20(1): [08 telas]. [citado 12 fev 2014]. Disponível em: http://www.scielo.br/pdf/rlae.v20n1/pt_04.pdf

Castellanos MEP, Fagundes TLQ, Nunes TCM, Gil CRR, Pinto ICM, Belisário SA, Viana SV, Correa GT, Aguiar RAT. Estudantes de graduação em saúde coletiva: perfil sociodemográfico e motivações. Ciência \& Saúde Coletiva.2013;18(6):1657-1666.

Ceccim RB, Carvalho YM. Ensino da saúde como projeto da integralidade: educação dos profissionais de saúde no SUS. In: Pinheiro R, Ceccim RB, Mattos RA. Ensinar saúde: a integralidade e o SUS nos cursos de graduação na área da saúde. 2ed. Rio de Janeiro: IMES/ UERJ, CEPESQ, ABRASCO, 2005. p. 69- 92.

Ceccim R, Ferla AA. Educação permanente em saúde. In: Pereira IB, Lima JCF (organizadores). Dicionário da educação profissional em saúde. $2^{\circ}$ ed. Rio de Janeiro: EPSJV; 2009. p. 162-7.

Ceccim RB, Feuerwerker LCM. Mudança na graduação das profissões de saúde sob o eixo da integralidade. Cad Saúde Pública. 2004;20(5):1400-10.

Ceccim RB, Feuerwerker LCM. O quadrilátero da formação para a área da saúde: ensino, gestão, atenção e controle social. Physis Rev Saúde Coletiva 2004a; 14(1):41-65.

Ceccim RB. Educação permanente em saúde: desafio ambicioso e necessário. Interface Comun Saúde Educ. 2005a;9(16):161-8.

Ceccim RB. Educação permanente em saúde: descentralização e disseminação de capacidade pedagógica na saúde. Ciênc. Saúde Coletiva. 2005c;10 (4):975-86.

Ceccim RB. Onde se lê "recursos humanos em saúde", leia-se "coletivos organizados de produção em saúde. Desafios para a educação. In: Pinheiro, R.; Mattos RA. (organizadores). Construção social da demanda: direito à saúde, trabalho em equipe, participação e espaços públicos. Rio de Janeiro: Cepesc; 2005a. p.161-80.

Cecílio LCO, Matsumoto NF. Uma taxonomia operacional de necessidades de saúde. In: Pinheiro R, Ferla AA, Mattos RA, organizadores. Gestão em redes: tecendo os fios da integralidade em saúde. Rio de Janeiro: EdUCS: IMS/UERJ:CEPESQ, 2006. p.37-50

Cecílio LCO. As necessidades de saúde como conceito estruturante na luta pela integralidade e equidade na atenção em saúde. In: Pinheiro R, Mattos RA, organizadores. Os sentidos da integralidade na atenção à saúde (organizadores). Rio de Janeiro: CEPESC:IMS/UERJ: ABRASCO, 2001. p. 113-126. 
Chaui M. A universidade pública, sob nova perspectiva. Revista Brasileira de Educação. 2003; 24:5-15.

Chaves M, Kisil M. Origens, concepção e desenvolvimento. In: Almeida M, Feuerwerker L, Llanos C M. A educação dos profissionais de saúde na América Latina: teoria e prática de um movimento de mudança. Editora Hucitec: São Paulo; Editora UEL: Londrina. Buenos Aires: Lugar Editorial; 1999. (Tomo 1:Um olhar analítico).p 1-16

Clark PG. Toward a trnstheoretical modelo f interprofessional education: stages, processes and forces supporting institutional change. Journal of Interprofessional Care. 2013; 27(1):43-9.

Conselho Federal de Enfermagem (COFEN). Resolução N. 389 de outubro de 2011. Atualiza no âmbito do sistema COFEN/ Conselhos Regionais de Enfermagem, os procedimentos para registro de título de pós-graduação lato e stricto sensu concedido a Enfermeiros e lista as Especialidades. Brasília, 2011.

Conil EM. Ensaio histórico-conceitual sobre a Atenção Primária à Saúde: desafios para a organização de serviços básicos e da Estratégia Saúde da Família em centros urbanos no Brasil Cad. Saúde Pública. 2008;24 (Sup 1):S7-S27.

Cooper H, Carlisle C, Gibbs T, Watkins C. Developing an evidence base for interdisciplinary learning: A systematic review. Journal of Advanced Nursing. 2001; 35:228-237.

Cooper H, Spencer-Dawe E, McLean, E. Beginning the process of teamwork: design, implementation and evaluation of an inter-professional education intervention for first year undergraduate students. Journal of Interprofessional Care. 2005; 19(5): 492-508.

Costa MV. A educação interpofissional como abordagem para a reorientação da formação professional em saúde [Tese]. Universidade Federal do Rio Grande do Norte; 2014.

Coster S, Norman I, Murrels T, Kitchen S, Meerabeau E, Sooboodoo E, Avray L. Interprofessional atitudes amongst undergraduate students in the helath professions: A longitudinal questionnaire survey. International Journal of Nursing Studies. 2008; 45:1667-81.

Curran V. Interprofessional Education for Collaborative Patient-Centred Practice. Center for Collaborative Health Professional Education Memorial University. Research Synthesis Paper. Health Canada; 2004.

D'Amour D, Oandasan, I. Interprofessionality as the field of interprofessional practice and interprofessional education: An emerging concept. Journal of Interprofessional Care. 2005; (Sup1): 8-20. 
D’Amour, Goulet L, Labadie JF, Martín Rodriguez LS, Pineault R. A model and typology of collaboration between professional in healthcare organization. BMC Health Services Research. 2008; 8:188.

Dias Henrique Sant'Anna, Lima Luciana Dias de, Teixeira Márcia. The trajectory of the national policy for the reorientation of professional training in health in the Unified Health System (SUS). Ciênc. saúde coletiva. 2013 [citado 2014 Julho 03] ; 18( 6 ): 1613-1624. Disponível em: http://www.scielo.br/scielo.php?script=sci_arttext\&pid=S141381232013000 600013\&lng=en. http://dx.doi.org/10.1590/S1413-81232013000600013.

Dickinson C, Carpenter J. Contact is not enough: Na inter-group perspective on stereotypes and stereotype change in interprofessional education. In: Colyer H, Heme M, Jones, coordinators. The Theory-Practice Relationship in Interprofessional Education. London: Higher Education Academy Health Sciences and Practice; 2005. P 24-31.

Donnangelo MC. Medicina e sociedade. São Paulo: Duas Cidades; 1975.

Donangelo, MC., Pereira L. Saúde e sociedade. São Paulo: duas cidades; 1976.

Ellery AE, Bosi MLM, Loiola FA. Integração Ensino, pesquisa e serviços em saúde: antecedentes, estratégias e iniciativas. Saúde Sociedade.2013;22(1):187-198.

Farias LO, Vaitsman J. Interação e conflito entre categorias profissionais em organizações hospitalares públicas. Cad. Saúde Pública. 2002 [citado 2014 Julho 03] ; 18( 5 ): 1229-1241. Available from: http://www.scielosp.org/scielo.php?script=sci_arttext\&pid=S0102311X200 $2000500015 \& \operatorname{lng}=$ en.

Fazenda ICA (organizadora). Dicionário em construção: interdisciplinaridade. $2^{\circ}$ ed. São Paulo : Cortez, 2002.

Fazenda, ICA. Interdisciplinaridade: história, teoria e pesquisa. Campinas: Papirus, 1994.

Felli VEA, Peduzzi M. O trabalho gerencial em enfermagem. In: Kucgant P, organizadora. Gerenciamento em enfermagem. Rio de Janeiro: Guanabara Koogan; 2005. p. 1-13.

Ferreira JR et al. Pró-Saúde e Pet-Saúde: experiências exitosas de integração ensino-serviço (editorial). Revista Brasileira de Educação Médica. 2012; 36(Sup. 1):34.

Feuerwerker L. Educação permanente em saúde: uma mudança de paradigmas. Olho Mágico. 2005;12(3):13-20. 
Feuerwerker, LCM, Sena, R. R. Contribuições ao movimento de mudança na formação profissional em saúde: uma avaliação das experiências UNI. Interface - Comunicação, Saúde, Educação. Botucatu. 2002;6(10):37-50.

Feuerwerker LCM. Micropolítica e saúde: produçãoo do cuidado, gestão e formação. [Tese livre-docência]. Faculdade de Saúde Pública. Universidade de São Paulo; 2012.

Feuerwerker LCM., Capozzolo AA. Mudanças na formação dos profissionais de saúde: alguns referenciais de partida do eixo trabalho em saúde. In: Capozzolo AA, Casetto SJ, Hens AO, organizadores. Clínica comum: itinerários de uma formação em saúde. São Paulo: Editora Hucitec; 2013. p. 35-68.

Flick U. Desenho da pesquisa qualitativa. Porto Alegre: Artmed; 2009.

Foucault M. A arqueologia do saber. 4 ed. Rio de Janeiro: Forense Universitária, 1995.

Fortuna CM, Mishima SM, Matumoto S, Pereira MJB. O trabalho de equipe no programa de saúde da família: reflexões a partir de conceitos do processo grupal e de grupos operativos. Revista Latino-Americana de Enfermagem. 2005;13(2):262-268.

Franco, TB, Magalhães Junior, HM. Integralidade na assistência à saúde: a organização das linhas de cuidado. In: Merhy, E.E. et al. (organizadores). O trabalho em saúde: olhando e experienciando o SUS no cotidiano. São Paulo: Hucitec, 2006. p.125-32.

Freeth D, Hammick M, Reeves S, Koppel I, Barr H. Effective interprofesssional education: Development, delivery and evaluation. London: Blackwell; 2005.

Freidson E. La profesión médica: um estúdio de sociologia del conocimiento aplicado. Barcelona: Ediciones península, 1978.

Freidson E. Renascimento do profissionalismo: teoria, profecia e política. São Paulo: Edusp, 1998. Tradução Celso Mauro Paciornik.

Frenk J, Chen L, Bhutta ZA, Crisp N, Evans T, Fineberg H, Garcia P, et al. Health professionals for a new century: transforming education to strengthen health systems in independent world. The Lancet 2010. 376:1923-57.

Furtado JP.. Reference teams: an institutional arrangement for leveraging collaboration between disciplines and professions. Interface - Comunicação, Saúde, Educação. 2007;11(22):239-5. 
Garcia MAA et al. Interdisciplinaridade e integralidade no ensino em saúde. Rev. Ciênc. Méd. 2006;15(6):473-85.

Gattás MLB, Furegato ARF. Interdisciplinaridade: uma contextualização. Acta Paul Enferm. 2006;19(3)322-7.

Gatti, Bernadete Angelina. Grupo Focal na pesquisa em Ciências Sociais e Humanas. Brasília: Liber Livro; 2005.

Gilbert JHV. Interprofessional learning and higher education structural barriers. 2005;(Sup1):87-106

Giovanella L, Mendonça MHM, Almeida PF, Escorel S, Senna MCM, Fausto MCR, Delgado MM, Andrade CLT, Cunha MS, Martins MIC, Teixeira CP. Saúde da família: limites e possibilidades para uma abordagem integral de atenção primária à saúde no Brasil. Ciência \& Saúde Coletiva. 2009;14(3):783-94.

Giovanella, L. Atenção Primária à Saúde seletiva ou abrangente? Cad. Saúde Pública. 2008; 24(Sup1): S7-27.

Goelen, G. et al. Measuring the effect of interprofessional problem-based learning on the attitudes of undergraduate health care students. Medical Education. 2006;40(6):555-61.

González AD, Almeida MJ. Integralidade da saúde - norteando mudanças na graduação dos novos profissionais. Ciência \& Saúde Coletiva. 2010a:15(3);757-62.

Habermas J. Consciência moral e agir comunicativo. Rio de Janeiro: Tempo Brasileiro; 1989.

Habermas J. Teoria de la acción comunicativa I: Racionalidad de la acción y racionalización social. Madrid: Taurus; 2001.

Habermas J. Técnica e ciência como ideologia. Lisboa: Edições 70; 2009.

Habermas J. Teoria do agir comunicativo I: Racionalidade da ação e racionalização social. São Paulo: Martins Fontes; 2012

Henriques RLM, Pinheiro R. Responsabilidade pública e extensão universitárias. In: Pinheiro R, Mattos RA, organizadores.. Cuidar do cuidado: responsabilidade com a integralidade das ações de saúde. (organizadores). Rio de Janeiro: CEPESC:IMS/UERJ: ABRASCO, 2008. p.41-60.

Hind M, Norman I, Cooper S, Gill E, Hilton R, Judd P, Jones SC. Interprofessional perceptions of health care students. Journal of Interprofessional Care. 2003;17(1):21-34. 
Honneth A. Jürgen Habermas: percurso acadêmico e obra. Revista Tempo Brasileiro. 1999;138:9-32.

Honneth A. A luta por reconhecimento: a gramática moral dos conflitos socisis. São Paulo: Editora 34; 2003.

Horsburgh M, Lamdin R, Williamson E. Multiprofessional learning: the attitudes of medical, nursing and pharmacy students to shared learning. Medical Education. 2001; 35:876-83.

Instituto Brasileiro de Geografia e Estatística (IBGE). Informações completas sobre o município de São Paulo. [acesso 2014 maio 12]. Disponível em: http://cod.ibge.gov.br/232IG

Instituto Brasileiro de Geografia e Estatística (IBGE). Serviços de Saúde do município de São Paulo em 2009. [acesso 2014 maio 12]. Disponível em: http://cod.ibge.gov.br/9VGR

Interprofessional Education Colaborative (IPEC) Group. Interprofessional Education Collaborative Expert Panel. Core competencies for Interprofessional Practice: Report on an Expert Panel. Washington; 2011. Available from: https://www.aamc.org/download/186750/data/ core_competencies.pdf. Accessed October 15, 2012.

Iribarry IS. Aproximações sobre a transdisciplinaridade: algumas linhas históricas, fundamentos e princípios aplicados ao trabalho em equipe. Psicologia: Reflexão e Crítica. 2003; 16(3):483-490.

Jakobsen F, Hansen TB, Eika B. Knowing more about the other professions clarified my own profession. Journal of Interprofessional Care. 2011; 25(6):441-6.

Jantsch E. Vers 1'Interdisciplinarité et la transdisciplinarité dans 1'Enseignement et 1'Innovation. In:OCDE. l'Interdisciplinarité. Paris: OCE; 1972.

Japiassu, H. Interdisciplinaridade: a patologia do saber. Rio de Janeiro: Imago; 1976.

Johnson M, Cowin LS, Wilson I, Young H. Professional identity and nursing: contemporary theoretical developments and future research challenges. International Nursing Review. 2012; 59(4):562-69.

Khalili, H., Orchard C., Laschinger H.K.S., Frah R. An interprofesional socialization framework for developing an interprofessional identity among health professions students. Journal of Interprofessional Care. 2013; Early On line 1-6. 
Kitson A, Marshall A, Basset K, Zeitz K. What are the core elements of patient-centred care? A narrative review and synthesis of the literature from health policy, medicine and nursing. Journal of Advanced Nursing. 2012; 69(1):4-15.

Kirchhof ALC. O trabalho da enfermagem: análise e perspectivas. Revista Brasileira de Enfermagem 2003;56(6):669-73.

Lancman S, Barros JO. Estratégia de saúde da família (ESF), Núcleo de Apoio à Saúde da Família (NASF) e terapia ocupacional: problematizando as interfaces. Rev Ter Ocup Univ São Paulo. 2011;22(3)263-269.

Lazzarato M, Negri A. Trabalho immaterial: formas de vida e produção de subjetividade. Rio de Janeiro: DP\&A Editora; 2001.

Leasure EL, Jones RR, Meade LB, Sanger MI, Thomas KG, et al. There is no "I" in teamwork in the patient-centered medical home: defining teamwork competencies for academic practice. Acad Med. 2013; 88: 585592.

Leite MTS et al. O Programa de Educaçao pelo Trabalho para a Saúde na formação Profissional. Rev. Bras. Educ. Med. 2012; 36(Sup 1):111-8.

Leopardi MT, Beck, CLC, Lynn MR, Nietsche EA, Gonzales RMB. Metodologia da pesquisa na saúde. Santa Maria: Pallotti; 2001.

Leopardi MT, Gelbcke F, Ramos F. Cuidado: objeto de trabalho ou objeto epistemológico da enfermagem? Texto \& Conetxto Enferm. 2001;10(1):3249.

Liedke ER. Processo de trabalho: In: Cattani AD. Trabalho e tecnologia: dicionário critic. Rio de Janeiro: Vozes; 1997. P.268-74.

Lima MADS, Almeida MCP. O trabalho de enfermagem na produção de cuidados de saúde no modelo clinic. Rev Gaúcha Enferm 1999;20(n.esp.):86-101.

Linassi J, Strassburger D, Sartori M, Zardin MV, Righi LB. Projeto terapêutico singular: vivenciando uma experiência de implementação. Rev Contexto e Saúde. 2011; 10(20): 425-434.

Lopes NM. Recomposição profissional da enfermagem. Coimbra: Quarteto editora; 2001.

Lugarinho R, Feuerwerker L. O que é o FNEPAS? Boletim da Associação Brasileira de Ensino Médico. 2006; 33(3/4):16-17. 
MacDonald MB et al. Knowledge of the professional role of others: A key interprofessional competency. Nurse Education in Practice. 2010;10:238242.

Magallhães Junior HM, Oliveira RC. Concretizando a integralidade nos serviços de saúde: a aposta do SUS em Belo Horizonte. In: Pinheiro R, Ferla AA, Mattos RA (organizadores). Gestão em redes: tecendo os fios da integralidade em saúde. EDUCS: IMS/UERJ: CEPESQ: Rio de Janeiro, 2006.

Mandu ENT, Almeida MCP. Necessidades em saúde: questões importantes para o trabalho da enfermagem. Rev Bras Enferm 1999;52(1):54-66.

Martín-Rodriguez L San, Beauliei M D, D’Amour D, Ferrada-Videla M. The determinants of successful collaboration: a review of theoretical and empirical studies. Journal of Interprofessional Care. 2005; 1(Supl)132-147.

Martins PH. Dom do reconhecimento e saúde: elementos para entender o cuidado como mediação. In: Pinheiro R, Martins PH (organizadores). Usuários, redes sociais, mediações e integralidade em saúde. Rio de Janeiro: UERJ/IMS/LAPPIS, 2011. p.39-50.

Marx K. O capital. São Paulo: Nova Cultural; 1996.

Mattos RA. A integralidade na prática ou sobre a prática da integralidade. Cad Saúde Pública. 2004;20(5):1411-6.

Mattos RA. Os sentidos da integralidade: algumas reflexões acerca de valores que merecem ser defendidos. In: Mattos $R$, Pinheiro $R$, organizadores. Os sentidos da integralidade na atenção e no cuidado à saúde. $3^{\text {a }}$ ed. Rio de Janeiro: ABRASCO; 2001. p. 39-64.

Matumoto S, Fortuna CM, Kawata LS, Mishima SM, Pereira MJB. A prática clínica do enfermeiro na atenção básica: um processo em construção. Rev Latino Am Enfermagem.2011;19(1):123-30.

McNair R, Stone N, Sims J, Curtis C. Australian evidence for interprofessional education contributing to effective teamwork preparation and interest in rural practice. Journal of Interprofessional Care. 2005;19:579-594.

Meirelles DS. O conceito de serviço. Rev Econ Polit. 2006; 26(1):119-36.

Melo C. Divisão social do trabalho e enfermagem. São Paulo: Cortez; 1986.

Mendes EV. As redes de atenção à saúde. 2 ed. Organização Pan-Americana de Saúde: Brasília DF, 2011. 
Mendes EV. O cuidado das condições crônicas na atenção primária à saúde: o imperativo da consolidação da estratégia da saúde da família. Brasília: Organização Pan-Americana da Saúde, 2012.

Mendes R, Vaz A. Educação Ambiental no ensino formal: narrativas de professores sobre suas experiências e perspectivas. Educ. Rev. 2009;25(3): $395-411$.

Mendes-Gonçalves RB. Práticas de saúde: processos de trabalho e necessidades. São Paulo: Caderno CEFOR; 1992.

Mendes-Gonçalves RB. Tecnologia e organização social das práticas de saúde: características tecnológicas de processo de trabalh na rede estadual de centros de saúde de São Paulo. São Paulo: Hucitec; 1994.

Mendonça MHM, Vasconcellos MM, Viana ALA. Atenção primária à saúde no Brasil. Cad. Saúde Pública. 2008; 24(sup1):4-5.

Merhy EE. Em busca do tempo perdido: a micropolítica do trabalho vivo em saúde. In: Merhy EE, Onocko, R. Agir em saúde: um desafio para o público. $2^{\mathrm{a}}$ ed. São Paulo: Hucitec; 2006. p 71-112

Minayo MCS. Interdisciplinaridade: uma questão que atravessa o saber, o poder e o mundo vivido. 1991;24(2):70-7.

Minayo MCS. O desafio do conhecimento: pesquisa qualitativa em saúde. $8^{\mathrm{a}}$ ed. São Paulo: Hucitec; 2008.

Minayo MCS. Pesquisa Social: teoria, método e criatividade. Rio de Janeiro, Vozes, 1994.

Miranda L, Rivera FJU, Artmann E. Trabalho em equipe interdisciplinar de saúde como um espaço de reconhecimento: contribuições da teoria de Axel Honneth. Physis Revista de Saúde Coletiva. 2012; 22 (4 ):1563-83.

Mirzaei M, Apin C, Essue B, Jeon YH, Dugdale P, Usherwood T, Leeder S. A patient-centred approach to health servisse delivery: improving health outcomes for people with chronic illness. BMC Health Serv Res. 2013; $13: 251$.

Moita FMGS, Andrade FCB. Ensino-pesquisa-extensão: um exercício de indissociabilidade na pós-graduação. Rev Brasileira de Educação. 2009;4(41): 269-393.

Moraes MAA, Manzini EJ. Concepções sobre a Aprendizagem Baseada em Problemas: um Estudo de Caso na Famema. Revista Brasileira de Educação Médica.2006:30( 3);125-135. 
Morin E. A cabeça bem-feita: repensar a reforma e reformar o pensamento. Rio de Janeiro: Bertrand Brasil; 1999.

Nancarrow S A et al. Ten principles of good interdisciplinary team work. Human Resources for Health. 2013; 11(19):1-11.

Nascimento S. Reflexões sobre a intersetorialidade entre as políticas públicas. Serviço Social \& Sociedade. 2010; (101):95-120.

Nelson GA, King ML, Brodine S. Nursing physician collaboration on medical-surgical units. Medsurg Nursing. 2008;17(1):35-40.

Nogueira NP. Trabalho e qualidade em serviçcos de saúde. In: Nogueira NP. Perspectivas da qualidade em saúde. Rio de Janeiro: Qualitymark; 1994. p. 71-90.

Nugus P, Greenfield D, Travaglia J, Westbrook J, Braithwaite J. How and where clinicians exercise power: interprofessional relations in health care. Soc Sci Med. 2010;71:898-909.

Nunes ED. A questão da interdisciplinaridade no estudo da saúde coletiva e o papel da ciências sociais. In: Canesqui AM. Dilemas e desafios das ciências sociais na saúde coletiva. São Paulo: Hucitec; 1995. p.95-113.

Nunes ED. Cecíclia Donnangelo: pioneira na construção teórica de um pensamento social em saúde. Ciência \& Saúde Colectiva.2008;13(3):909916.

Oandansan I. Interdisciplinary education for collaborative, patient-centred practice. Ottawa: Health Canada, 2004

Oandansan I, Reeves S. Key elements of interprofessional education. Part 2: Factors, processes and outcomes. Journal of Interprofessional Care. 2005; (Sup 1):39-48.

Olschowsky A, Silva GB. Integração docente-assistencial: um estudo de caso. Rev Esc Enferm USP. 2000; 34(2):128-37.

Olenick M, Allien LR, Smego JRRA. Interprofessional education: a concept analysis. Advances in Medical Education and Practice. 2010:75-84.

Oliveira AMC, Ianni AMZ, Dallari SG. Controle social no SUS: discurso, ação e reação. Ciênc. saúde coletiva . 2013 [citado 2014 Junho 11] ; 18(8): 2329-2338. Available from: http://www.scielo.br/scielo.php?script= sci_arttext\&pid=S141381232013000800017\&lng=en.

Oliveira MAC, Pereira IC. Atributos da atenção primária e estratégia saúde da família. Rev Bras Enfer. 2013 [citado 2014 fev. 12]; 66(n.esp.):158-9. Disponível em: http://www.scielo.br/pdf/reben/v66nspe/v66nspea20.pdf 
Onocko-Campos RT. et al. Evaluation of innovative strategies in the organization of Primary Health Care. Rev. Saúde Pública. 2012, vol.46, n.1, pp. 43-50. Epub Dec 13, 2011. ISSN 0034-8910.

Orchard C., King GA., Khalili H., Bezzina MB. Assessment of interprofessional team collaboration sacale (AITCS): development and testing of instrument. Journal of continuing education in the health professions. 2012; 32(1):58-67.

Orchard CA. Persistent isolationist or collaborator? The nurse's role in interprofessional collaborative practice. J Nurs Manag. 2010; 18:248-57.

Orchard CA, Curran V, Kabene S. Creating a culture for interdisciplinar collaborative professional practice. Med Educ Online. 2005; 10:11. [citado 2014 Maio 12]. Available from: http://www.med-ed-online.org

Paiva CHA, Pires-Alves F, Hochman G. A cooperação técnica OPAS-Brasil na formação de trabalhadores para a saúde (1973-1983). Ciênc. Saúde Coletiva. 2008;13(3): 929-39.

Peduzzi M. Equipe multiprofissional de saúde: a interface entre o trabalho e interação [tese]. Campinas: Faculdade de Ciências Médicas, Universidade de Campinas; 1998.

Peduzzi M., Oliveira MAC. Trabalho em equipe multiprofissional. In: Clínica Médica. Barueri: Manoele; 2009. p. 171-178.

Peduzzi M, Anselmi ML. O processo de trabalho de enfermagem: a cisão entre o planejamento e execução do cuidado. Rev Bras Enferm. 2002;55(4):392-8.

Peduzzi M, coordenadora. Análise dos processos educativos de trabalhadores e equipes de saúde e de enfermagem: características, levantamento de necessidades e resultados esperados [relatório de pesquisa na Internet]. São Paulo: Escola de Enfermagem, Universidade de São Paulo 2007. [citado 2011 set. 12]; Disponível em: http://www.ee.usp.br/observatorio/observatorio/relatórios/ re1092.pdf

Peduzzi M, Del Guerra DA, Braga CP, Lucena FS, Silva JAM. Atividades educativas de trabalhadores na atenção primária: concepções de educação permanente e de educação continuada em saúde. Interface Comunic Saúde. 2009; 13(20):121-34.

Peduzzi M, Et al . Trabalho em equipe na perspectiva da gerência de serviços de saúde: instrumentos para a construção da prática interprofissional. Physis. 2011;21,(2): 629-646. 
Peduzzi M, Trabalho em equipe. In: Lima JCF, Pereira IB, organizadores. Dicionário de educação profissional em saúde. 2.ed. Rio de Janeiro: EPSJV, 2009. p.419-26.

Peduzzi M. Equipe multiprofissional de saúde: conceito e tipologia. Rev. Saúde Pública. 2001;35(1):103-09.

Peduzzi M. Mudanças tecnológicas e seu impacto no processo de trabalho em saúde. Trabalho Educação e Saúde. 2002;1(1):75-91.

Peduzzi M. Trabalho em equipe de saúde da perspectiva de gerentes de serviços de saúde: possibilidades da prática comunicativa orientada pelas necessidades de saúde dos usuários e da população [livre-docência]. Escola de Enfermagem, Universidade de São Paulo, São Paulo, 2007.

Peduzzi M. Trabalho em equipe de saúde no horizonte normativo da integralidade, do cuidado e da democratização das relações de trabalho. In: Pinheiro R, Barros MEB, organizadores. Trabalho em equipe sob o eixo da integralidade: valores, saberes e práticas. Rio de Janeiro: IMS/UERJ, Cepesc, Abrasco, 2007. p.161-77.

Peduzzi M, Normam IJ, Germani ACCG, Silva JAM, Souza GC. Educação interprofissional: formação de profissionais de saúde para o trabalho em equipe com foco nos usuários. Revista da Escola de Enfermagem da USP. 2013;47(4):977-983.

Peduzzi M, Schraiber. Processo de trabalho em Saúde. In: Dicionário da Educação Profissional em Saúde. Rio de Janeiro: Ensp: Fiocruz; 2009

Pelzang R. Time to learn: understanding patient-centred care. British Journal of Nursing. 2010;19(4):912-17.

Pereira RCA, Rivera FJU, Artmann E. O trabalho multiprofissional na Estratégia Saúde as Família. Interface. 2013;17(45):327-40.

Perssinoto, R. M. Hannah Arendt, poder e a crítica da tradição. Lua nova. 2004; 61:115-38.

Pettigrew, Andrew M. The politics of organizational decision-making. London: Tavistock, 1973.

Pinheiro R, Ceccim RB. Experenciação, formação, conhecimento e cuidado: articulando conceitos, percepções e sensações, para efetivar o ensino em integralidade. In: Pinheiro R, Ceccim RB, MATTOS RA. Ensinar saúde: a integralidade e o SUS nos cursos de graduação na área da saúde. 2ed. Rio de Janeiro: IMES/ UERJ, CEPESQ, ABRASCO, 2005. p. 13-35. 
Pinto ICM, Espiridião MA, Silva IV. Trabalho e educação em saúde no Brasil: tendências da produção científica entre 1990-2010. Ciênc. Saúde Coletiva, 2013:18(6);1525-34.

Pinzani, A. Habermas: introdução. Porto Alegre: Artmed; 2009.

Pires DE. Divisão social do trabalho. In: Pereira IB, Lima JCF (organizadores). Dicionário da educação profissional. 2.ed. Rio de Janeiro: EPSJV, Fiocruz, 2008. P. 125-30.

Pires D, Gelbcke FL, Matos E. Organização do trabalho em enfermagem: implicações no fazer e viver dos trabalhadores de nível médio. Trabalho, Educação e Saúde. 2004;2(2):311-25.

Pollard KC, Miers ME, Gilchrist M, Sayers A. A comparison of interprofessional perceptions and working relationships among health and social care students: the results of a 3-year intervention. Health and Social Care in the Community. 2006; 14(6):541-52.

Poulton BC, West MA. The determinants of effectiveness in primary health care teams. Journal of interprofessional Care. 1999;13(1):7-18.

Proop KM, Apker J, Wendy SZF, Wallace N, Serbenski M, Hofmeister N. Meeting the complex needs od the health care team: identification of nurseteam communication practices perceived to enhance patient outcmes. Qualitative Health Research [periódico na Internet]. 2010 [citado 2013 Mar 12]; 20(1):15-18. Disponível em: http://qhr.sagepub.com/content/20/1/15

Programa de Educação Tutorial na Saúde (PET- Saúde). Projeto PET-Saúde Redes de Atenção à Saúde. [Internet]. 2013 [citado 2014 Jun 19].Disponível em: http:// http://biton.uspnet.usp.br/propetsaude/?page id=289

Queiróz ES, Penna CMM. Conceitos e práticas de integralidade no município de Catas Altas. Rev Min Enferm.2011;15(1):62-69.

Reeves S, Zwarenstein M, Goldman J, Barr H, Freeth D, Hammick M, Koppel I. Interprofessional education: effects on professional practice and health care outcomes. Cochrane Database of Systematic Review. 2008; Issue 1. Art. No.: CD002213. DOI: 10.1002/14651858.CD002213.pub2.

Reeves S, Lewin S, Espin S, Zwarentein M. Interprofessional teamwork for health and social care. London: Blackwell-Wiley, 2010.

Reeves S, Perrier L, Goldman J, Freeth D, Zwarenstein M. Interprofessional education: effects on professional practice and health outcomes (update). Cochrane Database of Systematic Review. 2013; Issue 3.

Ribeiro ECO. A educação dos profissionais de saúde na América Latina: teoria e prática de um movimento de mudança. 2000; 4(7):139-42. 
Ribeiro EM, Pires D, Blank VLG. A teorização sobre processo de trabalho em saúde como instrumental para a análise do trabalho no programa saúde da família. Cad Saúde Pública. 2004;20(2):438-46.

Ricouer P. Hermenêutica e ideologias. Editora Vozes: Petrópolis, Rio de Janeiro, 2011.

Rivera FJU, Artmam E. Planejamento e gestão em saúde: conceitos, história e propostas. Rio de Janeiro: Fiocruz; 2012.

Rivera FJU, Artmann E. Planejamento e gestão em saúde: flexibilidade metológica e agir comunicativo. Ciênc Saúde Coletiva. 1999;4(2):355-65.

Rivera FJU, Artmann E. Planejamento e gestão em saúde: flexibilidade metodológica e agir comunicativo. In: Rivera FJU. Análise estratégica em saúde e gestão pela escuta. Rio de Janeiro: Fiocruz; 2003. p. 17-35.

Rivera FJU. A gestão situacional (em saúde) e a organização comunicante. Cad Saúde Pública. 1996; 12(3):357-72.

Rivera FJU. Análise estratégica em saúde e gestão pela escuta. Rio de Janeiro: Fiocruz, 2003.

Rocha SMM, Almeida MCP. O processo de trabalho da enfermagem em saúde coletiva e a interdisciplinaridade. Rev Latino Am Enfermagem. 2000; 8(6):96-101.

Rossi FR, Lima MADS. Fundamentos para processos gerenciais na prática do cuidado. Rev Esc enferm USP. 2005;39(4):460-8.

Sanna MC. Os processos de trabalho em enfermagem. Rev Bras Enferm.2007;60(20):221-4.

Santos AFPR. Principais abordagens sociológicas para análise das profissões. BIB, São Paulo.2011;71:25-43.

Sargeant J, Loney E, Murphy G. Effective interprofessional teams: "Contact is not enough" to build a team. Journal of Continuing Educating in the Health Professions. 2008; 28(4):229-234.

Silva AM. Processo de trabalho e atividades educativas de trabalhadores de enfermagem em hospitais públicos [tese]. São Paulo: Escola de Enfermagem, Universidade de São Paulo; 2010.

Silva JAM, Peduzzi M. Educação no trabalho na atenção primária à saúde: interfaces entre a educação permanente em saúde e o agir comunicativo. Saude Socidade. 2011. [citado 2014 Julho 02]; 20(4):1018-1032. 
Available from: http://www.scielo.br/scielo.php?script=sci arttext\&pid $=$ S010412902011000400018\&lng=en.

São Paulo. Coordenação de Epidemiologia e Informação (CEInfo). Coordenadorias Regionais de Saúde e Supervisões Técnicas do Município de São Paulo. São Paulo, 2013a. [acesso 2014 maio 12]. Disponível em: http://intranet.saude.prefeitura.sp.gov.br/organizacao/supervisoes/supervisoe $\underline{\text { s.pdf }}$

São Paulo. Coordenação de Epidemiologia e Informação (CEInfo). Serviços de Assistência Médica Ambulatorial do Município de São Paulo. São Paulo, 2013c. [acesso 2014 maio 12]. Disponível em: http://www.prefeitura.sp.gov.br/cidade/secretarias/saude/atencao_basica/am $\mathrm{a} /$ index.php? $\mathrm{p}=1911$

São Paulo. Coordenação de Epidemiologia e Informação (CEInfo). Áreas Técnicas da Coordenação de atenção Básica do Município de São Paulo. São Paulo, 2013d. [acesso 2014 maio 12]. Disponível em: http://www.prefeitura.sp.gov.br/cidade/secretarias/saude/atencao_basica/ind ex.php? $\mathrm{p}=1936$

São Paulo. Coordenação de Epidemiologia e Informação (CEInfo). Boletim CEInfo em dados. Dados e Indicadores para a Saúde - Cidade de São Paulo. Ano XII, no 12. São Paulo, 2013f. [acesso 2014 maio 12]. Disponível em: http://www.prefeitura.sp.gov.br/cidade/secretarias/upload/saude/arquivos/pu blicacoes/Boletim_CEInfo_Dados_2013.pdf

São Paulo. Coordenação de Epidemiologia e Informação (CEInfo). Dados das Unidades Básicas de Saúde da Coordenadoria Regional de Saúde Centro-Oeste. Supervisão Técnica de Saúde do Butantã. São Paulo; 2013g.

São Paulo. Coordenação de Epidemiologia e Informação (CEInfo). Estabelecimentos de saúde por Supervisão Técnica de Saúde do Município de São Paulo. São Paulo, 2013b. [acesso 2014 maio 12]. Disponível em: http://intranet.saude.prefeitura.sp.gov.br/organizacao/estabelecimentos/crscentro-oeste/sts-butanta

São Paulo. Coordenação de Epidemiologia e Informação (CEInfo). Plano Municipal de Saúde 2010-2013 - Compromissos da Coordenação da Atenção Básica. São Paulo, 2013e. [acesso 2014 maio 12]. Disponível em: http://www.prefeitura.sp.gov.br/cidade/secretarias/upload/saude/arquivos/at encaobasica/CompromissosAtencaoBasica-PlanoMunicipal_2010-2013.pdf

São Paulo. Unidades de Saúde do Município de São Paulo. Prefeitura do Município de São Paulo. Secretaria Municipal de Saúde. Coordenação de Epidemiologia e Informação (CEInfo). São Paulo, 2011. Disponível em: http://www.prefeitura.sp.gov.br/cidade/secretarias/upload/saude/arquivos/or ganizacao/TabelaEstabServCRSSTS.pdf Acesso em: 10 de agosto de 2011. 
Saupe R, Budó MLD. Pedagogia interdisciplinar: educare (educação e cuidado) como objetivo fronteiriço em saúde. Texto \& Contexto Enferm. 2006;15(2):326-33.

Schmitt MH, Stewart AL. Commentary on "Interprofessional Ethics - A Developing Field?": A Response to Banks et al. Ethics and Social Welfare. 2011; 5(1):72-78.

Schraiber LB. O médico e seu trabalho: limites da liberdade. São Paulo: Hucitec; 1993.

Schraiber LB, Peduzzi M. Tendências e possibilidades da investigação de recursos humanos em saúde no Brasil. Educ Med Salud. 1993;27(3):295313.

Schraiber LB, Peduzzi M, Sala A, et al. Planejamento, gestão e avaliação em saúde: identificando problemas. Ciência \& Saúde Coletiva. 1999; 4(2): 221-42.

Schraiber LB; Mendes-Gonçalves RB. Necessidades de saúde e atenção primária. In LB Schraiber; MIB Nemes; RB Mendes-Gonçalves (orgs.). Saúde do adulto: programas e ações na unidade básica. São Paulo: Hucitec; 2000. p. 29-47. (Coleção Saúde em Debate).

Schraiber LB. A pesquisa qualitativa em saúde: reflexões metodológicas do relato oral e produção de narrativas em estudo sobre a profissão médica. Rev Saúde Pública. 1995;29(1):63-74.

Schraiber LB. No encontro da técnica com a ética: o exercício de julgar e decidir no cotidiano do trabalho em medicina. Interface. 1997;1(1):123-140.

Schraiber LB. O médico e suas interações: a crise dos vínculos de confiança. São Paulo: Aderaldo \& Rothschild; 2008.

Sguissardi V. Universidade no Brasil: dos modelos clássicos aos modelos de ocasião. In: Morosini M (organizadora). A universidade no Brasil: concepções e modelos. Brasília: Instituto Nacional de Estudos e Pesquisas Educacionais Anísio Teixeira (Inep). p.275-289

Siebeneichler FB. Encontros e desencontros no caminho da interdisciplinaridade: G. Gusdorf e J. Habermas. Rev Tempo Brasileiro.1989;98:153-180.

Silva GB. Enfermagem Profissional: análise crítica. São Paulo, Cortez Editora, 1986. 
Silva A. Helping measure person-centred care. London: The Health Foundation Inspiring Improvement; 2014. Available from: www.health.org.uk/helpingmeasurepcc

Silva JAM, Assano LN. Educação permanente em saúde: uma proposta de intervenção educativa através da humanização. [Trabalho de conclusão de curso]. São Carlos: Universidade Federal de São Carlos, 2006.

Silva JAM, Ogata MN, Machado MLT. Capacitação dos trabalhadores da saúde na atenção básica: impactos e perspectivas. Rev Eletrônica de Enfermagem [periódico na Internet]. 2007 [citado 2011 Ago 15];9(2):389-0. Disponível em: http://www.fen.ufg.br/revista/v9/n2/v9n2a08.htm

Silva JAM. Análise das atividades educativas de trabalhadores de saúde na atenção básica: concepções de educação no trabalho, levantamento de necessidades, público participante e resultados esperados [dissertação]. São Paulo: Escola de Enfermagem, Universidade de São Paulo; 2009.

Silva JAM. Capacitação dos trabalhadores da saúde na atenção básica. [Relatório de Pesquisa]. São Carlos: Universidade Federal de São Carlos, 2006.

Silva RHA. Educação interprofissional na graduação em saúde: aspectos avaliativos da implantação na Faculdade de Medicina de Marília (FAMEMA). Educar em Revista. 2011;(39):159-75.

Starfield B. Atenção primária: equilíbrio entre necessidades de saúde, serviços e tecnologia. Brasília: Unesco/Ministério da Saúde; 2002.

Stotz EN. Trajetória, limites e desafios do controle social do SUS. Saúde Debate. 2006; 30(73/74):149-160.

Sunguya BF, Hinthong W, Jimba M, Yasuoka J. Interprofessional Education for Whom? Challenges and Lessons Learned from Its Implementation in Developed Countries and Their Application to Developing Countries: A Systematic Review. PLoS ONE. 2014; 9(5): e96724. doi:10.1371/journal.pone.

Suter E, Arndt J, Arthur N, Parboosingh J, Taylor E, Deutschlander S. Role understanding and effective communication as core competencies for collaborative practice. Journal of Interprofessional Care. 2009; 23(1): 4151 .

Suter E, Deutschlander A, Mickelson G, Nurano Z, Lait J, Harrison L, et al. Can interprofessional collaboration provide health human resources solutions? A knowledge synthesis. Journal of Interprofessional Care. 2012; 26(4):261-8. 
Teixeira CFS, Coelho MTAD, Rocha MND. Bacharelado interdisciplinar: uma proposta inovadora na educação superior em saúde no Brasil. Ciência \& Saúde Coletiva. 2013:18(6);1635-1646.

Tesser CD, Poli Neto P, Campos GWS. Acolhimento e (des)medicalização social: um desafio para as equipes de saúde da família. Ciênc. Saúde coletiva [online]. 2010;15(suppl.3):3615-3624.

Thistlethwaite J, Moran M et al. Learning outcomes for interprofessional education (IPE): Literature review and synthesis. Journal of Interprofessional Care. 2010; 24(5):503-513.

Torres Santomé, J. Globalização e interdisciplinaridade. Porto Alegre: Ates Médicas; 1998.

Tronchin DMR, Mira VL, Peduzzi M, Ciampone MH, Melleiro MM, Silva JAM, Silva AM, Soares JMS. Educação permanente de profissionais de saúde em instituições públicas hospitalares. Rev Esc Enferm USP. 2009; 43(Esp 2):1210-15.

Vázquez AS. Ética. 5 ed. Editora Civilização Brasileira S.A. Rio de Janeiro, 1982.

Venturelli J. Os aspectos educacionais na reforma da educação e nas profissões de saúde. In: Almeida $\mathrm{M}$, Feuerwerker L, Llanos M, organizadores. A educação dos profissionais de saúde na América Latina: teoria e prática de um movimento de mudança. São Paulo: Hucitec; 1999. p.145- 64 .

Vilela EM, Mendes IJM. Interdisciplinaridade e saúde: estudo bibliográfico. RevLatino-am Enfermagem. 2003;11(4):525-31.

Villa TCS, Mishima SM, Rocha SMM. A enfermagem nos serviços de saúde pública do estado de São Paulo. In Almeida MCP, Rocha SMM, organizadoras. O trabalho e enfermagem. São Paulo: Cortez, 1997. p.27-61.

Wagner $\mathrm{J}$ et al. Developing interprofessional communication skills. Teaching and Learning in Nursing. 2011;6:97-101.

West MA. Illusions of teamwork in health care. Journal of Health Organization and Management. 2013; 27(1):134-42.

West M. Communication and teamworking in healthcare $\square 1999$ In: NT Research. 4, 1, p. 8-16. 9 p.

Whitehead C. The doctor dilemma in interprofessional education and care: how and why will physicians collaborate? Medical Education. 2007; 41(10):1010-16. 
Willig $\mathrm{MH}$, Lenardt $\mathrm{MH}$. A prática gerencial do enfermeiro no processo de cuidar. Cogitare Enferm. 2002; 7(1):249-57.

World Health Organization (WHO). Framework for Action on Interprofessional Education \& Collaborative Practice. Geneva: WHO; 2010. World Health Organization (2006) The World Health Report 2006: Working Together for health. Geneve: WHO; 2006.

World Health Organization (WHO). Learning together to work together for health. Report of a WHO Study Group on Multiprofessional Education for Health Personnel. Geneva: World Health Organization; 1988. (Technical Report Series, v.769) p.1-72.

World Health Organization (WHO). Learning Together to Work Together for Health. Geneva: WHO; 1998.

World Health Organization (WHO). Framework for Action on Interprofessional Education \& Collaborative Practice. Geneva: WHO; 2010.

World Health Organization (WHO). Patienty safety curriculum guide: Multi-professional edition. Geneve: WHO, 2011.

World Health Organization (WHO). Transforming and Scaling up Health Professionals Education and Training. WHO: Geneve, 2013.

Zandbelt LC, Smets EMA, Orrt FJ, Godfried MH, Haes HCJM. Patient participation in the medical specialist encounter: Does physicians'patientdentred communication matter? Patient Education and Couseling 2007. 65:396-406.

Zorzanelli RT, Ortega F, Bezerra Júnior. Um panorama sobre as variações em torno do conceito de medicalização entre 1950 a 210. Ciência \& Saúde Coletiva. 2014;19(6):1859-1868.

Zwarebstein M, Goldman J, Reeves S, Interprofessional collaboration; effects of practice-based interventions on professional practice and healthcare outcomes. Cochrane Database of Systematic Review 2009, issue 3. Art. No.: CD000072. DOI: 10.1002/14651858.CD000072.pub2.

Zwarestein M, Reeves S, Barr H, Hammick M, Koople I, Atkins J. Interprofessional education: effects on professional practice and health outcomes. Cochrane Database of Systematic Reviews 2000, Issue 3. [DOI: 10.1001/14651858.CD002213] 


\section{APÊNDICE 1 - ROTEIRO DE ENTREVISTA}

Local de trabalho

Cargo e/ou função no serviço

Categoria profissional

Idade

Sexo

Escolaridade

Superior incompleto

Pós-Graduação: Especialização ( ) Sim ( )Não

Área:

Mestrado/ Doutorado ～（） Sim ( ) Não Área:

Ano de conclusão do curso de graduação/educação profissional

Tempo de trabalho na área de educação/formação em saúde

Tempo de trabalho junto ao SUS

Cargos/ atividades realizadas na carreira em prol da formação em saúde

1. Conte-me sobre sua trajetória profissional no tocante às atividades de atenção à saúde relacionadas ao ensino na APS.

2. Na sua trajetória profissional o que você observou de mudança nos modelos de atenção e na formação dos profissionais de saúde de diferentes áreas?

3. Descreva uma situação em que você observou ou participou do aprendizado compartilhado de estudantes de diferentes áreas. Mencione as pessoas envolvidas, situação e desdobramentos.

4. Fale sobre uma situação potencial para o aprendizado compartilhado e reflita porque não aconteceu.

5. Quais as experiências de ensino e práticas em saúde mais integradas que você conhece?

6. As pesquisas revelam que a literatura não apresenta a distinção entre os termos: multi, pluri, inter, transdisciplinar e interprofissional. Você vê alguma diferença?

7. Como seria uma formação profissional integrada, pense em uma situação ideal.

8. Quais são as principais estratégias e características de ensino para o aprendizado compartilhado?

9. Que resultados esse tipo de educação pode produzir?

10. Quais os desafios e como estimular o ensino e aprendizado compartilhado?

11. Se você pudesse mudar as políticas de formação em saúde para a integração das diferentes áreas, o que você faria? 


\section{APÊNDICE 2 - ROTEIRO PARA OS GRUPOS FOCAIS}

Projeto de pesquisa: A educação interprofissional em saúde e enfermagem no contexto da atenção primária à saúde

PARTE 1 - Apresentação e sensibilização dos participantes para a discussão (10 min)

- Solicitar a apresentação dos participantes

- Apresentar a pesquisa e a definição de EIP do CAIPE

- Esclarecer que ao falar de formação na pesquisa nos referimos ao ensino dos graduandos em saúde

-Distribuir os cartões coloridos e combinar a sinalização no momento da fala

\section{PARTE 2 - Discussão grupal}

1. Na UBS em que vocês trabalham, quais são as diferentes áreas da saúde que realizam estágios? Existe alguma articulação entre as áreas para o estágio? Quais as atividades em que é possível envolver alunos de diferentes áreas? Como as áreas dos estudantes se articulam?

2. Relate suas vivências em formação interprofissional

3. Quais são os espaços de troca entre os estudantes de diferentes áreas e entre estudantes/profissionais de diferentes áreas? Quem são os sujeitos envolvidos? Todos tem espaço de fala e de escuta?

4. Quais os prós e contras do aprendizado articulado entre diferentes áreas quando comparado à formação em áreas específicas?

5. Quais são os objetivos dessas atividades articuladas de formação entre diferentes áreas no contexto da APS?

6. Como a formação de estudantes de diferentes áreas pode influenciar as práticas de saúde (o trabalho em equipe na APS) e vice-versa?

7. Sugestões para desenvolver a EIP na APS. 


\section{APÊNDICE 3 - TERMO DE CONSENTIMENTO LIVRE E ESCLARECIDO PARA AS ENTREVISTAS}

$\mathrm{Eu}$, inserido no

serviço/instituição

concordo em participar da pesquisa intitulada "Educação interprofissional em saúde e enfermagem na Atenção Primária”, que tem o objetivo geral de analisar como ocorre a educação interprofisssional na Atenção Primária à Saúde no contexto brasileiro. Para tanto, os objetivos específicos do estudo são: a) analisar as concepções de educação interprofissional em saúde na perspectiva de docentes, estudantes e trabalhadores da saúde da atenção básica; b) analisar a articulação da educação interprofissional com a prática interprofissional no cotidiano do trabalho da atenção primária à saúde.

Sou convidado a participar de entrevista individual sobre os temas, educação interprofissional em saúde, educação/formação em saúde. Autorizo a gravação da entrevista e a divulgação das informações fornecidas.

Fui orientado sobre o caráter científico da investigação, na qual a minha colaboração é estritamente voluntária, sendo-me assegurado retirar este consentimento em qualquer fase da pesquisa, sem nenhuma penalização ou prejuízo à minha pessoa e à instituição de ensino na qual estou inserido. Também foi assegurado que não haverá identificação pessoal ou institucional e que as informações fornecidas serão confidenciais. Este 'Termo de consentimento livre e esclarecido' é assinado em 2 (duas) vias, uma via permanece comigo, pois concordei em participar da pesquisa, e outra com o pesquisador.

$\overline{\text { Assinatura de consentimento do participante da }}$ pesquisa

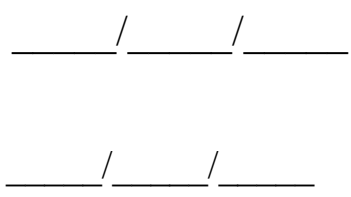

Assinatura do pesquisador responsável pela investigação Jaqueline Alcântara Marcelino da Silva

Escola de Enfermagem da Universidade de São Paulo (EEUSP), Departamento de Orientação Profissional. Av. Dr. Enéas de Carvalho Aguiar, 419. Cerqueira Cesar. CEP: 05403-000. São Paulo-SP. Telefone: (11) 3061-7551. E-mail: jaqueline.alc@gmail.com

Qualquer questão, dúvida, esclarecimento ou reclamação sobre os aspectos éticos dessa pesquisa, favor entrar em contato com: Comitê de Ética em Pesquisa da Secretaria Municipal da Saúde - CEP/SMS. Rua General Jardim, $36-1^{\circ}$ andar. Fone: 3397-2464 / Fax: 3397-2465. E-mail: smscep@gmail.com 


\section{APÊNDICE 4 - TERMO DE CONSENTIMENTO LIVRE E ESCLARECIDO PARA OS GRUPOS FOCAIS}

$\mathrm{Eu}$, inserido no serviço/instituição concordo em participar da pesquisa intitulada "Educação interprofissional em saúde e enfermagem na Atenção Primária", que tem o objetivo geral de analisar como ocorre a educação interprofissional na Atenção Primária à Saúde no contexto brasileiro. Para tanto, os objetivos específicos do estudo são: a) analisar as concepções de educação interprofissional (EIP) em saúde na perspectiva de docentes, estudantes e trabalhadores da saúde da atenção básica; b) analisar a articulação da educação interprofissional com a prática interprofissional no cotidiano do trabalho da atenção primária à saúde.

Sou convidado a participar de uma sessão de grupo focal sobre os temas, educação interprofissional em saúde, educação/formação em saúde. Autorizo a gravação e a divulgação das informações fornecidas.

Fui orientado sobre o caráter científico da investigação proposta, na qual minha colaboração é estritamente voluntária, sendo-me assegurado retirar este consentimento em qualquer fase da pesquisa, sem nenhuma penalização ou prejuízo à minha pessoa ou instituição na qual estou inserido. Estou ciente de que não haverá identificação pessoal ou institucional e que as informações fornecidas serão confidenciais. Este 'Termo de consentimento livre e esclarecido' é assinado em 2 (duas) vias, uma via permanece comigo, pois concordei em participar da pesquisa, e outra com o pesquisador.

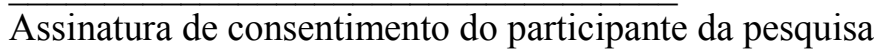

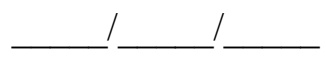

Assinatura do pesquisador responsável pela investigação Jaqueline Alcântara Marcelino da Silva

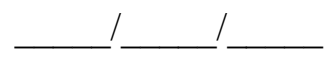

Escola de Enfermagem da Universidade de São Paulo (EEUSP), Departamento de Orientação Profissional. Av. Dr. Enéas de Carvalho Aguiar, 419. Cerqueira Cesar. CEP: 05403-000. São Paulo-SP. Telefone: (11) 3061-7551. E-mail: jaqueline.alc@gmail.com

Qualquer questão, dúvida, esclarecimento ou reclamação sobre os aspectos éticos dessa pesquisa, favor entrar em contato com: Comitê de Ética em Pesquisa da Secretaria Municipal da Saúde - CEP/SMS. Rua General Jardim, $36-1^{\circ}$ andar. Fone: 3397-2464 / Fax: 3397-2465. E-mail: smscep@gmail.com 


\section{APÊNDICE 5 - CARTA DE AUTORIZAÇÃO DO SERVIÇO DE SAÚDE}

Ao Sr.(a)

Responsável da Unidade Básica de Saúde

Vimos solicitar sua autorização para a coleta de dados para a pesquisa intitulada "Educação interprofissional em saúde e enfermagem na atenção primária”, que tem o objetivo geral de analisar como ocorre a educação interprofissional na atenção primária à saúde no contexto brasileiro. Para tanto, os objetivos específicos do estudo são: a) analisar as concepções de educação interprofissional (EIP) em saúde na perspectiva de docentes, estudantes e trabalhadores da saúde da atenção básica; b) analisar a articulação da educação interprofissional com a prática interprofissional no cotidiano do trabalho da atenção primária à saúde.

As informações serão coletadas através de grupos focais realizados com trabalhadores do serviço, participantes/promotores da educação/formação em saúde no contexto da atenção primária à saúde.

Salientamos o caráter científico do estudo proposto, no qual a sua colaboração e dos trabalhadores do serviço é estritamente voluntária, sendo-lhes assegurado retirá-la em qualquer fase da pesquisa, sem nenhuma penalização ou prejuízo à sua pessoa ou instituição. Também destacamos que não haverá identificação pessoal ou institucional e que as informações fornecidas serão confidenciais.

Desde já apresentamos nosso compromisso de retorno dos resultados da pesquisa ao serviço sob a forma de relatório.

Assinatura de consentimento do responsável

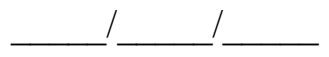

Assinatura do pesquisador responsável pela investigação: Jaqueline Alcântara Marcelino da Silva

Escola de Enfermagem da Universidade de São Paulo (EEUSP), Departamento de Orientação Profissional. Av. Dr. Enéas de Carvalho Aguiar, 419. Cerqueira Cesar. CEP: 05403-000. São Paulo-SP. Telefone: (11) 3061-7551. E-mail: jaqueline.alc@gmail.com

Qualquer questão, dúvida, esclarecimento ou reclamação sobre os aspectos éticos dessa pesquisa, favor entrar em contato com: Comitê de Ética em Pesquisa da Secretaria Municipal da Saúde - CEP/SMS. Rua General Jardim, 36 - $1^{\circ}$ andar. Fone: 3397-2464 / Fax: 3397-2465. $\quad$ E-mail: smscep@gmail.com 


\title{
ANEXO 1 - PARECER DO COMITÊ DE ÉTICA EM PESQUISA DA ESCOLA DE ENFERMAGEM DA USP
}

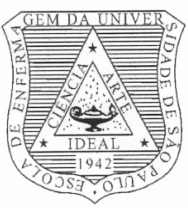

\author{
UNIVERSIDADE DE SÃO PAULO \\ ESCOLA DE ENFERMAGEM \\ Av. Dr. Enéas de Carvalho Aguiar, 419 - CEP 05403-000 \\ Tel.: (011) 3061-7548/8858 - Fax: (011) 3061-7548 - \\ São Paulo - SP - Brasi
}

São Paulo, 13 de outubro de 2011.

Ilm. ${ }^{a} \mathrm{Sr}{ }^{\mathrm{a}}$

Jaqueline Alcântara Marcelino da Silva

Ref.: Processo nº 1082/2011/CEP-EEUSP - SISNEP CAAE: 0096.0.196.196-11

Prezada Senhora,

Em atenção à solicitação referente à análise do projeto "Educação interprofissional em saúde e enfermagem no contexto da atenção primária à saúde", informamos que o mesmo foi considerado aprovado pelo Comitê de Ética em Pesquisa da Escola de Enfermagem da Universidade de São Paulo (CEP/EEUSP).

Analisado sob o aspecto ético-legal, atende às exigências da Resolução $n^{0}$ 196/96 do Conselho Nacional de Saúde.

Esclarecemos que após o término da pesquisa, os resultados obtidos deverão ser encaminhados ao CEP/EEUSP, para serem anexados ao processo.

Atenciosamente,

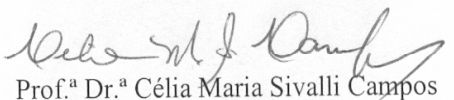

Coordenadora do Comitê de Ética em Pesquisa da

Escola de Enfermagem da Universidade de São Paulo 


\section{ANEXO 2 - PARECER DO COMITÊ DE ÉTICA EM PESQUISA DA SECRETARIA MUNICIPAL DE SAÚDE DE SÃO PAULO}

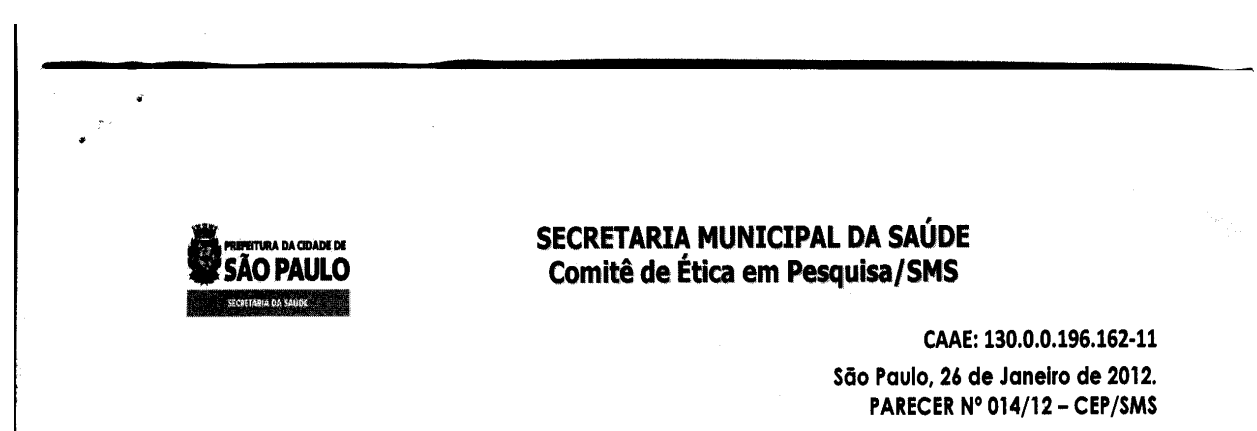

IIma. Sra.

Jaqueline Alcântara Marcelino da Silva

Projeto de Pesquisa Tíulo: "Educação Interprofissional Em Saúde e Enfermagem no Contexto da Atenção Primária à Saúde"

Pesquisador Responsável: Jaqueline Alcântara Marcelino da Silva

Tipo-Doutorado

Instifulção: Escola de Enfermagem da Universidade de São Paulo

local onde os dados serão coletados: UBS São Jorge e UBS Boa Vista da Coordenadoria Regional de Saúde Centro-Oeste do Município de São Paulo e na EEUSP.

Patrocinador: o próprio pesquisador

\section{Sumário Geral do Protocolo}

A descrição abaixo e que está entre aspas, faz parte do resumo que foi descrito pelo pesquisador e que está no corpo do projeto:

"A abordagem interprofissional na formação dos profissionais de saúde representa uma inversão da formação usual com enfoque nas práticas profissionais específicas. Assim, as profissões aprendem juntas sobre o trabalho conjunto e sobre as especificidades de cada uma na melhoria da atenção à saúde dos usuários. A educação interprofissional prioriza o trabalho em equipe, a interdisciplinaridade e o compromisso com a integralidade das ações que deve ser alcançado com o amplo reconhecimento e respeito às especificidades de cada profissão. O tema central deste estudo é a prática e a educação interprofissional na enfermagem e na saúde desenvolvido com o objetlvo geral de compreender a educação interprofissional em saúde na atenção primária no contexto brasileiro. Os objetivos específicos são: analisar as concepções de educação interprofissional na perspectiva docentes, estudantes e trabalhadores da atenção primária à saúde e analisar a articulação da educação interprofissional com a prática interprofissional no cotidiano de trabalho da atenção primária...".

Tipo de Pesquisa: estudo de abordagem qualitativa

Instrumentos para a coleta dos dados: entrevista e grupo focal

Forma de coleta de dados: Para a coleta de dados serão realizadas entrevistas semi- estruturadas com informantes-chave (pesquisadores dos temas educação/formação em saúde e atenção primária à saúde no SUS) e 3 grupos focais homogêneos com a participação de estudantes de diferentes cursos de graduação em saúde, docentes e trabalhadores de duas unidades básicas de saúde. 0 roteiro de entrevistas e dos grupos focais está estruturado mediante a breve caracterização dos participantes, as concepções sobre a EIP, experiências vivenciadas, referências de práticas de educação EIP em outros locais, desafios para operacionalização da educação interprofissional no contexto educacional formal e nos serviços de saúde. Os depoimentos de cada entrevista e grupo focal serão gravados e integralmente transcritos.

Número de amostras: 24 sujeitos, conforme a FR

Critério de inclusão: serão convidados a participar do estudo pesquisadores dos temas educação/formação em saúde e atenção primária à saúde no SUS (para as entrevistas). Posteriormente a coleta destes dados, ocorrerá mediante a constituição de três grupos focais homogêneos que serão compostos por participantes relacionados ao tema de estudo - prática e educação interprofissional em saúde e enfermagem na APS. Será constituído um grupo de docentes de cursos de graduação em saúde, um grupo de trabalhadores e gestores da APS e outro grupo de estudantes de diferentes áreas da saúde vinculados ao PET-Saúde, cada um com cerca de oljo participantes. Os critérios de participação

* Rua Ceneral Jardim, 36 - $1^{\circ}$ andar - V. Buarque - fone: 3397.2464 - email: smscep@gmail.com

http://www.prefeitura.sp.gov.br/cidade/secretarias/saude/comite_de_etica/ 
do grupo focal seguem os seguintes critérios: que possuam características comuns que os qualifiquem para o foco do trabalho interativo e da coleta do material empirico e que possuam vivência com o tema a ser discutido de modo que tragam elementos para discussão.

Análise dos dados obtidos: A análise dos dados será realizada por meio da técnica de análise categorial temática de Bardin e triangulação à luz do quadro teórico da teoria do agir comunicativo, trabalho em equipe, educação interprofissional e educação permanente em saúde.

\section{2-Consideraçōes.}

Este projeto foi aprovado no CEP-EEUSP.

Tema significativo e proposta bem embasada e documentada. Pesquisa bem apresentada e metodologia coerente com os objetivos.

A folha de rosto que acompanha o Projeto está devidamente preenchida. 0 currículo do pesquisador está de acordo com a proposta da pesquisa. A pesquisadora apresenta um orçamento e declara que todas as despesas da pesquisa serão custeadas pelo pesquisador responsável e sem quaisquer ônus aos participantes e/ou instituição proponente e instituiç̧̄es ou coparticipantes. 0 cronograma está de acordo com as etapas de pesquisa.

Os critérios de inclusão: e exclusão adequados.

O currículo da doutoranda mostra relação estreita com a temática proposta; inclusão do currículo da orientadora, e a sua repetida presença na bibliografia mostra igualmente a sua expertise.

0 orçamento é baixo e os gastos correrão por conta da doutoranda.

Bibliografia extensa e importante.

Inclui "Carta (de pedido) de autorização do Serviço de Saúde", dirigida ao responsável pela Unidade, contendo objetivos do trabalho e a intenção de realizar os grupos focais; garante que "não haverá identificação pessoal ou institucional". Compromete-se a informar os resultados da pesquisa.

Termo de Consentimento Livre e Esclarecido (TCLE)

O TCLE necessitava de retificaçōes. Feitas as retificações, o relator considerou adequado.

\section{3 - Situação do Protocolo - APROVADO}

Antes do inicio da coleta de dados, alertamos para a necessidade de contato com o gerente da unidade quando não fol ele quem autorizou a realização da pesquisa.

O sujelto de pesquisa (ou seu representante) e o pesquisador responsável deverão rubricar todas as folhas do Termo de Consentimento Livre e Esclarecido - TCLE apondo sua assinatura na úlitima página do referido Termo, conforme Carta Circular no 003/2011 da CONEP/CNS.

Salientamos que o pesquisador deve desenvolver a pesquisa conforme delineada no protocolo aprovado. Eventuais modificaçōes ou emendas ao protocolo devem ser apresentadas ao CEP de forma clara e sucinta, identificando a parte do protocolo a ser modificada e suas justificativas.

Ao pesquisador cabe manter em arquivo, sob sua guarda, por 5 anos, os dados da pesquisa, contendo fichas individuais e todos os demais documentos recomendados pelo CEP (Res. CNS 196/96 Hitem IX. 2. e).

O relatório final deve ser apresentado aO CEP, logo que o estudo estiver concluído

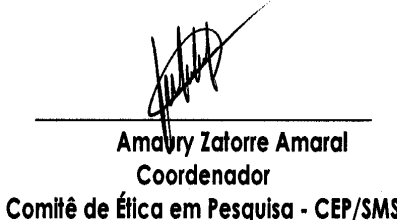

* Rua General Jardim, 36 - 1ªndar -V. Buarque - fone: 3397.2464 - email: smscep@gmail.com 